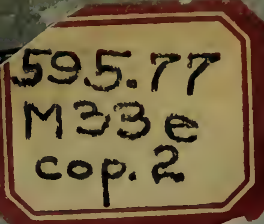

\title{
MONOGRAPHS OF
}

THE ROCKEFELLER INSTITUTE FOR MEDICAL RESEARCH

No. 13

November 15, 1920

THE EARLY STAGES OF TABANID $Æ$ (HORSE-FLIES)

$\mathrm{By}$

WERNER MARCHAND, PH.D.

NEW YORK

THE ROCKEFELLER INSTITUTE FOR MEDICAL RESEARCH

1920 
Copyright, 1920, BY

The Rockefeller Institute for Medical Research

WAVERLY PRESS

The Williams \& Wuikns Company

BALTMORE, U. S. A. 




\section{THE EARLY STAGES OF TABANIDÆE（HORSE-FLIES）}

BY

WERNER MARCHAND, PH.D.

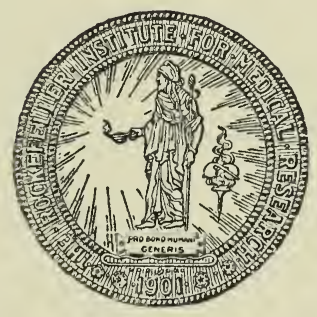

NEW YORK

The Rockefeller Institute for Medical Research 
Digitized by the Internet Archive in 2017 with funding from

University of Illinois Urbana-Champaign Alternates 
MONOGRAFH OF THE ROCKEFELLER INSTITUTE FOR MEDICAL RESEARCH, NO. 13, NOVEMBER 15, 1920.

\section{THE EARLY STAGES OF TABANID压 (HORSE-FLIES).}

\section{By WERNER MARCHAND, PH.D.}

(From the Department of Animal Pathology of The Rockefeller Institute for Medical Research, Princeton, N.J.)

Plates 1 to 15.

(Received for publication, April 23, 1917.)

CONTENTS.

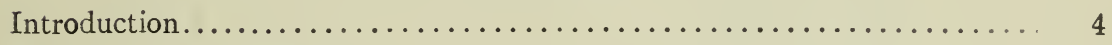

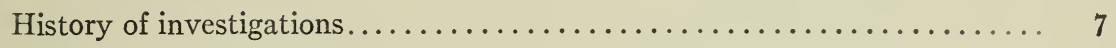

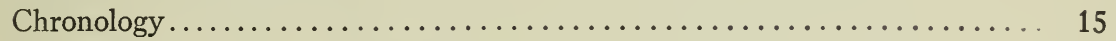

Tabanidæ, description of early stages $\ldots \ldots \ldots \ldots \ldots \ldots \ldots \ldots \ldots \ldots \ldots \ldots$

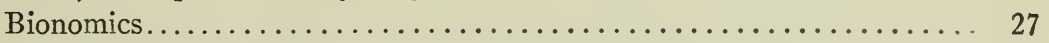

Special anatomy of tabanid larvæ; Graber's organ............. 29

Chrysops (Meigen), early stages in general................... 44

Chrysops bimaculosa Neave......................... 46

“ callidus Osten Sacken.......................... 46

" celer Osten Sacken........................ 47

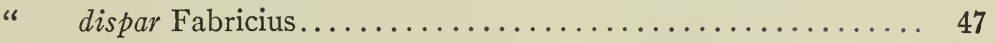

"indus Osten Sacken........................ 48

" longicornis Macquart...................... 48

" magnifica, var. inornata, Austen................... 49

" mechus Osten Sacken........................... 49

" merens Walker.......................... 50

“ relictus Meigen........................... 52

"vittatus Wiedemann........................ 52

“wellmani Austen.......................... 54

Dorcalcemus fodiens Austen............................. 55

Gastroxides ater Saunders........................... 55

Goniops (Aldrich), early stages in general. ................. 56

Goniops chrysocoma Osten Sacken..................... 57

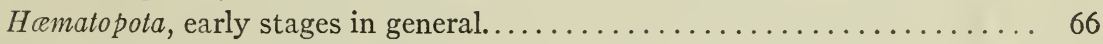

Hcmatopota crudelis Austen. .......................... 66

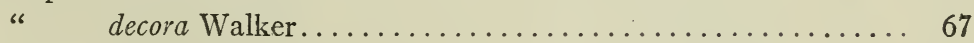

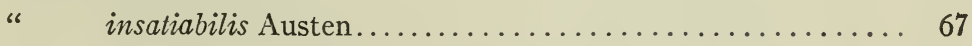

“ pluvialis Linné......................... 67

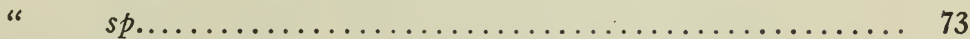

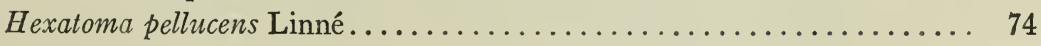


Tabanus, early stages in general........................... 77

Tabanus albimedius Walker.......................... 78

atratus Fabricius............................ 79

atrimanus Loew........................... 91

autumnalis Linné............................. 91

bicallosus Ricardo............................ 93

biguttatus Wiedemann........................ 94

bovinus Linné............................. 97

bromius Linné................................ 99

carolinensis Macquart............................ 101

corax Loew.................................. 101

cordiger Meigen................................. 103

costalis Wiedemann.............................. 105

desertus Walker.............................. 106

ditaniatus Macquart............................. 106

epistates Osten Sacken............................. 109

fraternus Macquart............................ 110

fronto Osten Sacken......................... 110

(Atylotus) fulvus Meigen............................ 111

fuscipes Ricardo............................. 111

glaucopis Meigen.............................. 111

gratus Loew................................... 112

hilaris Walker............................ 112

ignotus Rossi................................ 112

insignis Loew .................................. 114

kingi Austen................................ 115

lasiophthalmus Macquart.......................... 119

laverani Surcouf................................ 123

lineola Fabricius.............................. 123

maculatissimus Macquart.......................... 125

medionotatus Austen........................... 126

melanoceros Wiedemann........................... 126

nagamiensis Carter............................. 126

nigerrimus Zetterstedt........................ 127

nigrescens Palisot de Beauvois........................ 127

obscuripes Ricardo ............................. 128

(Neotabanus) ochrophilus Lutz..................... 128

orientis Walker............................... 129

par Walker................................. 129

pertinens Austen.............................. 132

quatuornotatus (quadrinotatus) Meigen................. 132

semisordidus Walker............................ 144

solstitialis Schiner.............................. 144

speciosus Ricardo............................. 145 
Tabanus spodopterus Meigen........................... 145

" striatus Fabricius............................ 145

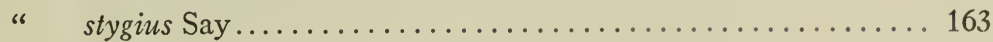

“ sulcifrons Macquart.......................... 167

“ taniola Palisot de Beauvois........................ 168

“ (Neotabanus) triangulum Wiedemann................. 171

“ trimaculatus Palisot de Beauvois.................. 171

“ tropicus Linné............................. 171

“ ustus Walker............................... 172

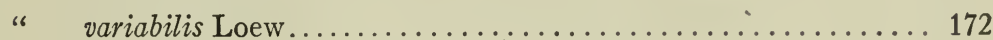

" virgo Wiedemann............................. 173

“ vivax Osten Sacken............................. 173

Unidentified species of Tabanus......................... 176

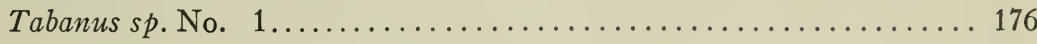

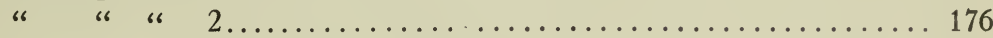

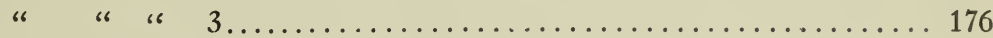

" " " 4

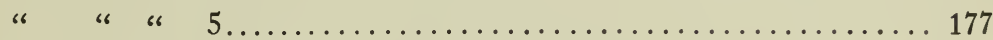

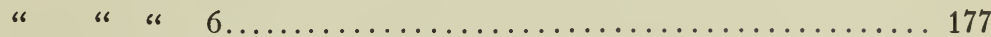

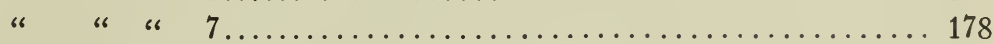

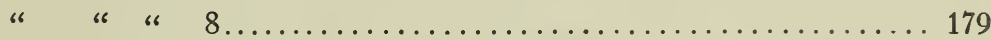

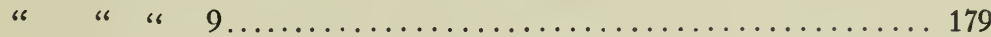

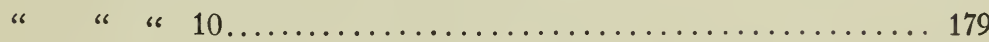

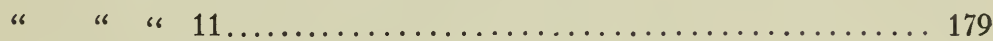

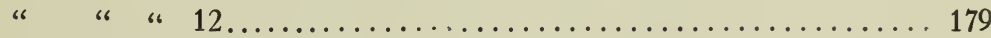

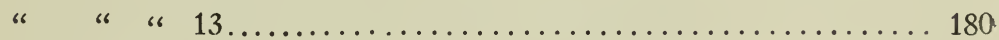

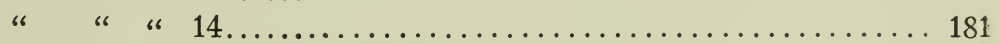

Parasites of the early stages of Tabanidx.................... 182

Hymenopterous egg parasites; early discoveries............. 182

Phanurus tabanivorus, Ashmead, n. sp................... 183

“ tabani Mayr............................. 184

“ emersoni Girault............................ 185

Telenomus benefactor Crawford....................... 186

" kingi Crawford........................... 186.

Unidentified parasites recorded....................... 186

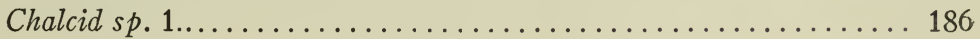

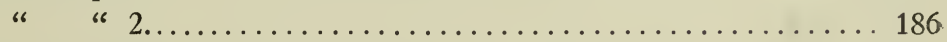

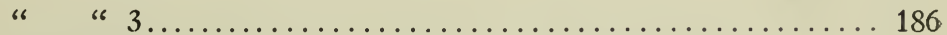

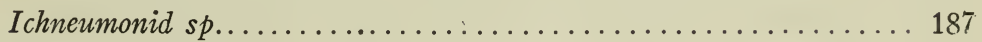

Parasites of the larvæ............................. 187

Discussion of Table II............................ 188

Table II. Statistical table of results on early stages.............. 190

Notes on methods of rearing and studying tabanids in early stages....... 196

Bibliography......................................... 200

Explanation of plates................................... 204 


\section{INTRODUCTION.}

The Tabanidæ are a group of blood-sucking insects which, though of less importance to medicine than mosquitoes and certain groups of flies, are nevertheless of sufficient interest to the student of animal pathology to warrant a closer study and a completion of our meager knowledge of the life history of these insects. As the group consists of many species spread over all parts of the world, it is natural that the work done hitherto has scarcely advanced beyond the systematic and descriptive stage; and the lack of information on development and early stages is especially felt by experimental science. In fact, although Tabanidæ play a considerable part in transmitting diseases of domesticated animals, and in spite of the trouble which their presence in large numbers causes to horses and cattle even under normal conditions, our knowledge of their life history is very incomplete compared with that which we possess of other groups of bloodsucking insects; for instance, Culicidæ. Only recently the study of tabanid life histories has been undertaken from the point of view of their economic importance, by King, British Government Entomologist in the Anglo-Egyptian Sudan, Mitzmain in the Philippine Islands, and others. However, these authors practically ignore previous or contemporary literature on the subject of their investigation. Thus Mitzmain states that the literature on the subject is meager and quotes only three publications. When rediscovering Graber's organ in the larvæ studied by him, he assumes that the organ is peculiar to this species or has been overlooked by the previous authors. The Zürich Index (Concilium Bibliographicum), however, contains reference to several publications of European authors on this organ.

I have undertaken a review of the literature on the subject because the entomological literature is especially difficult of access, being scattered over a number of small periodicals appearing in different languages. Field and experimental work on entomological subjects is often done at a great distance from large libraries, and it would be an advantage to the individual worker, especially in the tropics, to 
have all the facts on a definite subject concentrated in one publication. I have therefore decided to give not only a summary of the literature with the bibliography, as is usually done in text-books, but also a complete report of all the facts found in these publications, with very little change in the wording, literal quotation of all authentic descriptions, and with the reproduction of practically all the existing illustrations on the subject, sufficiently accurate to make the consultation of the originals unnecessary. By this means I hope to relieve the worker on the subject in question of the necessity of consulting libraries, except the future monographer of the whole group, who will prefer to go back to the original publications. On the other hand, as a full bibliography is given, in case of uncertainty about any detail, the originals can always be consulted and compared with this report.

There is, however, another consideration of some importance which has guided me in preparing this review; that is, the desirability of having, generally, all the facts on one subject of research concentrated in one language, preferably English. The diversity of languages is a great hindrance for the progress of science, and from the point of view of methodical unification, specialists in any branch of science should be encouraged to concentrate all the literature on their own subject in the language which they prefer to have used. Having given considerable time to the study of this question, I cannot see any serious objection to the more general adoption of English in science. It is to be hoped that the temporary disadvantages to the non-English-speaking scientists, resulting from its adoption would be made up by the advantages of a great progress in science which would undoubtedly follow. It is for the scientists of English-speaking countries to pave the way, by conquering the field systematically, subject after subject, and to facilitate the production of new work by a complete assimilation of work previously done in foreign languages.

I wish to express my indebtedness to the authorities of the American Museum of Natural History and of the Philadelphia Academy of Natural Science for giving me liberal access to their libraries and collections, and to Dr. Theobald Smith, Director of the Department of Animal Pathology under whose guidance this work was rendered possible. 
In grouping the material I have as far as possible followed a systematic arrangement, by bringing all the facts which could be referred with certainty to a definite species under the heading of that species, even where the facts appear to apply to a whole genus or to tabanids in general. In each species the egg stage is first treated, followed by the larval and pupal stages. Results obtained by one author in one paper have, consequently, often been separated and rearranged. On the other hand, no attempt has been made towards extensive generalization; the general statements on the family Tabanidæ and the more important genera are only such as are found already in the literature, and are not to be considered as final or as expressions of the author's opinion.

In the arrangement of the plates a slightly different plan has been followed, as it seemed desirable to facilitate the comparison of corresponding stages. I have therefore figured on Plates 1 and 2 all the existing illustrations of the egg stage of different species; on the following plates the larvæ and larval structures; following these the pupæ; and finally pupal structures, these being of especial systematic value. With this arrangement the different stages of the same species are necessarily separated and figured on different plates. In the details, the arrangement has been such as seemed most convenient. Occasionally an exception to the general order has been made and a group of figures illustrating one species or genus appears on the same plate. 


\section{HISTORY OF INVESTIGATIONS.}

In 1760 the Swedish naturalist Degeer published a paper, in the transactions of the Swedish Academy of Science, on the larval and pupal stages of the European horse-fly, Tabamus bovinus, which he found to be terrestrial in habit, and which he described in a paper bearing the title Bromsarnas ursprung (The origin of horse-flies). Degeer was a contemporary and compatriot of Fabricius, the first great entomologist, and both continued the work of Linné. It is stated by various authors that Fabricius' works also contain data on the early stages of Tabanidæ, though very few, but I have not been able to find such data in the Systema Entomologice (1775) or in the Entomologia Systematica. The statement that the larvæ of Chrysops are found in the ground cannot have been made by Fabricius, in this form, as the genus Chrysops was first established by Meigen (1803). If Zetterstedt makes this statement in Diptera Scandinavice, it is possible that it is from verbal information or from some later writings of Fabricius. Zetterstedt seems to doubt it, stating that he has seen large numbers of newly emerged Chrysops near the margin of a lake, which would indicate an aquatic habitat. The Swedish school for a considerable time dominated entomological work in all countries Degeer's observations are reprinted in his Mémoires pour servir à l'histoire des insectes, which appeared in French in 1776 and also in German translation (Goeze, 1882). These observations are given without change by Macquart in Histoire naturelle des insectes. Diptères (1834), and by Westwood in England, the illustrator of the Arcana Entomologica, in his paper Introduction to the modern classification of insects (1840). To the same school belongs Wahlberg, who in 1838 published, in Swedish, accounts of the larval stages and mode of life of many Diptera, which also contain, according to Brauer, notes on tabanid larvæ living inside lepidopterous larvæ, probably in a pseudoparasitic way. In one of his papers on this subject I could not find any reference to Tabanidæ.

The progress of entomology consisted chiefly in a greater specialization as to definite orders which were systematically studied and 
described, and in the greater attention which was given to the larval stages. A new school of investigation on this subject arose in the German-speaking countries with Vienna as its center, where Schiner had become an authority on the Diptera of Austria-Hungary, and where Brauer devoted himself to a comparative study of insect metamorphosis, particularly of dipterous larvæ. It is to be noted that Scholtz, in 1848, in Breslau, on an excursion in which von Siebold also took part, discovered some tabanid larvæ, indicating an influence of the growing science of general zoology on this subject. In 1854 Mann discovered oviposition in Tabanus autumnalis, and Kollar, at the Vienna Museum, observed the eggs of various other species of Tabanus, stating that since Degeer nothing had been known about the development of these insects. In the following decades great progress was made in the knowledge of dipterous and other insect larvæ, chiefly through the Vienna school. In 1868 one of Brauer's students, Marno, found the larvæ of Hexatoma pellucens, a tabanid not rare in Austria, this being one of the first instances known of an aquatic larval stage in this family. This larva was described more fully in 1883 by Brauer himself. In 1869 Brauer was able to describe the larva and pupa of Hamatopota pluvialis (Regenbremse), which is terrestrial, giving at the same time a careful drawing of the mouthparts with correct interpretation of all the details. At about the same time Brauer was working on the classification of dipterous larvæ. The larva of Hamatopota pluvialis was, however, described also by Perris in France in 1870, who found it in rotten pine wood, and gives a figure showing the fine striations which are not shown in Brauer's figures; and the same larva was described in 1875 by Beling, inspector of forests in the Harz mountains, both apparently independent of Brauer's studies. Beling was also the first to describe the pupa of Chrysops, in 1882. On the other hand, von Friedenfels, who found the larva of Tabanus autumnalis in the salt lakes of Siebenbürgen, belonged to the Vienna naturalist group, and the larva which he had supposed to be an annelid was identified by Brauer. The results of all these investigations are briefly summarized by Brauer in 1883 in the third volume of Die Zweiflïgler des Kaiserlichen Museums zuWien, in which the larvæ of Tabanus solstitialis, spodopterus, and bromius, and the larva of Hexatoma pellucens are described. 
During the period just mentioned the microscopic study of lower organisms had made continuous progress and the anatomical investigators soon began to discover favorable objects of research in the histology of insects. The study of sense organs of lower animals had since Johannes Müller become a favorable subject of research. On the other hand, the native fresh water fauna furnished the most varied and suitable objects for microscopic study, and this fact led to repeated observations on tabanid larvæ from the point of view of general zoology, the determination of the species at hand being omitted with an almost disconcerting regularity. We have, however, noted that tabanid early stages were observed by Scholtz in Breslau in 1848, and even the species was identified, as adults had hatched from the pupæ collected. In 1878 Graber, in Czernowitz, Austria, in his studies on the sense organs of insects, discovered a peculiar otocyst-like organ in a Tabanus larva, called Graber's organ by later authors, a discovery which he connected with that of similar organs in the larva of Ptychoptera by the zoologist Grobben. His paper called forth an article by Krauss in 1879, a pupil of Brauer in Vienna, according to whom this organ had already been demonstrated by Brauer in the tabanid larva in his zoological course. Krauss also declared the larva defined by Graber as a fly-maggot to be a Tabanus larva, and to belong to Tabanus autumnalis. Whether the species was really this or a similar one, no one can say at present. However, to Graber belongs the credit of the independent discovery of this organ and its minute description. In a later work (1882) on the chordotonal organs of insects, Graber figured another tabanid larva with many anatomical details, demonstrating in it the chordotonal organs which had been discovered by Leydig in Corethra plumicornis. These discoveries, especially the otocyst-like organ, gave rise to scientific controversy, Lécaillon in France (1905 and 1906) assuming that the organ must in reality be a gland, while Paoli (1907) in an extensive work undertakes to prove that it is not an auditory, but a sound-producing organ. At the same time Paoli advanced an interesting theory about the manner in which the organ is developed, though without reference to phylogeny.

With Lécaillon and Paoli an influence of economic entomology, especially of agriculture, is notable in stimulating research, unques- 
tionably a reaction on Europe from America. In America research on the early stages of Tabanidæ begins with Walsh (1863), who belongs entirely to the old type of naturalist like Westwood and others, describing facts of nature half as pioneers of discovery in strange countries, half as pioneers of religion, and filled with a deep admiration of the wisdom manifesting itself in creation. He is contemporary with Osten Sacken, the first systematic specialist of American dipterology, who published his Prodromus to a monograph of North American Tabanidæ. In Walsh's publication of previous work only Degeer is referred to, and Walsh believes that his larva, which was proved later to be that of Tabanus atratus, was the first instance of an aquatic tabanid larva. In fact, though the observations of Wahlberg, Zetterstedt, Scholtz, and Kollar were not known to Walsh, these authors give only indications but no full evidence of aquatic habits of life of the larvæ observed by them. While a member of the Boston Natural History Society, Walsh lived for some time in Illinois, where tabanids were numerous and annoying, so that the economic side of the subject inevitably received attention. We may say that with him begins the American or economic school of investigations on this subject. How curiously the economic considerations were mixed with a profound confidence in the wisdom of nature may be seen from the following quotation from his paper, with which few modern investigators will be found to agree, except perhaps the last sentence:

"The scheme of the creation is perfect, and nature is never at fault. It is only when nature's system is but half understood that we heedlessly complain of its imperfections. We blame the house-flies for annoying us, and fail to see that in the larva state they have cleared away impurities around our dwellings, which might otherwise have bred cholera or typhus fever. We execrate the blood-thirsty mosquito, and forget that in the larva state she has purified the water, which would otherwise, by its malarial effluvia, have generated agues and fevers. In all probability, when we rail at the Tabani, which torment our horses in the summer, we are railing at insects which, in the larva state, have added millions of dollars to the national wealth, by preying upon those most insidious and unmanageable of all the insect foes of the farmer-subterraneous root-feeding larvæ."

The larva of Tabanus atratus is redescribed by C. V. Riley in 1870 in the second of his Missouri Reports, this being the first publication 
on a tabanid larva issued from an agricultural institution. Riley apparently was interested in all insects and their development, and in fact included in his Reports also some insects of no economic importance.

A great step in advance was made when in 1895, Hart, in Illinois, probably interested by Walsh, who had lived there, but probably also not without some knowledge of the studies of the Vienna school, undertook to investigate the entomology of the Illinois River on a large scale. He described large numbers of new dipterous larvæ, and incidentally a number of tabanid larvæ, notably those of Chrysops vittatus, Tabanus stygius, nigrescens, lineola, and costalis, which were not known before, and giving a preliminary classification by which these larvæ could be separated. Hymenopterous egg parasites of Tabanus, previously seen by Kollar, were then for the first time exactly described by Ashmead, who cooperated with Hart. I do not think that Hart could have achieved his results without a knowledge of Brauer's monograph, which had, in fact, appeared ten years before, and which, as stated, contains references to most of the previous work. But as he, apparently following Agassiz's principle, "Study nature, not books," makes no mention of the previous literature on this subject, I assume this to be the reason why later authors, Hine, and even Lécaillon, have lost the thread of tradition pertaining to their subject, and why important results such as the descriptions of numerous larvæ and the discovery of Graber's organ have been overlooked by American and European authors. Shortly afterwards, in 1899, the insect volume of the Cambridge Natural History, by Sharp, appeared in England, which also does not mention the literature, but contains the description of an unknown tabanid larva, referred to by Sharp as Tabanus (? Atylotus fulvus).

In America new discoveries of tabanid early stages were made by Hine, who, continuing Osten Sacken's work in this field, has become the leading authority on the Tabanidæ of North America, especially from the systematic point of view. In 1903 he described the life history of Tabanus vivax; this paper was followed by a publication on the Tabanidæ of Ohio, which also contains notes on the early stages. It is worthy of note that Hart's as well as Hine's first publications were not issued by economic but by scientific institutions (Illinois Biolog- 
ical Survey, Ohio Naturalist, Ohio Academy of Science); later the connection with agriculture was established, first in Hine's Report on the Tabanidæ of the Gulf Coast (1903), then in his Habits and life histories of some flies of the family Tabanidæ.(1906), in which the early stages of Tabanus lasiophthalmus, and some others, are given for the first time. The Tabanidæ, long known as a stock pest, were at about that time suspected of carrying infectious cattle diseases (anthrax and surra), as was evident from Salmon and Stiles' Emergency report on surra published in 1902 in connection with a small outbreak of surra in the United States following the importation of Indian zebu cattle. The interest taken by entomologists in Hine's work called forth some smaller publications in America, as in 1908 that of Walton, containing descriptions of the early stages of Goniops chrysocoma, a peculiar species, and in 1909 that of Brimley, with notes on the early stages of several other Tabanidæ, one of them Tabanus fronto, being terrestrial in habit. On Goniops chrysocoma, under the auspices of the United States Department of Agriculture, a more detailed study was made by McAtee in $1911 . .^{1}$ On the other hand, in methods of control of Tabanidæ, some progress was made by the work of Portschinsky in Russia, in 1908; Lécaillon in 1905 in France; and Paoli in 1907 in Florence, also undertook studies on Tabanidæ, which apparently were stimulated by work already done on this subject in America, Lécaillon referring to Hart, and Paoli, while resuming the problem of Graber's organ, working at an agricultural school where he undoubtedly received Hine's publications. Lécaillon's work (1905), which acquaints us with the egg-laying habits of Tabanus quatuornotatus, cites the observations on this species made by Kollar in 1854 . The progress made in the meantime by the Vienna school is, however, ignored by him, which we understand if we realize that the wars of 1866 and 1870 had destroyed cooperation to some extent. The only new author cited by Lécaillon is Hart, who, as we have stated, did not quote the literature. At the same time, Lécaillon (1905) and Hine (1906) are perhaps the first writers in whom the influence of medicine on entomology is perceptible. The part that insects play in the transmission of disease, the theory of which is intimately con-

${ }^{1}$ Specimens of the larva of this species had been found before by Pergande. 
nected with the discoveries of Theobald Smith (1893), Bruce (1895), Ross (1897), Grassi (1900), and Reed (1901), had attracted attention to all blood-sucking insects as possible carriers, and the influence on the study of Tabanidæ showed itself in the progress of knowledge of their early stages. In the following period extending up to the present, studies on these have been made largely under the auspices of medical entomology. The progress resulting is considerable, the number of publications on the subject within the last fifteen years being about equal to that of papers published previous to 1900 .

To the interest aroused in the study of Tabanidæ from the medical point of view we owe in the first place a knowledge of life histories of tabanids of tropical countries, chiefly Africa and India, where the importance of these flies as carriers of disease is paramount. In 1908 King was sent by the British Government to the Sudan in charge of economic entomology in the Wellcome Research Laboratory in Khartoum. He goes into the subject more extensively than any of the previous authors, working out the life history of the black African horse-fly, Tabanus biguttatus (1908) and of Tabanus ditcniatus, taniola, kingi, and par (1910), succeeding for the first time in causing tabanids to oviposit in captivity, and giving minute descriptions of larval structures, which appear cumbersome but may well serve to separate the species described from others not yet known. At about the same time we learn of tabanid larvæ in India from MaxwellLeffroy and Howlett, Indian insect life (1909), a work, however, written more from the point of view of agricultural interests, while Baldrey and Mitzmain studied tabanids in captivity with the immediate object of determining their part as carriers of disease. Baldrey (1911-12) had Tabanus orientis oviposit in captivity, but made no observations on the larvæ. Mitzmain has made a very complete investigation on the life history of a single tabanid species, Tabanus striatus (1913). Mitzmain worked in the Philippine Islands and demonstrated experimentally the transmission of surra (1913) and anthrax (1914) by this species. His omission of reference to previous literature has been commented upon, but as his work was done far away from large libraries he was naturally handicapped in this respect. While Mitzmain raised his flies entirely in captivity, Bainbridge and Fletcher (1914) reported the oviposition of the same species in the 
free-living state. The text-book of medical entomology by Patton and Cragg (1913), who worked in Madras, again gives descriptions of egg and larval stages of various Indian tabanids, with information on habits, methods of rearing, etc., giving also for the first time a more complete idea of work previously done. The organ discovered by Graber (1878) is illustrated and discussed by these authors; Paoli's work on the same subject, however, seems to have remained unknown to them. At about the same time (1914) Lutz in Rio de Janeiro published the first meager observations on early stages of tabanids in Brazil, having found larvæ of Tabanus (Neotabanus) ochrophilus and triangulum, and of one undetermined species. The studies of Neave in the following year, 1915, furnish abundant information on early stages of African tabanids, and new studies on South American tabanid larvæ were published by Bodkin and Cleare in 1916. Some new species of egg parasites have also been described in recent years by Crawford from King's material, and by Girault (1916) from Tabanus eggs from Dallas, Texas.

The various text-books on medical entomology and related subjects which have appeared recently, besides those quoted by Bainbridge and Fletcher and by Patton and Cragg, those published by Göldi (1913), Herms (1915), W. A. Riley and Johannsen (1915), and Grünberg (1907), also Brumpt's Précis de parasitologie (1910), contain a good deal of information on tabanid early stages, including also quotations from previous literature.

While most of the recent work has been done by British and American authors, new and accurate studies on the oviposition of Tabanus quatuornotatus have been made by Lécaillon (1911), and another paper by Picard and le Blanc (1913) reports the early stages of another species. In the latter year there also appeared a paper by del Guercio on the tabanids of the rice fields of Bologna, which, however, contains little of scientific value.

The complaint made by some writers of the meagerness of our knowledge of the life history of this group, notably by Göldi, will probably soon be unfounded, if our knowledge progresses as rapidly as it has in the last few years.

South America, which is extremely rich in interesting tabanids, and Australia, where until now apparently no work has been done, 
should yield many new discoveries. On the other hand, European investigators have neglected the Tabanidæ somewhat, and it would seem desirable to reinvestigate the larvæ of the common Tabanus bovinus, which since their discovery by Degeer in 1760 apparently have not been found again.

\section{CHRONOLOGY.}

1760. Degeer bred Tabanus bovinus from terrestrial larva.

1775. Fabricius' Systema entomologix, said to contain notes on Chrysops larva.

1776. French translation of Degeer's Mémoires.

1798. Fabricius' Entomologia systematica.

1834. Macquart cited the observations of Degeer.

1838. Wahlberg, in Sweden, published notes on the larvæ as semiparasites.

1840. Westwood cited the observations of Degeer.

1842. Zetterstedt's observations on Chrysops.

1848. Scholtz observed pupæ of three tabanid species near Breslau.

1854. Kollar published Mann's observations on oviposition of Tabanus.

1863. Walsh, in Boston, described the larva of Tabanus atratus (aquatic).

1868. Marno, in Vienna, found the aquatic larva of Hexatoma pellucens.

1869. Brauer described the terrestrial larva of Hamatopota pluvialis.

1870. Perris, in France, independently described the same larva.

1870. Riley, in America, redescribed the larva of Tabanus atratus.

1875. Beling, in Germany, described (third) the larva of Hamatopota.

1878. Graber discovered an otocyst-like organ in the tabanid larva.

1879. Krauss claimed the discovery for Brauer.

1880. von Friedenfels found aquatic larva of Tabanus autumnalis in salt lakes in Siebenbürgen.

1882. Beling described the pupa of Chrysops relictus.

1882. German translation of Degeer's Mémoires.

1882. Graber described the chordotonal organs of Tabanus (Chrysops?) larva.

1883. Brauer gave notes and illustrations on various tabanid larvæ and briefly summarized the literature.

1895. Hart, in Illinois, described several American species of tabanid larvæ, notably Tabanus stygius, lineola, costalis, and Chrysops vittatus.

1899. Sharp, in The Cambridge Natural History, illustrated larvæ of Tabamus (? Atylotus fulvus).

1903. Hine, in Ohio, described the larva and pupa of Tabanus vivax.

1903. Hine's Monograph on the Tabanidæ of Ohio, with notes on life histories, containing also the first notes, and on oviposition in Chrysops.

1904. Hine's studies at the Gulf Biological Station. 
1905. Lécaillon, in France, gave detailed studies on the oviposition of Tabanus quatuornotatus.

1903-06. Hine's Gulf Biological Station Reports, containing new data on oviposition.

1906. Hine's Report to the United States Department of Agriculture, describing early stages of Tabanus lasiophthalmus, sulcifrons (in part), etc.

1907. Paoli, in Florence, continued the work of others on Graber's organ.

1908. Portschinsky, in Russia, summarized the previous knowledge of tabanid life histories, as an aid in the study and control of these insects.

1908. King, in Khartoum, described the early stages of Tabanus biguttatus.

1908. Walton, in Pennsylvania, described the egg and larva of Goniops chrysocoma.

1909. Brimley, in North Carolina, published notes on the larvæ of Tabanus fronto and other species.

1909. Maxwell-Leffroy and Howlett, in Indian insect life, gave notes on the larval habits of Indian tabanids.

1910. McAtee, in Washington, described further stages of Goniops.

1910. King, in Khartoum, published the life histories of Tabanus par, taniola, ditcniatus, and kingi, securing oviposition in captured specimens.

1911. Lécaillon gave additional studies on Tabanus quatuornotatus.

1911-12. Baldrey observed oviposition of Tabanus orientis.

1913. Mitzmain published the life history of Tabanus striatus, the carrier of surra in the Philippines.

1913. del Guercio, in Italy, reported on the larva of Tabanus ignotus.

1913. Picard and le Blanc, in France, observed the larva of Tabanus cordiger.

1913. Patton and Cragg published a text-book of medical entomology, containing information on the larvæ of several Indian tabanids.

1914. Bainbridge and Fletcher, in India, gave additional notes on Tabamus striatus.

1914. Lutz, in Rio de Janeiro, described the larvæ of three Brazilian tabanids.

1915. Neave presented abundant data on the larval and pupal stages of African tabanids.

1915. Riley and Johannsen, published a text-book, containing a few new illustrations.

1916. Girault described a new egg parasite (Phanurus emersoni).

1916. Bodkin and Cleare published notes on the early stages of tabanids in British Guiana. 


\section{TABANID E, DESCRIPTION OF THE EARLY STAGES.}

The Tabanidæ belong ecologically to the so called hydrophytic area, as has been pointed out by Osburn. On the whole, they may be called aquatic or semiaquatic, though not all of them pass their larval stage actually in the water; at the same time they show traces of an adaptation to plants which may serve to understand their phylogeny. The larvæ may be aquatic, semiaquatic, or even terrestrial in habitat, but always live more or less hidden and are seldom seen. They are, according to Malloch, "found rarely among decaying leaves or in low and somewhat marshy spots in fields." Neave and others, however, have obtained them in quantity from the muddy banks of rivers and brooks.

The eggs are laid in clusters of one or several layers, forming a compact flat or conical mass; they are rarely laid scattered, and never singly. The clusters may consist of several hundred eggs, the eggs being held together by a sticky substance. The whole mass is often covered with a dark shining varnish or with a chalky substance. These masses are deposited usually on plants or sticks at the edge of ponds, streams, and lakes, seldom on dry ground, and sometimes also on stones above water, but this is unusual. ${ }^{2}$ The single egg is spindleshaped or cylindric, and narrowed at the ends, white, yellow, or pale brownish when first laid, but later often pigmented, brown or shining black, the color being due to a pigmentation of the chorion. The period of incubation is short, from 3 to 9 days, but in some cases the hatching process is delayed for weeks by atmospheric conditions, while the embryo is fully developed and may be caused to hatch by artificial stimuli. All the eggs usually hatch at the same time, the young larvæ at first sticking together but soon losing their hold and tumbling down. In many cases only part of the eggs of one mass give birth to larvæ, about half of them being infected by small hymenopterous parasites.

${ }^{2}$ Macquart's statement that the female deposits its eggs in the ground is erroneous. 
The newly hatched larvæ drop into the water or onto the ground, according to the egg-laying habits of the species, and little is known about them. The young larvæ resemble the full grown in appearance, but are generally more transparent, showing the internal organs, a pair of black eye-spots, and Graber's organ in its primary condition, which is later described. The chordotonal organs have been described in young tabanid larvæ. The nervous system is clearly visible. The young larvæ may be fed on tiny crustaceans, crushed insect larvæ, etc., but are not always successfully reared.

Of the young larvæ some have strongly developed tracheal trunks which enable them to float, while others sink to the bottom.

All tabanid larvæ are highly predacious, feeding on other insect larvæ, earthworms, and probably all animals they can get hold of, not sparing their own kind. Wahlberg found them, according to Brauer, semiparasitic in lepidopterous (noctuid) larvæ. Perris reports that he has found them under stones feeding on larvæ of Rhizotrogus and on Melolontha (imago?). According to Brauer, young larvæ burrow into other larvæ (of beetles) and leave these only when they completely fill the skin of the host. Brauer once obtained the larva of Hamatopota from the larva of Helops lanipes, from which, as it seemed to be molting, the tabanid larva made its way. Walsh states that they feed on snails; Hine and others fed them on earthworms. Young larvæ can be fed on small crustaceans (King). It is not known what food they take in nature, and also whether they can subsist on vegetable food. Del Guercio's statements on this point are probably erroneous. Mitzmain and others have observed their cannabalistic tendency, at least in captivity. As Patton and Cragg have stated, the larvæ of the large species and of the nearly allied full grown stages of the smaller species feed almost exclusively on earthworms whose body juices they suck out; this explains why gregarine cysts (Monocystis) are not uncommonly found in the alimentary tract of the imago. Malloch says that the food of the species occurring in rivers is mostly tipulid and other larvæ which burrow in the soft banks of the rivers or occur in the river bottom or in drift.

Structure of the Mature Larva.-All the known larvæ of tabanids, with the exception of the somewhat aberrant Gonoips, are elongate, 
cylindric, slender, tapering at both ends, capable of contraction and extension, their body consisting of a head and twelve segments, the last segment being very short. The larvæ are eucephalous, with head well developed but small, bearing the three-jointed antennæ, attached to the anterior angles of the head just above the palpi, the basal joint being short, the others of varying length. A bunch of stiff spines, either short or moderately long, is situated above each antenna and on each side of the labrum. All the essential mouthparts are present and have been studied in many species. They are well adapted for seizing the prey, and constitute a very formidable apparatus (Patton and Cragg). The essential organs are the mandibles and first maxillæ, and of these the former are the most powerful weapons. Each mandible is a stout rod of chitin, slightly expanded at the base, to which the muscles are attached, and narrowed distally to a blunt point; the rod is curved downwards and forward, and on its concave border has many coarse serrations. The maxillæ are similar in shape and general disposition, but are smaller and less heavily pigmented, and are more pointed. Both pairs of appendages can be thrust out from the head in a downwards and forward direction when the larva attacks its prey, by means of the protractor and retractor muscles attached to the base of the rods. One sometimes becomes aware of the existence of these organs when handling the larvæ, as they are used in defense as well as in attack, and are capable of inflicting a sharp nip, though they do not draw blood. The maxillary palpi are simple and two-jointed, the distal joint being much smaller than the proximal one. The dorsal and distal extremity of the head is projected forward as a short and fleshy labrum. A labium is likewise present. The head is attached firmly to the pharynx, and is retracted and exserted together with it. The pharynx itself is an elongate chamber of the usual type and is easily seen in the living larva. The eye-spots are placed on the dorsal side of the pharynx, not on the outer cuticle, and follow the movements. of the pharynx. The pharynx leads posteriorly to the esophagus, which is narrow, but wider and more muscular than that of the adult. It is usual to find that the esophagus is wider and more muscular in insects whose food is solid or semisolid than in those which take only fluid food. 
The head itself, as far as it can be exserted, is strongly chitinized and usually brownish in color, while the rest of the body is generally pale, whitish or grayish, but in many species marked with a regular dark pattern, which in others may be absent. Following the head are the three thoracic segments, of which the first is the shortest, and these are followed by nine abdominal segments, the last one forming the respiratory tube, and the next to the last segment bearing ventrally the anus on a fleshy prominence. The body surface is generally smooth, well chitinized, and half transparent. The fourth to tenth segments are provided at their anterior margin, or not far from it, with a strong circular fleshy ridge, containing circular muscles, and bearing the parapodia, eight in number when all are present, or fewer if, as may be the case, the dorsal ones are lacking. The ventral parapodia are usually better developed and placed somewhat closer together. The parapodia may be retracted and exserted, and, provided with many curved spines outwardly, play a part in locomotion. The ridges in some species are not very prominent, are usually covered with a fine pubescence rendering part of the body surface opaque, and are often pigmented dark, forming the patterns spoken of. The spinous processes of the prolegs pass through imperceptible gradations into the fine pubescence of the dull or pigmented areas.

The larva of Goniops chrysocoma differs in appearance from the other known tabanid larvæ by being apparently much shorter and thicker in the posterior half of the body than in the anterior where the segments are much tapered and considerably longer, but as the figures are based on specimens preserved in alcohol, we cannot pass a definite judgment on their systematic position. ${ }^{3}$

Integument.-The integument in general can be divided into more or less distinct dorsal, ventral, and lateral areas, which differ in their finer structure, all being either longitudinally striated or more or less smooth and shining. The lateral areas may be subdivided into an upper, middle, and lower portion, marked off from one another and slightly differing in structure. All these structural features of the surface of the integument are probably vestigial-traces of formerly more marked characteristics, and are important in any effort to separate different species of larvæ.

${ }^{3}$ See also Goniops in general, p. 56. 
The structure of the chitinous membrane has been studied in detail by Lécaillon in Tabanus quatuornotatus Meig. The membrane consists of three layers or zones, the innermost soft and of greatest thickness, the two outer ones hard and elastic; of the latter the inner (median) is much thicker than the external one. By staining methods the three layers can be differentiated. The fine striation of the cuticle is formed by the median layer, which is thickened in the form of narrow longitudinal ridges. The hairs are formed exclusively of the external layer. The muscles to the integument are attached to the median zone.

The muscular system is strongly developed, consisting of the retractor and extensor muscles of the head, and probably similar muscles governing the retraction and extension of the syphon; also of muscle fibers arranged more or less vertically to the integument, and circular muscles which function in the contraction of the circular segmental ridges and the retraction and exsertion of the parapodia. The muscular system is partly illustrated but not described by Graber (1882) (Plate 8, Fig. 100, a). Lécaillon (1906) notes the muscular insertions in the integument, stating that the muscles pass through the inner chitinous layer, losing here their transverse striation, and being inserted in the median layer. Various muscles go to the organ of Graber, described later, by means of which this organ is displaced in various directions. (Plate 9, Figs. 104 to 106, and Plate 10, Figs. 112,115 , and 116.)

Alimentary Canal (Plate 7, Fig. 98). - This has been studied by Patton and Cragg in Tabanus albimedius (also in other species?). It is much shorter and less complicated than that of the larva of Stomoxys calcitrans, described by the same authors. The esophagus opens into a short, cylindric proventriculus, which is also a highly muscular structure, and is sharply distinguished from the succeeding part of the gut by its clear translucent appearance in the fresh condition. The mid gut extends from the proventriculus to the hind end of the body; and is thrown into one or two simple coils, not constant in their position. It is separated from the proventriculus by a short constriction, and is again constricted at the posterior end, just anterior to the opening of the Malpighian tubes. Between these points the lumen is wide and is thrown into numerous sacculations 
by the contractions of the muscle fibers in the wall. The mid gut is, at least in the species studied by Patton and Cragg, of a striking orange-red color in the fresh condition, and is filled with a semisolid mass of a light chocolate color, which oozes out if the wall is punctured in dissecting. The hind gut is short and simple, and is coiled up in the posterior end of the abdomen. The total length of the gut is about twice the length of the body of the larva. The salivary glands are simple and tubular, and bear a remarkable resemblance to those of the adult insect.

Respiratory System.-The respiratory system resembles that of the mosquito larva. There are two large lateral tracheæ which run the whole length of the body on each side of, and slightly dorsal to the alimentary canal. According to Patton and Cragg (1913), these communicate with the external air through an opening, which can be closed, on a small prominence on the dorsal surface of the penultimate segment. This statement appears to be erroneous. Brauer (1883) states that the tabanid larvæ are usually metapneustic, the last segment with a vertical respiratory fissure or the last two segments forming a respiratory tube. According to Malloch (1917), they are always metapneustic. The respiratory tube is of varying length, sometimes very short, sometimes more slender and tube-like, or forming a short acute spine. The two main air-filled trunks are much inflated in some species, enabling the larvæ to float at the surface of the water, and narrow, almost filiform in other species. As they pass forward, they give off slender branches of tracheæ to the body cavity in each segment. In the anterior part of the body the tracheal stems, in the species where they are generally much inflated, become slender, describing one or several semicircular loops and tapering into fine tracheæ going to various organs. The tracheal branches going to the body wall of each segment may be homologous with those leading to the abdominal spiracles in amphipneustic larvæ.

Dorsal Blood Vessel.-The dorsal blood vessel is easily seen in transparent larvæ and ends blind, in the cases observed, before the eleventh segment.

Malpighian Tubes.-The Malpighian tubes are, to judge from Patton and Cragg's figures, four in number, in young larvæ irregularly crowded in the posterior part of the body between the two tracheal trunks, and of brownish, greenish, or yellow color. 
Fat Body.-No observations of the fat body have been made, except that Graber (1878) describes it, in Tabanus autumnalis (?), as a network of pale lobes and trabecula with dendritic tracheal expansions, lying dorsally and above the new organ described by him.

Gonads.-These organs, which must be present in the larva, have not been noticed or described by any author.

Nervous System.-The nervous system of the larva consists, according to Graber, who studied the young larva of Tabanus (Chrysops ?), of a large upper and lower cephalic ganglion, and a chain of large ganglia arranged like beads and extending about half the body length. According to Graber, this would be the only instance of the nervous system having this structure (Plate 8, Fig. 99).

Sense Organs.-The eyes have been mentioned; their function is not clearly understood. Antennæ and palpi are probably olfactory. Tactile bristles occur on the body surface and have been studied by Graber who finds them connected with several ganglion cells (Plate 8, Fig. 100, b). Chordotonal organs, similar to those in Corethra, are found laterally in each segment near the surface of the integument, and are of the mono-, di-, and triscolop type (Graber), and are connected with the tracheæ. According to Graber, in small larvæ, the chitinous body walls themselves act as a tympanum, thus explaining the absence of any special tympanal apparatus (Plate 8, Fig. 100, a).

At the posterior end of the larva, situated dorsally and adjacent to the blind posterior end of the heart, on the eleventh segment, is an organ of unknown function, called Graber's organ, after its discoverer (1878). It consists of a pear-shaped sac, the broader end of which is anterior; the posterior end narrows down to a fine tubule which opens on the integument of the body between the last and the next to the last segments. Within this sac there is a series of capsules set one behind the other in the long axis, and within each of these capsules is a pair of small, black, pyriform bodies, each attached to the anterior side of the capsule by a delicate pedicel (Plate 9, Figs. 103 to 108, and Plate 10, Figs. 109 to 120). These bodies diminish in size from the anterior end, the first being considerably larger than the rest. They are easily seen through the integument of the living larva. The outer sac is an invagination of the integument, and as 
such has a chitinous lining. Graber believed that the structure is an auditory organ, but Lécaillon supposed it to be a gland. Berlese, according to Patton and Cragg, does not consider that it has been proved to be a sense organ, though it is well supplied with nerves. Paoli has shown that the young larva has only two pedunculate bodies, and that with each successive molt a new capsule with two more such bodies is formed. Having observed that Tabanus larvæ are able to produce a slight crackling noise, Paoli believes the structure to be a sound-producing organ, but it is difficult to understand what ecological meaning such an organ could have. ${ }^{4}$

The pupæ of tabanids are classified as orthorhaphous (Brauer), opening in the act of hatching with a dorsal longitudinal slit. They strongly resemble lepidopterous pupæ (Mumienpuppe, pupa obtecta), having wing and leg cases firmly attached to the body and covered with it by a chitinous membrane. The pupal body is subcylindric, abruptly pointed or rounded anteriorly, and tapering somewhat posteriorly; it is generally yellowish brown to ferruginous brown, finely wrinkled, and has a lateral tuft of hairs on each abdominal segment. On either side of the head are the antennal sheaths, pointing outwards, and on each side of the median line two large tubercles, each with a central hair; below these are two raised areas with sharp edges, separated by a deep ridge. Lower still there is a pair of elevations, also with raised edges, and on the ventral surface of the head one or more tubercles. The segments of the thorax are indistinct; the mesothorax bears the large raised ear-shaped spiracles. The abdominal segments are free and about equal in length, and have one or more fringes of hairs near their hind margins; the second to the seventh segments inclusive have well marked lateral areas, covered with long hairs which are continued into the dorsal and ventral surfaces and correspond to the lateral areas in the larval integument. These hairs increase in length from before backwards, and are best developed on the seventh segment. The eighth segment is short, and is provided with six projecting spurs or teeth, and with a large anal tubercle. In the male the tubercle is ribbed and bounded anteriorly by a continuous fringe of strong spines; in the female the tubercle is smaller and the

${ }^{4}$ For details concerning the structure of this organ, refer to pp. $29-43$. 
fringe of spines is widely separated. The pupæ of many of the larger species of Tabanus have in addition a lateral tuft of spines situated on a ridge. Patton and Cragg were the first to notice structural differences in the male and female pupæ.

Brauer (1883) says that he classifies the tabanid larvæ with the Leptidæ and Acanthomeridæ (to which they are undoubtedly nearly related, as also to the Asilidæ) under Homoeodactyla tanystoma, of which the larval characteristics are:

Larva meta- or amphipneustic or with tracheal gills, usually with eyes at the sides of the head capsule, the latter usually hidden in the following rings, generally more or-less retractile, and behind it eleven or twelve body segments. Mandibles hook-like; extending out of or under them in their concavity are the maxillæ, which are soft-skinned, and the laterally prominent maxillary palpi; antennæ short. Labrum hooked or horn-like, exserted. Pupa a free "mummy-pupa."

Malloch (1917) proposes to unite the Tabanidæ with the Leptidæ to a superfamily Tabanoidea, having the following characteristics:

"Larva.-Head small, wholly or partly retracted, permanently retracted portion with an arcuate dorsal plate over the longitudinal rods; mandibles strong, hook-like, curved downward; maxillæ well developed, wholly or largely membranous, the palpi well developed; antennæ distinct, pedunculate. Body cylindrical, with or without pseudopods; lateral abdominal spiracles absent in Tabanidæ, small, but no lateral spiracles distinguishable in Leptidæ; apical spiracles in a vertical fissure in Tabanidæ, exposed and separated in Leptidæ."

"Pupa.-Head with strong cutting armature; antennæ with or without distinct annuli. Thoracic respiratory organs sessile. Wings and legs closely fused to each other and to thorax; fore tarsi overlying midpair, the latter overlying hind pair, the pairs successively longer, hind pair not extending beyond apices of wings. Abdomen with seven pairs of lateral spiracles; segments armed with transverse series of slender bristles which become progressively stronger from base to apex of abdomen."

Brauer's characterization of the Tabanidæ is the following:

Family Tabanida.-Larva usually metapneustic. Eyes distant from the mouthparts, situated laterally and back of the head capsule; the latter divided by a fissure at the inserted end, at the hind end open and prolonged backwards into long rods, hidden in the following segments. Mandibles hooked, often serrated at the border; labrum forming a hook-like projected septum between them. Body eleven-segmented, often girdled with retractile fleshy tubercles which are often developed as prolegs at the ventral side only. Last segment with a ver- 
tical respiratory fissure, or the last two segments forming a respiratory tube. Pupa free, without crown of hooks at the fore end, antennal sheaths laterally exserted, parallel to the head. Between them four swellings or ridges, arranged in a curve and formed by chitinized folds. Above them three tubercles, forming a triangle (anlage of ocelli) and behind them outwards two larger tubercles. Beneath the wing sheaths on the inner margin of the sheath of the compound eyes on each side are two small tubercles lying one above the other. Anal segment with six divergent cone-shaped pointed hooks. Spiracles behind the head and on the seven abdominal segments distinct and large, the former with kidney-shaped or ear-shaped margin (Therioplectes) and often very large. The pupa rests in the ground or, in some species (Therioplectes), remains in the water.

Malloch describes the body of the larvæ as "circular in transverse section, elongate, tapering at both ends, and with encircling locomotor swellings at the segmental sutures in all genera except Goniops."

Malloch's description of the tabanid pupa, based on the study of a number of species, is the following:

"Pupa.-Head without projecting thorns. Thoracic respiratory organs sessile, connected subcutaneously with a large cavity on each side of median line close to anterior margin of prothorax. [Plate 13, Figs. 153 and 154.] Wings and legs rather short. Abdominal armature consisting of 1 , or 2 closely contiguous, series of bristles on each dorsal segment except first, and a weaker transverse series on ventral segments; apical segment ending in six stout processes which are more or less radiate and pointed. [Plate 13, Figs. 162 and 163.]"

On the habits of the larvæ before pupation, facts have been published by Neave (1915).

Before the larvæ have reached their full growth, which in many cases signifies the beginning of a resting period, they usually lie buried in the mud, head downwards, with their syphons projecting immediately above the surface of the mud or of a shallow layer of water above it if it is present. In the resting stage the syphons do not seem to be used and the larvæ remain several inches below the surface for weeks or even months. This is presumably an adaptation connected with a climate in which there is a very marked dry season, and, consequently, a risk of the mud in which they are lying more or less drying up. Pupation appears to take place in normal circumstances an inch or more below the surface, though occasionally in captivity individuals pupated lying horizontally upon it. The pupa is normally upright in the mud, and after pupation, as soon 
as the case has hardened, it works its way up by means of its rings of spines and the aster (a name proposed for the terminal whorl of spines), until the pupal head lies just below the surface, being often visible from above. The pupa at first is usually of a pale yellowish or greenish color, but darkens as the imago develops within, the process beginning with the eyes.

Neave observed that in normally fine weather the imagos of all species almost invariably emerged between noon and 3 p.m. They were more irregular during spells of dull and rainy weather. The process of emergence seems to be similar in individuals of a! genera, whether Chrysops, Hamatopota, or Tabanus. The head of the pupa splits in the median dorsal line and the imago rapidly emerges until only the end of the abdomen, which is at first enormously elongated, remains in the pupa case. The wings at this stage are milky white and the darker markings, if any, are barely visible. The imago usually remains in this position for two or three minutes before completely leaving the pupa case. It is capable of flight very soon after this, but if undisturbed sits for about half an hour on any suitable object near by while the wings dry and assume their normal coloration, and the abdomen its normal shape. During this period several drops of a milky white fluid (the meconium) are passed through the anus.

\section{Bionomics.}

On the bionomics of the tabanids in the early stages we possess many interesting notes by Neave (1915). From the results of a year's collection of adults in one locality, and from other evidence, it is probable that the majority of tabanids, at least of Nyasaland, have only one brood a year. This is certainly true of nearly all the species of Tabanus and of Dorcalcemus fodiens Aust. It is possible, however, that certain species of Chrysops and Hamatopota may be double-brooded; much doubtless depends on the larval food supply, climate, etc.

According to Neave, in the case of many species the larva grows very slowly after hatching and often takes six months or more to become full grown. It then, especially in species of Tabanus, goes through a resting period, during which it remains buried in mud or sand, sometimes at a considerable depth. In contrast to the lengthy 
larval stage, the pupal period is short, varying, in Neave's experience, from 10 to 16 or 18 days, according to the species and the climatic conditions, the longer period being usual for the larger species of Tabanus.

One difficulty connected with the question of these flies having more than one brood a year arises from the fact that even in larvæ from the same batch of eggs the rate of growth is extremely variable, and consequently the processes of pupation and emergence do not take place simultaneously in a certain proportion of the individuals. Some of the remainder take longer to reach maturity, others seem to pass through an extended dormant period. The adults arising from these emerge at irregular intervals, often months later. This probably explains the capture of odd specimens of any species long after the usual season. It would also seem not improbable that individuals which miss their normal season for pupation in some circumstances continue in the larval stage until the following year. Thus Neave possessed in his laboratory in January and February examples of larvæ of Tabanus corax, some still in a dormant state and others not yet mature, the season for the adult flies being over by the beginning of January. It would appear that these would not have produced imagos until the following December, though Neave was unable to decide this point on account of his return from Nyasaland to England. Hine states that the larvæ of Tabanus stygius-probablyhibernate twice before giving the adult.

Surcouf and Ricardo, however, assert that in spite of the opinions to the contrary the tabanids seem to have, at least in Algiers, often two generations in a year. These authors have taken from a horse several fresh specimens in May (1908), while the same species is taken in France and Algiers in the fall. Maxwell-Leffroy and Howlett state that at Pusa (Bengal) there are apparently three broods of Tabanus yearly, flies emerging at the beginning and end of the hot weather (about February and June) and at the end of the rains (October). These statements should be compared with those made by Neave. Hibernation takes place in the larval state in India in all species which were observed by Maxwell-Leffroy and Howlett; and the same holds good for all known American species (Hine), larvæ being found late in the fall and again in early spring. No pupæ have been found in the winter. 


\section{Special Anatomy of Tabanid Larve. Graber's Organ.}

Almost the only detail of the structure of tabanid larvæ which has been studied more extensively is a peculiar organ situated on the dorsal side of the segment before the last, and discovered first by Graber (1878), who, while conceding that it has very little resemblance to an auditory organ, nevertheless may have to be placed in this category. As the situation of the organ is rather unusual if it is auditory, Graber recalls the discovery by Grobben of similarly situated organs in the larva of another fly, Ptychoptera contaminata (Tipulidæ), and of which the auditory function seems fairly certain. Whether similar organs are found in other dipterous larvæ is not known; Malloch (1917) does not mention them. The organs seem to occur in all tabanid larvæ, but to be more easily seen in the young stages; they have been overlooked by some later investigators, notably Hart (1895) and Hine (1901-06), but have been seen and figured by Walton (1908) for Goniops chrysocoma (only as dots), and by Mitzmain (1913) for Tabanus striatus, all of whom have apparently overlooked the European literature on the subject, Mitzmain assuming that the organ must either be peculiar to the larvæ observed by him, or have been overlooked by the previous authors.

Graber found the organs in the abdomen of the larva, at the sides of the two last segments. They consist of a cornea-like inflation of the integument which is covered inside with its epithelium. The open inner side of this vesicular invagination seems to be closed by a membrane supported by radial elastic fibers, the fundus of which can be extended by means of a strong muscle. According to Graber, the presence of a special nerve, which, however, approaches the vesicle without any specialized termination, is proof that we are dealing with a sense organ.

However, what characterizes them as auditory organs are two or three otolith-like bodies found in the liquid contents of the capsule. These abdominal otocysts consequently differ from antennal structures described elsewhere by Graber, first, by belonging to the integument itself, second, by their inner wall not being formed by chitin but by the epithelium. As a consequence of this, the development of cuticular auditory hairs is naturally also suppressed, and a new type of 
auditory capsules is developed, which Graber distinguishes as otocysts without cilia (aciliate) from other known otocysts (ciliate otocysts).

The organs were found by Graber (Spring, 1878) on a dipterous larva collected with other material, on the bottom of a mud pond in a brick factory. The larva (Plate 9, Fig. 103) was when extended about $40 \mathrm{~mm}$. long, cylindric, strongly spindle-shaped, and pointed at the end, and except the dark intestinal system, of an almost glassy transparence. Eleven segments were counted, which with the exception of the terminal ones, were surrounded by a girdle of papilliform retractile processes. Unfortunately, as literature was not accessible, the species could not be determined.

In order to see the organ in the fresh condition, the larva is laid on its ventral side and fastened with an elastic holder. The organ (Plate 9, Figs. 104 to 108) lies in the median line of the dorsal side, behind the termination of the dorsal blood vessel, and immediately behind the border incision between the ninth and tenth segments. By focusing from above, at first the body cuticle becomes visible, which derives from the presence of longitudinal ridges the extraordinary elasticity characteristic of these larvæ. When focusing farther down, the epithelium is seen, consisting of flat polyhedric cells, and following this a network of pale lobes and trabeculæ with dendritic tracheal expansion; namely, the fat body. Immediately underneath these tissues lies the organ in question, which is consequently completely separated from the integument. It consists of a pale capsule $0.3 \mathrm{~mm}$. in length and pear-shaped, its free and broader end directed upwards, while its pointed hind end is prolonged into a narrow tube. The capsule being of considerable size is visible even at slight magnification. Moreover, it is not likely to be overlooked because of the intensely black bodies included in it, which strongly contrast with the light background.

In detail the structure of the organ appears to be peculiar. From the capsule proper with its tube the nerves and muscles attached to its anterior end may be distinguished. The whole capsule together with the terminal tube appears, as Graber says, to be a cecum-like invagination of the ectoderm. Unfortunately the origin of the terminal tube could not be found by Graber; it apparently lies in the 
last body segment and is in no way connected with the intestine, which terminates at the end of the segment before the last, or with the sexual organs. In Graber's account it remains questionable whether the terminal tube, as was supposed, really originates in the integument. The tube and the capsule forming its enlarged terminal part behave histologically like a glandular formation. The main layer is an epithelium consisting of large cells. This is seen best, especially after treatment with 35 per cent potassium hydroxide, at the distal (head) end of the capsule. The cells appear as elongated, sac-like, pale compartments, separated from one another by bridge-like septa, always showing a dark nucleus accompanied by a small nucleolus. In the remaining part no distinct cell borders can be distinguished, but only large granulated nuclei. In the terminal tube the latter are arranged alternating behind one another, similarly as in the narrow secretory ducts of true glands. The epithelial tube is covered at the outside by a thin homogeneous covering which may be considered as a tunica propria.

The structures belonging to the third stratum, that is, to the chitinous membrane, are peculiar. Leaving aside certain complications, we find first a chitinous capsule corresponding to the epithelial one, which is prolonged into a narrow canal corresponding to the terminal tube. This canal pursues, inside the terminal tube, an undulating course, curved alternately to the right and left, suggesting the muscle in the stem of a Vorticella.

The chitinous capsule enclosed within the epithelial vesicle is often very thin and delicate compared with the thickness of its matrix, and is perfectly transparent. Its free (inner) surface, however, shows at high magnification small tegula-like overlapping scales. In this chitinous capsule the black bodies already mentioned are enclosed.

At low magnification these bodies appear as simple homogeneous globules. At the highest magnification, however (Plate 9, Fig. 107), they are found to be hollow chitinous structures with a somewhat wrinkled surface, which after the fashion of a volumetric flask are prolonged into a narrow hollow stem or peduncle. The bodies remain perfectly black and opaque even when boiled in caustic potash; consequently they seem to have very thick and strong chitinous 
walls. Sometimes it seems as if they are filled with a dark tough substance, projecting in the shape of a papilla or of a granulated string into the lumen of the peduncle. Eight of these pedunculate bodies, as Graber calls them, were present in the larva examined, arranged in four pairs, lying one behind the other, giving to the vesicle the appearance of an internally segmented organ. The bodies of the first two pairs are of about the same size, $30 \mu$ in diameter, the length of the peduncle $26 \mu$, its width at the tip $1.8 \mu$. The bodies of the two following pairs immediately touching one another are considerably smaller than the rest, their diameter being only $20 \mu$.

The compound nature of the organ appears more distinctly than in the serial arrangement of the pedunculate bodies, in the repetition of the covers in which they are enclosed. There are not four such covers or secondary sacs, however, but only three, as the two posterior pairs of pedunculate bodies are contained in a common envelope. The first sac is formed by the capsule itself; that is, by its rounded (head) end. The pedunculate bodies are observed hanging by their pedicel from the slightly invaginated upper wall, and, like the following ones, turned from the inside towards the outside in a somewhat oblique direction. The space in which the bodies are found, however, is separated also from the remaining lumen of the capsule, and, as far as could be seen, by a transverse septum issuing from the side walls.

The second pair of pedunculate bodies is, however, surrounded by an independent sac entirely separated from the main capsule, the fixation of the pedunculate bodies themselves at the inner upper wall of the secondary vesicle being exactly the same as that in the first capsule. This second sac, however, is not completely closed behind the pedunculate bodies, but is forming here only a neck-like contraction, its walls otherwise being continued into the following sac.

The third inner sac resembles the second one in all essentials, but encloses, as already mentioned, two pairs of pedunculate bodies, which again, in a manner analogous to that in the former cases, are inserted into its walls.

Probably the last two sacs are evaginations of the fundus of the common capsule, fitted into one another like the sheaths of an onion. In this way the first pair is surrounded by one envelope, the second 
by two, and the third and fourth by four envelopes. The accessory parts of the organ have also been studied by Graber.

At a moderate magnification it is possible to discern, in addition to the tube extending backwards from the capsule, two other ligaments originating at the sides of the pear-shaped part, so that the whole organ appears to be held in place by three ligaments, one of which is the terminal tube. The two lateral ligaments extend obliquely, crossing the two large tracheal trunks, in a forward and outwards direction, inserted in a place not determined by Graber but probably lying in the seventh segment. At higher magnification the anterior ligaments are found to be muscles, and immediately behind the place of origin of these muscles two pairs of nerves are seen attached to the capsule. The first nerve being rather thin forms immediately at the head of the capsule a thick ganglion-like swelling, in which several pale nuclei are discernible. The character of the ending of this nerve has not been determined; Graber assumes that it enters into connection with the capsular epithelium. Nothing more is known about the termination of the second nerve which is much thicker than the first one.

All the parts described, the capsule, the terminal tube, the muscles, and nerves are connected with one another and with the surrounding organs, as also with the tracheæ and with the band-like extensions of the heart muscles, by a peculiar connective tissue. The latter shows the greatest affinity with certain elastic reticulate tissues of higher animals. These tissues play a part, according to Graber, in the extraordinary changes in the relative situation of the parts during the movements of the larvæ. Graber discusses the possible function of the organ he described, assuming that it must be either a gland or sense organ. The presence of a duct leading to the exterior seems to indicate the former, but the arrangement of the contents seems to contradict this view.

If the organ is considered a gland, this would imply that a secretion formed by the epithelial cells is discharged into the chitinous capsule. In this case, however, no explanation is found for the presence of the pedunculate bodies, not to mention the various interior secondary capsules. The pedunculate bodies have no free opening, and while they are hollow and possibly have been formed by invagination of 
the walls of the capsule, the place of invagination seems to have disappeared.

Graber therefore decided that the organ must be a sense organ, which, however, according to its peculiar structure and position cannot be either an organ of touch, smell, taste, or sight, and is consequently placed among the auditory organs. Graber also believed that he found the two main features of a cystoid auditory organ, namely a cyst-like cell system, connected with a nerve, and an internal fluid medium which may carry the sound. There were lacking only the characteristic elastic appendages of the auditory cells.

Graber assumes that under certain conditions the auditory cells may be stimulated by waves of sound even in the absence of special end organs, in the same way that the light-perceiving elements of the eye in part are also affected by light-waves in the absence of special terminal organs as found in highly developed organs of sight.

The presence of the peculiar pedunculate bodies seems, more than anything else, to have determined Graber's view, in as far as they form a good analogy to the otoliths commonly found in auditory organs of the cyst-like type. The pedunculate bodies are comparatively heavy, thick-walled bodies and are attached to the cysts by means of thin and probably elastic filaments or strings; they may be compared with the clappers of a bell, which facilitate their function as otoliths.

Graber classifies all auditory organs occurring among insects, as (1) elementary organs, consisting of isolated hearing cells or auditory hairs, (2) cystoid auditory organs, gymnotocysts, and chitinotocysts, found in crustaceans and many insects, and (3) tympanal organs, provided with auditory rods as found in Orthoptera. The chordotonal organs are related to the latter and differ by the absence of a tympanal membrane. The organ in question is classified among the cystoid organs.

Henneguy found the same organs in small larvæ resembling larvæ of Stratiomys (Lécaillon), (Plate 10, Fig. 109), which undoubtedly belong to Tabanus. The organ in this instance (Plate 10, Fig. 110) is different. It comprises a cellular mass situated in front of the organ and evidently connected with the dorsal vessel, a capsule following it, containing two pigmented bodies arranged as described by Graber, and, finally, a cyst prolonged backwards into a filament but 
not containing pigmented bodies. Henneguy is inclined to place the organ among the chordotonal organs.

Lécaillon, having in 1904 sent some larvæ of Tabanus quatuornotatus to Henneguy, studied the organ at the latter's suggestion. $\mathrm{He}$ records a number of facts which may facilitate further research on the subject. The principal results of his observations are as follows:

1. Graber's organ exists in all larvæ of Tabanus quatuornotatus. It should consequently be sought for among the tabanids, and possibly also in related families.

2. It already exists in the larvæ hatching from eggs, but it continues to develop as the larvæ grow.

3. In very young larvæ its structure corresponds to that described by Henneguy; in fact he made his observations on very young larvæ.

4. As the larvæ grow, the primitive structure becomes more complicated and more closely resembles the structure described by Graber. This author observed full grown larvæ.

5. Consequently it can be stated that Henneguy's description applies to the young condition of the organ, and that of Graber to the fully developed condition.

6. In Lécaillon's observations, as shown by the figures, the pigmented bodies do not always remain regularly arranged in pairs, contrary to Graber's description. They are seen frequently placed one behind the other in the posterior duct of the organs. Sometimes there is an odd number of them in this duct, which means undoubtedly that these granules can sometimes be discharged or expelled.

7. While nothing can be said with certainty about the function of Graber's organ, Lécaillon considers it glandular in nature rather than a sense organ.

The figure of the larva given by Lécaillon (Plate 10, Fig. 117) was obtained from a living larva of Tabanus quatuornotatus one month old, seen in dorsal aspect with light falling through, a larva at this stage being still very small. Two other figures (Plate 10, Figs. 118 and 119) give the aboral extremity of two other larvæ slightly older than the first one.

As seen in these figures, the main part of the organ of Graber occupies the median and dorsal region of the next to the last segment, in almost its entire length, and is situated not far from the two large tracheal trunks, which open, one near the other, at the end of the last abdominal segment. It consists mainly of an oval sac or cyst prolonged posteriorly into a tube. The oval and dilated part is subdivided by a septum in two cysts placed one behind the other. Careful 
study of this region shows that the two cysts are not completely separated and, on the contrary, communicate with one another in their axial region; in other words, the septum which separates them is incomplete. The tubular region which prolongs the posterior cyst begins towards the middle of the segment next to the last and opens in the median line not far from the openings of the two tracheal tubes. This tubular region is, consequently, about as long as the dilated portion of the organ. The fundus of the sac, that is its anterior region, has thicker walls than any other part. There is in this region a cellular mass similar to that described by Henneguy in the organ of the undetermined larva which he examined.

The ink-black bodies can be found, according to Lécaillon, in both capsules and in the tubular portion. The first capsule always contains two which are situated anteriorly, one to the right, the other to the left of the median line. By carefully examining their arrangement it is found that they are attached to the cellular mass at the fundus of the cyst, each by a small pedicel, as has been described by Graber and by Henneguy, whose observations are confirmed by Lécaillon. These pedicels do not show on Lécaillon's figures, which, as he says, were drawn from living larvæ under conditions when the details were not clearly visible. ${ }^{5}$ The second capsule contains sometimes also two of the black bodies, arranged as in the first capsule, but often it does not contain any of them.

The tubular region often contains no black bodies. But frequently and especially in older larvæ, it almost always contains a varying number. The maximum number which Lécaillon found was six, but there may be only five, four, three, or two, even in larvæ of the same age and living under the same conditions. As the caliber of the tubular region is narrow, the black globules are placed here in a lengthwise row, and not in pairs placed transversely, as in the capsules.

As Lécaillon wished to ascertain whether the black bodies could eventualiy be expelled to the exterior, a larva which had six globules in the tubular portion of the organ was placed under observation. Eight days afterwards Lécaillon found that the tube contained only

${ }^{5}$ I found that living tabanid larvæ up to $15 \mathrm{~mm}$. in size can be examined by means of a compound microscope, without suffering injury from the pressure necessary to hold them in place. 
two globules, four evidently having been expelled. At about the same time another larva of the same age was found to contain only the two bodies of anterior cyst; all the others had been thrown out. ${ }^{6}$ In summarizing Lécaillon states:

(1) The black bodies are formed by the cellular mass which constitutes the fundus of the capsule. (2) The globules are detached periodically to be expelled to the exterior after a longer or shorter time. (3) They are regenerated at the bottom of the cyst when the others have been expelled.

These conclusions of Lécaillon appear only partly warranted. From observations made hitherto there is no indication of a relation of the discharge of these bodies and their new formation.

Concerning the nature of the black bodies, Lécaillon states that they are not hard as if they were mineral granulations; they are not affected by reagents, as acid fixation fluids; they may be cut when the organ is sectioned. Consequently they seem to be a pigmented material, excreted by the cellular mass which forms the bottom of the cyst. Lécaillon alludes, in suppport of this view, to the fact that the larvæ of Tabanus quatuornotatus have a completely white body though the substances found in the digestive tract (organic relics) are usually blackish. The pigment derived from the alimentary substances, or formed normally in the body, might be excreted by means of this particular gland.

Paoli in Florence in 1907 studied the same organ in various tabanid larvæ which, on the authority of Bezzi, are said to belong probably to Tabanus cordiger Meig. or Tabanus autumnalis L. Paoli, however, asserts that in all probability many species of this family possess Graber's organ more or less developed and also with slight modifications in details of structure, according to age and species. For the description of the larvæ studied by Paoli see pages 91-93, Tabanus autumnalis.

According to Paoli's description, Graber's organ is found in the visceral cavity, situated dorsally under the subcutaneous muscular strata, in the anterior third of the eighth abdominal segment between the two large tracheæ (Plate 10, Figs. 115 and 116). It is a little pear-

${ }^{6}$ I have been able to confirm Lécaillon's observations in the larvæ of Tabanus atratus (1916). 
shaped cyst with a slight constriction in its wider part; its pointed end is turned hindwards. Inside this cyst are found, in the cases examined, several pairs of black rounded chitinous pedunculate bodies; each pair of these bodies is in turn enclosed in a special chitinous capsule filled with liquid. The attachment of the muscles and nerves to this cyst are described in detail. The cyst is continued, at its pointed end, into a contorted canal which opens in the deepest place of the infolding between the eighth and ninth abdominal segments (Plate 10, Fig. 115). The canal and the cyst are covered inside with chitin and completely surrounded by the hypoderma, so as to warrant the conclusion that the whole organ must be an invagination of the integument, as Graber had supposed, though he was unable to see the opening of the terminal tube.

According to Graber, the first cyst contains in its interior four pairs of pedunculate chitinized bodies; the first pair being in a closed capsule, the second inside another capsule, the latter not completely closed posteriorly, and finally the remaining two pairs contained in a common sac, open posteriorly.

Paoli states that the number of pedunculate bodies is not limited to four pairs, but varies according to the age of the larva. Graber also said (in his later work), that in the young larva there is only one pair of such pedunculate bodies, and that the second pair is formed later. Henneguy, who examined a newly hatched larva, found only one pair.

Paoli found four pairs in larvæ about $1 \mathrm{~cm}$. in length, but in specimens of larvæ in later stages of development he always found a greater number, up to seven pairs in larvæ of almost $3 \mathrm{~cm}$. in length. Each pair was found enclosed in a capsule which remains more or less open posteriorly, but which is always present; the largest of them, that is, that which is located anteriorly, has the thickest walls and is formed last, and it is only this one which is really living and in function, while all the others are dead and have no function whatever, differing little from one another, especially the capsules enclosing the smallest; namely, the oldest pairs of pedunculate bodies.

Each of the pedunculate bodies has the shape of a slightly elliptic ball, their surface being smooth or sometimes rugose. They are strongly chitinized, black, frail, and breakable, as under pressure 
they may be reduced to small fragments; the pedicel is inserted obliquely, equal to the latter in length. The pedicel itself is chitinous but not black; at most it is brown in the neighborhood of its insertion in the globule; at the other end it has a widening by means of which it fastens itself in a little cavity of the wall of the chitinous capsule. The pairs of pedunculate bodies are attached each one to the central portion of the anterior wall of the capsule itself, and the pedicels are a little divergent so that the two spherical bodies are located a certain distance from one another, suspended in the liquid which fills the cavity of the capsule. The pedunculate bodies are of dimensions increasing in the direction of the head; in a larva with four pairs these bodies measured for each pair 11, 15, 16.5, and $18 \mu$ in diameter.

Paoli explains the probable manner in which these cysts and the tube are formed. It has been stated that the latter opens into the innermost part of the sulcus which limits the eighth abdominal segment from the ninth; Graber did not see this opening but supposed that it was to be found in the last-ninth-segment and certainly independent of the alimentary canal and of the genital organs.

The origin of this organ is thought to be a sac-like invagination of the integument (Plate 10, Fig. 113). The most external part forming the terminal tube, the more internal one a cystiform enlargement, from the bottom of which the two pedunculate bodies originate, the latter consequently being nothing but modified hairs derived from the hypoderm surrounding the capsule.

In this way it is evident that in the young larva which has not yet undergone any molt there will be a primitive organ with only one pair of pedunculate bodies. At each successive molt the chitinous stratum of the organ remains in place, involved by a new stratum formed around it by secretion from the hypoderm, and the old capsule is pushed back distally. The new layer consequently forms a new cyst with a transverse division separating two halves in the anterior of which two new pedunculate bodies are formed, this being the new organ, while the posterior half consists of all that existed before. In this manner, with the successive molts, an increase in the number of the cysts and of the pedunculate bodies is brought about; the capsule wall which is thinner when it belongs to a younger stage; 
is no more easily visible in the final form. This hypothesis is, according to Paoli, the only one which explains satisfactorily the manner in which this strange organ is formed, and it is sufficiently supported by observation. In fact, the whole organ is covered by the hypoderm, the latter not being very different from that which covers the body integument internally.

In a preparation of a whole larva which had molted recently Graber's organ was made up of five pairs of black pedunculate bodies, and one pair, anteriorly located, had the pedunculate bodies already formed but entirely colorless; this capsule was evidently recently formed and its pedunculate bodies were not yet completely chitinized and fully colored.

The further fact, that the number of pairs of pedunculate bodies increases with the age of the larva, clearly demonstrates that they are formed successively, and inasmuch as we have to deal with an organ dependent on the integument, these successive formations must have something to do with the molts as modifications of the integument. All the cells and nuclei described by Graber as surrounding the cyst and the tube consequently are merely cells and nuclei of the hypoderm which surrounds the whole organ.

Paoli discusses further the muscles and ligaments observed by Graber. It is found that the muscles as well as the nerves are attached to the anterior capsule, which alone forms the living and functioning part of the organ, while the remaining part is to be considered dead, having functioned in previous stages of development.

While Graber described only one pair of muscles, Paoli observed four pairs and stated that probably Graber's second pair of nerves corresponds to the second pair of muscles. Two large anterior muscles are attached to the anterior part of the capsule with a large surface of insertion extending from the dorsal posterior side of the capsule upwards almost to contact with one another. These muscles are those seen by Graber who assumed that they were attached with the other end in the fifth abdominal segment, the seventh as he erroneously assumed. According to Paoli, they are shorter and inserted in the sulcus between the sixth and seventh abdominal segments; they diverge anteriorly passing across the two large tracheal trunks. By the contraction of these muscles the organ is displaced towards the head. 
The second pair of muscles corresponds probably to the elements which Graber assumed to be a second pair of nerves; their diameter is about the same as in those of the first pair; they are attached at the sides of the posterior parts of the cyst, extending backwards almost parallel to one another, and finally are found to be inserted at the sides of the opening of the terminal tube, in the furrow between the eighth and ninth abdominal segments. The action of these muscles consequently is directly opposed to that of the first pair, and displaces the organ posteriorly.

The two pairs of muscles described are the most important and are attached at the lateral walls of the cyst; the two following pairs are attached to the posterior border of the ventral side of the cyst. Of these, the third pair, more exteriorly located, is formed by two divergent muscles which are inserted at the sides of the ventral body wall, somewhat behind the sulcate prominence bearing the anus. The two muscles of the fourth pair are also attached to the ventral body wall, near the median line, in front of the lip-like hook-bearing expansion. Hence it appears that these two pairs of muscles pull the organ in the ventral direction, between the two large principal tracheæ.

Membranous ligaments are also described by Paoli. In addition to the four pairs of muscles and the terminal tube, the organ is held in position by membranes, the largest of which has the shape of a conical cap involving the capsule anteriorly and attached to the posterior extremity of the dorsal blood vessel, which terminates not far from the limit between the seventh and eighth abdominal segment. Other membranes, one on each side, envelop the basis of the muscles of the second pair, but Paoli was not able to find the insertion of their free end.

Concerning the nerves belonging to the organ, Graber ciaimed that it was richly innervated, describing two large nerves which formed ganglion-like masses near the capsule. These nerves, however, are muscles, according to Paoli, which are slightly inflated at their base. It is to be noted, however, that the ganglion-like swellings were reported by Graber not for the large nerves, but for the first thin pair. Paoli found two nerves which anastomose and fuse to a short tract, further on redividing into two branches, one more 
slender which goes to the base of the muscles of the second pair, one larger which, extending below the muscles themselves to the anterior part of the capsule, corresponding to the pedunculi, while it is not possible to affirm with certainty that it has a relation with these. Paoli seems not to attach any importance to the behavior of this nerve.

All the muscles, in addition, receive in their course the terminations of other nerves. Those of the first pair, not far from their place of insertion in the cyst, receive two branches derived from a nerve which bifurcates in the neighborhood of the muscle itself, in fact so near that it gives the appearance that the nerves go to the cyst.

All the nerves and muscles described are related to the head capsule which encloses the first pair of pedunculate bodies. The remaining section, which contains the dead parts of the organ, receives towards its middle the endings of a slender nerve which, while it is a single one in the region of the hypoderm, branches into a large number of thin ramifications.

Concerning the function of Graber's organ, Paoli likewise dismisses the hypothesis of a glandular function, there being no indication whatever of the presence of glandular cells.

That the organ should have an auditory function is also thought to be of little probability, especially as it would differ from other cystoid auditory organs, by having its inner surface covered with chitin, bearing no hairs, but instead of them, pedunculate bodies. Otoliths are, moreover, practically never found among insects, and the organ in question would be unique also in this respect. Furthermore, in this organ, there seems to be no special preponderance of nerves as one would suppose to be the case in a sense organ, but rather a preponderance of muscular apparatus, in as far as numerous long muscles are connected with it in various directions, these muscles being richly innervated. The organ is consequently, according to Paoli, destined chiefly to be set in motion or to be extended in various directions; in fact, displacements were observed in anterior, posterior, and vertical directions, and also lateral displacement seems to be possible if the muscles acted on one side alone. 
Paoli, in seeking for the function of this organ, recalls his own observation of the larvæ producing a crackling noise, under water as well as in the air, similar to the sound produced by small electric discharges. He thinks that these sounds might be produced by means of this organ. By the action of the muscles the cyst would be subjected to deformations by means of which the pedunculate bodies would be caused to hit against one another. The elastic membranes also would aid in this process as well as the chitinous walls of the capsule. The two large tracheæ would serve as resonators.

The objection that such an organ of sound should lie at the surface of the body rather than in its interior, is met with the consideration that these larvæ are aquatic, living below the surface of the water or in the mud, where the possession of an organ producing sound in the air would be of little value. The song of the Cicada becomes much feebler when the insect is submerged under water, but the larva in question produces its sound as well under the water as in the air. As the pedunculate bodies are enclosed in a liquid, the conduction of the sound would also occur easily in a liquid element. If the peculiar sound produced by the larva was not caused by the action of this organ, there would be, according to Paoli, no other organ by which it could possibly be produced. Paoli has consequently decided to assign to the organ a sound-producing function. ${ }^{7}$

${ }^{7} \mathrm{I}$ have in the meantime found occasion to observe tabanid larvæ, and was eager to test Paoli's observations. In fact the crackling noise was freely produced by full grown Tabanus atratus larvæ, and also, in harmony with Paoli's statement, it was chiefly heard when the larvæ were disturbed and defending themselves with their sharp mandibles. The coincidence of the two phenomena was so close that I am bound to assume that the sound is produced by means of the mandibles. As is well known, the mandibles of tabanid larvæ are strongly chitinized and provided with a serrate inner edge. Very near this and slightly below, the maxillæ, also chitinous, are situated. In the act of biting, the mandibles are suddenly exserted with considerable force and it is conceivable that in this act their serrate edge strikes the maxillæ, producing a sharp sound. The action itself may have some physiological importance, in as far as it serves in the laceration of the skin or body wall of animals attacked, while the sound produced appears to me more accidental, as, for instance, the gnashing of teeth in carnivora.

Hence it is not likely that Graber's organ has the function ascribed to it by Paoli. Also Paoli's opposition to Graber's view is not well founded in as far as he himself assumes that the pedunculate bodies are modified hairs. They could 


\section{CHRYSOPS (MEIGEN), EARLY STAGES IN GENERAL.}

\section{In Fabricius' Systema Entomologice and Entomologia Systematica}

I have found no statement of the early stages of any species of this genus.

Zetterstedt says that, according to Fabricius, the larvæ live in the ground. However, Zetterstedt himself saw a large number of apparently new emerged adults at the borders of a lake, which would indicate an aquatic habitat.

According to Hart, the larvæ and pupæ of Chrysops, as well as the imago, are distinguishable from those of Tabamus by the antennal structure. Otherwise the Chrysops larvæ closely resemble in structure small or young Tabanus larvæ. The dull pubescent annuli are partly present in Chrysops, but the longitudinal lateral lines, except on the prothorax, are shining and almost entirely without pubescence. There is very little pubescence here, however, in some young Tabanus larvæ. The species described by Hart (Chrysops vittatus Wied.) is easily recognized by the dark patch on the last segment.

The distinguishing characteristics given for larvæ of Chrysops compared with those of Tabanus are the following: "Last antennal joint much longer than the one preceding, dorsal areas of thorax striated like those of abdomen." Neave compared the syphon of the

consequently take the place of the auditory hairs which are missing, and as the pedunculate bodies, which in reality are modified hairs, would assume the function of otoliths, there would be no exception to the general rule that true otoliths are not found among insects. Functionally the organ could well belong to the group where it was placed by Graber. Also the fact remains that, even according to Paoli, nerves go to the fundus of the cyst, where the pedunculate bodies are attached. The problem cannot be regarded as solved by Paoli's hypothesis. On the other hand, to assume a true auditory function seems equally hazardous; it seems more probable that the organ might play a part in the senses of equilibrium and orientation, which, however, can only be determined by further investigation. 
Chrysops larva with that of Hamatopota (Plate 5, Figs. 73 and 74), and found the syphon much more elongated in Chrysops.

Beling (1882) is the first to describe the pupa of a Chrysops, which had been found at the edge of a brook. A Chrysops larva which pupated became known first through Hart (1895). This larva remains, until recently, the only one described. After Hart, our knowledge is increased chiefly by Hine, especially with reference to oviposition and egg stage, on which Patton and Cragg have also made observations. The larvæ and pupæ of several African species became known through Neave's work (1915).

The little Chrysops pupæ have longer antennæ, and the thoracic spiracular prominence is more nearly in a vertical plane than in Tabanus, its inner edge being more strongly elevated. The lower free edge is crossed by sharp folds, making it serrated. In Chrysops the abdominal spiracles are subcylindric near the apex; the spinose fringes consist of long teeth only; and the terminal teeth are long and rather narrow at the base.

The distinguishing characteristics of the pupæ are the following:

"Antennæ surpassing adjacent margin of head; fringes of abdomen of long spines only; inner margin of thoracic spiracular prominences sharply elevated, lower margin serrate-edged; abdominal spiracles slender, subcylindrical near apex; size small."

The eggs of Chrysops are deposited, as we learn from Hart, "in one flat tier, forming an oval or diamond-shaped area, pointed at one or both ends." We know, however, from Hine's observation on Chrysops celer, that there are exceptions to this rule and there are species of Chrysops which oviposit in several layers after the fashion of Tabanus. Most of the eggs of Chrysops are black, according to Hine, and are placed in a single layer, but there are exceptions to this, for the eggs of Chrysops celer are never darker in color than brown, and are placed in at least three layers one upon the other.

With regard to the habits of the pupal stage, Hine's observations are of interest, as he saw around fresh water ponds myriads of pupa skins of Chrysops with just the anterior end projecting above the surface of the ground.

The following are the notes which we possess on various species of Chrysops, arranged alphabetically. 
Chrysops bimaculosa Neave.-An African species, allied to Chrysops centurionis Aust., discovered by Neave (1915) on Mt. Mlanje, in southern Nyasaland. A typical male and female and one other of each sex were bred in October and November, 1913; one female was collected in November, 1912.

Of the four individuals above mentioned three were bred from collected pupæ and the fourth from a larva which resembled that of Chrysops longicornis, though considerably larger, with a somewhat less strongly pigmented anal segment and with well marked hairs on the syphon.

The hooks of the pupal aster, especially the upper and middle pairs, are decidedly elongate (Plate 13, Fig. 167, $a, b, c$ ).

Imago, larvæ, and pupæ had been taken on the banks of a wooded stream.

Chrysops callidus Osten Sacken.-A common and widely distributed species, recorded from most of the eastern states, reaching Florida in the South, Indiana in the West, but apparently not occurring in northern New England. Hine has described the oviposition of this species, indeed has watched the entire process of oviposition, which usually occupies from 20 minutes to half an hour, during which time something like one to three hundred eggs are laid.

The female alights on the leaf head downwards and begins to push the tip of the abdomen forward towards the sternum of the thorax, placing the protruding end of an egg against the leaf. This end sticks fast and she then moves the tip of the abdomen backwards until normal position is reached and the egg is free. By the same movement one or two eggs are then placed to one side of this one and two or three on the other side of it. The unfinished end is soon observed to be $\mathrm{V}$-shaped, the female moving gradually forward and placing the end of the abdomen to one side of the $\mathrm{V}$ and depositing eggs along down until the apex is reached, then changing the tip of the abdomen to the outer part of the other side of the $\mathrm{V}$ and placing eggs along it down to the apex on this side.

This process is kept up, the female changing regularly to the outer part of the opposite side of the $\mathrm{V}$ each time the apex is reached. Between 9 o'clock and noon seems to be the favorite time of day for 
oviposition, as with other species of Chrysops and Tabanus; Hine has seldom observed females ovipositing at other hours of the day.

The eggs when first laid are clear white but gradually get darker until they become permanently dark brown or black. It took eggs of Chrysops callidus 5 or 6 days to hatch, and it required about a day longer in the case where eggs were kept in the shade the whole time than in cases where the eggs were in the sun during the day. ${ }^{8}$

The writer has made some additional observations on Chrysops callidus, which are published elsewhere.

Chrysops celer Osten Sacken.-A species recorded from Maine, Massachusetts, Pennsylvania, New Jersey, Ohio, and North Carolina. This species is common in Ohio during the latter half of May. The eggs have been observed commonly by Hine along the margin of ponds and artificial lakes, clinging to various kinds of foliage overhanging the water. The female has been observed ovipositing on different occasions, and is the only species of the genus placing its eggs in masses composed of layers one above the other as in Tabanus.

Chrysops dispar Fabricius.-This species is widely distributed in India, Ceylon, Malay, and adjacent parts. We possess some information on its early stages through the work of Patton and Cragg in Madras (1913).

${ }^{8}$ In the summer of 1916, I collected the eggs of Chrysops callidus O. S., in Princeton, N. J., from which the young larvæ were obtained. These are half transparent, whitish, and their structure is analogous to that of most tabanid larvæ, differing, however, from the young larvæ of Tabanus, as far as known to me, by having the main tracheal trunks not inflated, but of about equal diameter all along their course. This character ("not provided with air sacs") is, however, given by Patton and Cragg for all "small tabanids" observed in Madras, including species of Chrysops, Tabanus, and Hamatopota. It causes the larva of Chrysops callidus to sink to the bottom instead of floating to the surface. The larvæ of this species molt soon after hatching, and can live under water for a considerable time, but as all the larvæ died in young stages, I am unable to say what their further habits are, and whether they spend most of their life in the water or later on invade the mud of the shore. At a pond where large numbers of Chrysops had oviposited the previous summer, in spring no larvæ could be detected in the mud of the margin, while other tabanid larvæ were numerous.

For further details see Marchand, J.N. Y. Entomol. Soc., 1917, xxv, 149. 
Chrysops dispar lays its eggs, as do all the small species of tabanids observed by these authors, invariably on blades of grass just at the edge of a shallow stream, or on the leaves of the lotus plant at the edges of small ponds, but never over deep water.

In Madras the smaller species of tabanids always lay their eggs in the afternoon, commencing about 4 p.m. Chrysops dispar has been seen ovipositing as late as 7 p.m. An egg mass of this species, on a blade of grass, and also a single egg, is figured by these authors (Plate 1, Figs. 14 and 15), but no description of the larva is given.

The larvæ of the smaller species of tabanids (including Chrysops dispar) contain no air sacs, according to these authors, and if they fall into deep water they die. It is important to recognize this in breeding experiments and to place them in trays with only a little water.

Patton and Cragg's text-book contains notes on smaller species of tabanids some of which may apply to this species, but are not clearly referred to it.

Chrysops indus Osten Sacken.-This species is recorded from New Jersey, New York, Canada, and Ohio. According to Hine, it appears in Ohio usually by the middle of May. It is the first species to appear in the spring and females have been observed ovipositing on plants growing along the margin of a small lake on the University grounds in Columbus, Ohio. The eggs are placed in single layers on grass blades that hang over the edge of the water.

Chrysops longicornis Macquart.-This is an African species, the early stages of which have become known through the work of Neave (1915). The species is the most abundant of the genus in the neighborhood of Mt. Mlanje, southern Nyasaland, where Neave's investigations were carried on. The flies prefer well wooded localities and Neave thinks it probable that all stages exist throughout the year.

The larvæ were first discovered at the end of August, 1913, and to Neave's surprise, in view of the habits of the adults, were found in the mud of a small marsh and stream bed in an open spot with only comparatively thin woodland near it. Many other examples were subsequently taken, both in similar places and in less unexpected spots on the banks of wooded streams, etc. Except for an occasional 
freshly emerged individual, the adult flies were not taken in these open places and appear therefore to migrate from them after emergence and to return to them for the purpose of oviposition. If this is the case, it is another example of the possibilities of error in searching for the breeding place of a species in the spot most frequented by the adults.

The larvæ, figured by Neave but not described, were obtained in considerable numbers from September on, a few being still obtainable even in January and February. In the figure (Plate 5, Fig. 72) the eleventh segment shows a broad dark pigmented band, dorsally reaching somewhat anteriorly to the middle of the segment, ventrally including the anal prominence, while the tube-shaped posterior third of the segment appears to be free from pigment, as also the slender tube-like twelfth segment (syphon). The circular ridges show only traces of pigmentation. A good illustration of the pupa is given (Plate 11, Fig. 130), which, however, shows no peculiar characteristics by which it could be differentiated from a Tabanus pupa. The pupal asters of male and female pupæ are shown and differ considerably (Plate 13, Fig. 171, $a, b$ ).

Chrysops magnifica, var. inornata, Austen.-An African species, according to Neave, not rare in the Mlanje district of southern Nyasaland, during the rains from October to April.

This species was bred from the larva by Neave, but the larva so closely resembles that of Chrysops longicornis Macq. that Neave never succeeded in separating it satisfactorily, since in both species the usually distinctive characters of the pigmented anal segment and syphon were variable.

The pupal aster (Plate 13, Fig. 166, $a, b$ ) resembles that of Chrysops longicornis, but the middle pair of hooks is stouter and somewhat more curved, and the shape differs somewhat, especially in the male. The pupal asters of the male and female are illustrated.

Chrysops mochus Osten Sacken.-A species recorded from New Jersey, District of Columbia, Illinois, Ohio, and Kentucky. Hine has observed the females ovipositing on foliage overhanging a mill race at Georgesville, Ohio, June 4, 1899, but does not describe the eggs. 
Chrysops moerens Walker (synonym astuans van der Wulp).Recorded from Illinois, North Dakota, Wisconsin, and Ohio. This is the species in which oviposition was first observed by Hart (1895), who saw these flies from August 3 to 10 flying among the marginal rushes of Fourth Lake, Sand Lake, and Slough Lake in Lake County, Illinois, and ovipositing on the stems of the rushes.

The egg is described by Hart as follows:

"Egg.-[Plate 1, Fig. 2, egg masses.] Length $1.6 \mathrm{~mm}$., diameter $0.25 \mathrm{~mm}$., cylindrical with rounded ends, straight or slightly curved, smooth, slightly opaque, cream color when laid, becoming dark fuscous brown, placed in a single flat layer, obliquely stacked as in Tabanus, about one fourth of the length of each egg being visible at the surface, the remaining three fourths being covered by those stacked against it. The mass is about $10 \mathrm{~mm}$. long and 3 or $4 \mathrm{~mm}$. wide, its outline variable, usually diamond-shaped, both ends pointed, or at one end short or truncate, making it more or less triangular."

Eggs of this species were observed by Hine (1906) at Sandusky, Ohio, during the first days of July and were present in varying numbers during the following two months.

While the female is ovipositing she is not easily disturbed; consequently one has an excellent opportunity to watch the procedure. An illustration given by Hine (Plate 1, Fig. 1) was made from a photograph of a living specimen which was found in the act of egg laying and was carried, with the leaf, to the laboratory where the picture was taken. "During the whole time," says Hine, "she continued ovipositing without showing any signs that she was aware of what was going on or that she had any concern for the welfare of her eggs."

The method of placing the eggs is similar to that recorded for Chrysops callidus.

The female alights on the leaf with her head downwards and begins the process by pushing the tip of the abdomen forward towards the under part of the thorax and placing the protruding end of an egg against the leaf. The end sticks fast in consequence of the glue-like substance which accompanies it, and she then moves the tip of the abdomen back to its normal position, thus freeing the egg. By similar movements one or two eggs are placed on one side of the first, and two or three on the other side of it. The unfinished end soon becomes V-shaped; she moves slowly forward and lifts the tip of the abdomen to one side of the $\mathrm{V}$ 
and places eggs along it downwards until the apex is reached; then changes to the other side of the $\mathrm{V}$ and places eggs along it, downwards to the apex on this side. It was noted in specimens of this species that sometimes a female would place as many as three rows of eggs on one side, one after the other, before changing to the opposite side. It is only necessary to study a mass of these eggs in order to see the precision with which the different specimens are arranged.

The eggs are placed on various aquatic plants, often standing in rather deep water and at times as much as 20 rods from shore. Hine always found them on scattering plants around the edges of grassy areas and not back among the dense growth; consequently they are easily seen, not only on account of their conspicuous location, but also because of their shining black color, which contrasts strongly with the green leaves to which they are attached.

Their coloration renders the egg clusters conspicuous, and Hine suggests that hand picking might be of consequence in the control of Chrysops. In order to demonstrate what could be done in the way of gathering eggs of this species, Hine went out on the morning of July 17 , in Ohio, in a small rowboat, and collected for an hour. At the end of this time a count showed 433 masses, and an average of 250 specimens to each mass, a result obtained by counting several and striking the average, giving a total of 108,250 single eggs taken as a result of the hour's work.

Eggs of Chrysops marens, laid from 8.45 to 9.30 a.m. on July 13, hatched before noon of July 19, thus making the incubation period 6 days. This is the shortest incubation period Hine has observed for any species of Tabanidæ.

Of the larvæ, Hine says that after hatching they drop into the water, and he states that, in the natural breeding grounds of the flies, it is almost impossible to find the very small larvæ after they have dropped from the eggs and have become more or less scattered among the debris which is usually plentiful in these places.

In order to ascertain whether the young larvæ can be killed by spreading a film of kerosene on the surface of stagnant water over which eggs are placed, Hine (1906) performed some experiments. A tank of water was used, on the surface of which half a pint of kerosene was placed to each square yard of surface. Sparganium leaves to which the eggs were attached were brought in from the marsh and 
put into a bottle as one would arrange a bouquet, and this was placed on the bottom of the tank so that the parts of the leaves to which the eggs were attached were a foot or more above the surface of the water which contained the layer of kerosene. Even under these conditions an exact count could not be obtained, because the kerosene appeared to affect different specimens differently. Some were killed very quickly, some died after an hour or more, while others did not appear to suffer particular inconvenience from the treatment. Further observation is necessary to be able to give conclusive statements regarding the matter.

Chrysops relictus Meigen.-A European species, and the first species of the genus in which reliable data were obtained, by Beling (1876), on the pupal stage. From three pupæ found on July 16, 1876 , in the sand of the border of a small meadow brook, two imagos were produced on July 24 and 25 . The third did not develop.

Beling's description of the pupa is as follows:

Pupa.-12 $\mathrm{mm}$. in length, $3 \mathrm{~mm}$. in diameter, of dirty brownish yellow color. Head shining, strongly brownish anteriorly; lower frontal margin with four broad, rounded teeth in a transverse row; above these teeth two small tubercles, each with two stiff brown moderately long hairs; further down posteriorly two similar tubercles separated by a larger distance and each bearing only one such hair. Dorsally, at the border between the head and thorax, are two brownish ear-shaped longitudinal ridges diverging posteriorly. Antennal sheaths laterally appressed to the head, short, terminating in a point, not much marked. Abdomen nine-segmented, brown, with blackish segmental incisions, less shining than the head and the leg and wing cases. First abdominal segment very short, deeply emarginated in the middle of the anterior margin; third to eighth abdominal segments inclusive dorsally near the posterior margin with a transverse row of densely placed backwardly appressed, pale bristle-like teeth of unequal length, gradually becoming longer on the posterior segments and extending also over the ventral surface of the segments. Anal segment ending in six claw-like spines arranged divergently, of which the two upper ones are slightly smaller than the remaining four.

Chrysops vittatus Wiedemann.-A common species distributed all over the eastern United States as far west as Kansas and Iowa. This is the first species of Chrysops of which the larva has been described (Hart, 1895). ${ }^{9}$ The larvæ were found, according to Hart, in

${ }^{9}$ Recently, in the spring of 1917 , I have found larvæ of this species from which a male imago was reared. 
connection with those of Bittacomorpha, Limnophila, and Sialis, in the weedy, swampy little stream at Station I of his entomological survey of the Illinois river valley. They were quite common here, occurring in the mud and the mats of dead stems, rarely floating at the surface. The first were seen March 28, but they continued to occur up to April 15, increasing slightly in size. In the breeding cage they burrowed in the mud and through the vegetation.

In the latter part of May the water was allowed to dry up and on the 28th all that remained was poured off. From June 1 to 3 three pupæ were formed in the damp mass of dead vegetable matter resting on the mud in the cage. Two imagos emerged June 9, both males, the third failing to transform.

The coloration of the larva readily distinguishes it from other known tabanid larvæ. Hart's description of larva and pupa is quoted below.

"Larva.-[Plate 3, Fig. 39.]10 Length 10-15 mm., diameter $1.6 \mathrm{~mm}$. Head light colored, mouth parts pale, tips of maxillary palpi in line with end of labrum; body whitish, a mottled appearance within, at the middle of the body."

"Dorsal and ventral areas striate, striæ entire, distinct, and not very fine, the lateral striation a little finer, that of the prothorax very fine, with a small smooth spot adjoining the smoother surface of its ventral area; the latter shorter than the dorsal, not including the anterior pair of setæ; median sulcus scarcely dull-pubescent. Meso- and metathorax with lateral impressed lines, and dull-pubescent pale annuli, but the lateral lines almost without pubescence. Fleshy false feet of abdominals rather prominent, dorsal pair united into one, there being no narrowing near the median line; annuli very pale except on the last two or three segments; last segment white basally, the remainder covered with dull blackish microscopic pubescence reaching forwards to the anal prominence, a triangular extension each side of the middle above, often a small spot accompanying each; respiratory tube whitish, spine sometimes projecting."

"Tracheal trunks sinuate posteriorly, crossing and recrossing in front of the middle."

"Pupa.-[Plate 13, Figs. 154 and 157.] Length 9-10 mm., diameter $2 \mathrm{~mm}$. Light brownish, ferruginous, obsoletely transversely wrinkled, head and thorax shining, abdomen duller."

${ }^{10}$ In the quotations, as well as in the rest of the paper, the figure numbers refer to the illustrations in the present monograph. 
"Antennal sheaths not very thick at base, surpassing the marginal angulation above them; carinated tubercles not prominent, lateral notches broad and shallow, palpal sheaths indefinite, rather distant; setiferous tubercles scarcely darker; ocellar tubercles replaced by pale dots. Rima of thoracic spiracles (Plate 13, Fig. 157) strongly elevated from inner side, so that the flat top of the prominence is nearly vertical, the upper edge of the rimal border forming a sharp carina and its anterior extremity ending at the tip of the marginal extension in an acute angle; the free lower edge is crossed by sharp ridges, giving it a serrate profile; rima less curved at middle, more strongly at each end, scarcely hooked; inner notch with radiating striations."

"The abdominal fringes consist of a single row of pale spines on each segment, rather long except dorsally on the second, where they are shorter and thicker. The abdominal spiracular tubercles arise from a slight elevation, tapering from a comparatively small base as far as middle, thence nearly cylindrical to apex, which bears a subcircular rima; on the anterior slope a small transverse groove, not longer than the rima; tubercle about as high as its basal diameter. Last segment with six nearly equal terminal teeth, their points marking the angles of a hexagon; slender, even constricted at base, twice 'as long as their diameter near base. Lateral spines almost wanting; ventral fringe in front of anal tubercle in male; a tuft of about five spines on each side in place of this fringe in the female."

Chrysops wellmani Austen.-An African species, which, according to Neave, occurs in fair numbers near Mt. Mlanje, southern Nyasaland, from September to January.

The larvæ of this species (Plate 3, Fig. 50), differ strikingly from any of the other Chrysops larvæ seen by Neave, in their strong pigmentation. In the figure it is seen that while segments 1 to 3 are free from pigmentation, segments 4 to 11 show the regular tabanid pigmentation on the transverse circular ridges, leaving an area around the prolegs free from pigment. There are no longitudinal stripes, but on segment 11 there are two subdorsal dark spots (in addition to the broad posterior band), traces of which are also visible in the figure of the syphon of Chrysops longicornis.

The larvæ were obtained in the beds of forested streams with those of Chrysops longicornis and Chrysops magnifica, var. inornata, but were much less common. They were found only between the middle of October and the end of November. There is considerable difference in the hooks of the aster in the two sexes of this species, the upper and lower hooks, especially the former, being much reduced 
in the female. The pupal asters of both sexes are shown (Plate 13, Fig, 168, $a, b) .{ }^{11}$

Dorcalcemus fodiens Austen.-An African species, on which some observations have been made by Neave (1915) in southern Nyasaland.

Some examples of what may be the larvæ of this species were found, though the point could not be decided, as Neave was obliged to leave before they reached maturity. They were captured during December, January, and February in some swampy ground on which a patch of maize was growing. These larvæ were of fair size, some $30 \mathrm{~mm}$. in length; the syphon was very short and had a distinct pigmented ring on the anal segment resembling that in Hcematopota larvæ. In the more mature specimens traces of intersegmental pigment were present.

At the time these larvæ were captured no other larvæ of so large a species were obtainable, and as Dorcalcemus fodiens is the only large tabanid which is on the wing in March and April, there are grounds for thinking that the larvæ belonged to that species.

Gastroxides ater Saunders.-A black species of a genus allied to Chrysops, with elongate slender legs and long antennæ, occurring in Pusa, Bengal, India (Maxwell-Leffroy and Howlett, 1909). The larva is said to breed in hollow trees. No more details are available. A picture of the adult is given by Maxwell-Leffroy and Howlett.

${ }^{11}$ In the summer of 1916 I found eggs of another species of Chrysops which differed considerably in appearance from the two types described hitherto. These eggs were found on the under surface of leaves of the yellow pond lily (Nuphar), four or five clusters in all, and one on a Poniederia leaf. The eggs were white, and placed vertically on the surface of the leaf, one beside the other, the cluster being roundish when seen from above, presenting an even dull white surface formed by the tips of the eggs, and with clean-cut vertical outer walls. After a few hours these egg clusters turned somewhat brownish, but never became very dark. In one case the female fly was observed ovipositing, but escaped before being captured. It appeared to belong to Chrysops univittatus or possibly Chrysops lugens. The larvæ hatched within 5 days, molted soon after hatching, and did not differ appreciably from those of Chrysops callidus.

For further details see Marchand, J. N. Y. Entomol. Soc., 1917, xxv, 149. 


\section{GONIOPS (ALDRICH), EARLY STAGES IN GENERAL.}

The following brief characteristics of the early stages of Goniops are given by Malloch (1917).

"Larva.-Mandibles stout, slightly curved, apically truncated; antennæ elongate, 3-jointed, basal joint stout, tapering apically, about twice as long as apical 2 combined; apical joint much shorter than preapical; maxillary palpi 2-jointed, the apical joint slender and distinctly shorter than the basal. Thoracic segments very distinctly tapered anteriorly, abdomen stout, roughly oval in outline, the whole body appearing pyriform or slightly club-shaped; abdominal segments with rather irregularly arranged transverse series of locomotor tubercles; spiracular chamber in form of a vertical slit."

"Pupa.-Head without projecting thorns; antennal sheath short, curved downward. Prothorax about one-third as long as mesothorax; wings short, extending to apex of first ventral abdominal segment; apices of hind tarsi slightly surpassing apices of wings. Armature of dorsal abdominal segments consisting of stout thorns in a transverse series, 2 of which, near middle of segments 2 to 7 , are much stronger than the others; later the series are discontinued some distance from margins; apical segment with three strong thorns on each side, between which are several weaker protuberances."

The eggs are, as stated by Malloch, (after Walton (?), McAtee (?)), usually deposited on the under side of leaves of various plants, and when the larvæ hatch they drop to the ground, living afterwards among the decaying leaves and other vegetable debris. They are probably predacious like other Tabanidæ.

The egg masses are parasitized by a proctotrypid parasite.

McAtee briefly compares the larva and pupa of Goniops, apparently the only native pangoniid genus of which these stages have been described, with the comparatively well studied immature forms of the true tabanids, such as Tabanus and Chrysops.

Hart says (quoted by McAtee):

"All the larvæ of Tabanidæ studied agree in the following general characters: Body tapering at both ends, which are somewhat pointed; skin shining and glassy, with opaque markings of a microscopic felted pubescence. The palpi have short thick joints; the basal joint of the antennæ is quite short, and there is a bunch of stiff diverging recurved hairs between each antenna and the median line above." 
The full grown Goniops larva, on the other hand, is pyriform and not at all pointed at the ends. Its skin, except on the head and prothorax, is not shining, but everywhere opaque and wrinkled or tuberculate. The palpi have long slender joints; the basal joint of the antenna is very long, much exceeding the two terminal joints, and the hairs on the antennal flap are flexible and attached to the surface of the head. The double second joint of the antenna of first stage larvæ is noteworthy.

Of the tabanid pupa Hart says:

"The mesothorax is one-half longer than the prothorax and the second to seventh abdominal segments are encircled by continuous fringes of slender spines."

In Goniops the pupal mesothorax is three times longer than the prothorax, and the fringes of spines on the abdominal segments are not continuous but interrupted and definitely grouped.

Goniops chrysocoma Osten Sacken.-A North American species, known from not very frequent captures, from New York, New Jersey, Pennsylvania, Ohio, and Maryland. Taken in June and July, usually on foliage.

Goniops chrysocoma (Plate 2, Fig. 28) is the only representative of the Pangoniinæ of which we know anything of the early stages, but in this species our knowledge is rather complete owing to the observations of Walton and McAtee.

Walton was the first to observe oviposition accurately and to describe the egg. However, Walton relates that the first fly seen by him was presented to him by Mr. Warren S. Fisher, of Highspire, Pa., who took a female in the act of ovipositing on a leaf of what proved to be Angelica on July 4, 1907, near Highspire. The plant overhung a small more or less permanent ditch of water, and it was naturally inferred that the larva might be aquatic in habit, in common with others of the family.

However, on June 14, 1908, while collecting on a dry hillside, in a brush patch, about five miles to the eastward of the former locality, Walton found another female of this species in the act of oviposition on the under side of one of the leaves of a small oak sapling, to which his attention had been attracted by a peculiar buzzing sound. The 
female made no effort to escape, indeed it required considerable force to remove the insect from her position near the eggs. The immediate locality was a hillside pasture lot, half covered with scrub oak and berry bushes, dotted with clumps of false indigo. The nearest water was a small overgrown ditch some 60 feet distant.

On June 18 Walton visited the same spot near Highspire, with the hope of securing additional data, and was rewarded by finding another fly in a similar position on a leaf of the wild cherry, thirty feet distant from the water.

The eggs (Plate 2, Figs. 28 to 32), "which are deposited upon the under surfaces of the leaves of various herbaceous plants and trees" (Walton), in a three-sided pyramidal heap, are described by him as "yellowish white in color, about $1.5 \mathrm{~mm}$. in length, slender, slightly curved, and resembling those of many other flies in general appearance." One of the heaps contained 534 eggs by actual count (Plate 2, Fig. 29).

The eggs of Goniops have been further observed, according to McAtee, during each of the years 1908, 1909, and 1910, on Plummer's Island, Maryland. On June 26, 1908, Mr. H. S. Barber collected a female and a large greenish white egg mass, which was laid on the under side of an oak leaf about 8 feet above the ground. The larvæ hatched June 28.

In 1910 McAtee found four egg masses on July 3 and two on July 10. One of the first four egg masses was collected. The larvæ hatched July 7. Another had been deserted by the female by July 10. The outer layers of eggs were black, and from these issued, on July 11, numerous proctotrupids, which Mr. J. C. Crawford says are Telenomus, probably an undescribed species. The two remaining egg masses of the lot found July 3 were covered by the females until July 10 (Plate 2, Fig. 28), a period of a week, during which time many eggs were added. These eggs, and the two masses discovered on July 10 as well (Plate 2, Figs. 30 and 31), were hatched by July 17. They were deposited on the under sides of Eupatorium, Bensoin, and Hamamelis leaves. Some of the empty egg cases (Plate 2, Fig. 32, McAtee), usually clung to the leaf after hatching, but in one instance not the slightest trace remained of an egg mass on a 
witch hazel leaf. A fly heard by Mr. E. A. Schwarz giving its peculiar buzz on July 13, and which undoubtedly was ovipositing then, was located by McAtee on July 17. On July 24 the female was absent and the eggs were hatching. The larvæ, dropping to the ground, immediately burrowed in.

These observations show that the female Goniops guards the egg mass sometimes for a week at least, a fact which has escaped Walton's attention; that this precaution does not always prevent parasitism; that the period of incubation varies; and that the larvæ are fitted for a subterranean life upon which they enter as soon as hatched.

Walton placed the two batches of eggs found by him in breeding jars and on the evening of July 25 the first larvæ made their appearance. The second lot appeared two days later. The eggs are, according to him, yellowish white when deposited and change but little if any in color before hatching. The process of hatching was observed. The larvæ were quite lively when hatched and "it was a curious sight to see them come tumbling out of the eggs by dozens when the cluster was brought under the bright light." According to him, the period of incubation is from 7 to 10 days.

According to McAtee, eggs have hatched in from 2 to 11 days from the date of collection. But from the fact that eggs are added to the mass for several days, and that all hatch at the same time, it must be inferred that the eggs within the body of the female keep pace in development with those laid. To determine the true period of incubation observations must cover the process from the laying of the first egg to hatching (McAtee).

All the egg masses found on Plummer's Island in 1910 (McAtee) were on the steep north slope of the principal elevation of the island, which is a well shaded, cool, and damp locality. The finding of seven egg masses in this area of less than an acre in one season shows that Goniops chrysocoma is not uncommon locally, even though little is known of it and recorded captures are not numerous (McAtee).

As to the larval stage, I have already related Walton's observations on the hatching process. The larvæ obtained by him were divided into three lots, the first placed in earth entirely submerged in water, the second in dampened sand without food of any kind, the 
third in a jar of damp earth together with some small angleworms. Twelve hours later the first lot were all dead; both of the other lots were lively and apparently in good condition. The second group continued to live without food for about ten days and then died. The remaining group lived for some weeks but finally died also, the angle worms being alive and uninjured.

Walton concludes that the larva is terrestrial (as confirmed by McAtee) and the period of incubation is from seven to ten days (see above).

The young larva (Plate 7, Fig. 93, $a, b, c$ ) is described as follows:

"The freshly hatched larva is slightly more than $2 \mathrm{~mm}$. in length, slender, but capable of contracting the body into an almost spherical mass; in color it is pale yellowish white, semitranslucent. The head, which is capable of being entirely withdrawn into the first thoracic segment, bears several pairs of antenna-like appendages and an obtusely pointed chitinous hook."

"On each side of the median line of the body, within the second thoracic segment, there is a distinct pinkish spot; also on the last segment there is a pair of round black spots resembling stigmata [Graber's organ (?)]; elsewhere the body seems to be absolutely devoid of hairs or tubercles."

McAtee's description of the larva goes much more into detail. He also described the adult larva from a specimen collected by Mr. Theodore Pergande, and the pupa collected by him. In fact the greater part of McAtee's article is devoted to the description of the newly hatched and full grown larva and pupa of this species. In the description of the larvæ the segments are numbered from the head backwards. McAtee does not accept the customary use of the terms pro-, meso-, and metathorax for the three anterior segments of the larvæ, but speaks of them as the first, second, and third body segments, which they really are. In the newly hatched larvæ they are scarcely differentiated from the following segments. In the full grown larvæ, while distinguishable by the surface markings, their exterior features are homologous with those of more posterior body rings. In comparing and describing them, therefore, it is more natural to use numerical designations. McAtee's description of the young larva follows:

"First Stage Larva.-The average length of first stage larvæ of Goniops chrysocoma which have been preserved in alcohol is about $1 \mathrm{~mm}$. In life they are 
about twice as long. The larvæ are not tuberculate, but the margins of each segment from the third to the tenth, especially the front margins, are more or less raised into low rounded rings. On a larva with arched body definite transverse impressions behind the anterior fleshy annulus of each segment are apparent under magnification. They render the annuli conspicuous enough, in fact, to give an impression as of false feet to the naked eye observing the larvæ crawling."

"The mouth parts are exceedingly minute and hard to observe. In arrangement they suggest those of the full grown larva, described below, and the homologies have been made out accordingly, and, it is hoped, successfully. The drawing [Plate 7, Fig. 95, $a, b]$ is strictly diagrammatic and is made up from a number of studies of larval heads, none of which showed all the parts in the position used in the drawing."

"Labrum (lbr.) short, pointed, black-tipped, and slightly curved downward. Labium triangular, not bifid as in full-grown larvæ. Maxillæ ( $m x$.) fleshy, truncate-conical, with a short downwardly projecting lobe on the inner side of the distal end; palpus ( $m x p$.) arising from the end of the maxilla, first joint long, somewhat enlarged distally, tipped by a number of short rods or spines, one of which is larger and blunt. It may be considered a second palpal joint surrounded at the base by a group of spines. Mandibles ( $m d$.) fleshy, blunt-tipped, crenulate on lower edge, lying just inside of maxillæ. Antennæ (ant.) straight, tapering, directed forward; basal joint as long as first palpal joint, somewhat expanded distally, second joint double, one of its divisions longer and apparently tipped with a seta."

"First segment of body slightly inflated, first and second segments convex above, flattened beneath, lower lateral edge rather prominent. Second and third segments with two or three longitudinal furrows on each side. Second segment with two conspicuous well separated elongate brownish spots visible (apparently somewhat under the surface) on the dorsal aspect. Hind margins of segments becoming more undulate posteriorly, markedly so on ninth and tenth segments. Last segment with two round black spots, (spiracles) Graber's organ (?), set close together on the median dorsal surface; this segment with two more prominent ventral tubercles, two similar lateral ones, and other minute tubercles."

Both Walton and McAtee have seen the organ of Graber in the young larva of Goniops; the former speaking of a resemblance to spiracles, while the latter seems frankly to believe that he is dealing with spiracles. For a possible derivation of this organ from spiracles we possess, however, no evidence, except that in tabanid larvæ all spiracles except the terminal ones have disappeared.

Full Grown Larva (Plate 7, Figs. 92, $a, b, c$, and 94).-The full grown larva described by McAtee is one of two collected by Theodore Pergande, near Cabin John Bridge, Maryland, April 13, 1899. They 
were found under stones covering the opening of mouse burrows. The color in life was gray. The general color of the preserved specimens was dark brown, the head black. The total length, when the head was retracted, is given as $17 \mathrm{~mm}$., the greatest diameter $7.5 \mathrm{~mm}$. With the head fully drawn out the larva measures $21 \mathrm{~mm}$. For the details McAtee's description is quoted:

"Head convex above, flattened beneath, its lower lateral edge a well marked ridge made by the stretching of the skin over the prolonged basal supports of mouth parts. Anterior part of head marked off from posterior part by a band of very thin wrinkled skin; anterior fold of this band beginning dorsally just in front of two large lateral smooth areas containing the indefinite bluish white eye spots; fold descending obliquely over side of the head, ending ventrally between bases of maxillæ. Anterior part of head and areas surrounding eye spots, with glassy surface, remainder covered with thin wrinkled skin."

McAtee describes the mouth-parts in detail (Plate 7, Fig. 95, a,b.)

"Epistoma and labrum $(l b r$.) forming a thin lance-like projection between upper parts of oral apparatus. Upper edge of labrum grooved from opposite middle of antennal flap (anf.) to base of the mandibles ( $m d$.); provided with an unequally two-lobed caruncle just back of the upturned tip (lbr.). Higher lobe of caruncle and tip of labrum each bearing a solitary anteriorly directed seta [see Fig. 95, a]. Lower edge of labrum applied to labium (lb.); latter flat; thin lateral strips diverging from a distinct ramus behind being chitinized, the remainder flexible. Labium ending in a pair of rounded conical fleshy lips; flexible portions closely set with short yellow hairs."

"Mandibles black, claw-like, blunt, sheathed at base by lobes of maxillæ ( $m x$.). The latter thin, flexible, following the curve of the mandibles; their slightly forward curved tips surpassing mandibles; their lower edge and inner side provided with numerous yellow hairs."

"Palpi ( $m \times p$.) arising from external basal flaps of maxillæ. First palpal joint inwardly and downwardly curved, second setiform, slightly curved downward and overlapping mandible.'

"Arising in the arch between epistoma and side of the head is a flap (anf.) which seems to be part of the antennal apparatus. It follows edge of epistoma nearly to base of mandibles, and curving down is attached to the posterior third of first antennal joint. From this point clear around the curve to where it parallels the epistoma the flap is fringed with long yellow hairs. First joint of antenna (ant.) slightly incurved (thus being directed outward), nearly three times as long as the two terminal joints together. Second joint conical, tapering gradually, directed forward and downward; third setiform and directed downward." 
"Anterior part of first segment very finely tesselated, the granules being arranged in irregular longitudinal rows. The head retracts into the posterior part of this segment, whose exterior is a longitudinally striate thin membrane inflated to gibbous barrel shape [Plate 7, Fig. 92]. The line of separation between the parts of this segment is marked by a ring of fine fleshy crenulations. Second and third segments surrounded about the middle by undulate crinkly thin-edged folds [Plate 7, Fig. 92, $a, b, c$ ] with five symmetrically placed backward angulations in each fold on each side. Parts of these two segments posterior to the folds with as many longitudinal sulci as there are angles in the fold, and longitudinally striate with fine irregular wavy ridges. Anterior third of second segment finely striate lengthwise. Part of second segment just in front of fold and anterior portion of third segment granular."

"On the fourth and following segments these folds are broken up into series of fleshy tubercles, on both sides of which the surface of the segments is raised into low ridges, which on the anterior segments have a few, and on the posterior segments several, low protuberances. The fourth and following segments more prominently ridged transversely on the dorsal area and longitudinally on the ventral area. A trace of longitudinal striation remains on posterior of three ridges (on each segment just described) or protuberances representing it. The fleshy teeth derived from the medium segmental folds largest and most numerous on the middle of lateral area of each segment, where they are heaped up into irregular elevations, with two more prominent points forming a series alongside; these elevations marked off by deep impressions both above and below and becoming more prominent posteriorly. There are three tubercles above (supralateral series) lateral prominences and about five below (infralateral series) on each segment behind the fourth."

"The fleshy fold is continuous across the dorsal area of fourth segment [Plate 7, Fig. 92]; back of this, dorsum of each segment marked by a depressed comparatively smooth elliptic area. These areas bounded in front by a varying number of thin fleshy teeth and posteriorly by a series of low broad longitudinally striate protuberances. Two of the latter fall into a series down the median line of the segments, on the ninth and tenth of which they become closely approximate, much more prominent, and round pointed. The first of the series (supralateral) of these tubercles above the prominent lateral elevations bounds the dorsal depressions at the sides and stand in a series along the back."

"Ventral series [Plate 7, Fig. 92] of protuberances marked off from infralateral series by a hiatus, by lower and thinner teeth, and by the forward arching of the series. It consists essentially of two stronger lateral teeth with a varying number of less prominent ones between. On the tenth segment the series is shortened and the middle elements are almost lacking. Between these arched series of teeth and posterior ridges on the ventral surface of the segments (which are represented by about four low round protuberances) are depressed areas similar to those of the dorsal surface. These are bounded at sides by 
first protuberances of infralateral series. Each segment from fourth to tenth has a pair of impressed dots on inner pair of elevations of the posterior longitudinally striate ridge. Segments six to nine have four of these impressions, one outside of each of the median pair."

"On the last or eleventh segment the anus is a semicircle with the convex side downward, overhung by four prominent tubercles in bilaterally symmetrical pairs. Mouth of the air tube a smooth oval surface just above the anal tubercles. It has a vertical slit and is surrounded by a projecting crenulate frill."

Pupa (Plate 11, Fig. 121, $a, b, c)$.- One of the full grown larvæ collected by Mr. Pergande pupated and a female imago issued May 29, 1899. McAtee's description follows.

"Length of the pupal shell $19 \mathrm{~mm}$.; greatest diameter $6.5 \mathrm{~mm}$. Head and thorax of the pupa a lighter, abdomen a darker ferruginous. Head and thorax finely and irregularly wrinkled; anterior half of each abdominal segment finely wrinkled transversely, posterior half with wrinkles less distinct or absent (especially on ventral surface), but very finely and closely punctuate. This makes the color appear more intense, in places almost orange. Middle of the segments, except the first, surrounded by an interrupted fringe of definitely grouped sharp pointed spines, the larger of which tend to be serrate."

"Vertex of head marked by a narrow rounded longitudinally wrinkled transverse ridge. In the depression between this ridge and the antennal prominences and in front of the extremities of the ridge are two outwardly directed setæ. Antennal sheaths short, appressed, downwardly curved, conical, arising from two low wrinkly protuberances (the antennal prominences above mentioned). These prominences separated by a deep fold, and from them curved and diverging impressed lines run down the face. Below each antennal sheath is a widely separated vertical pair of setæ."

"Prothorax longitudinally wrinkled, except for a smooth area behind and below each antennal sheath. A setiferous tubercle stands above each of these smooth areas. Prothorax angulate in the median line behind. Mesothorax three times as long as the prothorax, bearing two spiracular tubercles near anterior lateral angles (about opposite the middle of each lateral half of the prothorax). These tubercles similar to those described below, but complicated by flexures of the walls. They bear at the summit upwardly arched crescentshaped rimæ or air slits. The only setæ I can find on the mesothorax are one on each side directly back of these spiracular tubercles. Metathorax very short in the median line, but somewhat longer at the sides, which have two rounded angles anteriorly. Wing pads and leg sheaths, the latter slightly the longer, almost covering ventral surface of the first abdominal segment."

"Middle of each side of first to seventh abdominal segments with elevated round polished knobs bearing on the posterior portion of their summits the pos- 
teriorly arched crescentic spiracles. Second to seventh segments with a sharp pointed backwardly curved spine directly posterior to each spiracular tubercle. A short distance above this spine is a similar one, and between these two from one to four shorter ones. Some shorter teeth occur also both ventrally and dorsally from the stout spines. These lateral spines become stronger posteriorly."

"There is a definite break between the groups of lateral spines and the weak spines forming the lateral elements of the dorsal series. This break is marked by sharply impressed lines on segments 2 to 7 [Plate 11, Fig. 121]. Dorsal series of spines on second to seventh segments consisting of a pair of stout spines on each side of the median line [Plate 11, Fig. 121], the pair on the seventh segment being most widely separated. On each side of the mid-dorsal pair are about three other symmetrically placed strong spines. Between the larger spines are varying numbers of shorter ones, and gradually diminishing small ones terminate the series on each side. All spines sharp pointed and curved backward. Ventral surface of the second to seventh segments with smaller spines, having median pairs of stronger teeth, most widely separated on the third segment and nearest together on the seventh. There is a tendency for one of the minor spines on each side of the median pair to be larger than its fellows. These smaller spines of varying number but maintaining their series across venter of the segments, interrupted only by the stronger ones and diminishing gradually on each side. A wide hiatus exists between the last of the ventral series on each segment and the group of spines near the spiracular tubercle. Eighth or terminal segments with three strong spines on each side, connected by series of weaker points [Plate 11, Fig. 121]. The pair made by the uppermost of these strong lateral teeth is more widely separated than the corresponding ventral pair. In each case the interspace (that is, the dorsal and the ventral area of the segment) is devoid of points, except for small ones immediately adjacent to the large spines. The location of the larval anus is marked by a rounded transversely wrinkled knob and the spiracular eminence consists of two conspicuous tuberculate projections surmounted by sharp pointed downwardly curved spurs."

This is, so far, the longest description of a tabanid larva and pupa which we possess.

Of early stages of the many exotic Pangoniinæ nothing appears to be known. 


\section{HÆMATOPOTA, EARLY STAGES IN GENERAL.}

We owe to Neave notes on the early stages of this genus. $\mathrm{He}$ collected at Mt. Mlanje in southern Nyasaland, Africa. The larvæ were by no means easy to obtain as compared with those of Chrysops, a few individuals of three species only being found in September and October. Later in the season, in January, considerable numbers of the larvæ of an unidentified species were obtained, perhaps those of Hamatopota insatiabilis or an allied species. The larvæ all seem to resemble each other closely and it is very difficult to distinguish specific differences in them, though they differ in a marked manner from those of any other genus of tabanids seen by Neave. The differences between these larvæ and those of Chrysops are discussed under that genus (Plate 5, Figs. 73 and 74). The limitation of the pigmented areas to the anal segment and the abruptly truncated syphon seem to be characteristic of and peculiar to this genus, as also are the very short, sometimes almost invisible pseudopodia.

The genus Hamatopota is represented by a large number of species in the Old World, especially in tropical Africa; the species are less numerous in the New World and the genus is entirely absent in Australia.

Hamatopota crudelis Austen.-An African species, originally described from German East Africa, and by Neave found by no means uncommon near Mt. Mlanje, in southern Nyasaland, in the months of October and November.

The first larvæ of Hamatopota found in Africa, by Neave, belonged to this species. Several of the larvæ were found in September and October, and, though many were lost, two males and three females eventually emerged in October and November.

The larva, which is figured (Plate 6, Fig. 85) differs from that of Hamatopota insatiabilis only in that the pigmented areas are more pronounced round the anus and at the base of the syphon.

The pupal aster (Plate 13, Fig. 170) has hooks of nearly equal length and forms a very regular star. There is no true dorsolateral comb, though one female has a minute knob-like process in place of it. The pupal aster is figured. 
Hamatopota decora Walker.-An African species, which prefers low and dry country, therefore not common in the-Mlanje district of southern Nyasaland, where Neave made his studies. However, Neave has acquainted us with the larval and pupal stages.

The larva was of the usual Hamatopota type, but the pigmented areas on the anal segment were an orange color. This might, however, have been due to the mature condition of the larva, which was about to pupate. The pupal aster is regular in shape. A dorsolateral comb consisting of three spines is present. Pupal aster and dorsolateral comb of a female are figured (Plate 13, Fig. 169, $a, b$ ).

Hamatopota insatiabilis Austen.-An African species, abundant near Mt. Mlanje, southern Nyasaland, about November and early December, according to Neave (1915).

A few larvæ of Hamatopota insatiabilis were obtained, and from some of these, three females were bred between November 7 and 10, 1913. The three posterior segments of "what is believed to be the larva of this species" are figured (Plate 6, Fig. 86). There seems to be no pigmentation except a narrow double ring at the posterior end of the eleventh segment. The circular ridge on the tenth segment shows no pigmentation. The twelfth segment is very short and rounded.

The pupa is figured (Plate 11, Fig. 131) but not described. The pupal aster of this species (Plate 13, Fig. 172, $a, b, c$ ) is very remarkable, the upper hooks being reduced to mere knobs, while the middle pair are enormously enlarged. A well marked dorsolateral comb is present. Pupal aster of the female in side view and from behind is figured, also the dorsolateral comb.

Hamatopota pluvialis Linné.-One of the commonest and most widely spread tabanids in Europe, known also to torment the reindeer in Lapland, where it occurs in incredible numbers. It is the representative of a genus spread all over the world but absent in: Australia, while in Africa it is represented by a large number of species.

In the more recent literature nothing is found concerning the life history of this species, the earlier work having escaped attention of: recent investigators. 
Zetterstedt believed that the larvæ of Hamatopota live in the dung (Scholtz).

Scholtz reported, as early as 1850 , having found the pupæ of this species; we shall give his statement with the other facts available on the pupal stage.

Larva and pupa of this species have subsequently been described by three authors, independent of each other. All agree that they are terrestrial in habit.

Brauer (1883) once obtained the larva of Hamatopota from the larva of Helops lanipes (Coleoptera, Tenebrionidæ), from which when it seemed to be in process of molting, the tabanid larva came to light.

Brauer (1869) is the first to give accurate descriptions of the early stages (Plate 6, Fig. 83, $a-d$ ), with the exception, however, of the egg state, which remains unknown in Hamatopota pluvialis, while it has been observed in other species of Hamatopota.

Brauer found, in an excursion made in June, 1869, to Lang Enzersdorf, Austria, near the railroad embankment, in a region of scattered cottonwood (Populus alba), in entirely dry soil, a white grub, about $20 \mathrm{~mm}$. in length and 3 to $4 \mathrm{~mm}$. in diameter, which was unfortunately only briefly examined with a lens. When in the evening Brauer began to examine it more closely the grub had pupated, and it was only from the remainder of the larval skin that the character of the larva could be ascertained. However, the description obtained from this meager material is very accurate.

The larva (Plate 6, Figs. 83, $a, b, 84$, and 91) is cylindric, twelve-segmented "(head included). The head (Plate 6, Figs. 84 and 91) is formed after the type of tabanid larvæ, almost completely differentiated, the chitinous plates diverging behind and exceeded in length by two long rods in the middle, which are continuous with the middle chitinous plate of the head and with the labrum. The latter is narrow, somewhat curved downwards, widened at the tip, and ciliated laterally. Close to the sides are the hooked, downwardly curved parallel mandibles, their margin being convex and serrate. Below the mandibles and partly within the concavity formed by them are the maxillæ, which are soft in appearance. Their basal part is globular and slightly spiny, the distal part is formed by a finger-like piece; at the side of the latter, externally, a two-jointed palpus of twice its length, the two joints being of equal length. The terminal joint, moreover, is widened and excavated to spoon shape. Above and at the sides of the mandibles are the antennæ, of which the distal joints are cylindric and simple, 
the first one thick and long, the second short and narrow. There are no bristles at the base of the antennæ. The eye-spots are small, perhaps more distinct in life, and situated behind the middle of the head. The whole head is deeply retractile. The body is pure white in color with many longitudinal strix, and bearing, on the fourth to tenth segments, small fleshy warts on the lateral and ventral sides, each segment having four. These warts can be retracted, giving the larva an almost smooth appearance. The last segment ventrally with a thick half globular anal prominence, and posteriorly with a short conical structure with a vertical two-lipped fissure. The lips of the latter are strongly chitinized, transversely sulcated, each of them leading to one of the main tracheal trunks; they represent the posterior spiracles of the larva, while the small anterior spiracles are situated on the posterior half of the second segment.

The whole structure of these respiratory organs indicates that the larva had not lived in water or left it only for pupation, as, according to Brauer; in all tabanid larvæ of terrestrial habitat the posterior spiracles are analogous in structure, while the aquatic larvæ of $T a$ banus autumnalis and Hexatoma pellucens are enabled to extend the last segment like a telescope, showing a similar fissure only at the end of this tube.

A much more detailed description of this larva is given by Perris (1870), who found it twice, and each time in a single individual, in the decayed wood of old pine stumps. Of the two specimens found one was sacrificed to be studied; the second one metamorphosed and produced, to the surprise of the observer, the species Hamatopota pluvialis. This fly, as he says, is very common in regions of France where there are no pines, and so abundant in the Landes that he could not have missed the larvæ if the stumps or the bark of dead trees were its normal place of development, as he had especially studied all insects inhabiting the pine. Consequently, Perris assumes that the insect has deviated from its ordinary habits. However, the larvæ were found in the pine wood detritus itself where they apparently had lived, and in which the larva mentioned changed to pupa after three months.

A translation of Perris' description of the larva (Plate 6, Fig. 82, a-e) is given below:

Larva (figured) $12 \mathrm{~mm}$. in length. Smooth, hard, leathery (coriaceous), cylindric, attenuated at both ends, anteriorly more than posteriorly, very finely and densely striated in a longitudinal direction. 
Under ordinary conditions the head, which is small in comparison with the body, reddish and semicoriaceous, appears conical; but when protruded forward, it forms a sort of neck posteriorly. It is retractile to the extent that it can disappear completely in the first segment. The front is protruded into a fleshy mouthpiece which Perris assumes to be the labrum. To the right and to the left of this a black horny linear piece is seen, which is curved anteriorly and prolonged posteriorly into a rod, becoming more and more thinned out, which is observed through the transparent tissues and which is inserted deep in the first segment. These two rods are at first parallel, then somewhat diverging. They serve, according to Perris, as places of attachment to the muscles which move the head and the linear piece mentioned, which are the mandibles. Below, two fleshy subconical pieces are seen, fused together at their base, of which the inner is separated from the outer one only at the tip of the latter. The external piece, which is a maxilla, is surmounted by a rather long palpus of two joints, the first of these joints one and a half times as long as the second; the inner piece is the lobe of the maxilla. Above, on each side of the head, opposite to the base of the maxillæ, a rather long antenna is situated, which appears to consist of three joints, of which the first is very short, the second four or five times longer, the third slender and about one-half as long as the preceding.

This larva has, consequently, a protruded labrum, two horny serrate mandibles, two maxillæ with their lobes, two maxillary palpi consisting of two joints, two antennæ consisting of three joints, all extending beyond the head.

The body is formed of eleven segments; the first, or prothorax, truncated conical, is one and a half times as long as all the other thoracic segments, which are slightly shorter than the abdominal segments. The first six of the latter have eight fleshy and retractile protuberances, two dorsal ones distant from one another, two on each side placed close together, and two ventral ones placed at a distance from one another like the dorsal ones. These protuberances are of great help to the larva when it starts to walk. In this act, the larva presses the head against the surface on which it is to move and contracts the body, at the same time retracting the protuberances; then, freeing the head and exserting the protuberances which, all around, exercise a strong pressure, it pushes forward. The last segment of the abdomen, which is somewhat rounded at the sides, is rather suddenly and considerably narrowed down posteriorly, where it terminates. in a disk in the center of which a reddish vertical slit is observed with the aid of a lens. At high magnification this slit is recognized to be a spiracle the lips of which are transversely striated. In seeking for the remaining respiratory orifices, two of these oval and reddish spiracles are found at the posterior border of the prothoracic segment, one on each side. Under the last segment, in its anterior third, there exists a fleshy prominence, of the shape of an ellipsoid placed transversely, and retractile; it is traversed by a longitudinal fissure or sulcus which indicates the anus. This prominence also serves to aid locomotion. 
The body of the larva is completely covered, except in the anal region, with very fine and densely placed longitudinal striæ easily seen with the lens. They certainly play a part in the contractions and dilatations of the body.

The larvæ of this species have been found and described again by Beling (1875). ' One larva was obtained by him on March 24, 1873, from hog dung which had been collected from a meadow and piled up at the edge. This larva was kept in a room which was not heated, and pupated on June 24, producing a male imago on July 6 , after a resting period of twelve days. From December, 1873, Beling frequently found single larvæ in the soil of cultivated fields, several times also in the earth of hedges bordering on meadows. The larvæ which were collected were kept in a glass jar partly filled with humus and continued to live for months in this medium, without injuring one another. However, at the time when metamorphosis was to take place, they killed one another, apparently for the purpose of feeding on the killed individuals by sucking out their contents, and of the ten larvæ finally only one remained, which pupated on June 25,1874 , and produced a female imago on July 5, after 11 days of pupal condition.

According to Beling, the larvæ resemble closely those of Tabanus bromius in color, appearance, and habits, but are at once distinguished by being shorter and thinner, and by the much finer punctated $^{12}$ longitudinal striation. Concerning localities of capture, Beling states that the Hamatopota larvæ occur chiefly in humus of cultivated fields, while the larvæ of the terrestrial Tabanus species mentioned are found usually in grass-covered or meadow soil. Beling's description of the larva is translated below.

Larva. -10 to $12 \mathrm{~mm}$. in length, $2.5 \mathrm{~mm}$. in width, somewhat contractile; when fully extended, up to $15 \mathrm{~mm}$. and even more in length, twelve-segmented, pale yellow, strongly and glassy shining, with very fine irregular (punctated) longitudinal striation, somewhat narrowed in front and behind, and especially during locomotion narrowed down to spindle shape in the anterior part, with small narrow brown head completely retractile into the first segments, appearing, when seen from the dorsal side of the first two segments, as a brown longitudinal stripe, broadened behind and ending in two points. The last body segment is shorter and narrower than the preceding one, rounded at the posterior border,

12 The German word used is "Nadelrissig." 
with a cushion-like prominence on the middle of the rounded part. The prominence is often in the shape of a short thick cylinder, truncated at right angles, bearing in the middle the vertically placed stigmatal fissure. Anus prominent on the under side of the last segment. On the under side of the fifth to the eleventh segments inclusive are transverse locomotor swellings near the anterior margin, forming six longitudinal rows, of which four on the ventral side are arranged in two pairs, not far distant from one another, while in the outer rows ridges are placed at a greater distance from one another and are also placed farther back from the anterior segmental border.

Scholtz (1850) reports having found the pupæ of this species, together with those of Tabanus autumnalis and Tabanus tropicus, on an excursion with Prof. von Siebold and Dr. von Frantzius in the neighborhood of Breslau, in 1850, at the edge of a pond which was entirely covered with Lemna, and the water of which was polluted from manure piles surrounding it. Here the pupæ were found quite near the edge under a thick moist mass of decaying Lemna, together with the pupæ of Stratiomys, Syrphus, etc.

A translation of Brauer's description (1869) is as follows:

The pupa (Plate 6, Fig. 83, c, d) $15 \mathrm{~mm}$. in length, slender, with no spines at the anterior end, bearing here only two small tubercles. The wing and leg cases do not extend beyond the first abdominal segment; the second to tenth abdominal segments bear a circular armament of bristles, the last segment ending with a thick and only slightly diverging fork which is more or less embedded in the cast larval skin.

From Brauer's pupa there appeared, after two weeks, a male of the species in question.

More precise in detail is the description given by Perris (1870), obtained from the cast pupal skin:

The pupa (Plate 6, Fig. 82, $f, g$ ) presents all the parts of the perfect insect. The organs of the head can be guessed rather than seen. Two frontal tubercles (trouqués), surmounted by a bristle, seem to be the cases for the antennal bases; two other oblique tubercles overlapping with their borders, in the region of the mouth, seem to hide the palpi. Between these two tubercles and those preceding them two patterns are formed by small elevated lines, the upper ones forming a parenthesis, and the lower ones a sort of brace. Exterior to these patterns there exists, on both sides, a transversely triangular prominence, with its summit overlapping a little the border of the head. I (Perris) consider these prominences, to judge from their location and form, as the cases for the distant 
division of the antennæ. Below there are two small tubercles placed obliquely one below the other and surmounted by a little hair, and on the vertex four tubercles arranged transversely, the outer ones larger and bearing a hair. The dorsal part and the sides of the thorax bear some small hairs. The abdomen, consisting of seven segments, presents on the posterior thirds of each of the first six a circular series of stiff bristles, unequal in length, thick at their base and directed backwards. The last segment is small and ends in a small crown of six conical diverging teeth, the two upper ones a little smaller than the others. Rather near the anterior border of the thorax two obtuse protuberances are seen, somewhat more excavated and striated at the summit, crossed by an oblique furrow and inside showing a depression, the thoracic spiracles of the nymph. There are also visible the very conspicuous marks of six abdominal spiracles; they are situated laterally on the first six segments.

It is conceivable that the tubercles, the hairs, and the bristles with which this pupa is armed, are very useful when it wants to move or to reach the open air in order that the perfect insect should not be hindered in the act of eclosion. In the eclosion the shell of the pupa splits all along the median and dorsal side of the thorax.

Beling also describes the pupa of Hamatopota pluvialis.

Pupa.-10 to $13 \mathrm{~mm}$. in length, about $2.2 \mathrm{~mm}$. in width, cylindrically rounded, of a dirty brownish yellow color, slightly shining, somewhat narrowed behind. Below the two small front teeth placed beside one another, and above the frontal margin two small tubercles, not much farther distant from one another, and each bearing a long bristle. Above this tubercle, somewhat distant from it, is another separate hair, and, in addition, on each side of the thorax are two hairs, one directly located behind the other. Abdomen nine-segmented, first segment very short, hardly reaching to the fourth part of the length of the second segment; third to eighth segments inclusively surrounded, near the posterior margin, with a circle of rather densely placed brownish bristle-shaped teeth, of unequal length, appressed backwards, and shorter on the ventral than on the dorsal side. Last abdominal segment small, bearing in the middle of its under surface a row of similar bristle-like teeth as the other segments, and at the end with six outwardly divergent comparatively strong teeth with blackish tips, arranged in a hexagon of which the upper two are shorter and weaker than the remaining ones.

Hamatopota sp.-Two undetermined species of Hamatopota were observed by Patton and Cragg (1913) in Madras, to oviposit, as all the small tabanids observed by these authors, "on blades of grass just at the edge of a shallow stream, or on the leaves of the lotus plant at the edges of small ponds, but never over deep water." 
These species of Hamatopota would then fall under the heading of those larvæ which, according to Patton and Cragg, have no air sacs and, consequently, perish when falling into deep water. Like the other small species, these Hamatopota "spread out their eggs in one or more layers on blades of grass." The eggs of one species of Hamatopota are dark gray when deposited, according to the same authors. No descriptions or figures are given. The eggs are said to be torpedo-shaped (not cylindric) in all the smaller tabanids in Madras, which should hold good for Hamatopota.

Hexatoma pellucens Linné.-A European species, according to Schiner common in Austria, attacking man as well as animals.

In the middle of June, 1868, in a garden in Breitensee, Austria, Ernst Marno found in a reservoir 8 feet deep, filled with rain water and dung fluid, together with larvæ of Eristalis and Culex, some dipterous larvæ of about $25 \mathrm{~mm}$. in length, which were on the dorsal side beautifully mottled with black. Some of them kept in this water had died the following morning and were preserved in alcohol. Brauer, who was consulted, pronounced them to be tabanid larvæ of an unknown species.

Early in July, after a heavy rain, larvæ were again found, which in color and appearance seemed to be the same species, and of which in the middle of July when they apparently were full grown, a considerable number were collected from the mud of their habitation.

Of these, however, many perished which were continually replaced by new captures. On this occasion also empty pupal cases and some full ones were found; the latter had already made some progress in the transformation to the perfect insect, but had fallen into the water and had soon died and decayed.

Brauer determined the contents of these pupæ, as well as a dead fly which was found in the water, as belonging to Hexatoma. However, a search for the pupæ in the soil surrounding the reservoir was in vain, and there remained some doubt as to the identity of the larvæ and pupæ.

The larvæ captured by Marno were kept by him in a shallow flower pot, which was filled half with moist earth and half with moist decaying foliage, as it had been observed that the larvæ ap- 
parently showed a preference for this environment and had been seen to work their way into a decaying leaf. They did well under these conditions; only a few of them died, and on July 22, in the afternoon, the first soft pupa was found, the larval skin still adhering to it, and identical with those found dead in the water.

A few days later, when a search was again made for the larvæ, none of them were found, but instead it was discovered that they pupated in the interspaces of the somewhat defective brick walls of the reservoir, and here some pupæ as well as larvæ were collected, of which the latter were more or less contracted in preparation for their metamorphosis. From these pupæ the first fly was obtained on July 27 , in the morning.

The duration of the larval stage is about three weeks; the duration of the pupal stage Marno could not ascertain, leaving his material to Brauer to study.

The larva (Plate 6, Figs. 89, $a, b$, and 90, $a, b, c$ ) has been described by Brauer (1883), who reports it to be aquatic, being found in pools and puddles. A translation of Brauer's description is given below.

Larva, when extended, slender and spindle-shaped; when contracted, obtusely cylindric, the anterior and posterior segments being retracted in the latter case. The body consists of a head capsule and eleven segments. The cuticle has a striped appearance because of the many closely arranged longitudinal furrows. The first three segments and the under surface are bone-white (yellowish white), the dorsal surface of the remaining segments shows beautiful grayish brown patterns on a white background, brought about by microscopic pubescence. The head capsule (Plate 6, Fig. 90, $a, b, c$ ) is narrow, formed like that of all tabanid larvæ, compressed, and can be retracted into the second segment. It consists of four plates which posteriorly are not connected, and of which the two middle ones are drawn out into long rods. The lateral plates show on half their length on the outside an irregularly rounded and convex eye-spot on each side. At the anterior end is a comb-like upper lip reaching above and between the mandibles. On each side of its base there is a cushion-like projection thickly beset with mostly two-pointed bristles, on which the antennæ are inserted, which are short and twojointed. The first joint is cylindric, the second divided lengthwise into two parts. The exterior point is shorter than the interior. Below and to the inside of the antennæ are the hooked and more strongly chitinized mandibles, which may be moved up and down parallel to one another. Their surface is transversely sulcate; consequently the anterior convex margin is serrately incised. 
Within the concavity of the mandibles the softer maxillæ are placed. The extremity of the latter, curved hook-like in the same way, runs parallel with the mandibles, so that to the observer from the side, two hooks appear superposed one on the other. The maxillary palpus projects obliquely towards the outside and above, and has a thick cylindric basal joint and a thinner simple terminal joint of double length. Beginning with the third body segment, there appears a short intermediate segment, on which rather long bristly hairs are inserted. On the ventral side several circular protuberances with bristles are noticed on the intermediate segment. ${ }^{13}$ The fourth to tenth segments show on the dorsal side two, and on each side one spinous protuberance. The last segment has, on the ventral side, the paired anal prominence, covered with finer and stronger hairs and surrounded by a three-sided furrow.

At the basal angles of the anal prominence small wart-like swellings appear. From the last segment a respiratory tube may be extended which is rather sharply pointed and narrowly cone-shaped, showing at the tip a vertical fissure between two thickenings, the endings of the main tracheæ of the metapneustic larva.

The pupa is a free pupa, and is found in the ground.

The head of the pupa bears on each side above the base of the antenna a small wart with a bristle, and above and below the antennal sheath, on the eyes, similar but slightly smaller warts. Behind the prothorax are the anterior spiracles, placed on small cylindric prominences which do not project far. The wing and leg cases reach the posterior margin of the first abdominal segment.

Length of the larva: 27 to $30 \mathrm{~mm}$.; width in the middle $4 \mathrm{~mm}$.

${ }^{13}$ The German word used here is "Zwischenwulst" which means a swelling lying between the segments. 


\section{TABANUS, EARLY STAGES IN GENERAL.}

Much that can be said about Tabanus in general has been said already under the family Tabanidæ.

The eggs of Tabanus are not appreciably different from those of Chrysops, except that the latter resemble, according to Patton and Cragg, more those of the smaller species of Tabanus, the eggs of the larger species being of slightly different form. According to Hart, the eggs of Tabanus are always laid in clusters composed of several layers, but recent observations have shown that from this rule exceptions are frequently met with, when the eggs are spread out in one layer or even loosely scattered. As a rule, however, the eggs are laid in a cone-shaped or bilaterally symmetrical mass containing several layers of eggs and attached to various objects as specified under the heading of Tabanidæ.

The larvæ and pupæ, studied by Hart, form two groups, which may be called the lineola and the atratus groups. The larvæ show the most distinctive characteristics in the structure of the surface, especially of the prothorax, which has lateral, dorsal, and ventral shining areas, limited in front by an opaque pubescent annulus. Comparing the anterior extension of these shining areas, Hart found them all of about the same length in Chrysops and the lineola group of Tabanus, although this length varies in Chrysops. The lateral prothoracic areas are extensively invaded by the anterior annulus in the atratus group of larvæ, the striated shining space becoming basal, being not more than half as long as the dorsal area. The upper lateral space of the mesothorax is not closely striate, and is quite shining. In all except some of the atratus group the remaining lateral striation, including that of the prothorax, is not much finer, and is also shining, but in the others, as in atratus, the prothoracic and abdominal lateral striation becomes microscopically fine and even subopaque. A smooth spot near the lower hind angle of the prothoracic lateral area furnishes another good differential character. The dorsal and ventral striation varies in extent according to age, but the thorax is striated above in Chrysops, and smooth or nearly 
so in Tabanus. The three types of coloration observed are well shown by the three Tabanus larvæ figured (Plate 3, Figs. 40, 41, and 42).

Pupa.-The great difference between the abdominal spiracles and terminal teeth of the lineola group and those of the atrains group is evident from Hart's figures (Plate 13, Figs. 162 and 163). In both, the thoracic spiracles are in a plane nearly parallel to the adjacent surface and the spinous fringes contain long and short spines. The preanal fringe in the lineola group shows more or less of a chitinous web, uniting the bases of the spines.

A pair of short appressed palpal sheaths on the lower surface of the head, resembling the antennal sheaths, differs slightly in position in related species of the atratus group.

The species of Tabanus have been classified by various authors, but for convenience, I have listed them here in alphabetical order.

We possess data on early stages of fifty-five determined, and fourteen undetermined species of Tabanus. Those of some of the worst stock pests still await description.

Tabanus albimedius Walker.-This is one of the commonest Indian species of Tabamus, according to Patton and Cragg, and occurs almost all the year round in Madras.

Observations on the life history and early stages have been made by Patton and Cragg (1913). The species oviposits in a variety of situations, but most frequently on the leaves of some plant overhanging deep water. The egg masses have also been found on small rocks in the bed of a stream, and on pieces of string hanging over house drains; on one occasion a mass was found on a papaya tree, at the foot of which water was occasionally allowed to flow. The number of eggs laid is between 500 and 600 . The eggs, as in all the larger Indian species mentioned by Patton and Cragg (Tabamus striatus, albimedius, and speciosus) are subcylindric with tapering ends. The eggs of Tabanus albimedius measure 1.9 to $2 \mathrm{~mm}$. in length and $4 \mathrm{~mm}$. in breadth. The eggs are brownish white when deposited A chalcid parasite, which was not identified by Patton and Cragg, regularly destroys large numbers of egg masses of this species, and of striatus. This species, as the larger species of India in 
general, oviposits any time during the day, but as a rule in the morning.

When "one of the larger species" (including Tabanus albimedius) is about to oviposit "it alights on the leaf or blade of grass with its head downwards; it then thrusts the tip of the abdomen forwards under its thorax, and deposits an egg, which adheres to the leaf owing to the sticky substance which accompanies it. The abdomen is then returned to its original position, and as soon as the next egg is ready to be laid, is again flexed, and the second egg is placed at one or other side of the first. In this way three or four eggs are laid on one side of the first and three or four on the other. The mass at this stage has the shape of a V. The fly now moves forwards, and, raising the end of the abdomen to one arm of the $\mathrm{V}$, places a number of eggs down the side until the apex is reached; she then changes over to the other side and deposits eggs all down that arm up to the apex. In the end a raised compact mass of eggs is built up, which, if examined with a lens, demonstrates the precision with which the eggs are placed in reference to one another."

The larva of Tabanus albimedius has not been described and also not figured, by Patton and Cragg, though they evidently had it under observation. A good characterization of tabanid larvæ in general is given, but the differences of the various species are not entered upon.

Of the larva of this species, by the same authors, dissections have also been made, and detailed illustrations are given of the mouthparts (Plate 7, Fig. 97), and of the alimentary tract (Plate 7, Fig. 98).

The figure given of the head shows the mouth appendages: labrum, maxillary palpus, maxilla, antenna, and mandible; also the lateral area of spines behind the antennæ. On the figure the antennæ appear to be two-jointed, while the authors state that they are three-jointed in all tabanids.

The figure given of the alimentary tract shows the esophagus, proventriculus, the narrow salivary glands, apparently inserted in the pharynx, the mid gut, hind gut, and Malpighian vessels, four in number.

Patton and Cragg were the first to publish anything on the alimentary tract of a tabanid larva based on dissection.

Tabanus atratus Fabricius.-A species inhabiting eastern North America, as far west as Colorado, conspicuous by its large size and 
uniformly black color. About its early stages we are informed by Walsh, C. V. Riley, Hart, and Hine. As Hine summarizes, the eggs are deposited around marshy places on grass and sedges, and the larvæ are found by digging in the mud.

Hart (1895) is the first to give notes about its oviposition, which was noticed in Illinois, in July and August, and egg masses then became frequent. The last date for the imago was August 15. On August 11, a female was observed ovipositing on the side of a wooden frame standing over the water. The egg mass was placed in a breeding cage, and one week later, on the 18th, many larvæ hatched from it. Another egg mass of the same form and appearance, placed on the dark bark of.a stick projecting from the water, was brought in July 27, from which hatched on August 4 larvæ apparently of this species.

Hart's description of the egg mass and egg is given below:

"Egg Mass.-Blackish-brown, subconic, with oval base, 10-15 $\mathrm{mm}$. long and 8-10 mm. wide, height 5-7 $\mathrm{mm}$.; sides convex or concave, apex correspondingly rounded or pointed; eggs pointing obliquely upward and towards one end, both sides meeting upon that end in a more or less prominent longitudinal crest. The eggs are stacked in four or five tiers, one above another, and gummed together into a firm mass."

"Egg.-Length 2.5-2.7 mm., diameter $0.4 \mathrm{~mm}$. Dark brown, subcylindrical, ends more or less tapering and curved, surface minutely rugose and subopaque."

Hine completed these observations in 1906. According to him, the eggs of Tabanus atratus are generally placed in masses of various sizes on the leaves and stems of grasses and sedges and other plants growing in marshy or wet ground, but not necessarily in the water. A single mass may contain as many as 500 eggs, but often they are smaller and they may be larger; they are white when first placed, but soon turn brownish. The mass is very convex and composed of several layers, one above the other, the bottom layer being attached to the surface of the leaf or stem and the other layers each to the one that was placed before it. Each egg is elongate, spindle-shaped, between 2 and $3 \mathrm{~mm}$. in length, and narrowed at each end. A female was observed, in Ohio, ovipositing on June 23 at 11 o'clock. The eggs were taken and kept in a room out of the sun, where they hatched on the morning of July 2 before 6 o'clock, thus requiring an incubation 
period of nearly nine full days. It has been proven that the eggs of tabanids hatch more quickly when exposed to the sun during the day (see Chrysops), where they are usually deposited; therefore the time given is probably too long for eggs under natural conditions. There is no definite way, as far as our knowledge goes, according to Hine, of telling the eggs of the black horse-fly from those of other species of this genus, but being a large species the masses are much larger than in some others, and are more convex than usual. The particular place of oviposition is in a measure characteristic.

It is of interest to note that the egg masses of Tabanus atratus are often found to be parasitized.

When the two egg masses mentioned and described by Hart had produced larvæ they were placed in a dry vial, and a little later it became evident that both masses had been parasitized by Hymenoptera, minute black imagos emerging freely in the vial. An examination of one of the masses showed that about one-half of the eggs had been infested. Examples of the imago were sent to Mr. W. H. Ashmead, who found the species to be a new one. It was described by him as Phanurus tabanivorus (Ashmead).

I give the description of this insect at the end of the chapter on Tabanus, under the heading, Parisites of the early stages of Tabanidæ. The illustration of this insect, given by Hart, has been omitted.

Hart is also the first to tell us about the early larval stages of Tabanus atratus. From the two egg masses he obtained larvæ hatched as already stated, on August 4 and on August 18. In the latter case, the incubation period was determined to be one week. The larvæ were at this time commonly found in water among the vegetation, less commonly in the sand of the shore, and young individuals became frequent.

Larva, Newly Hatched (According to Hart).-- "In this stage the lateral areas are sculptured similarly to those of the adult, but the dorsal and ventral areas, though shining, are rather sparsely striated. Traces of the dark markings are visible, especially on the posterior segments."

According to Hine, the larvæ, when first hatched, are about $3 \mathrm{~mm}$. in length, white, and with a narrow darker shade at the union of each two segments. As soon as they drop to the ground they begin 
to burrow and are soon beneath the surface, where they cannot be seen. At first these larvæ are very hard to see on account of their small size; consequently not much has been learned of their habits under natural conditions; but when they are nearly grown they are to be found in a variety of places. We now come to a discussion of the adult larval stage.

Walsh (1863) gives a description of an aquatic Tabamus larva which he was unable to identify as the imago obtained from this larva was in too bad a condition to be identified, having remained many weeks without care, in the breeding jar. From his descriptions, however, and also from his remarks on the imago, it is evident that the larva belongs to Tabanus atratus. There is in Massachusetts no other Tabanus known of this size and with wholly brownish black wings, and the description of the larva agrees with that given by later authors for undoubted Tabanus atratus larvæ. However, some of Walsh's smaller specimens may belong to Tabanus stygius or other species.

Walsh found his aquatic larva, on many different occasions, "amongst floating rejectamenta." On one occasion he found six or seven specimens in the interior of a floating $\log$, so soft and rotten that it could be cut like cheese. Once he discovered a single specimen under a flat submerged stone, in a little running brook. Finally, once he met with one alive, under a log, on a piece of dry land which had been submerged two or three weeks before, whence it appears that it can exist a long time out of the water. Walsh had, on several previous occasions, failed to breed this larva to maturity, and the only imago he had was obtained in 1861 from larvæ which, suspecting them to be carnivorous from the very varied stations in which they had occurred, he had supplied with a number of fresh water mollusks, but the habits of which, in consequence of having been away from home, he was unable to watch. On September 2, 1863, he found a nearly full grown larva among floating rejectamenta, and between that date and September 23 this larva devoured "the mollusks of eleven univalves" (genus, Planorbis) from one-half to three-fourths of an inch in diameter; and on three separate occasions observed it work its way into the mouth of the shell. In this operation the pseudopods were energetically employed and Walsh found, on cracking the shells 
after the larva had withdrawn, that a small portion of the tail end of the animal was left untouched-no doubt in consequence of his being unable to penetrate to the small end of the whorl in the shelland also the skin of the remaining part and the horny tongue membrane.

Walsh's description of the larva of Tabamus atratus, including that of the imago which serves to establish its identity as to species, is given here:

"Tabanus -? Imago male. Blackish. Legs blackish, wings brownish fuscous. Length 0.70 inch. Expanse $1.30 \mathrm{inch}$. One decayed specimen came out between June 14 and July 14, 1861, from a larva found early in June."

"Larva, from the living specimens, obtained August 14, 1860, and September 2, 1863. Length 2.25 inches when extended, 1.75 inches when contracted; diameter 0.25 to 0.30 inch. The specimens found in 1863, 0.25 inch shorter. Body cylindrical, twelve-jointed, the three or four terminal joints much tapered at each side of the body, but more so anteriorly than posteriorly, and joints one and eleven, each with a retractile membranous prolongation at tip. Joints one to ten are subequal; eleven is about two-thirds as long as ten, and twelve about one-fourth as long, and 0.5 inch in diameter. Color a transparent greenish white, paler beneath, on the anterior and posterior margins of joints two to eleven, the anterior annulus laterally connected with the posterior by two to four dark green lines. On the dorsum of four to nine, and more obscurely on ten, a dark green basal triangle, extending half way to the tip; joint one with paler markings, and with no dark annulus behind; joint twelve entirely fuscous. Head small, apparently fieshy, pale, truncate-conical, 0.03 inch wide, and about 0.04 inch long in repose, inserted in joint one without any shoulder. The trophi occupy twothirds of its length, but it has a long cylindrical internal prolongation, extending to the middle of joint two, which is sometimes partially exserted, so that the head becomes twice as long as before. All the trophi are pale and apparently fieshy except the mandibles, which are dark colored and evidently horny, and they have no perceptible motion in the living insect. The labium is slender, a little tapered, and three times as long as wide, on each side of and beneath which is a slender thorn-like decurved brown-black mandible. The labium resembles. the labrum, but is shorter, and on each side of it is a slender palpiform but exarticulate maxilla, extending beyond the rest of the mouth in an oblique direction. No palpi. On the vertex are a pair of short fleshy exarticulate filiform antennæ, and there are no distinct eyes or ocelli. In the cast larval integument the entire head, 0.25 inch long, is exserted, and is dark colored and evidently horny, all the parts retaining their shape except the antennæ, labrum, and labium. The whole head has here the appearance of the basal part of the leaf of a grass plant, clasping the origin of the maxillæ on its posterior half, and 
bifurcating into the somewhat tapered cylindrical mandibles on its anterior half. The maxillæ are traceable to two-thirds of the distance from the tip to the base of the head, scarcely tapering, bent obliquely downward at two-thirds of the way to their tip, and obliquely truncate at tip. On the anterior margin of ventral segments four to ten, in the living insect, is a row of six large fleshy roundish tubercular retractile pseudopods, the outside ones projecting laterally, and each at tip transversely striate and armed with stout bristly pubescence; on the anterior half of ventral joint eleven is a very large, transversely oval, fleshy, whitish, retractile proleg, with a deeply impressed, longitudinal stria. On the anterior margin of dorsal joints four to ten is a pair of smaller, transversely elongate, retractile, fleshy tubercles, covering nearly their entire width, armed like the pseudopods, but not so much elevated as they are. No appearance of any spiracles. Anus terminal, vertically slit, with a slender retractile thorn, 0.05 inch long, visible in 1860 , but not in 1863 . Head, and first segment or two, retractile."

When handled, the larva is, according to Walsh, "very vigorous and restless," and burrows with great strength between the fingers, and even on a smooth table walks as fast as any ordinary caterpillar, either backwards or forward; when placed in a vessel of water it swims vigorously, twice the length of its body at every stroke, by curving its tail around laterally, sometimes to the right, sometimes to the left, so as to touch the side of the fourth or fifth joint, and then suddenly lashing out with it. In such a vessel it always keeps close to the surface, and at the end of every stroke, and also when in repose, elevates the anal slit out of the water, on which occasion Walsh once saw a bubble of air attached to it. In the breeding jar the larva scarcely ever comes to the surface, but burrows among the decayed wood, aquatic plants, etc.

The larva described by Walsh differs, according to him, remarkably from the one described by Degeer (Tabanus bovinus L.), in having ventral pseudopods as well as dorsal ones. Walsh says that it might be supposed that the dorsal tubercles were branchial, "but for the fact that they are found in the earth inhabiting species described by Degeer," and that like the aquatic larvæ of Prionoxyphon discoideus Say (Coleoptera) it has a branchial apparatus issuing from the anus, and the short retractile anal thorn, observed in 1860, was the form assumed by this structure when out of the water. This assumption by Walsh is partly confirmed in so far as the terminal spine con- 
tains the openings of the tracheal trunks. On the other hand, this spine has no connection with the anus, which is not terminal, as Walsh assumes, but lies in the fleshy tubercle of the eleventh segment, where Walsh observed "a deeply impressed, longitudinal stria."

The larva described by Walsh and which undoubtedly was Tabanus atratus, at least that specimen from which he obtained an imago, is found according to him from the beginning of June to the beginning of September, at which latter time he also met with a specimen only half the length of the full grown specimen (possibly belonging to a different species).

The pupa has also been described by Walsh, and the description is given here without change:

"The pupa (from the pupal integument) is cylindrical, suddenly rounded at the head, and tapering a little in the last two abdominal joints; the color is a very pale, semitransparent, yellowish brown. The mouth is represented by six tubercles, hexagonally arranged, above which, upon each side, is a trigonate threeor four-jointed antenna, pointing outwards. The pronotum commences immediately behind the antennæ and bears on its anterior dorsal submargin a pair of reniform tubercular spiracles, the mesonotum, to which the wing cases are attached, is twice as long as the pronotum, and bears on its anterior dorsal margin a pair of obliquely placed reniform tubercular spiracles, three times as long as the prothoracic ones. Then follows a very short metanotal piece, about oneseventh as long as the pronotum, bearing no spiracle, which is succeeded by eight subequal segments, all but the last bearing on their lateral dorsal surface a subbasal round tubercular spiracle. The first of these eight segments is simple and extends to the tip of the wing cases $;^{14}$ the others are all furnished two-thirds of the way to their tips with an annulus of appressed bristles directed backwards. The anal thorn is very robust, having a diameter of one-half the last abdominal segment, and is squarely truncate as soon as its length is half its width, and terminates in six small robust thorns, arranged in a regular hexagon. Length 0.97 inch; greatest diameter 0.21 inch. One specimen."

The second author to describe the larva of Tabamus atratus was C. V. Riley (1870). His description of the larva is quoted by Salmon and Stiles. ${ }^{15}$

14 "I believe this first spiracle-bearing segment to be metanotal, as also the corresponding piece in the pupa of Midas fulvipes, u. v.," (Walsh).

15 Salmon and Stiles, Emergency report on surra, pp. 100 and 101. 
"The larva [Plate 3, Fig. 46] is a large twelve-jointed cylindrical affair, tapering at each end, of a transparent, highly polished, glassy, yellowish or greenish appearance, shaded with bluish green and furnished above and below as in the figure (figure given by Riley) with large roundish sponge-like tubercles which are retracted or exserted at the will of the insect. Though the external integument is so transparent that the internal structure is readily visible, yet this integument is firm and the larva most vigorous and active, burrowing with great strength either backward or forward in the earth and between one's fingers when it is being held. Placed in water it will swim vigorously by suddenly curling round and lashing out its tail, but it is apparently not as much at home in this element as in the moist earth, for it is restless and remains near the surface with the tip of its tail elevated into the air. When the water is foul it moves about actively near the surface, but when it is fresh it remains more quietly at the bottom."

This specimen, which Riley succeeded in breeding, was sent to him by Mr. Adolph Engelmann, of Shiloh, St. Clair County, Ill. It was found by Mr. William Cooper, of the same county, about ten feet from a small but permanent body of water. Mr. Cooper at first took it to be a leech, but when he attempted to catch it it immediately commenced burrowing into the ground.

The larva is declared by Riley to be semiaquatic, for it is at home either in moist earth or water. This specimen was kept for over two. weeks in a large earthen jar of moist earth well supplied with earthworms. It manifested no desire to come to the surface. Riley found several pale dead worms in this jar, though not able to say positively whether they had been killed and sucked by this larva.

Hart (1895) reports that he has taken the larva of Tabanus atratus in every month of the season except June, at which time they had mostly reached the pupa or imago stage. They seemed to prefer the sandy shores, and were taken abundantly May 17 at Hart's Survey Station C, by running through a coarse sieve the surface layers of sand of the shore near the wave-washed margin. Station $\mathrm{C}$ is characterized by Hart as being located near the outlet of Quiver Lake, the shores being here near together and sheltered. The east bank was sandy, with a muddy coating over the part which is exposed at low water, while the west shore was of black mud grown over with willow trees and overflowed in moderately high water. The water was clear and on both sides thickly filled in summer with algæ and 
other aquatic plants, having little or no current in ordinary stages. The same process of sifting was repeated June 25, and not a single larva was found. Individuals placed in breeding cages failed to transform. A pupa was collected June 30, from which the imago appeared July 17. A cast pupal skin was also picked up July 18. Several imagos were taken in the same locality between May 23 and June 22 .

During the winter good sized larvæ sometimes occurred in dip-net collections, and March 18 they were again found to be common at Hart's Station C, in loose drifts, partly frozen, left by an early spring rise. The previous year they were common in April far from the margin, among sticks, logs, and other drift, marking the higher stage reached by the water on March 19 of that year. These situations remained moist for a long time, harboring a large variety of aquatic forms, some of which completed their transformations successfully while others apparently failed, the river remaining low and the weather dry.

Hart's description of the mature larva (Plate 3, Fig. 41) is as follows:

"Larva, Mature.-Length 45-55 mm., diameter 6-7 mm. Transparent whitish with a greenish tint, marked with conspicuous dark brownish or greenish fuscous, paler in younger specimens."

"Lateral prothoracic striated areas less than half as long as the dorsal, striation microscopically fine and opaque or scarcely shining, a small smooth spot on the anterior margin of the striated area, resting on the lower lateral line; remaining upper lateral areas of thorax much more coarsely and sparsely striate and shining; middle and lower thoracic areas-often much reduced, or even entirely covered by the lateral stripes-with distinctly finer and closer striation, but still shining; abdominal lateral areas with still finer striation, nearly as fine as that of the prothorax and feebly shining; dorsal and ventral areas all smooth and shining, rarely a few broken striæ about their margins, at the base of the prothorax or on the anal segment."

"Dark annuli distinct, broad, including false feet, transverse pale spot immediately in front of dorsal tubercles narrow or closed up in the mature larva; on the abdomen above, each annulus usually extends back on the median line in a triangular prolongation, often nearly attaining the next annulus, less developed in younger larvæ. Prothoracic lateral space occupied in front of the striated area by a dark opaque quadrate spot, extending from the anterior annulus. Lateral stripes of meso- and metathorax broad, at least the upper ones widened poste- 
riorly, the lateral edges of the dorsal areas therefore parallel behind the middle of the segment, as seen from above; lateral stripes of abdomen, especially the intermediate ones, more or less abbreviated and broken up posteriorly except on the segment next the last. In these stripes the punctures of the upper and lower rows are indicated by rounded pale dots, and those of the inner rows by elongate dots. Last segment with broad dark annuli about base of respiratory tube and around anal prominence, with lateral connections; also more or less invaded above by the basal annulus, often leaving there only a pair of pale spots posteriorly. Often a dark spot in the anterior angles of the ventral space on the seventh abdominal, and one behind the anal dark ring."

"False feet moderately elevated, with coarse whitish pubescence more or less tipped with fuscous or with brownish in younger larvæ, dorsal pair narrowly connected over median line. Main internal tracheæ usually subparallel, sinuated, not very conspicuous, although easily traceable. Stigmatal spine rarely visible."

A few larvæ have been obtained by Hart, which are like atratus except in one particular - the surface of the body, especially of the anterior abdominal segments, shows a fine undulate wrinkling resembling the sculpture of the pupa, but smoother. As the specimens showing this appearance were shrunken and in bad condition, it is surmised that it is an effect of letting the alcohol get too weak and then changing to strong alcohol.

Hine has taken the larvæ while digging in the ground in the vicinity of ponds, from under stones on ditch banks, from the water with dip-nets, and occasionally in most unexpected places. He says, however:

"If one is looking for them he is likely to meet with more or less disappointment, as the finding of one specimen does not indicate necessarily that others may be taken under the same conditions. The fact that specimens have been taken from floating logs and débris suggests that they may be transported for longer or shorter distances in this way, and during high water be stranded upon ground which, when the flood subsides, is high and dry and far removed from the bed of the stream. Since the species in all its habits is closely associated with water and wet ground, this seems to be the only way of explaining the appearance of larvæ in dry soil and in places remote from where the eggs are laid."

Hine's description of the larva follows, being in many ways more brief and accurate than that of Walsh given previously:

"Full grown larva nearly 2 inches in length. General color yellowish white, with wide dark brown bands at the union of each two segments. Prothoracic segment on each side with two lateral grooves, which do not quite, reach the 
posterior border of the segment, and a dorsal (?) groove continued for the entire length. These grooves and a number of irregular dots on the posterior part are dark colored, while the remainder of the segment is light. Mesothoracic segment, on each side, with four longitudinal grooves, which reach nearly the entire length. The dark markings on this segment include a narrow anterior border, the lateral grooves, and a number of irregular dots near the posterior margin. The metathoracic segment is like the last except that the dark color on the anterior margin is wider and the posterior, instead of being dotted, is uniformly brown. The abdominal segments are each similar to the metathoracic, but the dark markings in the region of the lateral grooves are more or less abbreviated. Last abdominal segment with two pairs of dark markings; the ventral pair extend the whole length of the segment and are connected just behind the anal prominence by a cross-band; the dorsal pair are oblong, somewhat irregular in outline, and extend from the anterior margin to beyond the middle of the length. At the anterior ventral border of each of the first seven abdominal segments is a transverse series of prolegs, three on either side of the midventral line. These prolegs. are located within the dark transverse bands, but are lighter in color than these and prominent enough to be seen easily. Above the prolegs on either side of the middorsal line is a small swelling which appears as a rudimentary proleg; before the two is a distinct transverse light spot still within the dark area."

"The head of the larva is very small for so large an insect and the mouth parts are minute. The mandibles consist of two strongly chitinized pieces, and work by being pushed endwise backward and forward. When drawn in, the anterior ends point directly forward, but when protruded, these same ends point downward and backward, thus forming a pair of hooks by means of which the prey is held. The larva is able to protrude its mandibles very quickly and to use them very effectively on soft-bodied invertebrates on which it is known to feed."

W. A. Riley and Johannsen (1915) have also figured the full grown larva of Tabanus atratus (Plate 3, Fig. 45), and Malloch (1917) figures the head and first segment of the larva (Plate 5, Fig. 77).

On the pupal stage we have information, in addition to Walsh's description, by C. V. Riley, Hart, and Hine.

Riley reports that his larva transformed to pupa within the ground during the early part of July; it remained in this state but a few days and the fly issued July 13, and soon made its presence known by its loud buzzing inside the jar. It was a perfect specimen, and the pupal integument was sufficiently firm and polished so that by carefully washing off the earth an excellent cabinet specimen was obtained, which retained almost the exact form and appearance of a living pupa. Before the escape of the fly, which was effected through 
a longitudinal fissure on the back of the head and thorax, reminding one of the mode of escape of the harvest flies (Cicadce), this pupa by means of the horns with which it is furnished had pushed itself up to the surface of the earth.

The pupa itself (Plate 12, Fig. 140) is, according to Riley, nearly an inch and a quarter in length and a third of an inch in diameter. It is cylindric, slightly curved, as in the figure, rounded at the head and tapering at the extreme hind portion. The abdominal segments are, all but the first one, provided with a ring of fine yellow bristles, pointed backwards. There is a stout thorn at the anal extremity, bearing six other thorns.

The pupa state lasts but a few days and before the emergence of the fly the pupa is pushed to the surface of the ground by means of the bristles and thorns of the abdomen, with bending movements of the body.

It splits along the dorsal line and the fly emerges, leaving the pupa case in perfect condition.

Hart's description of the pupa (Plate 13, Fig. 163) contains some additional details.

"Pupa, Male.-Length 30-35 mm., diameter $7.5 \mathrm{~mm}$. Yellowish fuscous with a brownish tint, thorax not paler. Palpal sheaths distinct, short, very narrowly separated by a depressed space. Abdomen roughly wrinkled and subopaque. Spiny fringes tipped and annulated with black. Otherwise as in the pupa (female) of $T$. stygius" (described by Hart in the same paper).

Hine (1906) gives another description of the pupa:

"Pupa [Plate 11, Fig. 124; Plate 13, Fig. 164] about $1 \frac{1}{4}$ inches in length. Color brownish yellow. Antennal and other tubercles of the head darker than the surrounding parts. Prothoracic spiracle slightly elevated, clear brown in color, reniform and oblique, rima gradually curved to near the dorsal end, where a distinct hook is formed by a sharp bend. Abdominal spiracles nearly round; rima of the first short and gradually curved and with a slight hook at the dorsal end. Terminal teeth [Plate 13, Fig. 164] arranged in pairs, a ventral pair and a pair on each side formed by a dorsal and a lateral tooth. The distances between these teeth are variable; the two dorsal are nearest together, then follows the distance between a dorsal and a lateral, the distance between the two ventral, while the distance between a ventral and a lateral on each side is greatest of any." 
This appears to be all that is known about the early stages of Tabanus atratus.

Tabanus atrimanus Loew.-An African species, common near Mt. Mlanje in southern Nyasaland, having a preference for the neighborhood of wooded streams, and being there most abundant in November and December.

Neave collected and bred the larvæ. On October 25 a number of larvæ were taken in the Ruo River among the roots of grasses in running water, but occasional individuals were also found in the mud in other wooded streams. Imagos, bred from these, began to emerge on November 25. At the same spot in the Ruo River some other larvæ were found which may be those of Tabanus pertinens, but they were not bred to the adult stage.

The larvæ, which are figured (Plate 3, Fig. 52) are strikingly distinct from those of the apparently closely allied Tabanus variabilis Lw. They are of a somewhat opaque yellowish color, with rather faint brown pigmented areas. The pseudopodia are well developed, as is the case with other species found in running water, and there are well marked hairs on the syphon. Though invisible in preserved specimens, two pseudopodia of considerable length are present immediately anterior to the anus.

The pupa is a clear orange-yellow color and the aster is remarkable for the erectness and large size of the dorsal pair of hooks, especially in the female. The dorsolateral comb consists of a few widely spread spines.

The larva (Plate 3, Fig. 52), the pupal aster of both sexes, and the dorsolateral comb of the female are figured (Plate 14, Fig. 173, a, b, c).

Tabanus autumnalis Linné.-Scholtz (1850) reports finding the pupæ of this species, which is common in Europe, with those of Tabanus tropicus and Hamatopota pluvialis (see also these species), on an excursion in the neighborhood of Breslau in June, 1850, at the edge of a pond covered with Lemna, the water of which was completely polluted from manure piles surrounding it. The pupæ, of which the flies emerged after a few days, were found quite near the edge under a thick moist mass of decaying Lemna, together with Stratiomys and Syrphus pupæ. 
The larvæ were first found in 1851, by Brauer and Göszy, on the shores and shallow places of the "Wienfluss" (Danube ?); also the pupæ were found. Kollar, 1854, gives only these few remarks on the subject.

Raillet says (quoted from Brumpt): The larva of this species lives in the water; it breathes the air at the surface of the water, like the larvæ of mosquitoes; they may be destroyed likewise by spreading kerosene oil on the swamps where they occur.

It is possible that the larvæ in which Graber discovered the organ named after him were of this species (Paoli).

Surcouf and Ricardo (1909) report on their observation of an egg mass of Tabanus autumnalis L. at Lamballe (Côtes-du-Nord) in August, 1907. The eggs formed a dense mass attached to a reed, and the female, turning the head towards the moist ground, remained immobile, making no effort to escape when it was captured. Unfortunately, the observers waited until the following morning to take the plant with its roots, and in the meantime the grass had been cut.

Graber (1882) gives the illustration of a newly hatched larva of Tabanus, which is supposed to belong to Tabanus autumnalis (Plate 8, Fig. 99). In this larva Graber studied the chordotonal organs, tactile bristles, and other microscopical details (Plate 8, Figs. 99 to 102). These details are discussed in the chapter on Tabanidæ, description of early stages (see also Tabanus sp. Nos. 10 and 12, page 179).

Tabanus autumnalis (Plate 8, Figs. 99 to 102; Plate 9, Figs. 103 to 108 ) is the species in which the organ of Graber was probably discovered for the first time. Krauss (1879) informs us that Brauer, in the spring of 1875 , demonstrated in his entomological class the larvæ of Tabanus autumnalis, which had been bred from eggs, and called attention to a peculiar and undescribed organ in the abdomen. Drawings of the organ were made by Krauss but not published; according to the latter, they agree so completely with those published by Graber that it is likely that Graber's "Fliegenmade" was in fact the larva of Tabanus autumnalis.

Krauss adds the statement that the larvæ of this species, in contrast to tabanids - the larvæ of which live in damp localities, manure, decaying plant material, or in the ground-spend all their develop- 
ment in the water, leaving it only for pupation, which takes place at the edge of ponds, in the mud, among plant detritus, etc.

Krauss expresses the opinion that the organ will doubtless also be found in the imago, and in that case the mystery surrounding it may be cleared up.

Von Friedenfels (1880) reports on a larva which he found in the salt lakes of Siebenbürgen. This larva was aquatic and transparent and was first thought to be an annelid. When sent to Brauer in Vienna, it was identified by the latter as a larva of Tabanus autumnalis.

Tabamus bicallosus Ricardo.-A smaller species of Tabanus, recorded from Pusa, Bengal, and Madras, by Patton and Cragg, to whom we also owe some notes on its early stages.

As in all the small species observed by these authors, the eggs are laid on blades of grass just at the edge of a shallow stream, or on the leaves of the lotus plant at the edges of small ponds, but never over deep water.

The eggs, as in all the smaller species in Madras, are torpedo-shaped, the eggs of this species measuring $1.1 \mathrm{~mm}$. in length and $0.2 \mathrm{~mm}$. in breadth. Figures of the eggs are given (Plate 1, Figs. 12 and 13).

The egg mass figured by Patton and Cragg seems to consist of two layers spread out one over the other, and the whole "moulded into the hollow of the blade right up to the tip" (as in other small Indian tabanids).

The mature larva of Tabanus bicallosis is figured by the authors (Plate 4, Fig. 62), but no description is given. On the drawing the eleventh and twelfth segments appear to be completely fused (?), dorsal pseudopods are well developed, which should indicate an aquatic mode of life. There seems to be a color pattern similar to that of the larva of Tabanus atratus.

The pupa is likewise figured (Plate 11, Fig. 135), but not described. In addition, figures are given of the abdominal tip of male and female pupæ (Plate 12, Figs. 144 and 145), showing the arrangement of the six terminal teeth. In the male pupa attention is called to the ribbed anal tubercle and the continuous fringe of spines in front of it, as differing from the condition in the female, which has a simple anal tubercle and an interrupted fringe of spines in front of it. 
This is the first and only attempt to separate the sexes of tabanids in the pupal stage.

Tabanus biguttatus Wiedemann.-The early stages of this species, which is widely spread throughout Africa, occurring from the Cape to the Egyptian Sudan, have been described by King (1908).

The eggs, which were obtained in the vicinity of Taufikia, Sudan, in the marshes, are deposited in a rounded mass (Plate 1, Fig. 18) on grass and reeds overhanging a pool. One egg mass that was counted contained about 450 eggs. The entire act of oviposition was not timed, but it lasted well over half an hour. When a female is ovipositing, although usually exceedingly shy, the stem on which she is resting may be plucked and carried away or put into a bottle without disturbing her. Having deposited the eggs, she covers the mass with a creamy white secretion which turns black after a short time.

The egg is spindle-shaped, slightly more pointed at one end than at the other, and white in color. Length $2.5 \mathrm{~mm}$. The eggs under observation hatched in about eight days, but possibly under natural conditions, exposed to the sun, the incubation period would be shorter. On hatching, the larvæ fell into the water, swam to the sides, and buried themselves in the mud.

The larvæ can swim only on the surface of the water, and progress either by a telescopic movement or by lashing vigorously from side to side.

Several methods of rearing them were tried. The majority were placed in a large glass vessel containing mud, living grass, and water. Some were put into jars containing only water, others in dishes containing moist sand, others again in vessels containing sand and water so arranged that there was a pool at one end of the vessel and moist sand at the other.

The larvæ in the vessel containing mud, grass, and water did well, but many were devoured by predacious insects-e.g., dragon-fly larvæ-introduced by accident in the mud and water, and others perished owing to the grass dying and fouling the water during transit. Eventually sand and water in Petri dishes were found to be best, as it could be kept clean and the larvæ easily located when wanted. 
At first they were fed on tiny crustaceans dredged from rain pools, but during transit, when these could not be obtained, scraps of freshly killed raw meat and congealed blood from the bodies of gorged mosquitoes were substituted. After arriving in Khartoum their diet consisted of earthworms, as a plentiful supply of these could always be procured.

They grew very slowly and at greatly varying rates. Two larvæ hatched from one egg batch on June 11 measured respectively, five weeks later, $4 \mathrm{~mm}$. and $15 \mathrm{~mm}$. Owing to their telescopic nature it was exceedingly difficult to measure them accurately, so the figure must be taken as merely approximate. They did not appear to be cannibalistic in their habits, as several of various sizes were reared in the same dish and sometimes kept short of food, but were never seen to attack each other. When one died, however, its comrades usually devoured it. When not feeding they spent most of their time buried in the sand, with just the tips of their respiratory syphons showing. If the sand was allowed to dry they became very restless, and would make continual efforts to escape from their jars until water was given them again.

Early in August, when they were about eight weeks old, they ceased feeding and were then transferred to jars containing sand to a depth of $6 \mathrm{~cm}$. They descended to the bottom of these jars and were still there when, about six weeks later, the author went to England on leave.

On January $28 \mathrm{King}$ returned to Khartoum, and it was found that the jars then contained several dead adults - all males-a few dead pupæ and larvæ, and a single live larva. This last died early in February without having reached the pupal stage. The empty pupal cases were all sticking up out of the sand, the pupæ having evidently worked their way up from the bottom of the jars by means of their abdominal spines. In several instances the old larval skin had remained attached to the caudal teeth of the pupal case.

Neave (1915) also found the larvæ of this species in the valley of the lower Shire and its tributary, the Mwanza, in southern Nyasaland. Here, in the sand and mud on the banks of the rivers, large numbers of larvæ were obtained, of which the majority belonged to this species, and these were chiefly found in mud among the Phragmites 
reeds on the banks and in the back-waters, etc., of the Shire River. They often occurred, especially if the mud was inclined to be dry, at a depth of as much as 6 or 8 inches. The locality figured by Neave represents a large flat sand bank partly covered with Phragmites, at the border of a river about 50 feet in width.

The lower part of the Mwanza River was dried up at the time of Neave's visit, except for a few isolated pools, on the banks of which many larvæ of Tabanus biguttatus were found in the mud. Many others were subsequently found in the Ruo valley in November.

The larva is, according to Neave, of a type which has many representatives, being of a clear white color, except in individuals about to pupate, with well defined pigmented bands and spots between the segments and on the anal segment (Plate 5, Fig. 69). Several species have larvæ of this type, only varying in the amount of pigment and in the distribution of it on the anal segment.

King's description of larva and pupa follows:

The larva (Plate 5, Fig. 75, $a, b$ ), when nearly hatched, is white in color, but later assumes a grayish to yellowish tinge.

Mandibles (Plate 5, Fig. 78) black, slightly serrated and with two tufts of curved hairs at the base.

First thoracic segment anteriorly brown. Laterally placed on the second and third thoracic segments are brown comb-like marks with the four teeth pointing backwards.

On the anterior portion of each abdominal segment-with the exception of the eighth-are two brown annuli, or rings, encircling the body. The former of these two rings is usually covered by the posterior margin of the preceding segment. The hinder ring bears a double line of fine black hairs and also a number of small fleshy projections or pseudopods. The eighth abdominal segment serves the purpose of a respiratory syphon. Its posterior margin is brown and from its extremity can be extruded a small process terminating in stigmata. A brown curved longitudinal mark is situated on either side of the eighth segment. The anus is placed at the base of this segment. Length $35 \mathrm{~mm}$.

The pupal case is chestnut-brown in color, with the thoracic tubercles darker. Each of these tubercles bears a spine. The abdominal segments are apically ringed with backward projecting spines. The anal segment terminates in a cluster of six teeth (Plate 12, Fig. 148), the dorsal pair larger than the lateral and ventral pairs. Length $20 \mathrm{~mm}$.

The pupal aster has been figured by Neave (Plate 14, Fig. 175, $a-d)$; it is of the regular type and the dorsolateral combs have 
long spines, which are, however, shorter and stouter (especially in the female) than those of Tabanus corax.

Tabanus bovinus Linné. - This is one of the commonest species of the genus in Europe, the largest species in Sweden. It has a wide distribution and occurs even in South Africa.

The larvæ were found by Degeer (1760) in the soil of a meadow. Placed in earth which was renewed from time to time some of them gave pupæ. I give Degeer's original report in translation from the German.

The larvæ of these flies, which have not been recorded by any one before me, live in the ground, and I have described them already in the Swedish Proceedings. ${ }^{16}$ When in the month of May, I turned over the earth of a meadow, I found many of them, and having placed seven or eight in a jar with fresh earth which was renewed from time to time, I was aware, on June 12, 1760, that one of them had turned to a pupa, and had in part crawled out from the earth, being still fixed in it by the abdomen. I dug for the remaining larvæ, but found only three of them, which pupated later, and in the same way protruded with half of their body from the earth. At last I found one more small dead larva. I presume that those which pupated have eaten up the others.

The largest of these larvæ (Plate 4, Fig. 59, a,c) was about $1 \frac{1}{2}$ inches long, and in the middle $3 \frac{1}{2}$ lines in diameter (as seen in the figure), very similar to the larvæ of the large crane-flies. The body was cylindric, of almost equal diameter all along its course, narrowed and pointed at the head, twelve-segmented, the last segment small and wart-like.

Color whitish gray and yellowish; a number of black transverse bands formed by the transverse ridges and some transverse stripes in the incisions between the segments. The small head is shining brown. Under the lens the skin appears also shining, and covered with very fine longitudinal ridges.

The head is elongate, horny, bearing several parts difficult to distinguish as they are constantly in motion, also with two small short antennæ, some pointed parts placed below, and two large horny black mandibles placed above the latter, as long as the head and curved downwards. If a larva was held between the fingers, it exserted the hooks, attached itself to the skin with them, and pulled the contracted body up. Probably it burrows its way in the earth by means of these hooks. While resting, the head is withdrawn into the first segment, and this in turn into the second segment, so that the anterior part becomes of the same diameter as the rest of the body. The two last segments can also be retracted into the third last one, in a similar way.

${ }^{16}$ Bromsarne's Ursprung. 
The last segment (Plate 4, Fig. 59, c) has the aspect of a small soft textured conical wart; at its end there is a small, elongate protruded horn-like brownish yellow piece placed vertically, which I assume to be a spiracle, as a longitudinal fissure is discernible. Under the segment before the last, near the segment preceding it, there is a fleshy prominence, also with a longitudinal fissure in the middle, the anus.

On the body seven prominent blackish ridges are found situated anteriorly on the fourth, fifth, and the following segments, to the tenth, including the latter. At the sides and below fleshy warts take the place of feet. In contracting the rings the interior parts are drawn in.

The nymph (Plate 4, Fig. 59, $b, d$ ), 1 inch in length, of the same thickness as the larva, cylindric excepting the last segment, which is much smaller. It transformed into a large horse-fly while I had expected that a large crane-fly would appear. The color was brownish gray; darker at the abdomen and the other parts. The abdomen was eight-segmented; at the posterior margin of each segment was a fringe of long gray hairs. On the last segment at the tip there are six hard horn-like points (Plate 4, Fig. 59, $d$ ), by means of which the nymph works its way out of the earth. Head, thorax, and wing cases, or the whole thoracic region together shorter than the rest. Anteriorly, on the head, there are two small brown tubercles, each of them bearing a hair, probably spiracles. At the side of each tubercle an elongate and equally brownish point, appressed flatly to the head, directed backwards and jointed in the middle, probably the antennal sheaths. If the nymph is touched, it carries out worm-like movements with the abdomen.

Early in July the fly hatched out. The pupal skin splits open dorsally alongside the thoracic shield, and at the sides of the head. Internally, there are in the cuticle of the head two long horn-like spines, the function of which is unknown to me.

These observations of Degeer are remarkable for their precision. A number of details which have been incorrectly represented in tabanid larvæ by several later authors, as the number of segments, position of the anus, etc., have been correctly described. Nothing essential is omitted. Degeer, in 1760, calls attention, like del Guercio in 1913, to the similarity between certain tabanid larvæ and those of crane-flies, but while the latter is satisfied to state that there is no appreciable difference between them, Degeer's description of the Tabanus larva remains fully characteristic of the group and probably also of the species, though before the larvæ hatched, he had expected them to become tipulids. 
Westwood (1840) has briefly translated Degeer's description, and I give his summary to complement the above rather imperfect translation:

"The larva of Tabanus bovinus Degeer (L) is found in the earth, and is of an elongated subcylindric form, attentuated at each end, especially in front; it is destitute of feet, twelve-jointed, having the head distinct, narrow, elongate, horny, armed with two strong curved hooks, antennæ, and palpi; the fourth to the tenth segments having an elevated dorsal papillose ridge used in progression; the terminal segment is minute and tuberculiform; the pupa is naked, incomplete, elongated, subcylindric, with six spines at the end of the body; the margins of the abdominal segments ciliated, and the forehead bi-tubercled."

Westwood also reproduced Degeer's figures, though very imperfectly; also Macquart, 1834.

No further observations have been published on the early stages of this species, since Degeer.

Tabanus bromius Linné.-The larvæ of Tabanus bromius live, according to Beling, by preference in the grass-covered soil of meadows, fields, and similar places. They are often brought to the surface by moles, and in the spring and summer, 1874, Beling found them, as also later on the pupæ, especially frequently on meadows in fresh mole hills. The pupal stage lasts usually between two and three weeks, and the imagos begin to appear in the second half of the month of June. The larvæ feed by sucking the contents of earthworms, larvæ and pupæ of other insects, and, if there is lack of other food, of their own kind, but they seem to be able to subsist in case of necessity on earth alone, in which, as Beling says, he kept them for months until pupation.

I assume that the larvæ, if they subsist on earth, will in fact subsist on its organic contents in a similar way, as is the case with earthworms. Moreover, small earthworms and insect larvæ are easily overlooked by the observer if the earth used is not specially sterilized.

Larva.-Length up to $16 \mathrm{~mm}$., width $4 \mathrm{~mm}$., color pale yellow, strong, silky, shining, with distinct dense and fine longitudinal striation, with twelve body segments, excepting the small narrow brown head, which can be retracted into the first segment. The latter in the middle of dorsal surface with a wall-like longitudinal prominence, which is covered in its anterior part with short hairs, and on 
each side is provided with a rounded densely brush-like denticulate tubercle. Antennæ not discernible, palpi very short, one-jointed, thick. First body segment short, obtusely cone-shaped, retractile, and merging into the second segment without distinct border. Last segment short and much narrower than all the preceding, cupola-shaped, bearing on the anterior part of the under side the more or less prominent half circular anus crossed by a deep longitudinal furrow or fissure. The tip of the last segment a roundish, wart-shaped, retractile prominence, bearing the vertical stigmatal fissure. Segments five to ten inclusive with marginal swellings anteriorly. In this ridge or ring eight protuberances are distinctly observable, of which two smaller ones are located on the dorsal side, one on each side, and two pairs, placed near to one another, forming the locomotory swellings of the under side. The surface of the retracted head capsule visible through the cuticle of the first segments appears as an extensive brownish yellowish area limited by two broad blackish stripes which, diverging from the middle, are pointed and drawn out behind.

The pupa is likewise described by Beling, a translation of which follows.

Pupa.-Pupa 16 to $18 \mathrm{~mm}$. in length, 3.6 to $4 \mathrm{~mm}$. in width, obtuse at the anterior end, slightly narrowed behind, of dirty greenish yellow color, smooth, somewhat shining, and if older, with blackish borders of the segments. Above the front five to six small flat brownish tubercles or warts, of which the two lowest are enlarged and tooth-like, the two upper ones flatly truncated, bearing a short blackish brown hair in the middle of the truncation. On each side of these frontal tubercles is a short tooth-like outwardly directed spine. Above the frontal tubercles are two small wart-like tubercles each bearing a short black bristle. Lower ventral side of thorax on each side with two small brown warts bearing a backwardly directed closely appressed hair, and with an elongate black spot, these together forming two rows diverging posteriorly. Abdomen nine-segmented, first segment very short, third to eighth segments inclusive on each side with two parallel longitudinal depressions rather distant from one another, together forming two depressed lines running laterally alongside the abdomen. In the middle of these depressions on each of the six segments mentioned and in its anterior part a short spine-shaped prominence and a similar prominence also on the second segment immediately behind the wing cases. Third to eighth abdominal segments near its posterior margin with a circle of densely placed yellowish to brownish or even blackish hairs of uneven length and more or less completely appressed backwards to the surface. Last abdominal segment with six short thick outwardly diverging spines with dark brown tips, of which four are placed in a horizontal row; namely, a strong one on each side and two weaker ones in the middle. Wing and leg cases not very strongly marked, of the same color as the rest of the body, reaching to the anterior torder of the third abdominal segment. 
The pupa of Tabanus bromius L. has been figured also by Surcouf and Ricardo (1909); the previous observations by Beling have not been observed by these authors.

This pupa (Plate 12, Fig. 151) was collected in the earth of a railroad embankment at Longny, Orne, France, by M. E. Cordier, from whom the authors received it. The adult died in the act of hatching; it proved to be a male of Tabanus bromius L.; having left the pupal shell half way, it had been unable to free itself in spite of numerous efforts as proved by the pupal shell being unusually drawn out in length. The manner of the hatching of the adult is evident from the examination of this rare piece; the head causes the top of the shell to burst and, consequently, to break open longitudinally, under the pressure of the insect, down to the base of the first abdominal segment, which remains intact like the following segments. When the adult has reached this stage of its development, it takes flight, and goes in search of food as soon as it is dry.

Tabanus carolinensis Macquart.-Of this North American species, Malloch has given us, in his synoptic table, the following data on the pupal stage:

"Pupa.-Dorsal abdominal segments, except first, armed with an irregular transverse series, or two such series, of very stout thorns, their bases very much dilated, slightly caudad of which series there are sometimes a few widely separated, much longer spines. Seventh dorsal abdominal segment with 10 or 12 moderately long thorns in a continuous transverse series, slightly cephalad of which is a transverse series of very stout thorns longitudinally in line with the spaces between the thorns of the posterior series."

No illustrations are given.

Tabanus corax Loew.-A large species with wings uniformly dusky to the edge of the apex. Habitat, Africa. According to Neave, common on the southern side of Mt. Mlanje, southern Nyasaland, in the more wooded areas within the belt of heavy rainfall. On the wing from the end of November to the beginning of January.

We are indebted to Neave (1915) for a knowledge of its life history.

The flies were kept by Neave in a comparatively large cage made of mosquito netting and wood, each partition measuring about 5 by 4 by 3 feet, in which were boxes containing grasses and growing plants. 
The mosquito netting was loosely attached to the cage, so that the shock to a fly in striking against it was minimized.

One or two captured females of Tabanus corax oviposited in these cages, the process in one instance taking nearly an hour, between 3 and 4 p.m. Many egg masses of this species were also obtained in the bush, always on reeds or grasses overhanging mud. While the female is ovipositing she is not easily disturbed, as in the case of $T a$ banus biguttatus (King), and on one occasion one of Neave's collectors brought him the reed, fly and all, from more than a mile distant without disturbing the female. The egg mass with its cement covering is pure white when first laid, becoming dark gray as it hardens. The cement which covers these egg masses must be, according to Neave, water-proof and insoluble, as some individuals from them succeeded in hatching even though the egg mass had been kept in 70 per cent alcohol for two days.

The egg masses of Tabanus corax are of the usual tabanid type, all the individual spindle-shaped eggs being laid with their long axes in the same direction. In the cases observed hatching took place about the fifth day, but this would be likely to be lengthened or shortened in some cases, according to the temperature. The process of hatching takes place very suddenly. The egg mass splits in the midline, following the long axis, and the small larvæ emerge almost simultaneously, forming a large quasi-viscous drop which falls bodily from the reeds, etc., into the water or mud below.

A number of newly hatched larvæ were obtained from collected egg masses, generally found on reeds overhanging swampy ground. The young larvæ grow very slowly at first. Neave figures the syphon and anal segment of one of these young larvæ. The figure (Plate 10, Fig. 120) shows the peculiar Graber's organ, somewhat tongue-shaped or triangular, and, according to Neave, attached by fine strands of muscle from each of the three corners, apparently to the body wall. It lies above the gut immediately below the dorsal integument and seems to be capable of motion independent of the general body movements. The organ contains a number of pairs of small black pyriform bodies.

Neave obtained the larvæ of Tabanus corax in considerable numbers. Adult specimens are large, from 40 to $45 \mathrm{~mm}$. in length, and 
distinct, having a thick rough integument of a dull reddish color, with a tendency to two more definite patches of darker red on the dorsal portions of the last two segments. The general coloration appears to be largely due to the presence of foreign bodies in the rough skin. The syphon is very short, as seen in the figure (Plate 5, Fig. 67).

These larvæ were most ferocious cannibals in all stages and very troublesome in the laboratory, as they seemed to have unlimited power of wandering about, even over dry surfaces. They frequently succeeded in reaching the receptacles in which other species were kept, and in destroying the larvæ in them.

In the pupal aster (Plate 15, Fig. 181, $a, b, c$ ) the dorsal hooks of the male are somewhat larger than those of the female. The dorsolateral comb is large and composed of very long and fine spines. The pupal asters of male and female, and the dorsolateral comb of the female are figured.

Tabanus cordiger Meigen.-A species described by Meigen (1820), and widely spread in Europe, chiefly in the South.

Brauer (1883) is the first to figure the larva of this species (Plate 6, Fig. 88, $a-d)$, but gives no description.

Picard and le Blanc report that they found, on March 4, 1913, in the trunk of a poplar at the edge of the Mousson River, near Montpellier, France, an elongate, whitish larva, pointed at both ends and having a ridge, or prominent ring, on each segment, a larva which appeared to them to be that of a tabanid. The larva was placed in a jar containing pieces of decaying wood from the poplar tree in which it had been found, and was left without any other food.

The exact time of pupation was not observed, but in the meantime it seemed justifiable to assume that the larva was satisfied with the vegetable food which it obtained from the decaying wood, since one month after its capture it had not yet transformed. On June 10, a male Tabanus was observed in the room, which had just hatched, and was determined by Dr. Villeneuve as Tabanus cordiger Meig.

The larva lived, at the time of its capture, in the stump of a poplar. The wood of the stump was not yet completely decayed, but rather soft and very moist. A careful search did not reveal any other 
larvæ of tabanids or other insects, while the felled trunk enclosed numerous larvæ of Tipulidæ, Asilidæ (Eryx), and some larvæ of beetles (Lamellicornia).

Picard and le Blanc's observations are insufficient for an exact morphological description of the larva, but a brief description of the pupa is given, based on the pupal shell left after the hatching. A translation of this description follows:

Pupa.-(Plate 12, Fig. 136.) Slightly curved inwards ventrally in its posterior part; measures $20 \mathrm{~mm}$. in length, $4 \mathrm{~mm}$. in width, and $3 \mathrm{~mm}$. in height. The anterior part (Plate 13, Fig. 155), extending to the scutellar segment, and comprising the head, thorax, legs, and wings, is smooth and unarmed, except for some dorsal hairs. The posterior part of the pupa (Plate 13, Fig. 158) is composed of seven segments, surrounded at about the second third from their base with a crown of stiff and unequal bristles. The tubercles described by Surcouf in an unidentified pupa were not observed. The last segment is terminated by two three-toothed tubercles, at the base of which is found ventrally a cup-shaped formation which possibly corresponds to the anus of the larva. The preabdominal segment and the first six abdominal segments bear on each side a spiracle placed towards the base of the segment, at the height of the anterior third. The crown of bristles of the seventh segment is incomplete and interrupted dorsally.

The emergence of the adult causes at the anterior part of the pupal shell a fissure which separates it into three wings, two dorsolateral ones and a ventral one of irregular shape. The latter, in the shape of an elongate hexagon of $4 \mathrm{~mm}$. length by $3 \mathrm{~mm}$. width, shows a characteristic ornamentation which can be traced on the figure given.

At the anterior part two tubercles are found, each bearing a bristle; somewhat below two slight ridges which meet in the median line, further down two doubled tubercles, placed between two triangular thickenings, finally, more posteriorly, two pairs of small tubercles between which two depressions with inner convexities are found. A little in front of the point of attachment of the piece, two lateral triangular expansions are observed. It is probable that the first two tubercles correspond to the antennæ of the larva and the others to the mouth-parts.

These observations show, according to Picard, that certain species of tabanids may have wood-inhabiting larvæ, and that their habits are more variable than one would suppose. Picard's paper is accompanied by three figures.

The observations made by Paoli on Graber's organ (page 37) have possibly been made on this species. 
Tabanus costalis Wiedemann.-Habitat, eastern North America. The species is very common, and a pest to stock. Of its early stages we know little. There are no data available on its oviposition, and although Hine (1903), while speaking of the control of tabanids in Louisiana, mentions that oviposition in tabanids often takes place not over water but over damp ground, and that "one finds the eggs of costalis and a number of other species in such places quite frequently," he gives no description of the eggs.

The larva seems, according to Hart, to be normally a terrestrial larva. He has found it two or three times in the earth of corn fields in Champaign County, Illinois. The dates given are May 31 and June 4. Specimens were placed in a breeding cage, and an imago of costalis was secured from them. ${ }^{17}$ Hart believes that the species is single-brooded. His description of larva and pupa follows:

"Larva.-Length $20 \mathrm{~mm}$., diameter $2.7 \mathrm{~mm}$. Prothorax with lateral shining areas about as long as the dorsal, coarsely striate, a smooth spot near center of disk; dorsal and ventral areas of thorax smooth, a few strix on those of metathorax, especially posteriorly; remaining areas moderately striate, lateral areas of abdomen a little more finely striate than the others; all more or less shining."

"Dark annuli pale, narrow, longitudinal stripes scarcely present; false feet with dull pubescent crests, their sides rather finely striate; a narrow dark annulus at base of respiratory tube, another around base of last segment, enclosing anal prominence and giving off a pair of lateral stripes, the lower one longer; no projecting spine seen."

"Pupa (from defective cast skin of male).-Length $20 \mathrm{~mm}$., diameter 3 $\mathrm{mm}$. Light fuscous brown, shining; abdomen smoothly wrinkled, slightly opaque; prothoracic spiracular tubercles slightly but nearly equally elevated, free margin rounded at tip, rima not vertical, evenly arcuate, slightly hooked in front."

"Abdominal spiracular tubercles small, subtriangular, narrower behind, obliquely subconical, much shorter than basal diameter, bearing a very small subcircular rima; fringes formed of unequal pale spines, the longer ones sparse on seventh segment above; outer terminal teeth twice as large as lower pair, directed laterally and slightly backwards; upper pair smallest, directed upwards; ventral fringe of last segment not noticeably webbed; lateral tufts rather high, not near ends of ventral fringe."

Hart's material was, as he says, "not in the best condition for accurate comparisons."

${ }^{17} \mathrm{I}$ have since found the larva of this species in the muddy banks of Lake Carnegie in Princeton, N. J., which shows that it is not always terrestrial. 
Tabanus desertus Walker.-South America, British Guiana. The larval and pupal stages have been observed by Bodkin and Cleare in the coast region of British Guiana. Numbers of larvæ were found in a damp accumulation of sweepings situated at the end of a drain leading from a large cattle pen. Several of these larvæ were secured and kept in the laboratory under frequent observation. Although supplied with a quantity of suitable food the largest larva eventually consumed its companions and pupated. After sixteen days a female Tabanus desertus emerged. The pupal aster (terminal end of the pupa, showing the arrangement of the spines) is figured (Plate 15, Fig. 180, $a, b)$.

Tabanus ditceniatus Macquart.-The distribution of this tabanid as given by Austen is wide. In Africa it occurs from the Transvaal in the South to Egypt in the North, while outside the bounds of Africa it is found in Baluchistan, India, Ceylon, China, and Japan. In the Anglo-Egyptian Sudan it occurs fairly commonly in the South, but until 1910 it had not been recorded from the northern provinces, when King began his studies on this species.

The larvæ were taken early in March, 1910, in a small water channel, locally known as a "Gadwal," on the estate belonging to the Sudan Plantation Syndicate Ltd., at Zeidab, Berber Province. The water was for the most part overgrown with a covering of green slime, and when this was cleared away a few larvæ could generally be seen on the surface. On stirring up the mud at the bottom and edges of the water more appear, while if one waited for an hour or so, specimens would continue to rise. They were apparently living in the mud at the bottom of the pools and coming periodically to the surface to breathe. They could be seen rising to the surface by a lashing motion, and if left undisturbed would after a few seconds sink out of sight again.

Some forty odd larvæ of various sizes were taken on March 9 and placed in a jar containing water, slime, and hollow grass stems; most of these had disappeared by the next morning, the larger ones having devoured the smaller ones. On March 10 more than a hundred were obtained, and, together with the survivors from the previous day, were divided among three jars (only three being available), two con- 
taining wet mud, and the third water with hollow grass stems and other debris. Earthworms were provided as food, but were not taken very readily; the larvæ seemed to prefer to eat each other. They were brought to Khartoum on March 11, and the following morning each of the thirty-three which were still living was placed in a separate jar containing clean river sand and water. They fed freely on tiny earthworms, but their numbers steadily decreased until about April 16, when thirteen survivors, having attained maturity, ceased to feed. Up to this stage, if the sand in which they were living was allowed partially to dry out, they became very restless until water was given them again, but hereafter they preferred sand which was only slightly damp. In appearance as well as habit they altered considerably at this stage of their existence. While young and growing, they possessed well developed prolegs and conspicuous dark dorsal markings; now, however, their prolegs became small, and in color they appeared uniform yellowish white.

These thirteen larvæ were left undisturbed until May 26, when one specimen was washed and was found to have pupated, probably within the previous two days, as the eyes had not begun to show the color which they acquired later. On the following day, two more pupæ were discovered in the sand. Prior to pupating the larvæ had made a number of tunnels in the sand, and the pupæ were lying in a more or less upright position in the tunnels and near the surface.

On April 28 King left Khartoum, and traveled in the provinces until May 30, by which date one larva had died and twelve completed their life cycles, producing eight females and four males. The first had emerged on April 29 or 30, so the period passed in the pupal stage was probably about six days.

King's detailed description is given in about the following words.

Immature Larva.-(Plate 3, Fig. 47; Plate 4, Fig. 57, a-d.) Length 18 $\mathrm{mm}$. Color yellowish white, with dark markings composed of pubescence. Mandibles dark brown to black, slightly serrated. Anterior margins of the meso- and metathoracic segments dark, except on the venter. A ring of pseudopods, eight in each ring, two dorsal, two lateral, four ventral, on the anterior third of each abdominal segment except the eighth, well developed, except the dorsal pairs on the first and second segments, and bearing spines or hooks. Spines are also present between the pseudopods on each ring. The rings on the first and 
second segments edged before and behind with dark pubescence, especially on the dorsum, the pubescence extending between the dorsal and lateral pseudopods, thus enclosing the dorsal pseudopods in a dark ring. On each of the third to the seventh segments inclusive is a patch of dark pubescence between the lateral and the dorsal, and between the dorsal pseudopods, three patches on each ring, the median patch being conspicuous. To the naked eye these median patches constitute a median dorsal line of black dots.

On each of the third to the sixth segments, inclusive, are two patches of dark pubescence, immediately anterior to the dorsal pseudopods. The posterior margin of the eighth segment bears dark pubescence. The surface of the larva other than that bearing pubescence is shiny and longitudinally striated.

Mature Larva.-(Plate 4, Fig. 57, b; Fig. 64, a, b, c.) Length $25 \mathrm{~mm}$. Color yellowish white. Mandibles dark brown to black, slightly serrated. Thoracic segments shining and longitudinally striated, except the anterior margins, which are opaque and pubescent. On the prothoracic segment are five longitudinal grooves, one ventral, two sublateral, two subdorsal, not extending to the posterior border. On the meso- and metathoracic segments are eight such grooves, four on either side. The first abdominal segment bears one pair of ventral pseudopods ${ }^{18}$ the second segment one pair of ventral and one pair of lateral; the third to the seventh, two pairs of ventral and one pair of lateral. Traces of most of the other pseudopods are present, especially of the dorsal pseudopods on the fourth to the seventh segments. The pseudopods bear small colorless spines or hooks, and similar though smaller spines are situated between the pseudopods and on the dorsum of the first, second, and third segments where the pseudopods are wanting. On the dorsum of the first and second segments these spines constitute a double band. The posterior third of each abdominal segment is shiny and longitudinally striated. The anus is edged with pubescence. The syphon when exserted appears rather shorter than the eighth segment.

Pupal Case.-(Plate 11, Fig. 129; Plate 12, Fig. 141.) Length $17 \mathrm{~mm}$. Color yellowish brown, thoracic tubercles and abdominal spiracles darker, the former bearing hairs. On the posterior third of the second to the seventhabdominal segments is a ring of backwardly pointed spines, shortest on the second segment and longest on the seventh. The eighth segment (Plate 12, Fig. 141, $a, b)$ terminates in a coronet of six teeth, chestnut brown in color, darker at the tips, the lateral pair by far the largest, the dorsal and ventral pairs being about equal in size, the former sometimes slightly the larger. The dorsal pair arises from between the lateral teeth, the four teeth constituting a row. Ventrally placed to this coronet are two rows of similar teeth, each row consisting of from two to five teeth, the two rows together constituting an interrupted transverse row. These teeth are unequal, and vary in size and number in different specimens.

${ }^{18}$ King uses the term "pseudopod" instead of "proleg" which should be used, pseudopod being used in protozoology. 
The pupa, when first formed, is yellow with a greenish tinge, especially on the thorax. Later, as the imago develops, the eyes show as deep maroon and the thorax becomes generally darker.

On Tabamus ditcniatus we possess also some notes by Patton and Cragg, who observed the species in Madras (1913).

Tabanus ditaniatus, being a small species, oviposits, according to these authors, "on blades of grass just at the edge of a shallow stream, or on the leaves of the lotus plant at the edges of small ponds, but never over deep water." It should then fall under the heading of those tabanids in which the larvæ are said to have no air sacs and to die when falling into deep water.

The eggs of Tabanus ditcniatus measure, according to Patton and Cragg, about $1.2 \mathrm{~mm}$. in length, and $2 \mathrm{~mm}$. in breadth, being slightly more slender than those of Tabanus bicallosus Ric., an Indian species, studied by Patton and Cragg (1913).

The egg is figured by Patton and Cragg (Plate 1, Fig. 17), evidently showing a dark band placed subapically, the extreme tip being also dark on the figure. The egg mass of the same species is figured as spread out in a single layer on a blade of grass (Plate 2, Fig. 21).

The mature larva is also figured (Plate 4, Fig. 61); attention is called to the short stout syphon tube.

The pupa is figured by the same authors (Plate 11, Fig. 133), and the eighth abdominal segment of the pupa is figured (Plate 12, Fig. 147) to show the arrangement of the terminal teeth and the anus.

With these observations our knowledge of the species is quite complete.

Tabanus epistates Osten Sacken.-Of this North American species, Malloch (1917) has given us, in his synoptic table, the following data on the pupal stage:

\footnotetext{
"Pupa.-Dorsal abdominal segments, except first, armed with an irregular transverse series, or two such series, of very stout thorns, their bases very much dilated, slightly caudad of which series there are sometimes a few widely separated much longer spines. Seventh dorsal abdominal segment with the posterior transverse series consisting of two long, widely separated spines on the middle portion, and several, closely placed, on each lateral extremity which are but little caudad of the much shorter thorns of the anterior series. The portion
} 
of head-capsule between bases of antennæ slightly elevated, rounded, fairly rugose, and not carinate or divided below; abdominal armature moderately strong, distinctly biserial laterally."

No illustrations are given.

Tabanus fraternus Macquart.-An African species, but uncommon in so damp and well wooded a locality as Mt. Mlanje, where a single female was bred by Neave on December 16, 1914, from a locally collected larva, which was not recognized as distinct from that of Tabanus tcniola.

The pupal aster (Plate 15, Fig. 182, $a, b$ ) resembles that of Tabanus maculatissimus in having a small papilla on each side of the midline. The dorsolateral comb consists of only a small number of spines, which though rather long are fairly stout. The pupal aster and dorsolateral comb of the female are illustrated.

Tabanus fronto Osten Sacken.-This American species has been recorded from North and South Carolina, Texas, and Florida. We know nothing of its egg-laying habits, but the species has been bred repeatedly from larvæ, by Brimley, in Raleigh, North Carolina. The larvæ of this species occurred freely in the soil in Brimley's garden, in a comparatively dry locality situated on the crest between two water sheds, the nearest permanent water being at least a quarter of a mile away. These larvæ are described as white with pale brown transverse bands, and transform into pupæ in June or July, and into flies some two or three weeks later. The earliest date on which an adult emerged was July 4, which is also the earliest date on which Brimley has seen the species in the fields. Two larvæ, which had been preserved in alcohol, were yellower than the trimaculatus larva described by Brimley, but showed no trace of the pale brown bands which exist in life. The largest of the two measured $36 \mathrm{~mm}$. long, and was taken July 5, while the smaller one was $33 \mathrm{~mm}$., taken on March 31. Both, as also the preserved trimaculatus (?) larva, were well, but not abnormally, extended.

The only pupa reported of this species was found by Brimley under a stone in his back yard.

Although horse-flies do not generally breed away from water, Tabanus fronto seems to be an exception, as larvæ have been taken in 
Brimley's garden in several different years, while the adults occur more commonly in the garden and house than any other species of the family, the flies quite frequently entering the house, while newly emerged specimens have been noted on a number of occasions.

Tabanus (Atylotus) ${ }^{19}$ fulvus Meigen.-A European species. Sharp describes a larva (Plate 4 , Fig. $60, a-d$ ) which he says may belong to this species. This description follows:

"In a larva, probably of this family (Tabanidx), found by the writer in the shingle of a shallow stream in the New Forest (England), the annuli are replaced by seven circles of prominent pseudopods, ${ }^{20}$ on the abdominal segments, about eight in each circle, and each of these feet is surmounted by a crown of small hooks, so that there are fifty or sixty feet distributed equally over the middle part of the body without reference to upper or lower surface. The figures of the larva of $T$. cordiger, by Brauer, and of Hamatopota pluvialis, by Perris, are something like this but have no setæ on the pseudopods."

Tabanus fuscipes Ricardo.--An African species reported by Neave from Lake Chilwa, southern Nyasaland, in January, 1914, in circumstances which render it extremely probable that they had bred in mud some distance from water, which had been hard and dry for some portion at any rate of the dry season. Neave is inclined to think that in this and other mid season species, such as Tabamus claritibialis Ric. and Tabanus sandersoni Aust., the larvæ hibernate fully fed at the beginning of the dry season and only pupate when the next season's rains release them from the hard ground.

Tabanus glaucopis Meigen.-A European species, occurring in Austria as well as in Scandinavia, but evidently rare. According to Brauer, the larvæ have been observed by Wahlberg (1838) in noctuid caterpillars. I was not able to find the statement quoted by Brauer, but it may be correct, as Wahlberg made numerous observations on parasitic and semiparasitic dipterous larvæ.

In as far as most of the Bombyliidæ are truly parasitic, and tabanid larvæ often burrow deeply into their prey, it is not unlikely that tabanids belonging to the Pangoniinæ which are apparently related

${ }^{19}$ Sharp (Insects, p. 483) uses the generic name Atylotus, which is a subgenus of Tabanus.

${ }^{20}$ Sharp, like King, uses pseudopod for proleg. 
to the Bombyliidæ, should be of more pronounced parasitic habits. In Tabanus glaucopis we have probably to deal with an occasional parasitism, not typical for the species.

Tabanus gratus Loew.-An African species, and, according to Neave, a very common one and one of the earliest on the wing in southern Nyasaland, occurring sometimes in August.

Larvæ and pupæ were collected in this month, the first individual emerging in the laboratory on September 1. The larva (Plate 3, Fig. 51) is moderately pigmented, though compared with that of Tabanus insignis the pigmented areas are nearly confined to the edges of the segments and are not nearly so dark in color. The syphon is somewhat longer than in that species. A few larvæ were obtained in the stream beds near Mt. Mlanje and a small series in Portuguese territory to the east of the mountain early in October.

The pupal aster (Plate 15, Fig. 186, $a-d$ ) is of the normal type, being regular in outline. The spines of the dorsolateral comb are much reduced, especially in the male.

Tabanus hilaris Walker.-A species of Bengal, Assam, and South India, on the early stages of which we have some notes by Patton and Cragg (1913). According to these authors its habits of oviposition are the same as in Tabanus striatus, that is, it oviposits as a general rule on blades of grass, pieces of stick, etc., at the edge of a river, stream, or pond. The eggs when deposited are brownish white. No figures or descriptions are given.

Tabanus ignotus Rossi.-A species not listed in Schiner's Fauna Austriaca, and, according to del Guercio, synonymous with Tabanus albipes Fabr. Del Guercio has given a somewhat unsatisfactory account of its life history, and its early stages. The species has appeared, according to del Guercio, in extraordinary numbers, in company with tipulids, in the rice fields of the region of Bologna (Italy), and the larva is said by him to have caused considerable damage to the rice fields.

The species, of which del Guercio furnishes a brief description, not stating, however, on whose authority the insects were identified, appeared in the region (Molinella) from the first ten to twenty days 
of June. The flies are found on plants like Arum, Sagittaria, Typha, etc., on which they move about frequently with a buzzing sound.

The eggs are deposited on the leaves of the plants mentioned and others, forming circular crusts, which were seen abundantly after oviposition had taken place, that is, during the whole month of July, while some belated specimens may oviposit as late as August. A more detailed description of egg or egg cluster is not given.

Larvæ were never found in the fall, but half grown larvæ were found in winter, most of them being ready to transform in April or May of the following spring.

Without insisting on the strangeness of the fact, de Guercio reports that these larvæ are so similar to those of the tipulids found by him (Tipula oleracea L.) that without an accurate examination it would not be possible to distinguish them. They are more robust, more cylindric, but of the same color; they are in the same way provided with brushes of hairs on the segments of the body, but the mouth-parts have mandibles of about twice the size and thickness of those of the tipulids, from which they differ only by the kind of velvety combs found on the clypeus and in the whole anterior part of the head. The figure to which del Guercio refers, is given (Plate 7, Fig. 96, $a, b)$ for comparison. The habits of these larvæ are said to be the same as those of the tipulids with which they are found, and to behave in the same way when transforming into pupæ.

I have given this description as it is the purpose of the present report to give a full account of all that is known about the early stages of Tabanidæ. But it may be permissible to express a reasonable doubt whether del Guercio did not eventually figure two tipulid larvæ, having taken one of them, erroneously, to be a Tabanus. As no reference is made to any previous descriptions of tabanid larvæ, excepting (see below) Tabanus autumnalis, and in this case also the literature is not quoted, and as there is no mention of the structures common to all known tabanid larvæ, as the prolegs, syphon, respiratory tube, serrated mandibles, the assertion that the larva of this Tabanus can hardly be distinguished from that of Tipula oleracea cannot be taken seriously.

The transformation takes place, according to del Guercio, from the end of May to early June, when the larvæ leave the rice fields in large numbers for their metamorphosis in the dams and meadows. 
While the Tipula appears in two generations, the life cycle of the Tabanus comprises only one generation, which begins at the end of spring of one year and is completed towards the middle or end of spring of the following year.

The larva of Tipula and those of Tabanus are, as del Guercio insists, of the same dark gray color as the soil in which they live and resemble one another not only in shape but also in many of their organs, including the mouth-parts, in such a way that there remains no point of resemblance, even in this regard, between the larva of the Tabanus of the rice field and that, for instance, of Tabanus autumnalis, the larvæ of which differ from it in every detail.

The pupa, however, is figured by del Guercio (Plate 11, Fig. 123) as the pupa of this Tabanus, for comparison with the tipulid pupa (Plate 11, Fig. 122), and is in fact in every way a real Tabanus pupa, except that on the figure no spiracles are visible, which were apparently overlooked by the author in making the drawing.

Del Guercio's statement that the damage done by tipulids and tabanids in the rice fields resulted in the destruction of the whole cultivation, has probably to be corrected in that as far as any larvæ, the tipulids may possibly have been responsible for the damage; for the tabanids, however, this is very unlikely, and, as long as del Guercio has, in fact, made no observations whatever on the food of his larvæ, we are bound to assume that the Tabanus larvæ, which were apparently numerous, but of which we are still awaiting description, fed on the larvæ of Tipula oleracea, and were in this instance certainly not injurious.

I wish here to call attention to the fact that Degeer has already spoken of a great resemblance between tabanid and tipulid larvæ; in fact, before he knew that the larvæ found by him were larvæ of Tabanus, he expected crane-flies to hatch. However, his description, the first one ever given of a Tabanus larva, establishes beyond doubt the characteristics of these larvæ by which they differ from those of tipulids.

Tabanus insignis Loew.-(Tabanus sharpei Aust.). An African species, common in southern Nyasaland, near Mt. Mlanje, from November to March. 
The very characteristic and strikingly pigmented larva (Plate 3, Fig. 53) was, according to Neave, common in the mud of the forested streams from the end of September. It may be distinguished at a glance from other similarly pigmented species by the white trefoilshaped area on the dorsum of the anal segment. This is a voracious and predacious larva and troublesome to keep in the laboratory for that reason.

The pupal aster is of the normal type, the spines of the dorsolateral comb being few in number but somewhat long. A small series of adults was bred by Neave from the larvæ above described. A certain number of these flies belonged to the type of Tabanus sharpei Aust., and the two forms, the larvæ of which are identical, are connected by a great variety of intermediates.

The larva is figured (Plate 3, Fig. 53), also the pupal aster of the male and the dorsolateral comb of both sexes (Plate 15, Fig. 184, a, $b, c)$. In the figure, the larva looks much like that of Tabanus atratus but the lateral stripes are poorly developed except on the thoracic and on the ninth and tenth segments, while on the eleventh segment they are more completely fused with the transverse ones into a broad pigmented band.

Tabanus kingi Austen.-Tabanus kingi, recorded from Khor Arbat, Sudan, Africa, is a species superficially resembling Tabanus treniola, and allied to species of Tabanus from Abyssinia at present undescribed. The life history has been worked out by King (1910), who observed the species in Khor Arbat, in a locality consisting of a stream of slightly brackish water running in a gorge on a rocky hill. On emerging from the hills into the plain the stream disappears in the sand. In the autumn, during the brief rainy season, it comes down in sudden overflow, and is then of considerable size, but in April, the month in which these observations were made, it is, except where there are pools, not more than a few inches in depth. The bed of the stream is stony and there is little or no vegetation on its banks.

The female fly deposits her eggs in a rounded mass on a rock rising sheer from the water generally slightly overhanging, and from six to fifteen inches above water level. Rocks chosen for this purpose overhang comparatively deep pools, from eighteen 
inches upwards, in which the water moves but slowly. Such rocks occur only here and there, in the mile or so of stream searched, only three rocks bearing traces of having been used by this tabanid for purposes of oviposition being found. On one of them were the remains of several hundred egg masses lining a small crack in the face of the rock from 2 to $3 \frac{1}{2}$ feet above the water level. As none of the fresh egg masses found were situated more than 15 inches above water level, these old masses had probably been deposited when that level was higher. Altogether seven females were taken in the act of ovipositing, and several more were seen. No particular time of the day seems to be chosen for the act; one was found ovipositing at 11.40 a.m. and another at 4.40 p.m., and unlike Tabanus biguttatus Wied., the only other horse-fly King has observed ovipositing in the field, this tabanid does not lose her natural wariness while engaged in depositing her eggs. In fact, she is often more difficult to capture then than when merely sunning herself on a rock.

The egg masses, figured by King (Plate 1, Fig. 20), vary in size, and no count of the number of eggs contained was made, but the average mass is believed to consist of about 500. When freshly laid the mass is glistening white and can be seen from a considerable distance, but within a few hours it takes on a mottled gray hue which so closely resembles the color of the rock that it is not easily detected. While the fly is occupied in laying her eggs, numbers of a tiny Hymenoptera assemble and proceed to add their eggs to the mass, continuing to do so after the fly has gone. From some twenty egg masses collected from the rocks about equal numbers of this egg parasite and of the tabanid larva were obtained. Specimens of these Hymenoptera were sent for identification to the Scientific Secretary of the Entomological Research Committee. They proved to be a new species of Chalcidæ, and have been described by Mr. J. C. Crawford, of Washington, under the name of Telenomus kingi (footnote to King's paper, by Mr. Guy A. K. Marshall).

One horse-fly ${ }^{21}$ taken in the act of ovipositing completed her egg laying in a collecting box on the evening of April 13. These eggs had

${ }^{21}$ King frequently uses the Arabic word "seroot," for horse-fly, by which the flies are known in the Sudan. 
hatched by the morning of April 19, the incubation period being therefore about five days. Under normal conditions, exposed to the sun, it may possibly be less. The larvæ from these eggs were allowed to fall from the egg mass into a basin containing water and stones and were provided with portions of earthworms, and tiny coleopterous and dipterous larvæ obtained from wet moss. They refused to feed, however, and all died; probably at this stage of their existence they require brackish running water.

In places the stream at Khor Arbat is very shallow and ripples over and around stones; under these stones larvæ of various sizes, mostly nearly mature, were taken. Apparently stones which were not quite or were barely covered with water were chosen by the larvæ in order that they might come up to breathe without losing their hold and so be in danger of being carried away by the current. Usually only a single larva was found under one stone, and, in every instance where two or three were together, a mortal combat was taking place. If a larva was placed on one's hand it would at once endeavor to drive its mouth hooks through the skin, and where the skin was thin, it would succeed in inflicting a sharp pricking pain. Owing to these cannibalistic habits the number of larvæ which could be transported was restricted to the number of vessels available, so, though nearly two hundred were taken from the stream, only forty-two were brought alive to Khartoum. There they were placed in jars containing coarse sand, brought from Khor Arbat, and water, and fed on medium sized earthworms. They took these willingly when hungry but appeared to need food only every two or three days. King left Khartoum on April 28, Captain W. B. Fry taking care of the larvæ during his absence, and on King's return on May 30 , the majority of these larvæ were dead. One, however, had completed its life cycle and seven were still living. Six of these seven pupated during the next few weeks but died as pupæ. The pupal period is probably about six days, for one which pupated on May 5 appeared to be mature on May 11, when it perished.

One empty pupal case was taken under a stone in the bed of the Khor Arbat stream; the fly must have crept up the stone through several inches of running water before gaining the air. 
Although this tabanid, according to King, in its adult form closely resembles Tabanus teniola Pal. de Beauv., in its larval stage it differs markedly from that species. The larva is admirably adapted for clinging to stones in rapidly running water, its usually long pseudopods with strong hooks, being retractile and capable of being used as suckers. None of the other tabanid larvæ observed by King possessed an anal proleg.

Besides the seven specimens mentioned above as having been taken in the act of ovipositing, two more were caught sucking blood from camels. No males were seen.

King describes the early stages in about the following words.

Egg.-Length $2 \mathrm{~mm}$. Color white, becoming darker as the embryo within develops. Spindle-shaped.

Mature Larva.-(Plate 4, Fig. 56 and Fig. 65, $a, b, c$.$) Length 35 \mathrm{~mm}$. Color pale gray to dusky gray to deep chestnut-brown. Mandibles dark brown to black, long and powerful, slightly serrated. Anterior margins of meso- and metathoracic segments dark. A smooth shiny pale area on the dorsum of each thoracic segment; on the prothorax this area is concave anteriorly, convex posteriorly, and with parallel sides. On the meso- and metathoracic segments it appears to the naked eye diamond-shaped, though sometimes it is actually hexagonal. On the venter of the prothorax are two shiny pale longitudinal areas, each bearing several long black hairs arising from a single pore; a similar but larger area is striated on each of the meso- and metathoracic segments, bearing two similar tufts of hair. On either side of the meso- and metathoracic segments are three longitudinal areas not extending to the margins of the segments, longitudinally and deeply striated. On the anterior margins of the meso- and metathoracic segments on either side are four paler lines extending backwards, to form the divisions and edges of the three striated areas. On the anterior third of each abdominal segment except the eighth is a ring of pseudopods, eight in each ring, two dorsal, two lateral, four ventral, except on the first segment, where the dorsal pair is wanting. The dorsal pseudopods are never well developed, and, with the exception of those on the fifth, sixth, and seventh segments, unprovided with hooks. The lateral and ventral pseudopods are very long and bear at the apcies long, strong hooks, chestnut-brown in color, sometimes darker at the tips. On the median pair of ventral pseudopods on the fourth, fifth, and sixth segments, these hooks form a complete circle, but on the remaining pseudopods bearing hooks the circle is incomplete. Immediately below these hooks is a row of tiny spines. Immediately behind the ventral pseudopods on the first to the seventh segments inclusive is a shiny striated area. On the venter of the eighth segment, anteriorly placed to the anus, is a pseudopod equal in size and similar to the ventral pseudopods on the other segments, and bearing an incom- 
plete circle of hooks. Scattered over the surface of the larva are occasional black hairs. The syphon, when exserted, is shorter than the eighth segment, and bears a number of black hairs. The dark appearance of the larva is due to tiny dots of pubescence arranged closely together, except on the shiny areas mentioned above.

The skin of the larva frequently bears scars of old wounds.

Pupal Case.-(Plate 12, Fig. $137 a, b, c$.) Length $20 \mathrm{~mm}$. Color yellowish brown, thoracic tubercles and abdominal spiracles darker, the former bearing hairs. On the posterior third of the second to the seventh abdominal segments inclusive is a ring of backwardly pointing spines, shortest on the second segment and longest on the seventh. The eighth segment terminates in a coronet of six teeth, chestnut-brown in color, darker at the tips, the lateral pair by far the largest, the dorsal and ventral pairs being equal in size. These teeth are arranged roughly in a circle. Ventrally placed to this coronet are two rows of five comparatively thin spines, of varying length, together constituting an interrupted transverse row. Dorsolaterally placed to the coronet are two rows of spines similar to the ventral row.

The dorsum of the abdomen is sometimes clothed with black pubescence arranged in four longitudinal stripes. On the sixth and seventh segments these stripes merge and on the seventh segment the pubescence is confined to the posterior third. The pubescence is wanting on the dorsum of the eighth segment but is present on the venter of the seventh and a small patch is situated immediately below the coronet on the eighth segment.

The pupa when first formed is yellowish. Later, as the imago develops, the eyes show as dark spots with a greenish tinge and the thorax becomes generally darker.

Tabanus lasiophthalmus Macquart.-This species, which is widely spread and occurs, according to Hine, in eastern North America, Columbia, and Chile, has been reared by Hine (1906) from the egg to the adult. The fly is one of the earliest of the genus to appear in the spring, adults having been taken at Columbus, Ohio, as early as May 20, and it is common during the first half of June. The eggs are placed in masses on various plants that grow in low, wet ground, but Hine has not observed them over water. The masses are shiny black when fully colored, rather small for members of the genus, only slightly convex, and accompanied with an unusual amount of cementing material, which nearly obscures the form and arrangement of the individual eggs. The mass suggests somewhat a drop of tar or other black substance fastened to the surface of a leaf of the common cattail reed (Typha latifolia), a sedge, or some other plant. 
The eggs are usually deposited after June 10, and the specimens from which larvæ for rearing hatched were taken in Medina County, Ohio, on a common sedge found growing near the outlet of a small spring. They were collected June 28 and hatched the next day and the day after. As Hine had not been successful up to this time in keeping very young larvæ for any length of time, it was decided to try different methods of treatment in order to find out, if possible, that which is best suited to their requirements. Some were placed in a jar containing water only (No. 1); others in a jar containing water with a couple of inches of sand in the bottom (No. 2). A third jar (No. 3), in which larvæ were placed, contained wet muck, while the fourth lot (No. 4) was placed in a jar containing moist sand to the depth of about 3 inches, covered over the top with a quantity of fine leaves of water plants. In all the breeding jars were placed plenty of small crustaceans and other minute invertebrates procured from water by means of a finely-meshed sieve.

It was soon observed that the larvæ in breeding jar No. 4 fed on the crustaceans, and at the end of a few days showed a distinct increase in size. Those in the jars containing water soon died, and jar No. 3 did not appear to be a success, so all but No. 4 were abandoned. The larvæ in this last, however, were separated, and placed in similar jars, one specimen in each, and reared to full size, the adult fly being procured the following spring.

Since, as stated, three of the four jars started were soon abandoned, what is said hereafter regarding the method used in rearing pertains to the single one retained. A glass jar was selected so that the actions of the larvæ could be observed; a small jar seemed desirable because the larvæ are predacious and eat their own kind as readily as anything else, for which reason it is necessary after a short time to place only a single specimen in a jar; also, even a small receptacle furnishes plenty of room and the long series which it is desirable to have takes as much space in the insectary as one cares to give to a single species. Only the quantity of sand and other material necessary to success should be placed in the breeding jar, as it is desirable once in a while to look this material over carefully in order to locate the very small specimens and find out what they are doing. 
Half pint jelly glasses were found by Hine to be well suited for the purpose and easily obtainable. Covers proved to be desirable in order to prevent too rapid evaporation of moisture, but a small perforation or two in them was necessary to furnish ventilation. As the muck which was tested as soil for the jars grew much mold, clean lake sand was chosen as decidedly preferable for the purpose. The covering of plant material mentioned furnished a resting place for the small crustaceans offered for food, and the larvæ themselves seemed to choose to remain in it in preference to burrowing into the sand, although they were apt to be found in any part of the jar. Algæ made good material for covering, but only a small amount could be used, and too much water was detrimental as either in excess tended to cause decay, and consequently a bad odor, which was observed to be unfavorable to the insects. The principal point in favor of the algæ was that they contained no hollow stems or large pieces into which the larvæ could crawl, but still, being composed of small soft particles, furnished a mat in which they could hide. When it was desired to locate these larvæ it was easily done by picking the mass to pieces. As odors, which are often fatal to the larvæ, were likely to develop from the material put in for food and also from other sources, it was found necessary to watch the jars continually, giving them a thorough cleansing once in a while, and perhaps putting in fresh sand and plant material occasionally.

Larvæ when first hatched were about $2 \mathrm{~mm}$. in length; they grew rather slowly, but in fifteen days after hatching had doubled their length. They fed readily on the small crustaceans which were given them. It was impossible to give these small crustaceans their proper surroundings, so many of them died, and it was observed that the young larvæ fed on these as well as on the specimens which they killed themselves. The larvæ could be seen crawling about in the jars; they appeared to remain very near the upper surface of the sand most of the time, and when food was scarce did much crawling, but when food was plentiful satisfied their appetites and hid among the plant material where they remained quiet.

A difference in size in the various larvæ soon became apparent, and the older they became the greater was this difference. On July 23, twenty-five days after hatching, some specimens measured as much 
as $7 \mathrm{~mm}$., while others measured only $3 \mathrm{~mm}$. At this date angleworms were given for food, and were accepted readily, and appeared to be as satisfactory as the crustaceans, but it would seem that the latter are preferable for the stage just after hatching.

On July 27 some of the larvæ were $10 \mathrm{~mm}$. in length, and on August 2 the same specimens measured $12 \mathrm{~mm}$; thus at this stage they grew more rapidly than when they were younger. They fed actively till about the middle of September, when they had become apparently full grown, or $25 \mathrm{~mm}$. long. Length in the larvæ of tabanids is, according to Hine, not a satisfactory means of indicating the size, for the segments telescope on one another in such a way that it is difficult to take two measurements exactly alike, but an endeavor was made in this case to make the different measurements similar, so I believe that those given are considered sufficient to indicate the comparative sizes of the different ages. After September 15 the few specimens remaining alive buried themselves in the sand of the breeding jars and were quiet most of the time until March 10, when one pupated, the adult emerging on the 25th of the same month. The others died before the pupal stage was reached. Hine has noted that larvæ of various species of tabanids taken from their natural habitats during the winter did not produce adults in the spring much before the same species appeared naturally, but in this case, where the specimens was kept under artificial conditions during its entire life, the adults appeared almost two months earlier than is normal in nature.

Hine's description of the larva follows:

"The mature larva [Plate 3, Fig. 44] is not notably different from those of other species of Tabamus so far as form and appearance are concerned. The color is a dirty white with a pinkish shade over most of the body; the prolegs are not so prominent as in many species, and on this account specimens appear somewhat maggot-like. On either side of the body is a longitudinal row of very small black spots or specks, one to each segment and located just above the ventral prolegs; these spots are lacking on some of the anterior and some of the posterior segments; their presence appears to be characteristic of the species, at least so far as my acquaintance with different larvæ goes. Mature specimens are about 25 $\mathrm{mm}$. in length."

Hine has not taken the larva of this species in its natural habitat, therefore he cannot say where it is to be found, but he thinks that 
it lives in debris, or in the ground around low places near where the eggs are laid. ${ }^{22}$

"The pupa [Plate 11, Fig. 127] is somewhat dusky in coloration, the thorax being almost black. The terminal teeth of the abdomen [Plate 13, Fig. 159] are quite different from those of any species studied so far, and these differences alone make its determination easy. The dorsal and lateral teeth are much larger than the ventral, the lateral being much larger than any of the others; the ventral teeth point almost directly backward, while the direction of the others is largely upward. The thoracic spiracle is rather small and nearly longitudinal, its rima is curved, but no distinct hook is formed at the posterior end. Length $18 \mathrm{~mm}$."

We owe our knowledge of the early stages of Tabamus lasiophthalmus entirely to Hine.

Tabanus laverani Surcouf.-An African species, being rare in Neave's locality, Mt. Mlanje in southern Nyasaland, where only occasional specimens were taken.

A single female was bred on November 25, 1913, from a larva collected near Neave's headquarters. The larva did not belong to the pigmented type like that of Tabanus gratus and resembled the larva of Tabanus variabilis in bearing lateral prolegs on the anal segment. It was, however, of a yellower color and less transparent than that species, and lacked any pigmentation on the syphon.

The pupal aster (Plate 15, Fig. 185, a) is remarkable for the great size and elongation horizontally of the middle pair of hooks. The dorsolateral comb is reduced to two very short processes, the main combs on the last segment being also of this character, as may be seen from the view in profile.

The pupal aster and dorsolateral comb of the female are figured (Plate 15, Fig. 185, $a, b, c$ ).

Tabanus lineola Fabricius.-A common species, inhabiting eastern North America, common in states as wide apart as Massachusetts, Ohio, New Jersey, and Louisiana.

We owe to Hart a description of larva and pupa. The larva closely resembles the young of nigrescens, and was not separated from it at first. Examples were taken at Hart's collecting station, C, near the

${ }^{22}$ I have since found (May, 1917) the larva of this species in the muddy bank of a rapid flowing brook in the neighborhood of Princeton, N. J. 
foot of Quiver Lake, Illinois, over sand, mud, and algæ vegetation; at Station I, in the bed of the slough with grass, rushes, and willows, and a very shallow stream of spring water when the river is low; and at Station $\mathrm{H}$, on the Illinois River below Havana, Illinois, where it is narrow, (the east bank steep and sandy, a layer of mud over sand at lower levels, the water quickly deepening, considerable current, a little vegetation; on the west bank mud, steeply sloping, trees but almost no vegetation, decided current), on April 14, 15, and 30; and in Flag Lake, (shallow, muddy, bordered with rushes, thick with floating vegetation), on April 27 -as shown by specimens preserved. The larvæ were also taken April 8 and June 15 and 24 in Sand Lake, Lake County, Illinois, and in ponds in Kane and Champaign Counties. I give Hart's description of the larva.

"Larva.-Length $20 \mathrm{~mm}$., diameter $2.7 \mathrm{~mm}$. Prothorax with lateral shining areas about as long as the dorsal area ${ }^{23}$ striation about the same as that of the upper mesothoracic area, no noticeable central smooth spot, a small one on the lower margin posteriorly; remaining lateral areas a little more finely and closely striate; dorsal and ventral areas of thorax nearly smooth on disk, with basal striæ; those of abdomen with moderately close striæ, more or less interrupted on disk; all areas more or less shining."

"Surface whitish, dull pubescent markings very light brown but distinct, annuli narrow, crests of false feet also dull pubescent, their sides striate; lateral stripes of thorax distinct, slender, not dilated posteriorly, lateral edges of dorsal areas of thorax diverging. An opaque dark ring about base of respiratory tube, and another encircling anal prominence, above it usually three light brown spots."

"Main internal tracheæ rather thick and noticeable, subparallel, not strongly sinuate, at least back of the middle. Terminal stigmatal spine often protruded."

Of Tabanus lineola Hart has obtained three pupæ on May 18 of different years. Imagos were obtained from these on May 27, 29, and June 6. The tabanid pupæ develop, according to Hart, much more rapidly in hot weather than in cold, and to this fact is probably due the difference in time of emergence. Another pupa was taken at Matanzas Lake on August 24. Hart's description of the pupa follows:

"Pupa.-[Plate 12, Fig. 149; Plate 13, Fig. 162.] Length 19 mm., diameter 3 $\mathrm{mm}$. Light ferruginous brown, shining, abdomen roughly wrinkled and sub-

${ }^{23}$ I cannot confirm this character from material collected in Princeton, Spring, 1917. 
opaque. Palpal sheaths indistinct, not distant; tubercles not dark; ocellar tubercles indistinct or wanting; thoracic spiracular tubercles slightly but nearly equally elevated, free margin rounded at tip, rima not vertical, evenly arcuate, slightly hooked in front."

"Abdominal spiracular tubercles subtriangular, narrower behind, obliquely subconical, much shorter than basal diameter, bearing a small subcircular or short and strongly arcuate rima; on anterior slope a transverse groove, usually longer than the rima; fringes formed of unequal pale spines, only one or two long spines above on seventh segment; outer terminal teeth much longer than the others, directed laterally and upwards, the tips of the four upper teeth about in line. Fringe anterior to anal prominence showing a chitinous webbing between the bases of the spines, so that the separated tufts of the female look like a pair of broad low teeth with several spiny points; lateral tufts low down, near ends of ventral fringe, formed of short spines."

The pupa is also figured by Malloch (from Hart's material), (Plate 12, Fig. 149).

Oviposition and eggs are not known. Also it remains to be determined whether there are one or two broods of this species in one year. Adults were taken as early as May 17, and as late as September 27, with dates of capture in June, July, and August.

Tabanus maculatissimus Macquart.-An African species common in the neighborhood of Mt. Mlanje, southern Nyasaland, where Neave obtained data on the early stages.

The larvæ were found in mud in a partially dried up stream, and from these a few individuals of the adult were bred during November. The larvæ were obtained in Portuguese territory to the east of Mt. Mlanje. These larvæ were not, however, at the time distinguished from those of Tabanus biguttatus, of which they were thought to be immature examples. The figure (Plate 5, Fig. 71) is from other individuals, obtained subsequently, which are believed by Neave to belong to this species. This figure shows the pigmentation pattern of the eleventh segment considerably developed, while the dark circular band at the posterior end of the segment is comparatively narrow.

The pupal aster (Plate 14, Fig. 178, c) is normal except for a papilla on each side of the middle line, about the middle. There is a well marked dorsolateral comb, consisting of comparatively short stout spines. The pupal aster and dorsolateral comb of the female 
and the dorsolateral comb of two different male individuals are figured (Plate 14, Fig. 178, $a-d)$.

Tabanus medionotatus Austen.-An African species, to which Neave attributes, with some doubt, a series of specimens collected in southern Nyasaland in 1915. Of this species five males and three females were bred between the end of September and the beginning of November.

The pale colored larva has rather long prolegs, a ring of pigment of varying width around the base of the syphon (Plate 5, Fig. 68), and another ring around the anus, which is usually prominent in the living larvæ. There are also present two prolegs immediately anterior to the anus, but these are not visible in the somewhat contracted preserved specimen and therefore are not shown in the figure. The pupal aster (Plate 14, Fig. 174, $a, b$ ) resembles that of Tabanus obscuripes in having a large and even longer, but less horizontal, middle pair of hooks. Not only the dorsolateral but also most of the lateral comb is absent.

Tabanus melanoceros Wiedemann.-A species recorded from the Atlantic States from New Jersey south.

Late in March, 1909, Brimley in Raleigh, North Carolina, found, while looking under stones in a small clear woodland stream, a Tabanus larva which was quite lively and seemed thoroughly at home in clear water. He kept the specimen in a bottle with some wet leaves and practically forgot it. However, on May 18 it had transformed to a pupa, and thirteen days later, on May 31, a male of Tabanus melanoceros emerged from the pupa. The larva was approximately the same size as the trimaculatus larvæ collected by Brimley, and was like them white without darker bands.

Tabanus nagamiensis Carter.-An African species, only recently described, of which a single female was captured by Neave on the Malosa River, the Anglo-Portuguese boundary south of Mt. Mlanje, southern Nyasaland, on October 8, 1913. A male was bred from a collected pupa on September 27, 1913.

The pupal aster (Plate 15, Fig. 179, $a, b$ ) somewhat resembles that of Tabanus laverani in the great development of the middle pair of 
hooks, the dorsolateral comb is absent, a characteristic which Neave has not seen in the pupa of any other species of Tabanus, except in Tabanus medionotatus. The other combs are, however, striking and characteristic, as may be seen from the figure.

Tabanus nigerrimus Zetterstedt.-Of this European species we have some indication that it is lignicole in its larval stage. Scholtz (1850) expresses the opinion that perhaps some Tabani live in their early stages in the detritus of old tree trunks. He found, in July, 1848, in a deep wooded ravine near Charlottenbrunn, on the decaying trunk of a tree of Fagus sylvatica, a newly hatched but already fully colored specimen of Tabanus nigerrimus Zett., which had previously been found in Sweden and Norway.

Tabanus nigrescens Palisot de Beauvois.-This species is nearly related to Tabanus stygius, occurring in the Atlantic States (New Jersey), and also in Illinois. Of its oviposition nothing is known, but Hart has observed the larva and given us a description of the pupa.

An undersized larva, supposed to belong with those of stygius, pupated May 18, and on June 1 produced an imago of Tabanus nigrescens. Most of the larvæ, treated in Hart's paper as stygius were very uniform in size and characteristics; Hart, though unable to separate the two species at this stage, believes that the bulk of his material at least was stygius. The imago of nigrescens had been taken previously near the Mississippi, in southern Illinois, on August 10.

"Pupa, Male.-Length $25 \mathrm{~mm}$., diameter $5.5 \mathrm{~mm}$. Palpal sheaths narrowly separated, about one fourth as far apart as the setæ borne by the large frontal tubercles, a smooth depressed space between them, without tubercles. Lobes of carinate transverse ridges of head more rounded and separated by a deeper notch than usual. Abdomen a little more shining and more smoothly wrinkled. Otherwise not different from the pupa of stygius (female) next described."

From Malloch's analytical table the following data are obtained on the pupa:

"Pupa.-Dorsal abdominal segments, four to six at least, with one or two transverse series of short irregular spines, the bases of which are not much dilated, 
and slightly caudad of these is a transverse series of closely placed, very long, slender bristles. Length at least $25 \mathrm{~mm}$.; abdominal spiracles with very much elongated vertical rima, the upper and lower extremities slightly curved forward. The long spines on dorsal abdominal segments either black-tipped or all pale, without a black preapical ring; short spines in anterior dorsal series slender and very uneven. A small but distinct tubercle just in front of base of middle leg in addition to and some distance above the one bearing the paired hairs."

Malloch's material, which was partly the same as that collected by Hart in 1895, contained only one specimen of nigrescens (in very poor condition).

The prothoracic spiracle of the pupa has been figured by Malloch (Plate 13, Fig. 156).

Tabamus obscuripes Ricardo.-An African species, occurring in southern Nyasaland, chiefly on the plains in Portuguese territory to the east and south of Mt. Mlanje, in October and November.

A single male was bred by Neave from a pupa collected on October 1. The pupal aster, which is figured (Plate 15, Fig. 183, $a, b$ ) somewhat resembles that of Tabanus laverani and has the same large middle pair of hooks. The dorsolateral comb is reduced to a single knob-like process.

Tabanus (Neotabanus) ${ }^{24}$ ochrophilus Lutz.-A common Brazilian species. On its early stages we possess some notes by Lutz in Rio de Janeiro (1914).

Larvæ of this species were found in muddy or sandy soil below and at the sides of a small brook with slowly flowing water. Large quantities of sand had to be sifted to obtain them. As food, tubifex was given. The full grown larvæ measured $30 \mathrm{~mm}$. Color creamy white, integument shining and transparent, intestine reddish or blackish. Tracheæ silvery. Mandibles dark, serrate beneath. Digestion slow, four to five days. Before pupation, contracted; in spontaneous death, expanded.

Culture in moist sand, but for observation purposes moss in glass jars was preferred. The larvæ have to be kept in the dark during the intervals of observation. The pupal stage lasted about ten days.

${ }^{24}$ The few species of Neotabanus of which early stages are known are here classified with Tabanus. There is no doubt that the genus Tabanus could be subdivided into smaller genera or subgenera but opinions on this point are not definite. 
The eyes change color after two or three days. Eye coloration and stripes of abdomen visible two to three days before hatching. Pupal shell very transparent.

Tabanus orientis Walker.-A Tabanus occurring in North India, Nepal, Bhutan, particularly in high elevations; according to Baldrey, "by far the largest of the species caught at Muktesar (7,500 feet); it is caught at the beginning of March and appears then to be quite full grown (owing to its torn and worn out condition)."

According to Baldrey, who tried to breed the species for experimental purposes, it begins laying its eggs during the last weeks in April, and all flies dissected up to June 19 were found full of eggs.

The eggs when first laid are of a creamish white color, but after a few hours this changes to a cigarette-ash color. They are laid in batches resembling bunches of bananas.

Four lots of eggs were found in jars containing flies; in two cases the only fly in the jars was found dead.

Tabanus par Walker.-Of this African species we possess full descriptions of the egg, larval, and pupal stages by King (1910), who not only secured oviposition in captivity, but also bred the species through from the egg to the adult stage.

Occasional specimens of this tabanid were met with on the White Nile from Gebelein southwards. In the country behind Bor females were abundant and seemed to spend their time resting on foliage, waiting for approaching animals which they would attack at once. No eggs could be found, though a careful search was made in all the places that were considered likely to serve as breeding grounds; hence a number of females, gorged with blood, were placed in a breeding cage, in which was also a dish containing mud, water, and growing grass and weeds. The flies fed on sugar and water, and though the majority died within the first two days, the survivors eventually produced three small batches of eggs (Plate 1, Fig. 10). The eggs obtained in this manner were deposited on May 23 and 24, on the under sides of the leaves of a water weed. Unlike the eggs of most members of the genus Tabanus, they were not closely packed in a rounded mass, but placed vertically and separately though in a 
cluster. The single egg is "spindle-shaped, about $1.15 \mathrm{~mm}$. in length and white in color, becoming darker as the embryo within develops."

The eggs obtained hatched on May 30, consequently after an incubation period of six to seven days, and the tiny larvæ (Plate 1, Fig. 11) were divided into three lots, and placed in glass basins containing mud, water, and growing grass. These basins for purposes of reference were labelled A, B, and C. At the time when the eggs hatched, King was in the Sudan region, where it was impossible to land and obtain any subterraneous insect larvæ or tiny fresh water crustaceans for them, so they were offered the expressed stomach contents of gorged female ticks-Rhipicephalus simus-taken from a dog. A few fed once or twice but the majority refused, and all buried themselves in the mud.

On June 11, the larvæ from A were transferred from mud to clean river sand and water, and given freshly killed mosquito larvæ. They fed on these readily and grew apace, though at greatly varying rates.

The larvæ in B were also given mosquito larvæ from June 11, but they refused to feed, and the mud in which they were living was several times allowed to dry up. On July 11 they were placed in clean river sand and water, and at once began to feed and grow.

On July 19, when King returned to Khartoum, their diet was changed, owing to the difficulty of obtaining mosquito larvæ, to freshly killed and bruised earthworms. They did not take readily to this food, and some died, while others disappeared from the basins. At the time it was thought that they had become cannibals, but eventually it was found that they were being taken by mice. The stock of larvæ from A and B had by this time become reduced to one, which appeared to be full grown and so was killed and preserved.

On July 26 the larvæ from $\mathrm{C}$ were transferred to clean river sand and water. It was then fifty-seven days since they had emerged from eggs, and they had spent a great part of that time in a dry cake of mud. Occasionally this mud had been moistened, and food offered them, but they had very rarely taken it. Most of them were alive, but with the exception of a few which were slightly larger than when just hatched, they had not grown at all. They now under more favorable conditions fed readily on a mixed diet of earthworms and mosquito larvæ and grew, some rapidly, others more slowly. 
On September 3 and 4 one pupated, lying on the surface of the sand, partly submerged in water, and six days later gave rise to an adult female. By October 18 several more had completed their life cycles, and on that date, as King was proceeding to England on leave, the remaining ones were killed and preserved.

All those that pupated did so on the surface of the sand, some high and dry, others half in and half out of the water. "Probably," says King, "under' more natural conditions, the pupal stage would be passed buried in the soil-the structure of the pupal case seems to indicate this."

The average pupal period was from six to eight days.

The following are practically King's descriptions of larva and pupa (that of the egg having been quoted previously) of Tabanus par.

The mature larva (Plate 3, Fig. 48) when fully extended measures about 13.5 $\mathrm{mm}$. Color white with a grayish tinge. Mandibles dark brown to black, serrated. On the anterior third of each abdominal segment except the eighth is a ring of pseudopods, eight in each ring - two dorsal, two lateral, and four ventralexcept on the first abdominal segment, where the two dorsal ones are wanting. On the second abdominal segment the two dorsal pseudopods are very small. The pseudopods are largest on the third, fourth, and fifth abdominal segments, and are always more developed on the ventral than on the dorsal surface. Each pseudopod bears a crown of colorless spines or hooks, and there are patches of dark spines between the pseudopods. The spines on the dorsal sections of the rings on the first and second abdominal segments are dark. The anus is situated ventrally, at the base of the eighth segment, and is fringed with blackish hairs. The syphon tube consists of two segments, and, when exserted is as long as the eighth abdominal segment.

The pupa (Plate 12, Fig. 142, $a, b$ ) is from $12 \mathrm{~mm}$. to $15 \mathrm{~mm}$. in length and at first yellowish white in color, becoming darker as it nears maturity. The eyes show plainly through the pupal case as dark greenish purple. The empty pupal case is yellowish brown, the thoracic tubercles and the spiracles being darker than the surrounding parts. On the apical third of the second abdominal segment is a fine ring of backwardly pointing spines. Similar but broader rings, bearing longer and stronger spines, are on the third, fourth, fifth, and sixth abdominal segments, and one of intermediate breadth on the seventh. The eighth abdominal segment terminates in a coronet of six teeth, in color shining brown, becoming darker at the tip. The dorsal pair are smallest and close together, the ventral pair next in size and wider apart, and the lateral pair longest and arising from almost the same level as the dorsal pair. Ventrally placed to this coronet of teeth are two rows of small teeth, from two to four in each row, 
together forming an interrupted transverse row. These teeth are of unequal size and vary in their relative size in different specimens.

Tabanus pertinens Austen.-An African species, according to Neave usually confined to comparatively low-lying country where the river beds are of a sandy nature. In southern Nyasaland it was found common on the Mwanza River, in the Shire Valley, as early as the end of July, but did not occur on Mt. Mlanje, though a few specimens were taken by Neave at some distance from the mountain.

A pigmented larva (Plate 3, Fig. 54), which it was thought might belong to this species, was taken in some numbers in the Shire River in August, and in the Ruo River in October. It was found in both cases in water amongst the roots of grasses or water plants, and seems to prefer rivers with a sandy bottom and banks. The striking larva is remarkable for the development of the dorsal prolegs, which perhaps are associated with its comparatively free-swimming existence. The prolegs are also present immediately anterior to the anus.

Tabanus quatuornotatus (quadrinotatus) Meigen.-Common in Europe. This was the first species of tabanid in which the eggs and the act of oviposition became known. The credit of the discovery is due to Joseph Mann, Curator of the Imperial and Royal Zoological Cabinet in Vienna, who, according to Kollar's report in 1854, during a naturalist's trip to Carniola, Austria, in May and June, 1854, succeeded in observing in a damp meadow at Wippach the female of Tabanus quatuornotatus in the act of oviposition. Mann's own words, quoted by Kollar, are translated as follows:

On June 25 at 11 a.m., I found a Tabanus just beginning to deposit eggs on a grass blade; as it did not attempt to escape, I cut off the blade and took it home. Towards 2 p.m. the Tabanus flew to the window; I at once looked at the grass blade and found on it a cluster of eggs completed. These were wax-yellow at first, later on they took on a grayish color, and two days afterwards they appeared almost black.

Mann later on found, in the field and also on other plants, several egg masses similar to the first, bringing them all to Vienna.

By this discovery it was known for the first time that the Tabanus does not deposit the eggs on the ground where, according to Degeer, the larva lived, but on plants; further, that the Tabanus does not 
scatter its brood as many other species of flies do, but deposits the eggs in a single mass.

The eggs were counted, and their number found to be about 350 to 400. Also the hatching of young larvæ was observed, and the duration of the egg stage found to be from ten to twelve days (Kollar).

From the egg masses collected by Mann, besides young Tabanus larvæ, also ichneumonid flies (parasitic Hymenoptera) were observed to hatch; to Kollar and Mann consequently credit is to be given for the first discovery of hymenopterous egg parasites in tabanids, though no description is given (see under Parasites of the early stages of Tabanidæ, page 182).

The publication of Kollar has been quoted in detail by Lécaillon, to whom we owe further studies on the early stages of Tabanus quatuornotatus, chiefly on the oviposition of this species. Lécaillon found the species, with a related form, Tabanus bromius, abundantly at Gouy, Aisne, France, in May, 1904. Oviposition of Tabanus quatuornotatus was observed on May 24, 1904. In the afternoon of a sunny day, on a wooded and not especially damp hillside, a female was found sitting immobile on a dry branch of a weed (Origanum), the head turned downwards, at a distance of 35 to $40 \mathrm{~cm}$. from the ground. The eggs already laid formed a conspicuous white mass. On coming nearer, Lécaillon ascertained that the Tabanus, which under every other circumstance is likely to take flight, was not disturbed and continued to oviposit. Lécaillon broke off the branch with the insect on it, placing the whole in a jar. The female continued to oviposit for about ten minutes, when it ceased and left the branch. The egg has been figured by Lécaillon.

Lécaillon calls attention to the fact that, as already stated by Kollar, the ovipositing female is somehow indifferent to what is going on around her, a fact which should be taken into account in understanding the habits of adult tabanid flies.

Concerning the early stages, we learn from Lécaillon's observations on this species that oviposition in some tabanids may take place in comparatively dry and not necessarily in a damp environment. In both Mann's and Hart's observations it took place in a moist environment. As among insects frequently not only the necessities of embryonal but also of larval life may be anticipated from the manner 
and conditions of oviposition, Lécaillon thinks that as in tabanids oviposition may take place, according to species, either in a dry or in a damp locality, "not only the embryo but also the larva" can live under very variable conditions of humidity. Lécaillon considers that observations on the larval life of Tabanus quatuornotatus verify this hypothesis.

Later, in 1905, again large numbers of egg masses of this species were found by Lécaillon, and his first observations could be generalized to some extent. The eggs were always laid on warm sunny days in early June about the middle of the day, and almost without exception on dried out twigs of various herbaceous plants. In fact, of sixty egg masses collected in 1905, not a single one was found on a green leaf or stem. During the subsequent years, few exceptions to this rule were noticed. In 1907, however, Lécaillon found an egg cluster fastened to a green stem of a grass, and in 1908 a cluster fastened to the dry branch of a tree (bouleau) which had been rammed into the ground. Lécaillon discusses (1906) this fact, putting the question whether we might be dealing with mimetic resemblance. This he thinks hardly probable. The females, avoiding the green objects, would alight only on twigs of grayish or blackish color. More likely it seems to Lécaillon that the females oviposit on dry twigs because these are more rigid than the green stems. In fact, it is observed that during the act of oviposition, the stems of weeds on which the insects alight are curved, especially when agitated by the wind. On the dried out twigs the Tabanus is in a much more stable situation and can with greater facility give to the egg mass its rather complicated form. ${ }^{25}$

The places where eggs had been deposited were in all cases examined on woody slopes distant from any water courses. This fact alone is certainly sufficient to prove that the larvæ of Tabanus quatuornotatus are not aquatic but terrestrial.

The egg masses are found in large numbers assembled in certain places on hillsides which evidently present all the favorable conditions to which the ovipositing females are adapted. This circumstance is

${ }^{25}$ Lécaillon's explanation is more than doubtful. Many species of tabanids complete their egg masses on quite slender reeds and grasses. Also for Tabanus quatuornotatus it remains doubtful by what stimuli it is attracted to the twig. 
favorable to the destruction of the eggs in the case of very dangerous species which should be brought under control. The egg masses are in fact very conspicuous and may be collected easily and quickly. All egg masses observed were placed about 30 to $50 \mathrm{~cm}$. above the ground.

The latest date on which oviposition was observed was June 14; however, it may be that it takes place even later, as Lécaillon found eggs containing larvæ as late as July 22 (1907). The period of reproduction extends in this species, at least in certain years, from the end of May to the end of June. The period given in Lécaillon's note in 1906, of two to three weeks, was evidently too short.

A detailed description of the egg mass is given (Plate 2, Figs. 33 to 38). The egg mass presents the aspect of a roughly subconical body which under natural conditions is placed with the base below and the vertex above. The axis of the cone is arranged about parallel to the branch or stem which serves as support, and is placed in such a way as to cut lengthwise through the conical surface and to be partly enveloped by it. However, it would not be accurate to speak of the egg mass as subconical, as certain authors (Brauer and Hart) have done. The body of the mass is distinctly bilaterally symmetrical, as shown in the accompanying figures. The plane of bilateral symmetry is determined by the stem which serves as a support and by a crested longitudinal line placed on the side opposite the egg mass (Plate 2, Figs. 34 and 35). On the other hand, it is possible, with regard to the mass, to distinguish a vertical direction or orientation, a horizontal anteroposterior one, following the plane of symmetry, and a horizontal lateral one, placed at right angles to this plane. In the anteroposterior direction the base of the mass has its greatest dimension (5 $\mathrm{mm}$. in a specimen examined). In the two other directions the dimensions are about the same and somewhat smaller than in the preceding one. Posteriorly, the surface adhering to the support is much larger than the opposite surface anteriorly. Finally, in the specimens examined, the base of the mass was not flat but perceptibly and progressively excavated from the periphery towards the center.

The egg mass is composed of eggs which are placed quite regularly on top of each other, if observed vertically, or placed in successive 
horizontal layers, if observed horizontally. The eggs are, moreover, glued together by a substance which hardens after deposition, and causes the eggs to adhere strongly to each other. It goes without saying that the number of eggs contained in a horizontal layer diminishes if we proceed from the base of the mass towards its summit.

The color of the egg mass, which is white at the moment of deposition, is changed rapidly into brown and later into black. The change of coloration begins some time after oviposition is completed; it appears at first at the summit of the mass, thence it spreads towards its base, which after a few hours has turned almost completely dark brown or black. This change of coloration in the egg masses of tabanids has already been observed, as Lécaillon emphasizes, by Mann and also by Hart. However, Mann, who observed the same species as that studied by Lécaillon, speaks of a wax-yellow color which later passes into blackish brown, and Lécaillon assumes that Mann has not noticed the primitive white color of the eggs when first laid, or that he possibly dealt with a different species. Hart's statement that in the eggs of Chrysops moerens (estuans) the first color is cream, seems better to agree with Lécaillon's observation. This may possibly be merely an inexactness of terms, as one author may call an object white which another would call pale yellow or cream.

The change of coloration which takes place in the egg mass a short time after oviposition must be considered as advantageous, as we have to deal with the substitution of a protective color (black) for a white color which as actually observed, renders the eggs very conspicuous to the eye.

According to Lécaillon, the color of insect eggs may be due either to a coloration of the yolk, or to a coloration of the egg envelopes. Changes of coloration can consequently be due to changes taking place inside the egg, or to changes taking place in the envelopes. In the case of Tabanus quatuornotatus, the substitution of the white color by a dark color is due to a brown pigment which develops in the chorion after oviposition, probably by the slow effect of air and light. This pigment is very strongly developed and hides completely the contents of the egg. Consequently even at the end of embryonic development when the eggs contained wholly white larvæ, they still are in external appearance completely black. 
The pigment is, according to Lécaillon, not altered by alcohol, while in eggs in which the color is due to the yolk the latter is usually decolorized by the action of alcohol.

The female constructs its egg mass, depositing the eggs one after the other, beginning at the anterior end. At last, when the mass has reached a certain width the eggs are found arranged in horizontal and more or less regular layers, while the lower border of the mass forms a pronounced projection, the beginning of the depression of the lower surface. While the female is sitting with head turned downwards the tip of the abdomen is placed upwards, towards the point where the egg is to be laid.

The eggs themselves are of curved shape, they measure about 2.5 $\mathrm{mm}$. in length and only $0.5 \mathrm{~mm}$. in width. Their convex side, which is chiefly visible in those which lie at the periphery of the egg mass, is always directed towards the outer side of the latter.

Lécaillon calls attention to the significant regularity of tabanid egg masses. Among the greater part of insects which deposit their eggs freely on leaves, twigs, walls, etc., the egg mass consists generally of an agglomeration of any shape which it may assume under the conditions presented by the object on which the eggs are laid. In Tabanus quatuornotatus, however, the case is different; the egg mass has a very complicated structure, which to a great extent is independent of the shape of the supporting object, and of a strictly bilateral symmetry which can certainly be regarded as a characteristic of evolutionary perfection. From Hart's figures it is seen that the same character is found also in the egg mass of Tabanus atratus and Chrysops astuans (morens); and it is probably generally found among tabanids.

In a later paper, in 1911, Lécaillon reports additional observations made on this species in 1906, 1907, and 1908, on the conditions under which the eggs are laid, and a more amplified description of the egg masses themselves.

Since the first publication, a considerable number of egg masses of Tabanus quatuornotatus were examined and a number of individual differences were found in the arrangement of the egg masses. Some of the more interesting forms met with were figured in the plate added to the second publication. The egg mass previously described is 
consequently incomplete; moreover, they are found frequently in places where this Tabanus oviposits. But in many cases the egg masses have been found to be much larger than the one described in 1905. In cases where the egg mass, fastened to a twig, reaches its maximum of development, it is much more prolonged vertically than the one figured in Lécaillon's first report, and it possesses a second plane of symmetry which is horizontal and at right angles to the principal plane of symmetry passing through the stem which serves as support and through the anterior tip which presents the egg mass. But only rarely will the egg mass be found entirely completed in this manner, and all the intermediate forms are found between that described in the first publication and that described later, with two planes of symmetry.

Frequently the egg masses are found grouped together on the same stem, numbering two, three, or four (Plate 2, Figs. 35 to 38).

Finally, as stated also in Lécaillon's short note of 1906, two egg masses are frequently not only contiguous but actually form the continuation of each other (Plate 2, Fig. 33). Of these joint egg masses Lécaillon is uncertain whether they are produced by one female or by two different females. Probably the latter, inasmuch as in the figures given their size is considerable; also from our knowledge of the egg-laying instinct of the female, it does not discern between the eggs laid by itself and eggs laid by another; consequently it will be likely to continue the process of oviposition started by another female in case it, by chance, had alighted on a stem where already other females were laying. As during the process of laying the single egg is always placed beside another previously laid, one would expect that in starting an egg mass, preference would be given to a place where eggs are already present instead of places where only a smooth surface is given.

Sometimes the herbaceous stem which supports the egg mass is very fine, and in these instances the latter surrounds it almost completely, even from behind, following the median line of the stem. In other cases the egg mass is attached to the top of the spike of a grass plant; in this instance it envelops only a small part of the object, so that from behind the egg mass appears as of considerable width. 
Besides, the egg masses are never found of a strictly geometrical form, and numerous irregularities in details of their structure are always observed. In general, however, it can be said, that the eggs are placed horizontally and in rows which when observed horizontally or vertically always present a more or less regular arrangement.

On the larval stage of this species we possess the results of Lécaillon's first studies (1905), amplified by later additions. At the time of Lécaillon's studies knowledge about tabanid larvæ was still very meager; he believes that the larvæ are predacious, and there are certain species which are aquatic and others in which the larva lives in the ground or in moist soil.

Lécaillon made an attempt to raise the larvæ of Tabanus quatuornotatus from the egg, but did not succeed completely, as many of the larvæ died in spite of all precautions; but he was able to keep them alive for several months and some of them were still living when the paper was published (December 15, 1905), having survived for more than six months. Lécaillon made some observations on the hatching of the larvæ.

According to Mann, the duration of embryonic development in this species is ten to twelve days. Lécaillon placed eggs laid May 24 in a moderately damp atmosphere (the stem with the eggs was simply placed in a crystallizing dish), and observed that on June 6, thirteen days after oviposition, no hatching had taken place. Taking two eggs out of the mass, he saw, as a result of the slight pressure or traction to which they had been submitted, the hatching of completely developed larvæ.

On the following day the egg mass was vigorously rubbed, and as a result all the larvæ hatched at once, showing that embryonic development had been completed in all the eggs. The difference in time appearing in Lécaillon's observation as compared with that of Mann is said to have no significance as the duration of embryonic development is very variable, in a given species, according to the temperature in which the eggs are kept.

The medium duration of embryonic development was, according to Lécaillon's first publication, from twelve to thirteen days. But later he found that the larvæ generally do not hatch as soon as they are completely developed; they may remain inside the egg shells for 
a period which seems to be rather long. In 1907, Lécaillon found that eggs which were laid on June 11 had not yet hatched on June 8 . Eggs collected on July 11, which had certainly been laid a long time, produced larvæ on July 22. Embryonic development is, however, completely terminated at the end of twelve or thirteen days, because, after that period, it is sufficient to rub the egg mass only slightly in order to cause the larvæ to hatch.

It can be assumed, consequently, that the larvæ do not leave the egg shells in which they have developed, until they need food; from the time of their formation to that of hatching, they probably find an efficient protection inside the egg shells. Perhaps also the egg shell which has to be pierced by the larvæ in the act of hatching is of a variable resistance according to the conditions of the environment. In a damp environment, for instance, the shell would be less resistant than in a dry atmosphere, and the larvæ could hatch much more easily in the first than in the second instance. The larva appears in this case to be adapted to remaining enclosed in the chorion of the egg for a time long enough to wait for favorable atmospheric conditions. Lécaillon has not made exact studies to determine this point.

When the larvæ hatch, they remain sometimes for a few moments on the surface of the egg mass. They carry out very varied movements of contraction and finally fall to the ground into which they burrow immediately. Often they are also attached to one another, forming sort of batches which finally lose hold on the egg mass and fall to the ground. They are, as Lécaillon says in 1906, extremely lucifugous (negative phototropic), and they could not be easily destroyed.

Immediately after hatching, the larvæ are white in color and this color is retained. The body is also somewhat transparent, and the arrangement of different internal organs can be observed with facility. It is seen that in the middle intestine there remains a rather large quantity of nutritive yolk, a remainder of the primitive egg contents. At the level of the yolk the intestinal tract is opaque. When placed in damp earth, the young larvæ appear not to take food for several days.

In order to ascertain whether these larvæ were carnivorous, Lécaillon supplied them with ant nymphæ freed from their cocoons, with flies killed previously, and with larvæ of Chironomus. He 
found that they did not attack these with great alacrity, but seemed rather to avoid their contact when placed near them. However, after having pierced Chironomus larvæ by means of a pointed scalpel, Lécaillon observed some of the larvæ to suck up the blood, their intestinal tract assuming a characteristic red color; he even saw them penetrate into the body of the animal in order to devour it. On the other hand, it was observed that the larvæ placed in moist earth absorbed the organic detritus, giving their intestine a distinct dark color. These facts led Lécaillon to assume that the larvæ of Tabamus quatuornotatus can feed, according to circumstances, on animal or vegetable matter in process of decomposition, and probably also on certain soft larvæ selected by the experimenter.

Lécaillon goes on to investigate the conditions of humidity favorable for the larvæ. Generally he left them in very moist earth. But once, having placed within the crystallizing dish, which contained the larvæ, another dish the under side of which was wet and rested on the former, from which the earth had been partly removed, Lécaillon found that fifteen larvæ had assembled under the smaller dish, between the two glass surfaces, and were completely submerged in water. $\mathrm{He}$ subsequently placed a number of larvæ in a cup filled with water, and observed that they appeared to be at home in the water, remaining in it and making no attempt to leave it. Later, Lécaillon placed the larvæ which he intended to rear in mud taken from an aquarium; they remained completely burrowed in this mud and could even find nourishment in it.

On the other hand, Lécaillon repeatedly allowed the earth in which larvæ were kept to dry out completely and found that the larvæ not only did not suffer but remained quite active.

His conclusion was that the larvæ of Tabanus quatuornotatus are capable of adapting themselves to a variable degree of humidity, and can live, at least for some time, in dry ground as well as in water. Concerning the range of humidity, and also concerning food habits, these larvæ, as probably other tabanid larvæ also, appear not to be adapted to limited conditions, in contrast to many other insects.

In his later publication, Lécaillon emphasizes the great resistance of the larvæ of Tabanus quatuornotatus to humidity and draught, explaining the fact by the presence on the body surface of a chitinous, 
thick, and impermeable integument. In acetic sublimate, at a temperature of $24^{\circ}$, the larvæ remain alive for more than half an hour. It may be mentioned that many dipterous larvæ behave in this relation exactly like the larvæ of tabanids.

Lécaillon has again tried to rear larvæ of this species which had hatched on June 27, 1905. He found that they succeed best in moist ground. In February, 1906, a rather large number of these larvæ were still alive; they had grown comparatively little, measuring only 7 or $8 \mathrm{~mm}$. in length, against 2 or $3 \mathrm{~mm}$. at the time of their birth. Some lived for a year without having reached a much greater size than this. Some of the larvæ were still found alive in July, 1906.

Under the conditions mentioned, the intestinal tract of the larvæ almost always contains particles of soil, giving them a blackish color.

From these observations it is probable that in Tabanus quatuornotatus the duration of the larval stage is more than one year. However, Lécaillon believes that this need not necessarily be, as it is apparent that the larvæ when kept in moist earth do not find exactly the conditions under which they live in nature. Their growth is consequently much diminished and cannot be compared with normal growth. This subject, however, requires further investigation.

The chitinous cuticle of the larva was also studied by Lécaillon (1906). It is thick and resistant, as generally in dipterous larvæ. Its thickness in a larva of $630 \mu$ in diameter being about $17 \mu$. This resistant and impermeable covering protects the larva efficiently. It may be left in the water, for instance, for several hours without being appreciably injured. It can be left, on the other hand, in dried soil for a considerable time without being killed. If one wishes to fix the larvæ in toto, even in the case of very small larvæ, great difficulties are encountered because of the impermeability of the chitinous membrane.

The free surface of the chitinous layer appears to the unaided eye to be smooth and devoid of hairs. But with a lens it is found that it presents numerous longitudinal parallel ridges and numerous hairs of reduced length. This characteristic has been found to be a general feature of tabanid larvæ, and the examination of the striæ can furnish the means to distinguish the genera and species. 
The finer structure of the chitinous layer is easily studied on cross sections of the larva which is fixed and stained before. On section the chitinous layer is found to consist of three zones; first, an inner zone, which is in immediate contact with the hypothelium; second, a median zone, resting on the former; third, an external zone, which limits the body of the larva exteriorly. These three zones present different characteristics.

1. The inner zone is highly developed; it is much thicker than the two other layers taken together. It is of a lamellar structure, as on cross-section it presents numerous concentric striæ. This inner zone is slightly affected by acid stains.

2. The median zone is much less thick than the inner, but much thicker than the external zone. This zone or layer forms the thickenings which project exteriorly in the form of longitudinal ridges on the surface of the integument. It follows that it is much thinner at the level of the intercostal furrows than at the level of the ridges. It appears not to be lamellar in structure, but rather to present at the level of the ridges vertical striæ. Finally, its most remarkable property is its great affinity for basic stains.

3. The external zone is extremely thin; unless high magnifications are employed to observe it, it easily escapes detection. It covers the median zone in the intercostal furrows as well as on the ridges, and is not thicker at their level. It is not affected by either basic or acid stains. This layer forms the hairs. Neither the median nor the internal zone takes part in the formation of hairs.

It follows from the difference in affinity with regard to stains, shown by the two first layers, and the inability to stain the outer layers, that the three chitinous layers are easily distinguished by a combined staining method. By means of magenta red and picric indigo carmine, for instance, the inner zone becomes greenish and the median zone dark red, while the external layer remains colorless. Similarly, by a combination of hematoxylin and light green, the inner layer stains green and the median layer deep black, the external layer always remaining colorless.

The descriptions of the chitinous integuments of insects do not completely harmonize with those given by Lécaillon of Tabanus quatuornotatus. Lécaillon assumes two reasons for this fact: first, 
the staining methods employed have undoubtedly been insufficient; second, the different types of insect may show important differences in the integument. If the integument is not very thick, it may often be of simpler structure. But only exact observations can determine this point. In the meantime, Lécaillon points out that the structure of the integument of this larva suggests strongly that described by Dubosq in the myriapods.

Lécaillon describes also the attachment of the muscles on the chitinous membrane of the larva of this species. The muscular fibers inserted in the integument do not end at the epithelium but cross the chitinous layer, becoming attached at the median zone. But the striation of their fibers disappeared where they reach the integument, and the whole section contained between the hypothelium and the median chitinous zone is formed by non-striated fibrils forming a sort of a tendon. All the muscles attached to the integument present this type of insertion. Lécaillon points out that the middle and external layers form the really hard and resistant part of the chitinous membrane of the integument, as Dubosq has shown in the myriapods. This aids in the understanding of the mode of insertion of the muscle fibers in the highly contractile larvæ of tabanids, in this region of greatest resistance. About Graber's organ, in this species, see page 35 and Plate 10, Figs. 111 to 116.

According to Bezzi, the Tabanus larva in which Paoli studied Graber's organ, may have belonged to this species (Paoli). See p. 37 (Special anatomy of tabanid larvæ).

Tabanus semisordidus Walker.-The egg masses of this South American species have been observed in British Guiana, by Bodkin and Cleare, in 1916, to be deposited on the leaves of aquatic grasses and in some instances on the leaves of young rice plants. They are laid in a little bundle consisting of twenty or more cigar-shaped, shining black eggs adhering to one another and to the leaf surface.

Tabanus solstitialis Schiner.-A common European species. Brauer (1880) states that the pupa is found in the water, being green in color and provided with large ear-shaped anterior spiracles. The larvæ are not mentioned. 
Tabanus speciosus Ricardo.-In Madras, India, but rather rare; feeding on cattle with Tabanus striatus and albimedius, and similar in size and appearance to the latter.

According to Patton and Cragg, this species lays its eggs always on the leaves of water-lilies growing in deep water. The number of eggs laid is between 500 and 600 . The process of oviposition is said to be similar to that of Tabanus albimedius, but Tabanus speciosus, instead of forming a V-shaped mass as is usually the case with the larger tabanids, lays its eggs in a round heap, which it then plasters over with a chalk-like substance, almost completely covering the eggs. The egg mass is figured (Plate 1, Fig. 19).

The larvæ of the larger Indian tabanids, including this species, are powerful swimmers and have air sacs connected with their tracheal tubes, so that they can float or sink at will. A description of the larva is not given.

Tabanus spodopterus Meigen.-A common European species. According to Schiner, very common in Austria, at the Neusiedler See. Brauer (1883) gives an illustration of the larva (Plate 6, Fig. 87, $a-f$ ), which he found, in the month of May, under dry leaves on the ground.

Tabanus striatus Fabricius.-The early stages of this species have become known through Mitzmain's work, which is the most thorough investigation into the life history of a tabanid species which we possess. We cannot enter here upon his results in as far as the habits of the adult fly and its part in the transmission of disease is concerned, but have to limit ourselves to report on the results obtained on the early stages of this species.

The eggs of Tabanus striatus (Plate 2, Figs. 22 to 27) were not found in the field, but Mitzmain was able to obtain them from females ovipositing in captivity. A large case was built for this purpose provided with a tank of water, growing plants, and two animals (carabaos) as a source of food for the flies. In a short time females were observed feeding on the hosts and several were found ovipositing in various places about the enclosure.

The time selected for egg laying under the conditions provided was invariably during the early afternoon, never later than 2 o'clock. This was observed in nearly fifty instances. 
The eggs were laid in a compact mass either extended on a flat surface or surrounding various attached objects, usually of small diameter, such as projecting splinters of wood, suspended fibers of jute sacking, fine brass wire, a single animal hair, and coarse iron wire. Upon these materials the eggs were laid in an ellipsoidal form sometimes surrounding the objects completely or nearly so. On one occasion two egg masses were found upon a small splinter of wood which they entirely enveloped. The surfaces of the egg masses were continuous, so that the double mass resembled a single large one. When eggs were found deposited on a flat surface, on two occasions a leaf was the object selected. These were leaves of an ornamental plant which was used for shade purposes in the breeding cage. The plant grew close to the cement water tank in the breeding cage. In all other instances the eggs were deposited upon woodwork on the sides and ceiling of the cage, invariably upon the shaded portions, as the under side of beams and partitions. In egg laying upon flat surfaces there was a strikingly constant geometric form. Usually the form assumed was roughly a pentagon with a biconvex center.

At the beginning of oviposition (Plate 2, Fig. 24) usually two eggs are deposited in the position of an inverted V. Three to four eggs are then laid on either side of the apex of this $V$, and then one side and then the other is built up, rather irregularly at first, until the sides of the pentagon are completed. The eggs are laid cleanly and definitely, each line slightly overlapping the preceding one. When the eggs are laid in the extended order, they are deposited three or four layers in depth, but usually as many as six layers are required to complete the mass when the eggs surround a convex object.

In the process of laying, "the body is held away from the egg mass, the legs being planted firmly." When the eggs are attached to one of the objects mentioned above, the insect stands with head downwards, the fore legs suspended alongside the head, the hind and middle legs supporting the weight of the body. At the first movement, the anal end of the body is bent towards the thorax under the abdomen, and with a slight jerk the egg is laid, while the brush-like appendage of the ovipositor exudes a tiny drop of liquid coating the egg as it is deposited. The movement of deposition is very much like squeezing a bit of pasty material from a collapsible metal tube. 
In several counts that were made by Mitzmain, the fly was observed to lay with clock-like precision at the rate of ten eggs per minute. This did not vary whether the attached object was above or below the fly. In three instances observed, the process occupied from forty to forty-five minutes. Both the beginning and completion of the egg-laying process were without deliberation, the insect walking away from the mass of eggs and flying off as soon as the last egg was deposited.

When disturbed during oviposition, the insect does not fly and can readily be carried without attempting to escape. While in the act of laying, if interrupted and dislodged from the position, it immediately begins to deposit a new egg mass. This was twice repeated with one female, and three distinct egg masses were deposited, all identical in geometrical arrangement.

The eggs of this species of Tabanus are laid with very little cementing material. The cement used is a transparent substance "and not dark and opaque as found to exist in the species described by Hine" (Tabanus lasiophthalmus). The cement provided by this species was tested and found to be water-proof, as well as insoluble in various grades of alcohol and xylene.

The eggs (Plate 2, Fig. 25) when laid are a pale clay-yellow, but within twenty-four hours become slightly darkened with an ashy gray tinge. Microscopically fine black striations can be seen running lengthwise for nearly $0.5 \mathrm{~mm}$. from the end opposite the micropyle.

The shape of the individual egg is that of the muscid type with more sharply pointed ends; it is not quite spindle-shaped. Several eggs were measured and found to average in size 1.6 by $0.4 \mathrm{~mm}$. The size of the mass varies from 9 to $12 \mathrm{~mm}$. in length by 6 to 9 $\mathrm{mm}$. in breadth.

The number of eggs laid in a mass varied greatly. In four masses counted there were respectively $270,340,417$, and 425 . Ten masses dissected from the bodies of killed flies were found to average 405; the greatest number found in any female was 495 .

Mitzman gives a detailed description of the hatching process. Two egg masses were observed microscopically during the entire process of hatching, and fourteen egg masses were noted as to the length of the incubation period. The minimum period observed 
was three days and the maximum five days. Four days is probably the average length of time required for incubation. It was observed that the degree of temperature and moisture influenced the time of hatching. Slight changes in either of these factors can be used to control the time of emergence from the egg. Mitzmain's observations on the hatching of an egg mass are the following:

"Twenty-two hours previous to the hatching of the embryo, certain unmistakable activities were discernible in the egg. The first signs of these were seen in the two eggs which formed the nucleus for the egg mass and which are the first eggs laid. These movements, as indicated by either of the dark eye spots, could be seen with a hand lens at intervals of a few seconds; their action was similar so that of the bubble in a spirit level. In about an hour the movement was teen to be rather general in the egg mass, accompanied in the eggs first laid by an alternate collapsing and distending of the exochorion. This action is the result of the torpedo-like movement of the head capsule of the embryo in the direction of the micropyle of the egg. The movement is effected by the piston-like action of the apophyses of the cephalopharynx, which appear to work alternately, bringing the saw-toothed mandibles in contact with the micropyle canal. These movements proceeded uninterruptedly during the hours of the night, the only change observable being that the body segments of the embryonic larva became better defined. At 4.25 the next morning the segments of the embryo could easily be counted through the chorion. The dorsal surface of the exochorion was seen to be slightly shrivelled."

"Fully one hour and thirty minutes intervened during which there was no action worth noting. This quiescence was interrupted by a sudden remarkable activity of all of the visible eggs of the mass. At 6.08 there was a general upheaval of the surface of the egg mass, an agitation within the eggs, and an alternate collapsing and distending of the eggshells. At 6.10 the first layer of eggs gave birth to a silvery horde of young larvæ, which at 6.12 had crawled from view [Plate 2, Fig. 27]. Then ensued another spasmodic agitation giving birth to another lot of larvæ, which crawled from the mass of empty eggshells [Plate 2, Fig. 26]. The emergence which is effected by the head structures is aided by the posterior protuberances, which functioning as prolegs push the body of the larva clear of the eggshells."

Mitzmain's discussion of the egg stage and of the hatching process is followed by a description of the morphology and habits of the young larvæ.

Immediately after emerging from the egg, the young larvæ (Plate 5 , Fig. $80, a, b)$ seek concealment. In nature, no doubt, resort would be had to the convenient water course where aquatic plants, drift- 
wood, and stones would be the probable hiding places. The larvæ under observation became very active and crawled out of the slender dish, a height of $9 \mathrm{~cm}$., and fell into the water of the basin provided. When collected and placed in a deep glass vessel with some water, the entire mass took refuge behind the filter paper in the glass. There they crowded side by side with their syphons projecting from the upper edge of the paper. When disturbed and forced to take to the water, they were found in thirty minutes reassembled in the characteristic gregarious fashion behind the filter paper against the glass.

For convenience in study, a majority of the larvæ were transferred when 1 day old to individual glass jars one-third filled with clean wet sand from the lake shore and provided with strips of filter paper soaked in muck from the creek bottom. The jars, which were the common half pint jelly glasses recommended by Hine, were kept covered with filter paper, held in place by the tin lid which had a disk cut from its top to admit air. By renewing the moisture on the strip of filter paper in the jars, the filter paper cover serves ideally to control the humidity.

A considerable number of the larvæ were not separated, but were left together for observation in a glass dish with a few strips of paper saturated with muck from the creek. The young larva is briefly described as follows:

"The larva one hour after hatching [Plate 5, Fig. 80, $a, b$ ] is $1.5 \mathrm{~mm}$. in length. The following day several were found to measure $1.8 \mathrm{~mm}$. The general color is a dirty white with a tracheal system of waxy white, the abdominal contents pale green, and the Malpighian tubules of a lilac color. There are 2 black eye-spots located midway on the head capsule. The latter tapers to a sharppointed mouth with a prominent pair of great hooks or mandibles. The segments are provided with typical, conical, truncated, prolegs, each armed with a chaplet of medium long, brown hairs. The siphon which is carrot-shaped at this stage is a prominent feature."

Food in a variety of forms was furnished the larvæ. They thrived from the start on minute crustaceans, larvæ of Stomoxys, mosquito larvæ, and young angleworms. Full grown angleworms were found unsuitable, and larvæ of the blow-fly and flesh-fly were not satisfactory unless killed previously, as they were capable of killing or in- 
juring even well developed Tabanus larvæ. As soon as the insect becomes aware of the presence of food, the claw-like mandibles are protruded from the head capsule, and bury themselves in the live food like meat hooks. With a slight curve dorsally, the larva's body is brought forward, and a small portion of the food is lacerated. This is aided by a twisting of the head and a pulling with the extended jaws. The mandibles are brought together with a rapid clawing action, the parts working in apposition. When prehension is effected, the jaws move alternately upwards and downwards and laterally, and the bolus is swallowed in fibrous strands.

Seeking and devouring food is not a continuous operation as it is in the case with Stomoxys and the dung-flies. The Tabanus larva requires a long rest after a sufficient meal is taken. A 2 day old Tabanus is capable of devouring two half grown larvæ of Stomoxys in twenty-five minutes. In one instance a full grown Stomoxys larva was destroyed in exactly twenty minutes. Here the attack on the Stomoxys was made through accidental collision, the Tabanus instinctively thrusting out its mouth and tentatively taking a bite. It apparently became greatly excited (this was its first meal), and thrusting its head into the body of the Stomoxys larva, commenced to probe by twisting its head rapidly. In less than a minute the cuticle was broken through and an ample slit was made through which the entire head was buried in the body of the victim, whereupon an energetic gouging took place. The Tabanus worked through the cephalic third of the body upwards to the head, then worked in the other direction on the lower two-thirds. This gouging was continued until the Stomoxys had become completely eviscerated, during which time the head of the Tabanus kept steadily probing, twisting. its pharynx from side to side, and pushing forward with its rostrum until the Stomoxys larva was completely devoured with the exception of the cuticle.

The full grown Tabanus larva does not wait for its food, as is the tendency in the young stage, but actively pursues its prey. When an angleworm is seen, perhaps $2 \mathrm{~mm}$. distant, the elastic head capsule of the larva darts forth, curves its claw-like hooks about the worm's body, and with its head curled under its struggling prey, retreats quickly into the sand until all but its cephalic end is hidden. 
It begins to feed then, devouring in twenty minutes an angleworm fully four times its own length.

The intestinal tract seen through the hyaline cuticle soon partakes of the color of the food ingested. The color is pale brown when the food consists of the wet muck in which crustaceans and minute forms are sought. As a result of feeding on blow-fly larvæ and angleworms, the young Tabanus assumes a variegated color. The intestinal tract then appears tinted with green, yellow, brown, and red particles of the food.

In one set of larvæ, as Mitzmain says, "The origin of cannibalism as an acquired habit was observed." This was seen in larvæ which had been kept together for four days since their birth. Until that day no food was offered them except that which they might have obtained from the surrounding creek water. Apparently they lived together amicably with their bodies compressed against the glass dish and the bit of filter paper. A live angleworm was placed in the glass dish while the resting larvæ were observed with a lens. The worm was not placed in the immediate vicinity of the mass of larvæ, but nearly $4 \mathrm{~cm}$. distant. The presence of the food appeared to act as a stimulus. No movement was made towards the worm, but each larva appeared to become greatly excited and began to prod the larva nearest to it and to nip its neighbor's appendages; several instances of laceration were noted. This doubtlessly marked the beginning of systematic cannibalism. From this cause, 39 of the 365 larvæ kept in the large glass dish were destroyed within four days. Four dead bodies were recovered. Upon another occasion the extent of cannibalism was much more marked. A lot of 415 larvæ which hatched on November 12, 1912, was placed in a deep glass dish with moist lake-beach sand, and fed daily on angleworms. Each morning it was observed that only about one-half of the worms supplied the previous day were eaten, so that with the daily fresh supply more than enough food was present. Another lot of 300 larvæ, the same age as the preceding, was kept in individual glasses under similar conditions. On December 6, counts were made of the survivors in the large glass dish. Thirty-five larvæ remained, of which eighteen were the maximum size, eleven were a little more than one-half this size but equal to the largest found in the individual 
jars, and the remaining six larvæ were so small as to be easily overlooked. The count of the larvæ from the individual jars showed a loss of twelve, or less than 5 per cent. Allowing 5 per cent for loss from other causes, it appeared that above 85 per cent of the larvæ kept together in the large jar was destroyed through cannibalism.

It has been observed by Hine in other species that a Tabanus larva is enabled to survive for a few days in the absence of food. In this species, likewise, there seems to be a decided resistance to starvation, two instances showing periods of ten and twelve days.

Mitzmain found the movements of the body to be in general similar to those of larvæ of the muscid type. There is a general progressive peristaltic movement, invariably accompanied by a decided telescoping of the segments. The head is raised as the prolegs of the anal end push the body forward, then it is lowered. The mouth is projected when the head capsule is extended, but recedes quickly when the glass sides of the container or any obstacle is encountered. The larva can easily move backwards for a considerable distance. This it does if wedged in a tight place or in capturing food when it retreats into a channel previously made in the sand.

The larvæ readily adapt themselves to a watery medium. They can remain submerged for several minutes at a time without apparent discomfort. When placed in deep water the movements of the body consist of a general struggling without apparent definite purpose. At any rate, there is little or no progression, the body doubles like a bow, the head and tail meeting, then straightens with a whipping action. In swimming, the body is held along the surface of the water and the syphon is extended towards the air in a manner suggestive of the larva of an anopheline mosquito. The principal movement observed is that of simple telescoping of one segment into another. When speed is required or an obstruction is to be passed, there is a vigorous whipping movement of the syphon laterally, towards and away from the head. This latter movement is also noted when the insect is disturbed.

When a young larva is placed in water containing entomostracans or other minute animals, a barely perceptible churning of the liquid occurs in the region of the mouth. This disturbance is no doubt caused by the movements of minute tentacles which assist in procur- 
ing food. These tentacles form the armature of the stomal disk, consisting of a process arranged like a turnstile mounted on a pitted chitinous plate at the base of the great hook or mandible. In the very young larva the stomal disk appears as a chaplet of delicate chitinous rods. When a larva is treated with strong caustic potash, the stomal disk appears to be the only structure which resists its action, the other chitinous structures, even the heavy pharyngeal apophyses, are bleached. In common with the other chitinous portions of the head capsule the stomal disk is shed at each of the three ecdyses.

An account of the general development of the larva follows:

The young larva shows in its form and behavior its adaptability to an aquatic life. This is well illustrated when a larva is placed in an aquarium containing mosquito wrigglers. The Tabanus has no difficulty in keeping afloat with them and foraging at will upon the active culicid larvæ. Tabanus larvæ have been observed capturing wrigglers, holding them by their jaws under the water, and actually killing the culicid through drowning. In one instance a Tabanus larva held its victim, which was fully five times its size, suspended beneath it in such manner that the culicid was unable to project its syphon for breathing purposes, while that of the Tabanus was functional. The Tabanus, obtaining a secure perch by dragging itself and the prey above the water, devoured the mosquito wriggler in a few minutes. In another instance the weight of the culicid pulled its captor under the water to the sandy bottom a distance of nearly $30 \mathrm{~cm}$. Here the Tabanus showed its superior vitality by remaining attached for nearly. two minutes until apparently assured of the immobility of its prey, then, releasing its hold, the Tabanus larva struggled to the surface where it rested with syphon extended. The mosquito larva meanwhile moved feebly several times, and succumbed within a few minutes.

This adaptability is lost, however, in the developed larva which becomes more slothful in movement and grub-like in superficial appearance. Both extremities, the head and the syphon, become obtuse in form, and the ventral protuberances functioning as prolegs become more truncated. Growth after the second molt becomes noticeably less in length and more in thickness. The greatest growth 
observable was shown to be between the periods of the first and the second molts.

The following table is given by Mitzmain to show the normal growth of a larva. The measurements and the critical stages of life are indicated.

TABLE I.

Progress of Development of a Larva.

\begin{tabular}{|c|c|c|}
\hline Date. & Length. & Stage of development. \\
\hline Sept. 15 & 1.5 & At birth \\
\hline " 16 & 1.8 & 1 day old. \\
\hline “ 20 & 3.0 & \\
\hline " 21 & 4.0 & \\
\hline " 22 & 5.0 & - \\
\hline " 23 & 6.5 & \\
\hline " 26 & 11.0 & After first molt. \\
\hline “ 30 & 20.0 & \\
\hline Oct. 8 & 22.0 & \\
\hline 《 9 & 25.0 & Second molt. \\
\hline " 12 & 27.5 & \\
\hline 《 17 & 29.5 & Mature larva. \\
\hline “ 21 & 27.5 & \\
\hline 《 24 & 17.5 & Pupa, third molt. \\
\hline
\end{tabular}

In all biological accounts of the Tabanidæ there appears to be one phenomenon which is uniformly noted. This is the remarkable difference in growth shown by individual flies of the same species. The only process in the development which seems to be synchronous is the hatching of the eggs. After that the variations in time of development are extreme. In Tabanus striatus, for example, some larvæ twelve days old measured $3 \mathrm{~mm}$., while others under precisely the same conditions measured fully $11 \mathrm{~mm}$. In another instance two flies emerged as well developed imagos October 31, while twentyseven of the same brood still remained apparently healthy in the larval stage December 20.

Mitzmain is the first to mention molting or ecdysis in tabanids, stating that he has been unable to find, "in the very meager literature available," any reference to the molting process in Tabanidæ. It is referred to indirectly by King at Khartoum, who found in 
Tabanus biguttatus the shed larval skin adhering to the "puparium."' 26 Mitzmain had, however, not seen Paoli's work on the organ of Graber, in which also mention is made of moltings.

By Mitzmain the process of shedding the skin was observed in Tabanus striatus in a great many instances. The time of molting of a brood of larvæ is extremely variable, which is consistent with the great variations noted in the time of development in general. The process has been accurately noted in two individual larvæ, although observed superficially in numerous others. The three molts are similar in their general aspects, the main distinction being the more profound changes produced in the insect at the later molts.

The usual preparations for molting were observed in this species. The premonitory signs were the refusal of food, uneasiness when exposed to light, desire to find a remote corner, and finally the stiffening of the cuticle. In one instance the larva was found in one spot pressed against the glass for three days. Here, between the sand and the glass of the jar, an excrementous cement was used to fasten the end of the abdomen. This material holds the end of the body very securely, although the remainder of the body requires free lateral movement. By the time the ecdysis is completed, the head has moved $3 \mathrm{~mm}$. from the spot where preparations for the process were made, while the anal end has retained its original position.

The shedding of the skin usually requires several hours; in one instance, due no doubt to interference by the observer, the time was nearly twenty-four hours. In the first and second molts, splitting of the cuticle begins at the thorax, resulting in the tearing out of the entire head capsule which adheres to the molt during the remainder of the process. The anal segments are molted finally and the larva, emerging in its new skin, crawls its length on the cast skin and rests alongside it for two or more hours.

The first molt begins with larvæ 7 days old, the majority molting before the tenth day. The second molt usually occurs after an interval of at least four days, and in some larvæ as late as eight days,

${ }^{26}$ The use of the term "puparium" for the tabanid pupa should not be encouraged. The tabanid pupa is a true pupa, in contrast with that of muscids, or syrphids, where the true pupa is enclosed in the last larval skin, justifying the name puparium to differentiate it from a free pupa. 
when fifteen to eighteen days old. The time of the third molt precedes immediately the appearance of the puparium. This period, as has been noted, shows the greatest diversity among individuals of the brood. The third molt in twelve instances was shed between the ninth and twelfth days of life.

In other individuals the process was not completed within three months, yet the adult fly was an apparently healthy insect.

Certain unimportant changes in morphology, dependent on the molting process, are noticeable. The loss in size due to contraction of the cuticle preparatory to ecdysis is usually compensated by a substantia extension immediately following the process. The extent of shriveling of the cuticle is represented by $1 \mathrm{~mm}$. in the first molting, 1.5 to $2 \mathrm{~mm}$. in the second stage, and 2 to $3 \mathrm{~mm}$. preparatory to the third stage. There is a notable increase in length resulting from the second ecdysis. A larva, measuring $22 \mathrm{~mm}$. on the day previous to the shedding of the skin, measured fully $25 \mathrm{~mm}$. the following day. In measurements of this sort one must make allowance for the extraordinary amount of telescoping of segments. As much as 5 $\mathrm{mm}$. may be involved in this process.

The structures mainly involved in the ecdysis are the tracheal system and the appendages of the head. The anal ring of the trachea constituting the syphon is drawn off in each molt in a perfectly cylindric form. The body trachea is torn from its connections in irregular strands. The entire head capsule, including the chitinous pharyngeal framework, the great hook, and other mouth structures, are found in perfect form in the various exuviæ. These parts upon renewal in the larva become more heavily reinforced.

The exuvia (Plate 5, Fig. 81, $a, b, c$ ) is usually in a good state of preservation; crumpled, to be sure, but it can be extended in alcohol to three-fourths the length of the larva. Following each ecdysis, the larva is invariably leaden gray with tracheal strands of waxy white. Three anal segments including the syphon become leadcolored and stiffened in structure. They are at this stage more truncated, with an anal band of cuticle $1 \mathrm{~mm}$. in depth, making the syphon appear somewhat atrophied. This is no doubt consistent with its restricted function. The color of the viscera has changed from the brilliant red and yellow to an indeterminate white, and the 
lilac tint of the Malpighian tubules has changed to a salmon color. The latter changes are due probably to a clearing process, in which the larva indulges during the quiescent stage preceding each ecdysis.

After the second molt the fleshy protuberances functioning as prolegs become reinforced with a slight cuticular ring at their bases. The mouth-parts at this stage are heavily chitinized. The great hooks or mandibles show a marked serration of the biting edge. The head projects more, exposing the dark brown ocelli, which, prior to the second molt are seen only through the cuticle of the thorax situated nearly on the middle of the concealed head capsule.

The signs characteristic of the final molt which results in pupation are refusal of food, restlessness, attempted migration, and finally burial in the sand at the bottom of the jar. The body decreases slightly in length, but the thickness remains the same.

On the extremity of the abdomen, tiny tubercles appear which project more from time to time, becoming tapering and spike-like. Near the caudal end of the abdominal segments, roots of hairs appear. These at first resemble brown spots of pigment and gradually lengthen into stiff brown hairs. The cuticle on the body becomes stiffened and shingle-like at the joints of the segments. The latter telescope less, and one can see numerous particles of sand embedded in the joints of the segments. These sand particles have been carried in during the telescopic movements of the abdomen.

After the fully developed larva passes through a period of semidormancy buried in the sand, the skin is seen to be ridged with cuticular plates. The head region is reinforced by stiffened cuticle, and the mouth orifice is closed by a plug of hard rose-colored cut:cle. This pigmented material lines the entire pharyngeal sinus, plugging the mouth and the cephalopharynx. The cuticular plug has a substantial fold which forms a slit for the passage of the molting mouth. Caudally a similar impervious mass closes the opening of the syphon. A cuticular collar strengthens the base, and the connective tissue surrounding the trachea of the tract of the syphon tends to contract. Then the supports of the central trachea are gradually cast loose by a gentle wriggling of the insect's body. About this time there is a general wrinkling of the epidermis, the folds telescoping upon each other, and the surface becomes like parchment. 
Synchronous with the primary contraction of the segments, a light pea-green suffuses the last three segments of the body. The remainder of the larva changes to this color over night. By morning the abdominal segments have changed from green to ocher, when the molting of the cuticle ensues. The shedding takes place in sections. The chitinous framework of the head is thrown off like a hood. This portion is everted upon the body, and remains dangling from the exuvia during the process. One-half the length of the skin is loosened on the side opposite that to which the chitinous framework of the head is attached. This is shed by a peculiar auger-like movement of the tail end which is not attached to the glass or other object in the container, as in the previous molts. The skin is virtually unrolled from the detached head to the anal end, where it lies in a crumpled heap. Then the skin of the other side of the body begins to be shed. The chitinous framework constituting the former head capsule of the larva becomes rolled up in the exuvia, while the skin is torn slowly from the new membrane. When the first half of the skin is peeled off to the anal tip, the cast skin becomes attached to some object. In this instance the glass of the jar served as an anchorage during the remainder of the ecdysis.

The upper half of the body of the newly molted larva is encased as in an armor in pouches and pads of integument, outlining in a gauzy film the future appendages of the fly.

Mitzmain's description of the full grown larva (Plate 5, Fig. 80, c) is given below:

"The length is 28 to $29.5 \mathrm{~mm}$.; the width, 3 to $4 \mathrm{~mm}$. The anterior half of the body is a greenish yellow, the remainder is a dirty white. At this stage the form is grub-like."

"The head capsule, which occupies one-fifth the length of the larva, is a cylindrical bulb, formed by the invagination of the thoracic ectoderm. It supports the eyes, the antennæ, and the mouth parts. It is bound by a framework of chitinous rods, the cephalopharyngeal apophyses. This structure, observed through the thorax when the insect is in action, is composed of four black, medium-thick, skeletal pieces running the length of the three cephalic segments in the form of a pyramid, with its apex provided with the external mouth parts. It terminates in the claw-like mandibles which are similar in color and texture."

"The mandibles [Plate 5, Fig. 79] are heavy, powerful structures, slightly serrated on their inner surfaces. The musculature of these appendages permits the 
two elements working in apposition. At rest they are held horizontally, and can be projected suddenly and thrust vertically downward, which is obviously of great assistance in grasping the prey."

"The palpi and antennæ in this species are silvery white, and usually found glistening with moisture."

"The eyes are oval in shape, with the long axes parallel. When the larva is prepared to molt, the pigmented spots are usually distorted. In this species the eye spots or ocelli are very prominent, especially in the younger stages of the larva. They can be first seen in the embryo where they appear as dark beaded structures through the chorion of the well developed egg. In the young stage of the larva the eyes appear in the pharyngeal cavity midway between the mouth and the cephalopharynx, and as growth continues they are located nearer the distal end of the head capsule; so that when the larva is full grown and the mouth structures protrude in locomotion or prehension the eye spots are seen to project on the head capsule with the mouth parts."

"The trachea which terminates in the conical tubular syphon is lead gray in contrast to the dense white of that portion anterior to the anal segment. Anterior to the syphon there is a cuticular cellar of slightly darker shade."

"The prolegs are formed by truncated projections, six in number, three on each side of the midventral line and extending laterally. Each protuberance is provided with a tuft of short, fine, brown hairs. These hairs appear to be surrounded by a secretory substance, which is slimy in character."

"At the base of the syphon, beneath the cuticle on the dorsal side opposite the anal capsule, is a tiny structure which attracts attention on account of its movements and peculiar arrangement. In the newly hatched larva it is a process composed of four lustrous black disks arranged in two pairs, one in front of the other, and set in a mass of fat bodies. The larger of the disks, the anterior pair, is less than $0.1 \mathrm{~mm}$. in diameter. The movement of the process is similar to that of a pendulum, and is active only when the larva moves. With each molt these disks become smaller and increase in number. In the full grown larva the process becomes a triangular mass of loosely arranged beaded disks. They appear to be mere specks of pigment beneath the skin, but their structure and action are so constant that either the process is characteristic of the species or investigators have overlooked or ignored them in other species."

The description of the pupa (Plate 12, Fig. 152, $a, b$; Fig. 143, $a$, b) after Mitzmain is given below:

"The average length is $18 \mathrm{~mm}$., and width, $3.5 \mathrm{~mm}$. The color is pale brown, the last 2 segments of the abdomen being slightly darker. The head tubercles are not clearly defined; color, dark brown. The prothoracic spiracular tubercle is slightly elevated, oblique; rima, salmon-colored and crescentic in form."

"The first abdominal spiracle is perfectly round and larger than the others, which are slightly ovoid; the rima of all the spiracles curves from above posteriorly." 
"The terminal abdominal segment [Plate 12, Fig. 143, $a, b$ ] shows a sexual distinction in the arrangement of the short spines midway on the ventral side, anterior to the terminal teeth. In the male ten to twelve of these spines form a continuous serrated border. In the female the spines occur in two groups of four to six spines similar to those of the male, but separated by space equal in width to that of one of the groups."

"The terminal teeth of the posterior segment are arranged with two pairs close together on the dorsal side and one pair on the ventral side. These teeth are black-tipped and acute; all of them are directed slightly outward. The lateral teeth of the two dorsal pairs are the longest. The ventral pair is smaller and is set slightly in from the periphery of the segment."

"After the final ecdysis which results in the formation of the puparium, the nymph, at first a light green, gradually changes to yellow. Upon the second day, the eye spots change from yellowish to pale brown, then to a chocolate color. Beginning with the third day the pads of the wings and the legs, at first light brown, assume the same color as the eyes. The chitinous pad enveloping the wing is densely opaque, so that only the plications of the developing wing can be discerned. Upon the penultimate day, the fifth or sixth usually, the abdomen, which heretofore has been a uniform yellow-brown, becomes striped with light orange and brown, which colors gradually deepen until the time of emergence."

The process of emergence from the puparium is also described by Mitzmain (Plate 12, Fig. 152, b):

"In emergence, the puparium which lies buried to some depth in the sand is invariably dragged to the surface where the final acts of emergence are completed. Two or three days prior to the act of emergence, the puparium shows considerable mobility when disturbed by handling or stimulated by light. Certain movements, which one learns through numerous observations to be characteristic, can be considered as actually premonitory. These occur usually from ten to twenty minutes prior to the breaking of the cuticle, and serve the observer as warning signs. If during this interval a low power lens is focussed on the compound eye, the epidermis of the fly separating from its connective tissue fastening of the puparium can easily be seen. This action resembles strikingly a wave of water moving between the walls of the puparium and the epidermis of the fly. It may be considered as the movements of a semiliquid layer between the fly and its puparium. Another movement, which can be observed within a few minutes after that previously described, is the momentary contraction and expansion of the sides of the abdomen between the two lateral ridges. This too, no doubt, is effective in tearing the connective tissue lining to facilitate emergence. A few minutes later the anal end of the abdomen is torn loose from its fastening, and emergence of the fly begins." 
Since the puparium is unrolled from the head, the compound eyes are soon exposed to view, so that the sex of the fly may be distinguished. The appendages, antennæ, palpi, and mouth-parts are dimly visible. The head appendages are freed primarily by the spasmodic wriggling of the abdomen, but the labellum, which is seen to become turgid and flaccid in turn by the injection of air into, and withdrawal of air from, the "extensive tracheal sacs which lie in the cavities," and the erectile stomal disk through the pressure downwards against the walls of the puparium, assist also in the process. That these head appendages assist effectually in the emergence is evident from the lines of cleavage in the enveloping membranes.

The puparium splits on the median line of the thorax; simultaneously the hood enveloping the head drops by a sternal hinge. The labellum can be seen still pressing upon the interior of the hood as the head emerges. In a minute the wings are rent from their envelopes by the sturdy pressure of the legs, which have slid out of their sheaths simultaneously with the cleavage of the thorax. The legs directly assume their normal position, and the fly walks forth bodily, spreading its plicated wings. The liberated wings show a clear expanse of unwrinkled membrane which at first is soft in texture and clear lead-colored throughout. Finally the inflated abdomen appears in the dorsal slit, and at once is drawn clear of the encumbering puparium.

The time from the appearance of the head to the evacuation of the puparium requires less than two minutes. This time is increased a minute or two whenever the wing sticks to the lining of the puparium, resulting usually in a torn wing.

Directly after emergence the wings are shorter than the body, but, constantly vibrating, they gradually lengthen, whereupon they become hardened and prepared for flight. The fly does not spend any time preening itself, as is the case with some of the Muscidæ at this stage. The time prior to flight is spent, however, in a clearing process. This begins with a copious discharge of meconium within three to five minutes after emerging. At first the defecation is performed at least five times per minute, then once per minute for a period of twelve minutes. At the end of this time the excretions become more watery in character. In the meantime the fly walks 
about in a restless manner, constantly vibrating the balancers and flapping its wings, while the distended abdomen becomes reduced to more normal proportions.

The meconium, which is deposited in large quantities, is pale brown in color, rapidly changing to amber, then becoming clear. The primary, heavier excretion appears decidedly oily in nature, when examined with the microscope.

In from fourteen to twenty minutes, voluntary flight takes place. This is at first tentative, the insect alighting upon the floor about a meter distant. After a minute of rest, flight is resumed, the fly escaping through the open window.

The puparium left behind shows certain points of cleavage which prove to be very constant. There is a dorsal slit on the median line of the thorax which extends nearly the length of the notum. Another slit extends midway across the orbital region through the genæ to the wing pouches. A third slit extends between the two wing envelopes, and a slight one behind the prothoracic spiracular tubercle.

In the thirty-two emergences recorded, the males preceded the females by an average of half a day. The males spent from three to seven days in the pupal stage, averaging five and one-half days, while this period required four to nine days with an average of six days in the female flies.

Bainbridge and Fletcher (1914) observed Tabanus striatus near Madras, and give the following statements which may serve to complement Mitzmain's work in as far as it seems based on field observation:

"Eggs are laid in a large mass, usually on a leaf or twig overhanging water into which the young larvæ drop on emergence, thence-forward leading an aquatic life burrowing in the mud at the water's edge and feeding on worms or living or dead insects. The full grown larva is 40 to $50 \mathrm{~mm}$. long, dull whitish, elongate, tapering at each end with protuberances at the edges of the segments. When full fed it leaves the damp mud at the water's edge and after a quiescent period pupates in the earth above water-level."

An egg mass of Tabanus striatus on a paddle leaf is figured (Plate 2, Figs. 22 and 23).

Patton and Cragg state that Tabanus striatus oviposits as a general rule on blades of grass, pieces of stick, etc., at the edge of a river, stream, or pond. 
The larvæ are said to be powerful swimmers having air sacs connected with their tracheal tubes, so that they can float or sink at will.

Large numbers of egg masses are regularly destroyed in Madras by a small chalcid parasite which was not identified.

The eggs are brownish white when deposited (Patton and Cragg).

Tabanus stygius Say.-A species of the Middle and Southern States, recorded from Massachusetts, New Jersey, Illinois, Ohio, etc., the life history of which is comparatively well known through the observations of Hart (1895) and Hine (1906).

On its oviposition and egg Hine is the first to give us information. The species oviposits principally on the leaves of Sagittaria standing in shallow water, habitually placing the eggs just above the point where the petiole meets the expanded part of the leaf (Plate 1, Figs. 3 and 4). ${ }^{27}$ The precision with which this habit is followed becomes a matter of interest. Out of hundreds of masses of eggs observed, only a few were placed on other species of plants or in a different position on the leaf (Plate 1, Fig. 5). The female is occupied for a half hour or more in placing the several hundred eggs composing a single mass, and during this time the observer can take a position close by and watch the proceedings without frightening her away, but species of Tabanus are more particular about the approach of intruders than are various Chrysops.

The egg mass is white when first placed but soon turns brown; it is convex, and is composed of about five layers, one above the other. Individual eggs are nearly the same size as those of Tabanus atratus, and are similar to them in form. Hatching as observed, occurred in seven days after oviposition. From a careful study of microscopic sections of eggs killed as soon as laid, it was concluded that development does not begin until after oviposition, consequently the time given is the entire incubation period.

When first hatched the larvæ contain a considerable amount of unused yolk, which furnishes them food for a time; it is therefore unnecessary for them to eat anything for a few days. This is ad-

${ }^{27}$ The leaf represented in Fig. 4, is a leaf of Peltandra, similar in shape to the Sagittaria leaf (Plate 1, Fig. 3). 
vantageous no doubt, for food is not always at hand, and in case it is not, the fact that nourishment is furnished naturally gives them an opportunity to investigate their surroundings.

At hatching time nearly all the larvæ that come from a single mass of eggs appear at the same time and when they have freed themselves from the shells, go tumbling down into the water, scattering more or less and sinking to the bottom, where it is difficult to observe their further actions.

Hine found that small catfishes (Ameiurus melas) are enemies of these larvæ, and he observed two of them devour 200 young larvæ of Tabanus within a few hours.

Hine's attempt to rear the larvæ from the egg to the adult was not successful. On July 21, a number of larvæ just hatched were placed in a breeding jar containing damp sand covered over the top with fine plant material, and small crustaceans were put in for food. The larvæ took kindly to the surroundings, accepted the food offered, and began to grow at once. After about two weeks, as angleworms were much easier to obtain, these were substituted for the crustaceans, with no bad effect on the larvæ, which continued to grow, though rather slowly. The largest attained a length of about $10 \mathrm{~mm}$. by the beginning of winter, when they ceased eating. They appeared to be in good condition in the spring, but for some reason died without further increase in size.

On August 2, of the same year, Hine took a large larva of this species in Summit County, Ohio, from under a flat stone along a brook that ran from a spring. When taken this specimen measured over $40 \mathrm{~mm}$. in length and had every appearance of being mature, but it continued to eat the angleworms given it until late in the fall. It then ceased feeding until the following spring, when it took a small amount of food and entered the pupal stage about the middle of May, the adult, a male, issuing June 14.

Hine thinks that it is hardly possible that this species passes all its transformations in a single year, for the larvæ reared from eggs were not over $8 \mathrm{~mm}$. long when the specimen over $40 \mathrm{~mm}$. long was collected; and as the latter did not produce the adult until about the normal time for adults to appear under natural conditions, it does not seem possible that the first mentioned larvæ could have reached maturity and produced adults before the second year. 
The young larva is briefly described by Hines as follows:

"Larva, when first hatched, $4 \mathrm{~mm}$. long; entirely light colored; form as in older specimens. As growth continues size is the only noticeable change."

The mature larva has been figured and described in detail by Hart (Plate 3, Fig. 40). This species was the most abundant tabanid larva found in the vicinity of Havana, Illinois, in the spring of 1895. It first appeared in Hart's collections September 14, 1894, when a number were noted swimming among vegetation near the margin at Station B, on the wet springy shore of Quiver Lake, with sandy and muddy ground, grass, and coating of algæ. In the spring they were, however, found at nearly all of the stations, but more particularly in connection with tipulid, muscid, and Eristalis larvæ in matted accumulations of dead stems and leaves over mud. They were especially abundant on March 30 in Flag Lake, where large plump larvæ appeared at every turn. It was a surprise to find a few of them upon the bottom in the open shallow water, far from shore, in the middle of Quiver Lake at Station A, for which locality Hart gives the characteristics: "Shallow, mud and sand, grass and floating vegetation, variable." Young larvæ have been common in connection with larvæ of Bittacomorpha and Limnophila, at Station I (see Tabanus atratus) since March 17. At others of Hart's stations they have been common in moist drifts of fine rubbish washed up by waves. Pupæ were formed in the breeding cages May 10 and 23. One emerged May 27, and another tried to emerge June 2, but died and was removed from its case.

The làrvæ of Tabanus stygius resemble, according to Hart, those of the lineola group in their striation and coloration, but differ in their short lateral prothoracic areas and larger size. They are like atratus in size, but may be readily separated from it by their coarser lateral striation, straw-yellow tint, slender lateral pigmented stripes, and usually projecting terminal stigmatal spine.

Hart's description of the mature larva follows:

"Larva.-[Plate 3, Fig. 40.] Length 45-55 mm., diameter 6-7 mm. Bright straw-yellow, varying in some young larvæ to nearly clear white; marked with light fuscous brown microscopic pubescence, usually paler at each stage than atratus." 
"Lateral prothoracic striated areas are not more than half as long as the dorsal, striation not finer than that of the middle and lower lateral areas of the mesothorax, striated portion shining; a small smooth spot adjoining the impressed line below; remaining upper lateral thoracic areas a little less coarsely striated, but not strongly different from that of the prothorax; abdominal lateral areas a little more finely striate; dorsal and ventral areas with margins striated, disks nearly smooth in adult larvæ, last segment more strongly striate, especially beneath."

"Dark annuli distinct, broad, including false feet, a distinct transverse dorsal and ventral pale spot in front of the false feet; abdominal annuli often with a small triangular backward prolongation on median line above. Prothoracic lateral space occupied by a pale brownish fuscous quadrate spot in front of the striated space. Meso- and metathoracic lateral stripes usually distinct, but slender, scarcely dilated posteriorly, lateral edges of dorsal areas diverging; lateral stripes of abdomen almost wanting, except on last two or three segments. In these stripes the punctures of the upper and lower rows are indicated by rounded pale dots, and those of the inner rows by elongate dots. Last segment with bases of respiratory tube and anal prominence encircled with dark rings; joined by a lateral connection, its dorsum with at most a short basal line or pair of dots on each side. Coarser pubescence of false feet tipped with pale brownish."

"Main internal tracheæ thick and noticeable, especially in young larvæ, lustrous, subparallel, not strongly sinuate, nearly straight posteriorly; terminal stigmatal spine dark reddish brown, smooth, usually protruded."

The pupa (Plate 11, Fig. 125; Plate 13, Figs. 153 and 161) has been described by Hart as well as by Hine, both of whom reared the adult from pupæ obtained from adult larvæ taken in nature. The following is Hart's description.

"Pupa, female.-Length about $30 \mathrm{~mm}$., diameter about $6 \mathrm{~mm}$. Light brownish fuscous, thorax paler, shining, abdomen roughly transversely wrinkled, and subopaque. Palpal sheaths distinct, as far apart as are the setæ borne by the larger tubercles at the center of the anterior surface of the head [Plate 13, Fig. 153]; surface between them rounded, bearing a small wrinkled tubercle at middle; antennæ and tubercles darker than surrounding surface; ocellar tubercles distinct; prothoracic spiracular tubercles slightly but evenly elevated in a plane parallel to that of the surrounding surface; rima nearly straight in its outer half, inwardly curving strongly forward, and ending in a conspicuous hook; free margin of tubercle rounded at tip."

"First abdominal with two distinct setæ each side above the spiracles; abdominal spiracular tubercles rounded, broad behind, low-subhemispherical, rima long, following posterior border "of tubercle, slightly curved at middle, more strongly curved forwards at each end; on anterior surface a transverse groove extending across the tubercle, but not as long as the rima. Fringes of unequal 
spines, often tipped with blackish, all but two of the long spines wanting in a broad space above on seventh segment. Terminal teeth [Plate 13, Fig. 161] nearly equal, tipped with blackish, their points marking the angles of a hexagon, slightly wider than high. Ventral fringe of last segment not webbed together; lateral tufts high-on a level with upper lateral line."

Hine's description is shorter:

"Pupa [Plate 11, Fig. 125] $29 \mathrm{~mm}$. long; color dark, approaching fuscous; prothoracic spiracle strongly bent at the middle; rima oblique and straight for the outer half of its length, remainder gradually curved, with a broad hook at the inner end. Teeth at the end of the abdomen [Plate 13, Fig. 161] six in number, nearly equidistant from one another, of nearly the same size, with the extreme tips slightly turned inward."

The pupa of stygius is, according to Hine, much like that of sulcifrons, but there is some difference in the prothoracic spiracles and in the abdominal teeth.

Tabanus sulcifrons Macquart.-A North American species inhabiting Pennsylvania, New Jersey, Ohio, Illinois, and Louisiana. Closely related to Tabanus exul and abdominalis, and like the two latter, appearing late in the season, in Ohio abundant in the latter part of July and all of August, in Louisiana recorded from September 7 to October 16.

Hine has made many interesting observations concerning the habits of the adult flies of this species, but was unable to work out its life history. Although the eggs were procured in many stages of development by dissecting the females, the habits of oviposition have not been observed. The form of the eggs and the number produced by a single female are the same as in other species of its size. Specimens containing eggs almost fully developed were taken in various places, but Hine could not get any clue as to where oviposition occurred by dissecting the females where they were collected, as he had hoped to do.

The pupal case of the species was procured by locating a female which had just emerged. The place where this pupal case was taken was on a side hill, about 75 feet above the bed of a small stream. The description follows: 
"Pupa.-[Plate 11, Fig. 126; Plate 13, Fig. 165.] Length 26 mm., diameter $6 \mathrm{~mm}$. Color yellowish brown, the thorax being nearly the same color as the abdomen. Tubercles of the head region well marked and distinctly darker than the surrounding parts. Prothoracic spiracular tubercle brown in color, elevated, narrow, ventral half oblique, dorsal half turned directly forward, thus forming a distinct bend near the middle of the length; rima nearly straight from outer end to the middle and evenly curved for the remainder of its length, inner tip curved backward, thus forming a well-defined hook. First abdominal spiracle nearly round; its rima following the posterior curvature, very narrow, but a little widened above; remaining abdominal spiracles a little smaller than the first one, each with a short, slightly curved or straight rima. Terminal abdominal segment [Plate 13, Fig. 165] with several small spines near the middle of its length and six larger spines at its apex. These spines are all brown in color, with the apex of each approaching black. Six apical spines of nearly the same size; the dorsal pair point upward, outward, and slightly backward, the lateral one on each side outward and backward, while the ventral pair extend almost directly backward. These six spines mark the corners of a hexagon with nearly equal sides, but the ventral pair are a little nearer together than the dorsal pair."

This appears to be all that we know about the early stages of this species. From the place where the pupa was found, the larva appears to be terrestrial in habit, like that of Tabanus fronto, but one should bear in mind that possibly the young larva is aquatic and leaves the water at a later stage of its development.

Tabanus taniola Palisot de Beauvois.-This species is, according to King, the most common and most widely distributed tabanid found in the Anglo-Egyptian Sudan, and the most frequently accused of causing the death of camels. Occurring on the White Nile as far north as Dueim, stray specimens have occasionally been taken in Khartoum. King was able to secure oviposition in captivity in this species as well as in Tabanus par, and has described the egg and larva. The pupal stage is not known.

In order to secure eggs, gorged females were taken in May, on cattle grazing near Bor, and placed in a breeding cage with a dish containing grass and weeds growing in mud and water. They were fed on sugar and water, and a few batches of eggs were obtained. A single egg batch was taken in May on a blade of grass overhanging a dried up water pool near Kanissa wood-station, and a number of batches of eggs were collected early in July from grasses and weeds overhanging rain pools at Gebelein. 
The eggs (Plate 1, Figs. 8 and 9) are placed by the female fly on the upper side of a blade of grass or some similar plant, and, with the exception of the single batch taken at Kanissa wood-station, all those found were overhanging water. An unfinished batch of eggs resembles an arrow-head. The eggs are closely applied to each other and left bare, so the batch can easily be seen when freshly laid, owing to its shining white to yellowish white color. Prior to hatching, the egg mass becomes darker. According to King, "the egg is spindle-shaped, about $1.75 \mathrm{~mm}$. in length and, when first laid, is white in colour. It becomes darker as the embryo within develops."

The eggs obtained in the breeding cage were laid on May 24 to 25, and hatched on May 29. This would correspond to the very short incubation period of four to five days. The larvæ (Plate 1, Fig. 9, a) were placed in glass basins containing mud, growing grass, and water, and were offered the expressed stomach contents of female ticksRhipicephalus simus - taken from a dog. They fed readily on this until June 11, when they were placed in clean river sand and water, and their diet was changed to mosquito larvæ. These mosquito larvæ were either killed or laid living on the wet sand out of reach of the water, in which position the tabanid larvæ were able to kill them. In water the mosquito larvæ were too active to be caught. On July 16 their food was changed again to freshly killed and bruised earthworms, and these they also ate readily. While still young they became vicious cannibals, and consequently each larva had to be given a separate dish. They were brought to Khartoum on July 19 and a few days later it was noticed that the majority were not taking their food. They were then nearly if not quite full grown, so it was thought that they had buried themselves in the sand prior to pupating. A thorough search, however, revealed the fact that they had disappeared, and it was not until later that mice were identified as the cause of the loss. The two remaining larvæ were then killed and preserved. It is possible, therefore, that the larva described by King is not quite mature.

The larvæ of Tabanus taniola are more active and ferocious than those of Tabanus par, vigorously attacking any other larva with which they may come in contact. They have not, however, the power possessed by Tabanus par of lying dormant in the soil for at 
least fifty-seven days if the conditions are unfavorable for their development.

King describes the larva somewhat as follows:

"The larva [Plate 3, Fig. 49], when fully extended, measures about $29 \mathrm{~mm}$. Color white to grayish white, mandibles black. On the anterior third of each abdominal segment, except the eighth, is a ring of pseudopods, eight in each ring - two dorsal, two lateral, four ventral-except on the first abdominal segment, where the dorsal pair is wanting. On the second abdominal segment the dorsal pair is very strongly developed. The ventral pseudopods ${ }^{28}$ are always larger than the dorsal. Each pseudopod bears a crown of colorless spines or hooks, and between the pseudopods there are also spines or hooks, often darker in color, and forming a continuous ring. The anus is situated ventrally at the base of the eighth abdominal segment and is edged with dark hairs. On either side of the anus is a patch of dark hairs, roughly kidney-shaped, and beyond each patch, laterally placed on the segment, are two small round spots of dark hair. The syphon tube consists of two segments, and when exserted is shorter than the eighth segment. The whole surface of the larva is more or less shiny, with varying longitudinal striation, the areas bearing very fine striæ being markedly duller than the rest. The prothorax has the dorsal area smooth in the anterior two-thirds and rather coarsely striate posteriorly; the ventral area is almost entirely smooth and divided in two by a medium furrow; the two lateral areas are finely striated in the basal third and more coarsely so in the anterior parts. The mesothorax has the dorsal and ventral areas smooth and shining in the anterior two-thirds, and rather coarsely striate posteriorly, the ventral area having no furrow; the lateral areas are a little more finely striate than those of the prothorax, and there is a rather broad dull non-striated band at both the anterior and posterior margins. Similar dull bands occur on the metathorax and the abdominal segments, but completely encircling the segments. The abdominal segments 1 to 7 have the dorsal and ventral areas moderately shining, and the striation is rather coarse and irregular; the lateral areas appear much duller, owng to the extreme fineness of the striation. On the eighth abdominal segment the strix are moderately well marked and of similar appearance on all the faces."

The pupa of Tabanus taniola is not known. From the egg mass a natural enemy parasite was obtained by King, adding hereby one more example to the cases of egg parasitism observed in tabanids. These small Hymenoptera were bred from an egg mass of Tabanus tcniola, taken at Gebelein. The species had not yet been identified at the time when King's report appeared, but figures were given, together with the parasitized egg mass, showing the exit hole of the

${ }^{28}$ See p. 108 , foot-note 18. 
parasites. To judge from the illustration it might be a species of Phanurus, but as the figures are life size, not much can be seen of structural details.

As elsewhere in tropical Africa, this is probably the commonest species of the genus in the Mlanje district, where Neave bred it also from larvæ.

The larva is, according to Neave, chiefly remarkable for its white color and lack of pigment, and for the presence of a row of bristles immediately anterior to the anus. It is one of the most active and restless species Neave had to deal with.

Tabanus (Neotabanus ${ }^{24}$ ) triangulum Wiedemann.-This Brazilian species was reared by Lutz, at Manguintros, Brazil, in February, 1914, from full grown larvæ, which were obtained by sifting the mud from the edges of a small brook (together with those of Neolabanus ochrophilus), and breeding in damp moss. No morphological differences were observed between this species and Tabamus ochrophilus.

Tabanus trimaculatus Palisot de Beauvois.-A species occurring in the middle and southern states west to Kansas (Hine). We possess very few'data on its early stages.

Hine mentions (1903) that he has been in possession of the eggs, in connection with his studies on extermination of tabanids by collecting and destroying the eggs. By counting it was found that twenty egg masses of Tabanus trimaculatus averaged over 500 eggs each.

Brimley found, on April 15, 1909, two larvæ of Tabanus, under the bark of a soggy log which was an inch or two above the water. One died; the other was put into a bottle with some wet dirt and rotten wood, and "from this a male of Tabanus trimaculatus was bred on May 18 of the same year. The larva that died and which was presumably the same species was preserved in alcohol. It measures $37 \mathrm{~mm}$. in length and is white without markings." ${ }_{29}$

Tabanus tropicus Linné.-A species found in Europe (Laibach and Trieste, according to Schiner), but also in India (same species?) and here said to be a carrier of surra (Neveu-Lemaire).

${ }^{29} \mathrm{In}^{*}$ the meantime, I have repeatedly found the larvæ in Princeton (1917) and bred the adult. 
Scholtz (1850) reports that he has found the pupæ, together with those of Tabanus autumnalis and of Hamatopota pluvialis in the neighborhood of Breslau in June, 1850, at the edge of a pond covered with Lemna, the water of which was polluted from manure piles surrounding it. The pupæ were found near the edge under a thick mass of moist Lemna, together with Stratiomys - and Syrphuspupæ; $; 30$ the flies hatched after a few days.

Tabanus ustus Walker.-An African species, observed by Neave in enormous numbers around a pool in a nearly dry stream bed, on the plains in Portuguese territory, southern Nyasaland.

One male and three females were bred in the laboratory at the end of October and beginning of November. The larva, of which the terminal segments are figured (Plate 5, Fig. 66), resembles that of Tabanus biguttatus, but is less pigmented.

The upper hooks of the pupal aster are considerably larger than the remainder. The spines of the dorsolateral comb are much reduced, especially in the male.

The pupal aster of the male and the dorsolateral comb of both sexes are figured (Plate 14, Fig. 177, $a, b, c$ ).

Tabanus variabilis Loew.-An African species, not rare near Mt. Mlanje, southern Nyasaland, on wooded streams in the neighborhood of the mountain in October and November, occasionally later.

The larvæ were found in this locality by Neave, in abundance. They are entirely different from those of Tabanus atrimanus, being almost colorless, though in quite mature individuals the base of the syphon and the syphon itself are of an orange color. The most striking peculiarity of this larva is, however, the presence of a distinct papilla of a dark color on each side of the anal segment. This is easily recognizable in life and distinguishes this species from any other seen by Neave. The anus is also unusually prominent.

The pupa is also remarkable for its dark coloration, especially on the dorsum of the thorax. The aster is characterized by the large horizontally extended middle pair of hooks, and its outline is therefore entirely different from that of the closely allied Tabanus atri-

${ }^{30}$ See also pp. 72 and 91. 
manus. The dorsolateral comb consists of a few short and rather stout spines.

Figures are given of the syphon of the larva (Plate 5, Fig. 70), the pupa (Plate 12, Fig. 138), pupal aster, and dorsolateral comb of both sexes (Plate 14, Fig. 176, $a-d$ ).

Tabanus virgo Wiedemann.-A small species, recorded for Bengal and South India. On its early stages we possess notes through the work of Patton and Cragg.

As in all the small tabanids observed by these authors, the eggs are laid on blades of grass just at the edge of a shallow stream, or on the leaves of the lotus plant at the edges of small ponds, but never over deep water. The larvæ, as in the other small species, are said to have no air sacs, and to die when falling into deep water.

The mature larva of Tabanus virgo is figured by the same authors (Plate 4, Fig. 63). Attention is called to the openings of the trachex being flush with the body. In fact the syphon is extremely short when compared with that of Tabanus bicallosus, while as shown in the figures, in Tabanus ditcniatus it is of medium length. On the figure given, the larva of Tabanus virgo shows no striation or color pattern, but the mouth-parts appear larger than in the other species, and the prolegs are large, fleshy, and somewhat modified.

A small egg mass of this species is figured (Plate 1, Fig. 16) as laid on a dry twig, and consisting of only five eggs, attached to a twig which in fact is much smaller in diameter than the eggs themselves.

The pupa is figured (Plate 11, Fig. 134) by Patton and Cragg, and in addition, an enlarged figure of the eighth abdominal segment of the pupa is given (Plate 12, Fig. 146), showing the six terminal teeth and their arrangement.

Tabanus vivax Osten Sacken.-A North American species which apparently is never very plentiful, but has been taken in a number of the eastern states (New York, Maine, Ohio, etc.). In Ohio it is on the wing during the last half of June.

The life history has been worked out by Hine. The eggs are deposited in masses composed of several hundreds, on stones that project above the water in riffles of streams. The egg mass is nearly round in outline, only slightly convex, composed of about three 
layers one above the other. The color of the whole mass is brown, mottled over the top with white. In these respects they do not differ in particular from the eggs of other species of the genus, but the masses observed were not so convex as those of Tabanus atratus, and being placed on stones of a color similar to themselves are rather difficult to see. Females have been observed ovipositing as early as June 8 , but most often eggs are deposited after this date.

The larvæ (Plate 3, Fig. 43) occur in the streams in the fall. Hine states that in September and October each year they collected the larvæ of the dobson-fly (Corydalis cornuta L.) for study in the laboratory. By turning stones at the edge of swift riffles, or by means of a net stretched across the riffles to catch such specimens as are dislodged by turning stones behind the net in the stream, in addition to Corydalis larvæ, a large number of the larvæ of this horse-fly were found. Though having done much collecting in streams, Hine asserts that the larva of Tabanus vivax is the only tabanid larva taken in riffles so far. It was not found difficult to rear these larvæ. Larvæ taken late in the fall were placed in damp sand and fed on angleworms. As winter approaches they refuse to eat and remain quietly in the sand until the following spring; then they feed actively for a few days and change to pupæ. They reach the adult stage in late spring or early summer. Like other tabanid larvæ, the larvæ of Tabanus vivax are not particular as to their food; all that appears to be necessary is that they obtain small soft bodied animals. Crustaceans serve them as well as insects and their own species as well as some other species-whatever, in fact, is in the sand of the breeding cage.

Hine has never observed the larvæ in nature in the spring; consequently their habits at this time of the year are not exactly known, but Hine supposes that they leave the water and pupate in the earth near at hand.

Hine's description of the larva and pupa follows:

"Larva.-[Plate 3, Fig. 43.] When full grown, about $25 \mathrm{~mm}$. long. General color yellowish white, anterior margin of each thoracic segment and a narrow band, including the prolegs, on the anterior half of the first seven abdominal segments opaque, and appearing darker than the other parts, which are more or less shining and usually finely striate longitudinally. Prothoracic segment di- 
vided by longitudinal grooves into four nearly equal parts, which may be called the dorsal, ventral, and lateral areas. The lateral areas are shining and finely striated on the posterior third and opaque on the anterior two-thirds; the dorsal and ventral areas are opaque on about the anterior fourth and distinctly shining on the remaining parts. The ventral space is plainly divided into two equal parts by a longitudinal groove. In order to see the character of this segment, it must be fully extended. The mesothoracic and metathoracic segments have a number of longitudinal grooves, some of which are very narrowly bordered by opaque darker coloring, which proceeds backward from the narrow anterior border of these segments. Each of the first seven abdominal segments has on its anterior part a transverse row of eight tubercles which encircles the segment. These all bear short spines or claws at the apex, excepting a dorsal pair on each of the first three or four segments. They may be called prolegs, since they have the parts necessary to such organs and, what is more, are used as prolegs. On the posterior dorsal border of most of the abdominal segments there may be a narrow, irregular, opaque marking of the same color of the narrow band in the region of the prolegs; eighth segment on each side with two narrow, curved markings which have the appearance of being composed of contiguous punctures. These markings are of the same shade of color as the other darker areas, and the lower one is more than twice as long as the upper."

"Pupa.-[Plate 11, Fig. 128.] $18 \mathrm{~mm}$. long and $4 \mathrm{~mm}$. in diameter. Light brown in color, thorax somewhat paler than the abdomen. Antennal and other tubercles of the head and thorax prominent and darker than the surrounding parts. Prothoracic spiracular tubercle slightly elevated, reniform, oblique; rima uniformly curved for nearly its whole length; but just before the anterior end the curvature is stronger, although no hook is formed. First abdominal spiracle nearly round; rima almost uniformly curved, posteriorly very slightly widened just at the end, anteriorly slightly narrowed and curved so as to form a short hook. The other abdominal spiracles agree with the first one in general, but there is slight variation in the enlargement and curvature of the extreme ends. Terminal teeth [Plate 13, Fig. 160] prominent, shining brown in color, darkest at the extreme tips. Dorsal pair of teeth smallest and closer together than the ventral, lateral teeth longer and larger than the ventral and located much beneath the dorsal, in fact they are nearly midway between the dorsal and ventral." 


\section{UNIDENTIFIED SPECIES OF TABANUS.}

Tabanus sp. Nos. 1 and 2.-Following Mann's observations, Kollar succeeded in finding freshly laid eggs of another species of Tabanus, which was not determined, in a damp meadow at Dornbach near Vienna, of which, after nine days, similar larvæ hatched as were obtained from the egg masses from Wippach, of Tabanus quatuornotatus. Kollar also found a parasitic wasp ovipositing in the Tabanus eggs; this wasp was found to be specifically different from that obtained from the eggs of quatuornotatus.

At about the same time eggs of another undetermined species were found by Hofmann, quoted by Kollar. No descriptions are given.

Tabanus sp. No. 3.-Riley and Johannsen (1915) give a photographic illustration of the egg mass of an American species of Tabanus, the name of which is not given (Plate 1, Fig. 6).

Tabanus sp. No. 4.-(Hart's sp. a.) Two examples of larvæ of this peculiar species have been collected by Hart, from diverse situations. One was taken under bark in woods near Urbana, Illinois, April 6; the other, from a prairie ditch, in Kane County, Illinois, which was swollen by a heavy rain. Hart's description is as follows:

"I Iarva.-Length $19 \mathrm{~mm}$., diameter $2.5 \mathrm{~mm}$. Last antennal joint short and very slender, epistoma not sulcate anteriorly, but with an elongate puncture. Whitish, lateral pubescent stripes wanting, annuli much reduced and pale except upon false feet. Prothorax shining, with anterior opaque annulus; lateral areas as long as the dorsal, their upper and lower thirds rather coarsely striate, middle third smooth, with several punctures; ventral area smooth, middle groove with three striæ, dorsal area nearly smooth. Striæ of upper lateral spaces of meso- and metathorax and of dorsal and ventral areas of abdomen moderately coarse; those of lateral area of abdomen somewhat finer; dorsal and ventral areas of mesothorax with a few striæ; of metathorax rather sparsely striate. All areas more or less shining. On the anterior side of each dorsal false foot, at its outer end, an opaque light brown elongate fleck. False feet shining and rather finely striated on each side. No projecting spine posteriorly; only a narrow pale annulus on last segment, at base of breathing tube." 
Tabanus sp. No. 5.-(Hart's sp. b.) Hart reports that, in collecting the larvæ of Limnophila and Bittacomorpha in the swampy slough of Station I, many small tabanid larvæ were found in the mud and debris, and among them occurred, on April 15, two examples of a distinct very white form with faint markings like those of stygius, but laterally striate more like atratus, and with a conspicuous isolated smooth spot in the lateral striated area of the prothorax. He describes the larva as follows:

"Larva.-[Plate 3, Fig. 42.] Length $22-23 \mathrm{~mm}$., width $2.5 \mathrm{~mm}$. Very pale whitish, markings like those of stygius, but pale yellowish fuscous and inconspicuous. Head pale brownish."

"Lateral prothoracic areas not more than half as long as the dorsal, striation scarcely visible, microscopically fine and opaque, much finer than that of the middle and lower lateral areas of the mesothorax, which are somewhat shining; a rather large smooth spot included in the striated lateral area of the prothorax, not far from the shining ventral area but entirely isolated from it; remaining upper lateral thoracic areas distinctly more coarsely striated than the areas below them, and quite shining; abdominal lateral areas more finely striate, feebly shining, microscopically striate on the posterior portion of each area. Dorsal and ventral areas shining, with sparse marginal striæ interrupted on the disks, those of thorax especially smooth."

"Dull annuli broad, including the false feet, a distinct transverse dorsal and ventral pale spot in front of the false feet. Lateral prothoracic area occupied by a very pale fuscous opaque quadrate spot in front of the striated area. Meso- and metathoracic lateral stripes usually visible, but slender, not dilated, lateral edges of dorsal areas diverging; lateral stripes of abdomen almost wanting, except on last two or three segments. Last segment with bases of respiratory tube and anal prominence ringed with opaque fuscous, that around anal prominence sending up an indistinct stripe, with posterior extensions. Pubescence of false feet whitish or pale fuscous. Respiratory tube slender, no spine protruding."

Tabanus sp. No. 6.-Malloch (1917) describes briefly, and without illustrations, an unknown tabanid larva, which differed from other larvæ he had before him, in being entirely white and without lines or patches of pubescence, as well as in being more robust, and less tapered at the extremities. In general appearance it very closely resembled an asilid larvæ, the resemblance being accentuated by the small size of the locomotor organs; and it stood as "Asilidæ" in the Illinois State Laboratory collection. The specimen was obtained in Pulaski, Illinois, June 1, 1910, in a pit-cage used in rearing white 
grubs. This is a surprising occurrence, as most of the species of Tabanus are confined to damp ground or to aquatic surroundings.

In his analytical key, Malloch gives the following characteristics of this larva, "Body without markings either of color or hairs. Body very closely and finely striated, entirely white." The size of the larva is not given.

Tabanus sp. No. 7.-Unknown European species, observed by Surcouf and Ricardo (1909). Only the pupa is figured (Plate 12, Fig. 150).

Larva.-Surcouf and Ricardo have reported on the capture and rearing of a tabanid larva, of which, however, the species was not determined. Roubaud had given them "a young larva of Tabanus" which he had collected on October 3, 1905, at Meudon in the muck of a pond; this larva was reared for eight months in water, feeding not on living prey but on organic matter introduced with a bunch of moss which covered the bottom of the crystallizing dish in which it was kept. On May 13, 1907, it was seeking a protected place in this moss, lost its mobility, turned more translucent than usual, and, on May 16, had transformed into a pupa, which, unfortunately, perished in consequence of an accident. The larva is described as elongate, whitish, very active, pointed at both ends, and provided with a sort of crested ring on each of its segments; these rings are equipped all along their course with retractile tubercles serving as means of locomotion.

Pupa (Plate 12, Fig. 150).- The pupa which Surcouf and Ricardo obtained from this larva measured $17 \mathrm{~mm}$. in length and $4 \mathrm{~mm}$. in diameter. This pupa has the aspect, according to the authors, of a lepidopterous pupa; the upper anterior part was smooth above, comprising the thorax and head, the lower anterior parts bearing under their chitinous coverings, the antennæ, the palpi, the eyes, and the first pair of legs. The wings are contained in a case which reaches the top of the scutellar segment, unarmed. The posterior region of the pupa comprises seven segments which have at the tip a crown of rigid hairs intermingling with pointed tubercles with enlarged bases. The last segment has two tubercles, each one consisting of three irregular more or less curved spines. The third thoracic segment and the first six abdominal segments all have a spiracle on each side. 
These spiracles appear slightly projecting above the surface.

Tabanus sp. No. 8.-An unidentified African species. No description but good illustration of ventral and dorsal aspect of larva is given by Brumpt (1910). The larva shows dorsal prolegs well developed which indicates an aquatic mode of life (Plate 4, Fig. 55, $a, b, c)$.

Tabamus sp. No. 9.-Unidentified African species of which a poor illustration is given by Grünberg (1907), (Plate 4, Fig. 58).

Tabanus sp. No. 10.-A young specimen of an unidentified European species is figured by Graber in his work on the chordotonal organs (1882-83) (Plate 8, Fig. 99); it is supposed to belong to Tabanus autumnalis, and may belong to Chrysops. (See also page 23.)

Tabanus sp. No. 11.- Henneguy (1904) gives the illustration of a young Tabanus larva (Plate 10, Fig. 109), with typically inflated tracheal trunks, in Europe. (See also pages 36 and 38.)

Tabanus sp. No. 12.-Paoli (1907) gives an illustration of the larva (Plate 10, Figs. 111 to 116) in which he studied Graber's organ. Though this larva is supposed to belong either to Tabanus cordiger or to Tabanus autumnalis, it is not unlikely that it is another species. The two species mentioned happened to be, with Tabanus bovinus and Tabanus quadrinotatus, and one or two others, the only European species which had been found in the larval state up to that date, but the descriptions are all insufficient.

The larvæ which were studied by Paoli live in slow flowing rivers, especially in the soft mud containing decomposing organic matter, among the algæ, especially Characea, which grow in the water, in places where they can easily utilize the atmospheric air as they are not provided with organs adapted to locomotion in water.

The body consists of thirteen distinct segments, of which one is the head, three belong to the thorax, and nine to the abdomen; the tenth segment of the abdomen is much reduced and fused with the ninth; the eleventh is absent. 
Graber, as Paoli mentions, gives his larva (in the figure) erroneously, only ten segments, while it is known that the larvæ of Diptera have fourteen segments, of which the last one is vestigial.

The largest specimens of the larvæ examined are, when completely extended, 30 to $32 \mathrm{~mm}$. in length. The body is fusiform (Plate 10, Fig. 111), the color a dirty yellowish white, the head is elongate, retractile; the three thoracic segments do not present any peculiarities. The first seven abdominal segments are furnished each one with eight papillæ, arranged all around the anterior third of each segment, which consequently in cross-section presents itself with eight prominences arranged like the corners of a regular octagon. These papillæ are retractile, and each of them is furnished at the tip with numerous strong hooklets. The larva moves in the mud and among the algæ, in addition to making worm-like movements due to the contractions of the subcutaneous muscular stratum, also by protracting and retracting the fifty-six papillæ which in this way form a support and assure to the larva its locomotion. The eighth segment bears on its ventral side a thick sulcate prominence, in the middle of which the opening of the anus is situated. Anterior to this prominence a large lip-like expansion is formed, with numerous strong hooklets which are curved forward at the free margin. Behind the anal opening the eighth segment is narrow and curved upwards; the ninth segment is short, cylindric, thin, more or less retracted into the inside of the eighth, bearing at its extremity the rudiments of the tenth, in which the two stigmata open.

Paoli, after thus briefly describing the larvæ, adds that when disturbed by contact or pressure, they undergo contortions in every direction, making a sound like the crackling of small electric sparks. They feed on animal matter and ferociously attack small larvæ of other aquatic insects, and also devour one another; when they are attacking one another the crackling sounds are heard repeatedly. For the description of Graber's organ in these larvæ see page 29 and following.

Tabanus sp. No. 13.-Maxwell-Leffroy and Howlett (1909) give, on a colored plate, illustrations of the egg mass, young larva, full grown larva, pupa, and an ichneumonid parasite of an unidentified Indian 
species of Tabanus. The egg mass (Plate 1, Fig. 7) is yellow in the original and not very convex in structure. The young larva (Plate 5, Fig. 76, a), is whitish and semitransparent. The full grown larva (Plate 5, Fig. $76, b$ ) is yellow, its natural size $47 \mathrm{~mm}$. The pupa is yellow in color, the thorax grayish (Plate 12, Fig. 139). The hymenopterous parasite figured (Plate 5, Fig. $76,{ }^{\circ} \mathrm{C}$ ) is the only parasite of this (ichneumonid) type observed so far as a tabanid parasite, the other being cases of Proctotrupidæ.

Tabanus sp. No. 14.-Only the pupa of this Indian species (no name given) is figured by Maxwell-Leffroy and Howlett (1909) (Plate 11, Fig. 132).

Eggs and young larvæ described by Lutz (1914) of an unknown Brazilian species which he supposes may belong to the tabanids, probably belong to a leptid species. 


\section{PARASITES OF THE EARLY STAGES OF TABANIDE.}

\section{Hymenopterous Egg Parasites; Early Discoveries.}

Kollar (1854) is the first to mention an egg parasite of Tabanus. From egg masses of Tabanus quatuornotatus collected at Wippach, Austria, by Mann, June 25, 1854, there were observed to hatch not only young Tabanus larvæ but "also another completely developed insect belonging to an entirely different order and family, a little animal which belongs to the extraordinarily large and still inextricable army of the parasitic wasps (Ichneumonidæ)." It was concluded that, immediately after the Tabanus had deposited its eggs, a parasitic wasp had appeared and deposited its eggs in those of the Tabanus. Parasitic wasps were then known to develop in the eggs of Lepidoptera, chiefly Bombycidæ, and of various Hemiptera, but in Diptera such egg parasites had not been observed (Kollar). The length of one of these parasites is given as two-thirds of a line; the size of the Tabanus eggs as one line in length, and one-seventh of a line in diameter; Kollar thinks it probable that several wasps develop from a single Tabanus egg, which is probably not the case. ${ }^{31}$

On egg masses of a second species of Tabanus, collected by himself at Dornbach, near Vienna, Kollar found a similar but specifically different parasitic wasp, which was just ovipositing its eggs in those of the Tabanus. In order to learn how much time was necessary for the development of the wasp, Kollar kept the Tabanus eggs in a small bottle closed by means of perforated paper, and obtained on the fifteenth day several hundred wasps. From the number of parasites he believed he was justified in assuming that from one Tabanus egg more than one wasp may develop. However, the number of eggs in the cluster had been said, for Tabanus quatuornotatus Meig. to be 350 to 400 , and it is not said whether the number of wasps hatching exceeded the number of eggs.

The two sexes of the parasites could be differentiated; a description and figures were promised but apparently have never been published.

${ }^{31}$ See Hart (1895), Phanurus tabanivorus, p. 272. 
Hart (1895) is the next observer who noticed the egg parasites of Tabanidæ. Two egg masses of Tabanus atratus which had already produced larvæ were placed in a dry vial, and a little later it became evident that both masses had been parasitized by Hymenoptera, minute black imagos emerging freely in the vial. An examination of one of the masses showed that about one-half of the eggs had been infested. Examples of the imago were sent to Mr. W. H. Ashmead, who found the species to be a new one; and it was described by him as Phanurus tabanivorus (Ashmead). An egg of the Tabanus is figured, containing one imago of the parasite. ${ }^{32}$

The description of the parasite by Ashmead is given here:

Phanurus tabanivorus (n.sp., female).--"Polished black, impunctate, the head and thorax clothed with a fine sparse pubescence. Head subquadrate, roundly emarginate behind, a little wider than the thorax; eyes oval, faintly pubescent; antennæ eleven-jointed, black, if extended backwards not quite reaching to the apex of thorax, and terminating in a long fusiform five-jointed club, the first joint of which is not quite as wide as the second; ob-trapezoidal, twice as wide as long, the second, third and fourth joints transverse quadrate, a little wider than long; the fifth or last joint conical and a little narrower than the preceding joint; the scape is about as long as the funicle with the pedicel, the latter obconical; joints of funicle a little narrower than the apex of the pedicel, the first joint scarcely longer than thick, the second and third small, transverse moniliform."

"Thorax subovoid, not twice as long as wide, the mesonotum scarcely longer than wide, the scutellum lunate, polished, without pubescence; wings hyaline, ciliated, the cilia on the anterior and posterior margins long, much shorter at apical margin; tegulæ black; venation brown, the marginal vein a little shorter than the stigmal, the latter only slightly thickened at tip, the postmarginal vein very long, fully two and a half times as long as the stigmal; legs fuscous, the trochanters, knees, tips of tibiæ and tarsi honey-yellow or testaceous. Abdomen elongate, pointed fusiform, about twice as long as the head and thorax united, polished, the first segment not longer than wide, with an elevation above at base, the second segment the longest, twice as long as wide at apex, the suture between it and the first striated, the third segment hardly half as long as the second, the fourth about two-thirds the length of the third, the three following forming a cone of which the fifth is very short, its apical margin with a median sinus, the sixth twice as long as the fifth, the seventh very short, scarcely discernible; sheaths of ovipositor a little prominent."

${ }^{32}$ Ashmead's illustrations (Figs. 55 and 56 of his paper) have been omitted. 
"Male.-Length $0.8 \mathrm{~mm}$. Black, but with the head, prosternum, and legs testaceous; the antennæ twelve-jointed, brown-black, with all the joints of the flagellum, except the pedicel and the last joint, small, moniliform, joints three to five increasing in size but smaller than pedicel, joints six to the penultimate a little wider than long; abdomen not, or only slightly, longer than the head and thorax united, the genitalia long, exserted, curving downwards."

"Habitat.-Havana, Illinois."

"Types in collections of the Illinois State Laboratory of Natural History and in my (Ashmead's) collection."

"Described from eleven male and nine female specimens bred from the eggs of a common horse-fly, Tabanus atratus Fabr."

Hine (1906) also has observed Phanurus tabanivorus and reports that he reared more than a hundred specimens from a single cluster of eggs.

Phanurus tabani Mayr.-In his monograph of the N. A. Proctotrypidæ, ${ }^{33}$ Ashmead characterized four species belonging to this genus, none of which, however, are closely allied to Phanurus tabanivorus. On the contrary, it appears to resemble more closely three European species described under the genus Telenomus; viz., Telenomus othus Hal., Telenomus laricis Hal., and Telenomus tabani Mayr.

Dr. Gustav Mayr, "in his excellent revision of the European species of Telenomus" did not recognize the validity of Thomson's genus Phanurus.

Ashmead, however, believes that, as defined in his monograph, the genus can be readily separated from Telenomus, although both Haliday and Walker have described Telenomi which should now be relegated to Phanurus; while Thomson, in his definition of Telenomus, has included species that really belong to the genus Hadronotus Förster.

These errors, according to Ashmead, probably induced Dr. Mayr to reject the validity of Phanurus in his work (cited above).

It is interesting to note that Phanurus (Telenomus) tabani Mayr has habits similar to Phanurus tabanivorus, the species having been bred by Brauer from a European horse-fly, Tabanus $s p$.

Phanurus tabanivorus, although evidently related, is somewhat larger in the female sex, smoother, with the joints of the antennæ

${ }^{33}$ Ashmead, N. A. Proctotrypida, Monograph, pp. 140 and 141. 
and the segments of the abdomen relatively different, while the male is much smaller, differently colored, and with the antennal joints totally dissimilar.

Dr. Mayr's species, Phanurus tabani, approaches nearest to Telenomus laricis Hal., ${ }^{34}$ with which he makes comparison; while Phanurus tabanivorus agrees more nearly with Telenomus othus Hal., represented on the same plate, Fig. 4 (Mayr's paper).

Phanurus emersoni Girault.-A new Phanurus egg parasite of Tabanidæ was discovered by Girault quite recently (1916), Phanurus emersoni Girault, and was reared from tabanid eggs at Dallas, Texas. Girault gives descriptions of three allied species.

1. Phanurus opacus Howard.-Both sexes are black; the thorax above is subglabrous.

2. Phanurus floridanus Ashmead.-The head and thorax are polished, the tibiæ and knees pale brown; segments one and two of abdomen have very short striæ at base. The club is stouter than in ovivorus.

3. Phanurus ovivorus Ashmead.-The club is slenderer than in the preceding, the tibiæ dark, the thorax above showing faint reticulation, cephalad but mostly glabrous. The first two segments of the abdomen do not have striæ at base, or else these are extremely minute and short. In flavipes the vertex and scutellum are uniformly finely reticulate. The species ovivorus is very close to opacus, if not identical with it.

4. Phanurus emersoni Girault.-Female, length $0.90 \mathrm{~mm}$. Black, the wings subhyaline, the venation pale dusky, the tarsi yellow. It differs from Phanurus opacus Howard in that the male is varicolored in the latter, and from the female opacus, floridanus, and ovivorus in that the vertex and scutum of the latter are densely reticulated. It differs from tabanivorus in that the abdomen of the latter is only somewhat longer than the rest of the body, the third segment is not a fourth the length of the third (second?), the thorax above is reticulated, and the male has the entire thorax honey-yellow, also the antennæ (besides the legs and head as in tabanivorus). It is closely related to the female of ovivorus, which it resembles. The stigmal

${ }^{34}$ Mayr, Entomological Magazine, ii, Plate XIII, Fig. 2. 
vein is nearly twice as long as the marginal, and about half the length of the postmarginal. Funicle 1 is half as long again as it is wide, two-thirds the length of the pedicel, No. 2 a little shorter than No. 1, No. 3 still shorter, No. 4 globular, smallest, No. 5 cupshaped, No. 6 the same, larger, wider than long, Nos. 7 and 8 subquadrate, No. 9 ovate, longer than wide. Short distinct striæ at base of segment No. 2 of the abdomen.

In the male, Funicles 1 to 3 are somewhat longer than in the female, while Nos. 4 to 9 are moniliform, wider than long, small; the club joint is ovate and as long as Funicle 1 and stouter.

Described from a large number of both sexes reared from tabanid eggs at Dallas, Texas (Bishop).

Types.-Catalogue No. 19,664, U. S. N. M., one male, eight females, on two tags and a slide bearing one male, four females.

Types of opacus, ovivorus, floridanus, and flavipes examined.

Telenomus benefactor Crawford.-Patton and Cragg (1913), (page 298), say that Telenomus benefactor Crawford is another chalcid which parasitizes the eggs of tabanids in the Sudan.

Telenomus kingi Crawford.-This species has been reared from eggs of Tabanus kingi.

\section{Unidentified Parasites Recorded.}

Chalcid sp.1. King (1910) has bred, from an egg mass of Tabanus teniola, taken at Gebelein, numbers of a small Hymenopteron, which, in 1910, had not been identified, but was figured, together with the parasitized egg mass, showing the exit hole of the parasites. As the insects are figured in natural size, not much can be said about structural details (see Plate 1, Fig. 8, and text, p. 170).

Chalcid sp. 2. In Madras, a similar insect, which has not been identified (Patton and Cragg, 1913), regularly destroys large numbers of egg masses of Tabanus albimedius and Tabanus striatus.

A parasitized egg mass can be recognized, according to Patton and Cragg, by the almost black color which it assumes when the development of the embryos of the Hymenopteron is almost complete.

Chalcid sp. 3. A hymenopterous parasite has also been found to infest the eggs of Goniops chrysocoma (McAtee). Consequently the phenomenon seems to be quite general. 
Ichneumonid sp. An unidentified ichneumonid parasite of an unidentified Indian species of Tabanus is figured (Plate 5, Fig. 76, c) by Maxwell-Leffroy and Howlett (1909), apparently the only known instance of a true ichneumonid parasitic in Tabanidæ. ${ }^{35}$

\section{Parasites of the Larve.}

On parasites of the larvæ we possess only a few remarks by Hart (1895), who found a larva covered with small whitish scales which were possibly the eggs of a parasite. Nothing further is known. ${ }^{36}$

${ }^{35}$ On an egg mass of Tabanus atratus F., found in 1915, I noticed a small Hymenopteron which I took for an egg parasite and which I found to belong to Trichogramma. However, no Trichogramma hatched from the egg mass, but instead of it, a large number of the well known Phamurus, apparently tabanivorus Ashmead.

${ }^{36}$ To these should be added the author's own observation of Nematode parasites which were repeatedly found in larvæ of Chrysops. 


\section{DISCUSSION OF TABLE II.}

Of 91 species data are available ${ }^{37}$ but this is not much if we consider that more than 2,000 species of Tabanidæ have been described, and 76 species have been recorded for the State of New Jersey alone. Moreover, in a number of these 91 species from all parts of the world, we have only very fragmentary data, as for instance in the twelve species of Chrysops listed; of five of them we possess only notes on their oviposition; the whole life history of none of them has been worked out. There are also comparatively few data on European species. ${ }^{38}$

From the list it is evident that the majority of Tabanidæ of which the life history is known, are aquatic in habitat: of 91 species noted, 65 are aquatic or probably so, 18 are terrestrial or probably so; of 8 species nothing definite can be said about their habits. The terrestrial habit is then to be considered the exception. It is worthy of note that all the known species of Chrysops are aquatic, in as far as the eggs are deposited above water, or the larvæ have been found in the mud. The limit between an aquatic and terrestrial mode of life is, of course, not always very sharp when the habitat is in fact the soft mud at the border of ponds, brooks, and streams, as seems to be usually the case, but most authors agree that the larvæ live in mud saturated with water, an environment which differs physiologically very little from water itself. I have therefore listed all species as aquatic the larvæ of which have been found in the mud near water, or where the eggs are deposited above water. But there is no doubt that some tabanids live in the larval condition at con-

${ }^{37}$ Of two or three of the 91 species discussed here, we have in fact only indications about their breeding habits, no actual knowledge of the stages, so in Gastroxides, Tabanus fuscipes, and Tabanus nigerrimus. Leaving these out, we still have about 88 species on which some data are available.

${ }^{38}$ Recently, I have obtained larval stages of 9 other North American species, bringing the total number of species on which data are known close to 100 . These species are: Chrysops niger, obsoletus, univittatus, Tabanus reinwardtii, pumilus, orion, two undetermined species of Tabanus, and one genus incertum. 
siderable distance from water and probably a greater number than is apparent from this table, because terrestrial larvæ will be found much more rarely being less accessible and spread over wider areas. Since the genus Tabanus is on the whole phylogenetically the younger, in comparison with Chrysops, it would appear that in some species of this genus the larvæ have become secondarily terrestrial, a possibility which is of importance for the understanding of the group as a whole. This may also apply to Hamatopota, a genus absent in Australia and apparently of more recent origin-while retaining a rather primitive wing-pattern-showing aquatic tendencies in the oviposition of some species, yet in its common and widely spread species, Hamatopota pluvialis, completely terrestrial in the larval and pupal stages.

Practically nothing is known, with the exception of the few instances listed, of the early stages of the mumerous remaining genera of the family Tabanidæ other than Chrysops and Tabanus proper, and here is a splendid opportunity especially for workers in tropical countries.

In regard to continents, the data in our possession are distributed as follows:

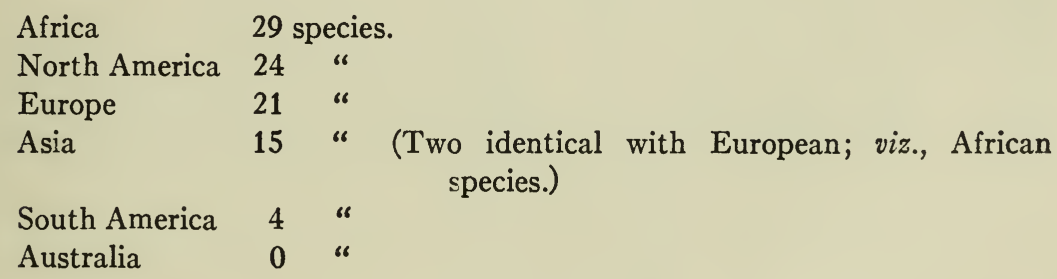

It is seen that Africa ranges highest, and concerning this particular subject, has ceased to be a "dark continent," as compared with North America or Europe. 


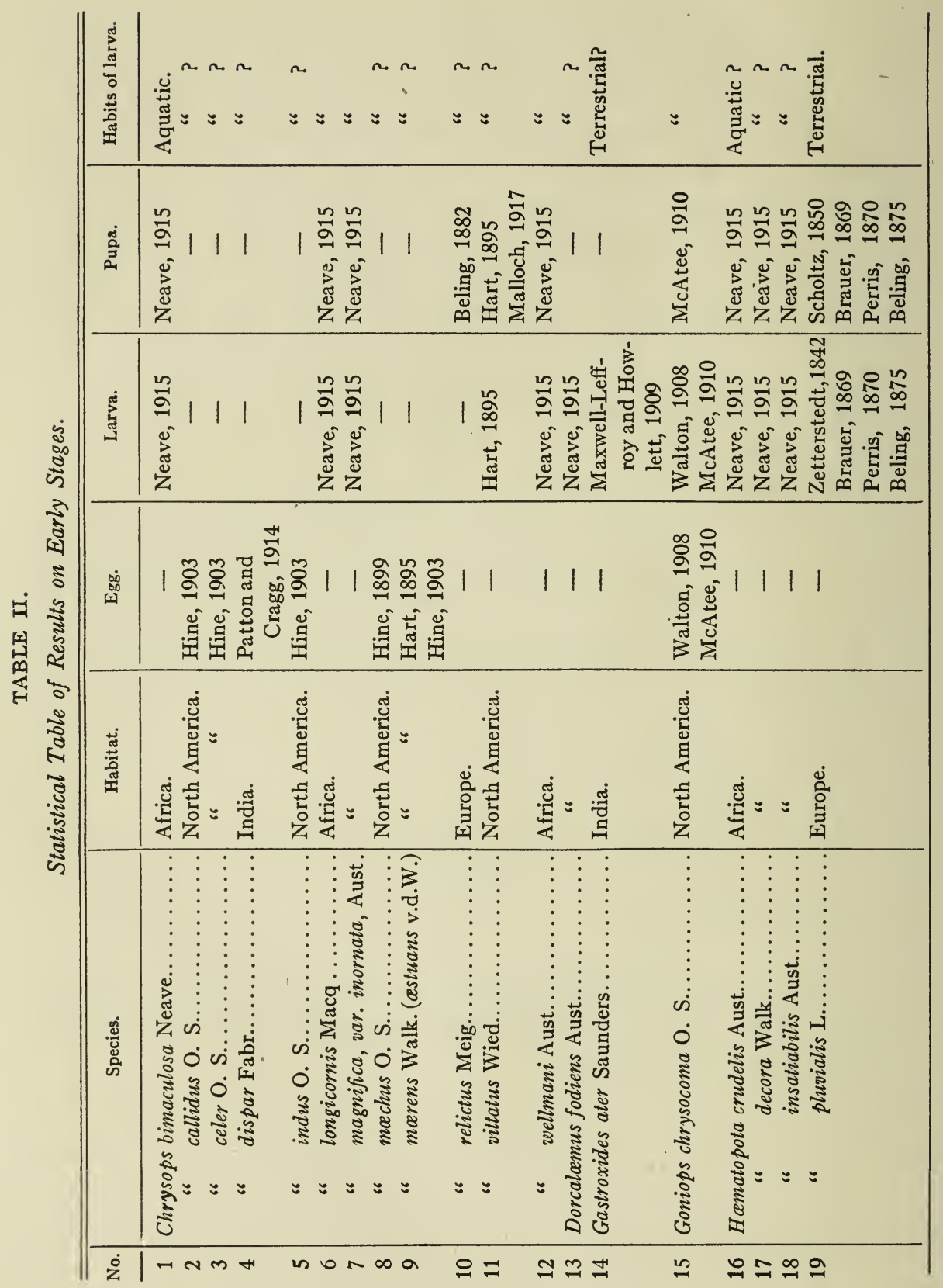




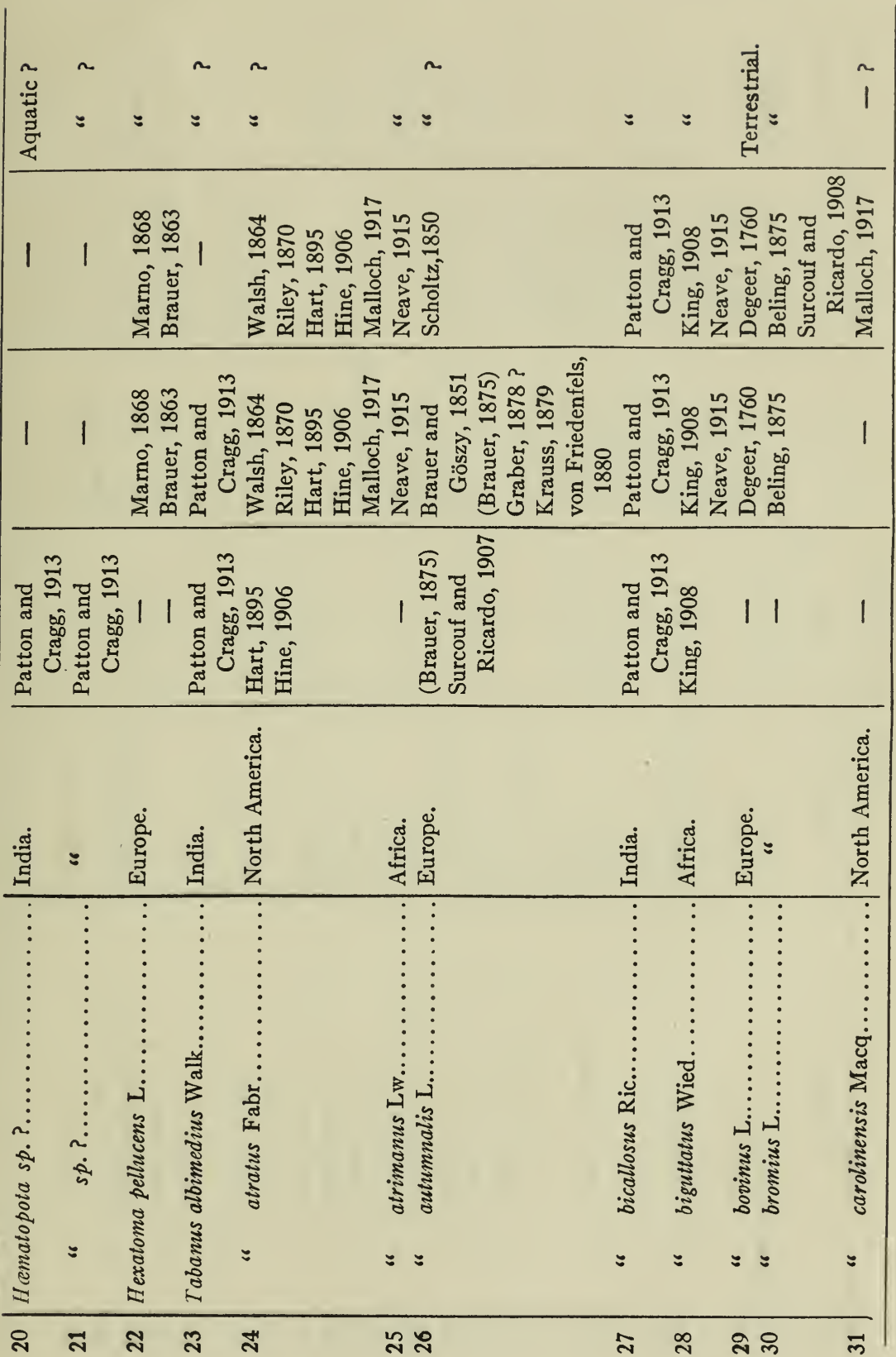




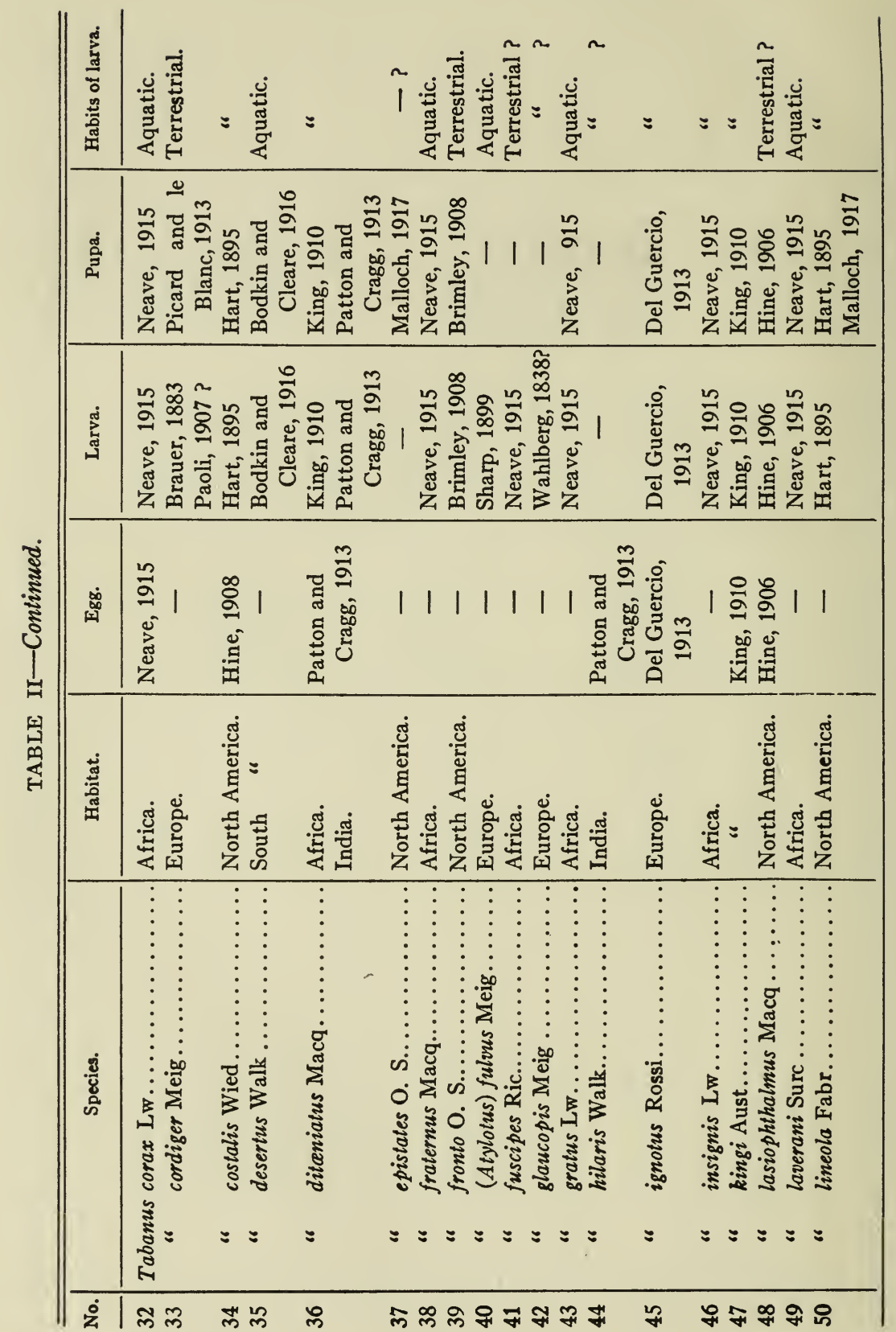




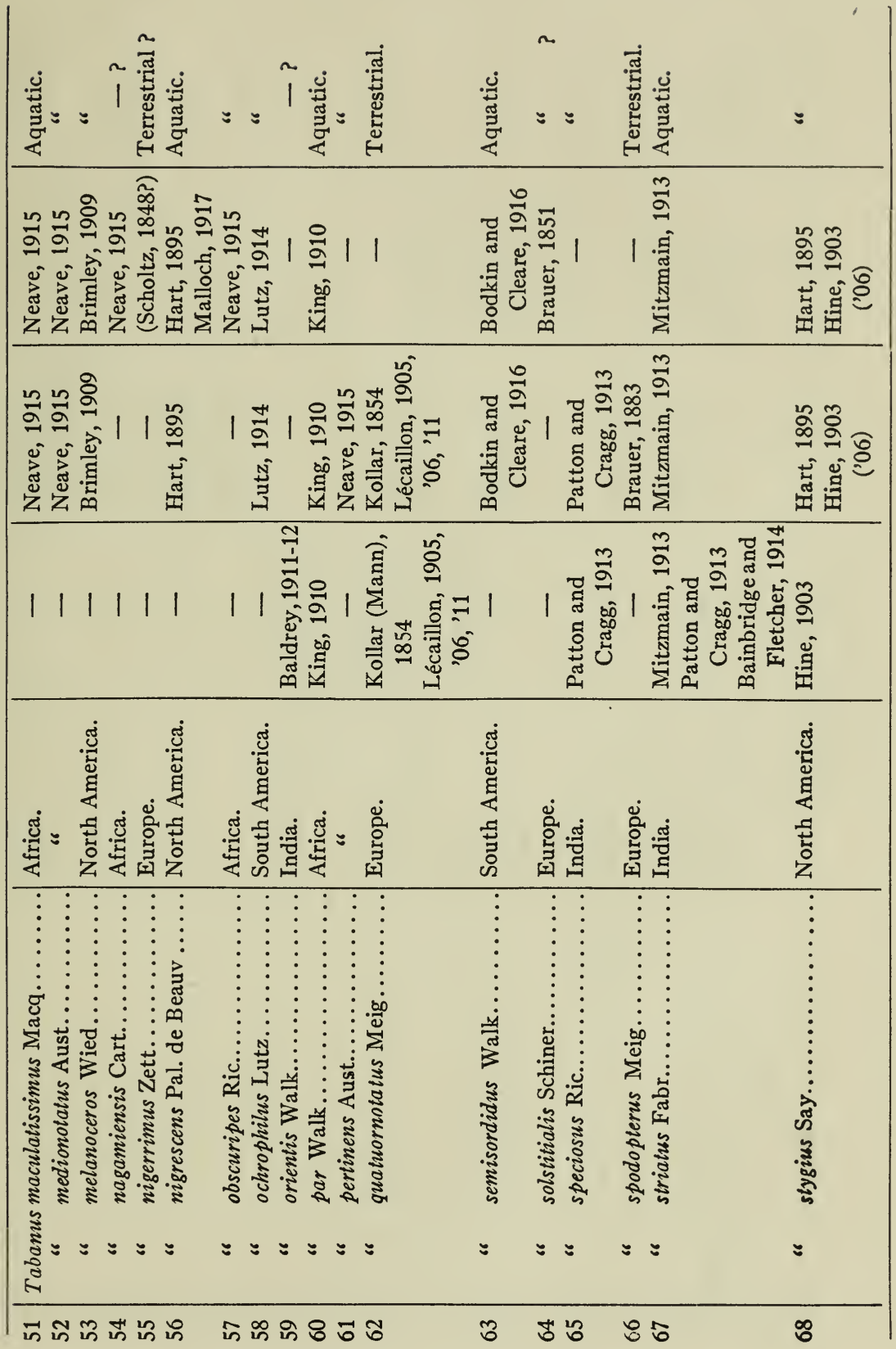




\begin{tabular}{|c|c|c|c|c|c|c|c|c|c|}
\hline 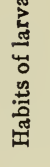 & 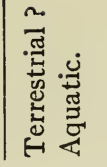 & $==$ & $==$ & 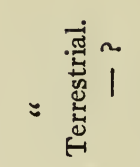 & $\ddot{i}$ & 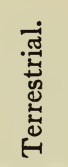 & 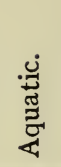 & 通 & $\approx$ \\
\hline 离 & 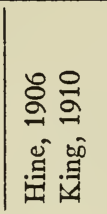 & 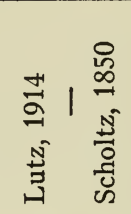 & 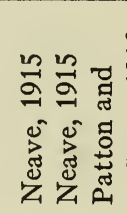 & 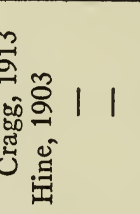 & 1 & 1 & 1 & 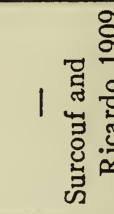 & \\
\hline 怤 & 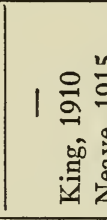 & 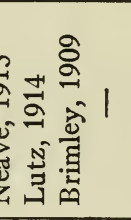 & 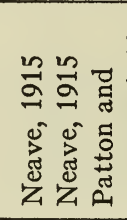 & 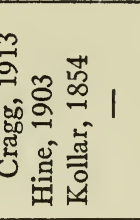 & 1 & 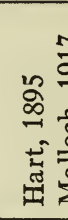 & : & 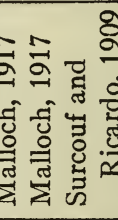 & 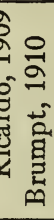 \\
\hline 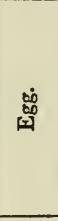 & $1 \stackrel{0}{9}$ & 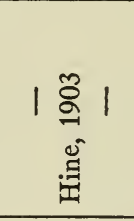 & 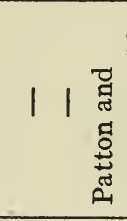 & 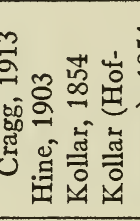 & 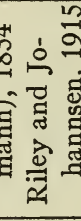 & I & 1 & 11 & 1 \\
\hline 薦 & 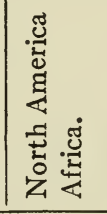 & 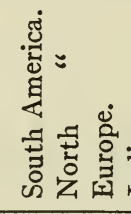 & 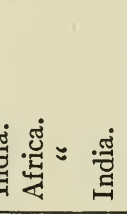 & 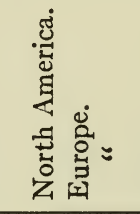 & 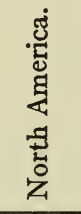 & $\begin{array}{l}= \\
\Xi\end{array}$ & $\begin{array}{l}= \\
=\end{array}$ & 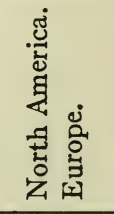 & 芯 \\
\hline 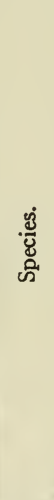 & 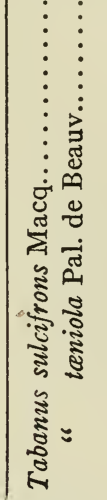 & 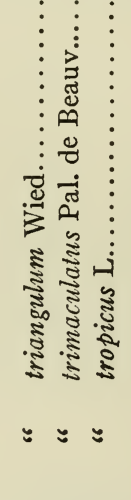 & 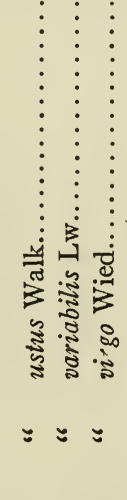 & 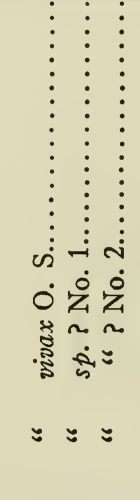 & $\begin{array}{c}\vdots \\
\vdots \\
\dot{m} \\
\dot{z} \\
\approx \\
\vdots \\
\vdots\end{array}$ & $\begin{array}{c}\vdots \\
\vdots \\
\vdots \\
\vdots \\
+ \\
\vdots \\
z \\
\vdots \\
\vdots \\
\vdots\end{array}$ & $\begin{array}{c}\vdots \\
\vdots \\
\vdots \\
\vdots \\
\vdots \\
i \\
\dot{z} \\
\vdots \\
\vdots \\
=\end{array}$ & 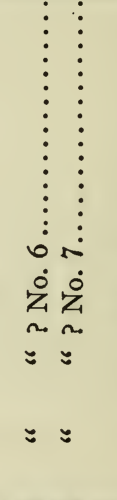 & $\begin{array}{c}\vdots \\
\vdots \\
\vdots \\
\vdots \\
\infty \\
\dot{0} \\
\vdots \\
\vdots \\
\vdots \\
=\end{array}$ \\
\hline$\dot{8}$ & $18 \%$ & 조 & 조는유 & $\leqslant \infty R$ & 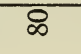 & $\vec{\infty}$ & స్ & க. & $\infty$ \\
\hline
\end{tabular}




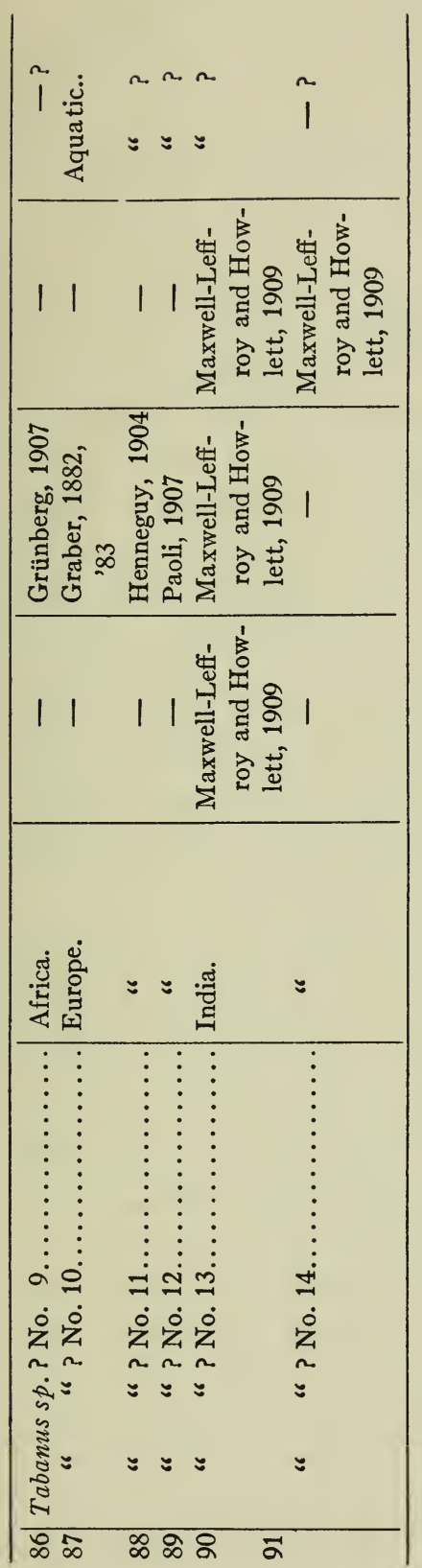




\section{NOTES ON METHODS OF REARING AND STUDYING TABANIDS IN EARLY STAGES.}

Collecting the Larva. - The natural habitat of tabanid larvæ is the wet mud or sand in the immediate neighborhood of water, hence they are rarely caught by the usual method of collecting aquatic insects by means of a net. The lack of a practical collecting method is probably the main reason why these animals while very common have passed almost unnoticed in an epoch of fresh water biological investigations. Neave seems to have employed large nets, as did Hart also, but Neave was able to send out a collecting staff of negroes to obtain his material. The use of an ordinary sieve, first applied by Hine to collect the larvæ of Tabanus vivax in rapid streams, is more advisable for collecting the larvæ from the mud. Patton and Cragg suggest placing lumps of mud and sand with water in a pail; by stirring the mass the large larvæ appear floating at the surface. The smaller ones are caught when the muddy water is passed through a sieve.

Rearing Vessels. - The methods of various authors in rearing tabanid larvæ have been treated in connection with the species. Thus in the paragraphs on Tabanus lasiophthalmus and vivax, details of Hine's method in rearing these species are found, and Mitzmain's valuable contributions to breeding technique are found under Tabanus striatus.

Hine proposes to keep the larvæ in jelly glasses the covers of which are perforated by a few holes, and which are half filled with wet sand. Mitzmain uses dishes with some mud and wet filter paper.

Patton and Cragg have advised the use of very large trays, several feet long and six inches high, in which large numbers of larvæ may be reared under almost natural conditions. The bottom of the tray has to have a hole closed by a cork stopper, to make it possible to change the water in the tray from time to time. Pupæ should be taken out, as the larvæ may injure them, and placed in separate cages, in little vertical holes. Near each pupa a little flag is fastened, bearing the number of the pupa, or other data. 
Neave, who was raising many different tabanid species in southern Nyasaland, found that the best receptacles which he could obtain locally were the small basin-shaped vessels made of hard clay by the natives. These were of various sizes, from six inches to a foot in diameter. They were placed separately under cages made of mosquito netting on a wood framework. Neave recovered the larvæ for examination or other purposes merely by washing them out of the mud or sand in which they were placed. This of course requires great care in the case of the smaller species. ${ }^{39}$

Feeding.-While most authors give earthworms as food to the larger larvæ, Neave advises the use of immature larvæ of muscid flies, collected from the carcasses of rats, etc., trapped for the purpose. These larvæ buried themselves at once in the mud, where they were apparently consumed by the tabanid larvæ, which thrived under these conditions. The larger species also greedily attacked the freshly killed bodies of small tadpoles, mollusks, and bits of fish, placed on the surface of the mud, though they were seldom actually seen to do this unless examined at night. It was found in most cases that the tabanid larvæ did best in mud or sand, this point being usually decided by the conditions under which they had been found, which was very wet, but without standing water on the surface.

Transportation.--If it is necessary to transport for any distance larvæ which have not reached the resting stage, it is important that the jars, etc., in which they are placed should contain only wet mud or sand and that there should be no standing water on the surface. Some of Neave's earliest captures, which had to be transported 50 or 60 miles from the Shire River to Mlanje, were nearly all lost from this cause, the larvæ being apparently drowned by the movements of the water on the surface.

Treatment of Pupal Stages.-Neave found that the soil in which the pupæ are kept should be considerably drier than that which suits the larvæ.

Patton and Cragg have proposed to remove the fresh pupæ from the vessels in which the larvæ are kept and to place them vertically

${ }^{39}$ For rearing tabanid larvæ in test-tubes, see Marchand, J. Econ. Entomol., 1917, x, 469-72. 
in open holes in sand, where they wriggle themselves soon into the desired position. Each pupa receives a label in the form of a little flag which is fastened in the sand. As soon as a pupa has hatched, it is taken out with its label.

According to Neave, it is difficult to obtain good specimens from bred material, as the imagos begin to fly about and to injure themselves before they are hard enough to be killed. They should therefore be placed in larger cages and kept there until they are sufficiently hardened.

Points Important in Description.-Specific differences in tabanid larvæ are not always easy to detect, especially in those of Hamatopota. They are generally found, according to Neave, in the distribution of the pigmented areas on the last segment around the base of the syphon and the anus. These so called pigmented areas are really areas of pigmented hairs (Waterston) in which are entangled small foreign bodies. Their actual color therefore varies to some extent with that of the medium in which the larvæ have lived. The amount of pigmentation, though not its distribution, also varies with the age of the larvæ.

Hart considers the striation of the lateral areas of the prothorax of great systematic importance in the description of the larvæ.

For practical purposes of description the following points should be noted (Patton and Cragg): In the larvæ, abdominal markings, presence or absence of striæ, ${ }^{40}$ characteristics of the pseudopods (prolegs), length of the syphon tube, and structure of the antennæ. In the pupæ, length of the antennal sheath, character of the thoracic spiracle, particularly its inner margin, length of the hairs on the abdomen, structure of the abdominal spiracles, and shape and size of the spines and teeth on the eighth segment.

Mr. James Waterston, of the Imperial British Bureau of Entomology, is quoted by Neave as having suggested the convenient name "aster" for the group of hooks at the termination of the last segment of the pupa. The form of this differs a good deal in the various species, and another characteristic which seems of some specific value is the nature of the uppermost section, often isolated,

${ }^{40}$ Especially on the thoracic segments. 
of the series of combs on the anterior part of the last segment; this is called by Neave the dorsolateral comb. It is not always present and varies much in form.

Preserving.-To preserve the larvæ and pupæ, for purposes of dissection, etc., our methods are still undeveloped. Hart ${ }^{41}$ (1895) says: "The best results with most larvæ of any size were obtained by heating them in water, not too rapidly, to about $200^{\circ} \mathrm{F}$., and setting them aside till cool. A small percentage of acetic acid will prevent the collapsing of very soft larvæ." The principal trouble with this method arises from the expansion of the air within, but a slight inflation is sometimes desirable. This method is not suitable for pupæ generally, and Hart advises the use of 80 per cent alcohol and water for their preservation. Experiments with formalin indicate that it will satisfactorily preserve small and easily penetrable forms.

Malloch (1917) has given further methods for preserving the larvæ and pupæ.

${ }^{41}$ Hart (1895), pp. 159 and 160. 


\section{BIBLIOGRAPHY.*}

Ashmead, W. H., Descriptions of three new parasitic Hymenoptera from the Illinois River. Phanurus tabanivorus, Bull. Illinois State Lab. Nat. Hist., 1895-96, iv, 274-276. (See Hart (1895).)

Bainbridge, T., and Fletcher, Some South-Indian Insects, Madras, 1914.

Baldrey, F. S. H., The evolution of Trypanosoma evansi through the fly: Tabanus and Stomoxys, J. Trop. Vet. Sc., 1911-12, vi-vii, 271-282.

Beling, T., Beitrag zur Metamorphose der zweifluegeligen Insecten, Arch. Naturges., 1875, xli, 35-39.

Beling, Beitrag zur Metamorphose zweiflügeliger Insecten aus den Familien Tabanidæ, Leptidæ, Asilidæ, Empidæ, Dolichopodidæ, and Syrphidæ, Arch . Naturges., 1882, xlviii, 187-240; C. relictus, pp. 187-190.

Bodkin, G. E., and Cleare, L. D., Notes on some animal parasites in British Guiana, Bull. Entomol. Research, 1916, vii, 179-190.

Brauer, F., Beobachtung Marno's über Hexatoma, Verhandl.zool. bot. Ges., 1868, xviii, 74-75.

Brauer, Kurze Characteristik der Dipteren-Larven, Verhandl. zool. bot. Ges., 1869, xix, 448.

Brauer, Beitrag zur Verwandlungsgeschichte der Regenbreme (Hamatopota pluvialis L.), Verhandl. zool. bot. Ges., 1869, xix, 921-922.

Brauer, Die Zweiflügler des Kaiserlichen Museums zu Wien. III. Die TabanusArten der europaeischen, mediterranen und sibirischen Subregionen, Denkschr. kaiser. Akad. Wissensch., Mathem. Naturw. Classe, 1880, xlii, 151 (pupa of Tabanus solstitialis).

Brauer, Die Zweiflügler des Kaiserlichen Museums zu Wien. III, 1883, p. 24, Tabanidæ. (Contains description of larva of Hexatoma pellucens, illustrations of the latter and of larvæ of Tabanus spodopterus and cordiger.)

Brimley, C. S., Notes on the life-histories of Tabanidæ (Diptera), Entomol. News, 1909, xxii, 133.

Brumpt, E., Précis de parasitologie, Paris, 1910.

Degeer, C., Mémoires pour servir à l'histoire des insectes, 1752-58, 7 vols.

Degeer, Bromsarnas ursprung, uptaeckt af Carl Degeer, Konigl. Vetenskaps Academiens Handlinger for Ar 1760, xxi, 276-291, Plate IX, Figs. 1, 2, 3 , and 4. (The illustrations of Tabanus bovinus are identical with those given in the Mémoires, but the illustration of the pupa is more exactly reproduced in the Mémoires.)

Degeer, Mémoires pour servir à l'histoire des insectes, 1776, vi, 5th Mémoire. German edition (Goeze), 1882.

Dufour, L., Notices entomologiques. I. Consultation sur une larve aquatique, Ann. Soc. entomol. France, 1862, Plate II, Fig. 2, a and b.

* Reference is made to the larval stages of Tabanidæ in a number of textbooks or other papers all of which were not mentioned in this Bibliography if they contained no original information. 
Fabricius, J. C., Entomologia Systematica, 4 vols., Hafniae, 1772-94; Supplement 1798.

von Friedenfels, E., Ueber Artemia salina und andere Bewohner der Soolenteiche in Salzburg, Verhandl. Mitt. Siebenbïrg. Vereins für Naturwissenschaften in Herrmannstadt, 1880, xxx, 112-178 (p. 168 Tabanus autumnalis).

Girault, A., A new Phanurus from the United States, with notes on allied species, Canad. Entomologist, 1916, xlviii, 149-150.

Göldi, E. A., Die sanitarisch-pathologische Bedeutung der Insekten und verwandten Gliedertiere, namentlich als Krankheits-Erreger und KrankheitsUberträger, Berlin, 1913.

Graber, V., Ueber neue otocystenartige Sinnesorgane der Insecten (Neues Organ einer Fliegenmade), Arch. mikroskop. Anat., 1878, xvi.

Graber, Die chordotonalen Sinesorgane und das Gehör der Insekten, Arch. mikroskop. Anat., 1882-83, xx, xxi.

Grünberg, K., Die blutsaugenden Dipteren, Jena, 1907.

del Guercio, Le tipuli ed i tafani nocivi nelle risaie de Molinella (Bologna), Redia, 1913, 299-345.

Hart, C. A., On the entomology of the Illinois River and adjacent waters, Bull. Illinois State Lab. Nat. Hist., 1895-96, iv, 220-247. (Gives photographic pictures of the larvæ. Same volume contains original description of Phanurus tabanivorus Ashmead.)

Henneguy, L. F., Les insectes, Paris, 1904. (Graber's organ, p. 488.)

Herms, W. B., Medical and veterinary entomology. A textbook for use in schools and colleges as well as a handbook for the use of physicians, veterinarians and public health officials, New York, 1915.

Hine, J. S., On the life history of Tabanus vivax, Ohio Naturalist, 1903, iv, 1-2. Hine, Tabanidæ of Ohio, Ohio State Univ. Contribution from the Dept. of Zool. and Entomol., Ohio Acad. Sc., No. 10, Special papers, No. 5, 1903.

Hine, Insects injurious to stock in the vicinity of the Gulf Biologic Station, U. S. Dept. Agric., Division of Entomol., Bull. 44, 1904, 57-60. (Mentions eggs of $T$. costalis.)

Hine, Same paper reprinted in Second Rep. Gulf Biol. Station, 1903, Bull. 2, 1904. Hine, Some economic considerations with reference to the Tabanidæ, Proc. XVIth Annual Meeting Assn. Economic Entomologists, U. S. D. A. E., No. 46, 1904, 23-25; Gulf. Biol. Station Rep., Bull. 2, 1904, 86-87, mentions eggs of trimaculatus.

Hine, Habits and life histories of some flies of the family Tabanidæ, U. S. Dept. Agric., Bureau Entomol., Technical Series 12, 1906, pt. 2, 19-38.

Howard, L. O., The insect book, 1901. (The family Tabanidæ is treated on pages 131-133. Riley's figures of Tabanus atratus are reproduced.)

Keilin, D., Sur certains organes sensitifs constants chez les larves de Diptères et leur signification probable, Compt. rend. Acad., 1911, cliii, 977-979. Quoted in Brauer (1883). No tabanids mentioned.

King, H. H., Report on economical entomology, Rep. Wellcome Research Lab. Gordon Memorial College, 1908, iii, 212-214. (Life history of Tabanus biguttatus.) 
King, Third Rep. Wellcome Research Lab. Gordon Memorial College, and Bull. Entomol. Research, 1910, i, pt. 2. (Bionomics of Tabanus par and taniola.)

King, Some observations on the bionomics of Tabanus ditaniatus Macquart, and Tabanus kingi Austen, Bull. Entomol. Research, 1910, i, pt. 4.

Kollar, M. V., Beitrag zum Haushalte der sehr lästigen Viehbremsen (Tabanidæ), Sitzungsb. math. naturwissensch., Classe d. k. Acad. Wissensch, 1854, xiii, 531-535.

Krauss, H., Otocystenartiges Organ bei Tabanus autumnalis L., Zool. Anz., Carus, 1879, ii, 229-230.

Lécaillon, A., Sur la ponte des œufs et la vie larvaire des Tabanides, particulierment du Taon a quatre tâches (Tabanus quatuornotatus Meig.), Ann. Soc. entomol. France, 1905.

Lécaillon, Sur l'organe de Graber de la larve de Tabanus quatuornotatus Meig., Compt. rend. Assn. anat., 1905, vii, 130-131, 3 figs.

Lécaillon, Sur quelques points de l'histoire naturelle des tabanides, en particulier de Tabanus quatuornotatus Meig., Compt. rend. Soc. biol., 1906, lx, 459.

Lécaillon, Deuxième note sur l'organe de Graber, Compt. rend. Assn. anat., 1906, viii, 65-67.

Lécaillon, Sur la structure de la couche chitineuse tegumentaire et sur les insertions musculaires de las larve de Tabanus quatuornotatus Meigen, Compt. rend. Assn. anat., 1906, viii, 68-70.

Lécaillon, Nouvelles observations sur la ponte des oeufs et la vie larvaire du Tabanus quatuornotatus Meig. (Dipt.), Ann. Soc. entomol. France, 1911, lxxx. Lutz, A., Dipteren. Mem. Inst. Oswaldo Cruz, Rio de Janeiro, 1914, vi, 43-49. Macquart, Histoire naturelle des insectes. Dipteres, 1834, i, 193. (Degeer's figure reproduced.)

Malloch, J. R., A preliminary classification of Diptera, exclusive of Pupipara, based upon larval and pupal characters, with keys to imagines in certain families. Bull. Illinois State Lab. Nat. Hist., 1917, xii, pt. 1.

Marno, E., Zur Biologie von Hexatoma, Verhandl. zool. bot. Ges., 1868, xviii, 74-75. Maxwell-Leffroy, H., and Howlett, F. M., Indian insect life, Agric. Research Inst., Pusa, India, Calcutta, and London, 1909. (Tabanidæ, pp. 592-595; Tabanus striatus, etc.; larval habits of Gastroxides ater.)

McAtee, W. L., Facts in the life history of Goniops chrysocoma (Diptera, Tabanidæ), Proc. Entomol. Soc. Washington, 1911, xiii, 21-29.

Mitzmain, M. B., The biology of Tabanus striatus Fabricius, the horsefly of the Philippines, Phil. J. Sc., Section B, 1913, viii, 197-221, Plate 7.

Neave, S. A., The Tabanidæ of southern Nyasaland, with notes on their life histories, Bull. Entomol. Research, 1915, v, pt. 4, 287-320, 4 plates.

Osburn, R. C., Tabanidæ as inhabitants of the Hydrophytic Area, J. Nerw York Entomol. Soc., 1913, xxi, 63-65.

Packard, A. S. Textbook on entomology, New York, 1898, gives on page 627, Fig. 520, an illustration of the pupa of Midas clavatus which is erroneously referred to Tabanus atratus. Fig. $520 \mathrm{c}$ probably represents atratus (after Riley?, very imperfect), $520 d$ is Proctacanthus. The pupa of Tabanus lineola is represented on p. 630, Fig. 585. 
Paoli, G., Intorno all' organo del Graber, nelle larvae di ditteri tabanidi, Redia, 1907, iv, 247-258.

Patton, W. S., and Cragg, F. W., Textbook of medical entomology, Christian Literature Society for India, London, Madras, and Calcutta, 1913.

Perris, E., Histoire des insectes du pin maritine, Ann. Soc. Entomol. France, 1870, x, 135-232. (Description of larva of Hamatopota, pp.196-198; pupa, pp. 198-199; tabanid early stages in general, pp. 199-201.)

Picard, F., and le Blanc, G. R., Sur les moeurs lignicoles de la larve de Tabanus cordiger Meig. (Dipt. Tabanidæ), Bull. Soc. Entomol. France, 1913, 318-321, Fig. 1.

Portschinsky, Biologie, Beschreibung, Bekämpfung von Tabaniden, (Russ), 4th edition, Trd. B. entom. Ucen. Kom. M. Zeml., St. Petersburg. (Travaux de Bureau entomologique de Comite scientifique du Ministere d'Agriculture et des Domaines. St. Petersbourg, Russe), 1908, i, 1-52, 21 figs. (This paper contains an illustration of the egg mass of the European species Tabanus montanus which is black and placed on the leaf of a grass plant above water, and two illustrations of the pupa of Tabanus tarandinus. These two species have to be added to the list of species on which data are available. The illustrations are not reproduced because the paper which I have seen on one occasion, became unavailable.)

Riley, C. V., The black breeze-fly-Tabanus atratus Fabr., Second Ann. Rep. on the noxious, beneficial, and other insects of the State of Missouri, made to the State Board of Agriculture, 1870, 128-132.

Riley, W. A., and Johannsen, O. A., Handbook of medical entomology, Ithaca, 1915, (gives illustrations of the larva of Tabanus atratus and of eggs of a common unknown species).

Scholtz, H., Ueber den Aufenthalt der Dipteren während ihrer ersten Stände, Z. Entomol., 1848, 25-34. (p. 28, tabanid larvæ.)

Sharp, D., The Cambridge Natural History, Insects, 1901, vi, pt. 2, 483. (Tabanus larva, supposed to be that of Atylotus fulvus).

Surcouf, J. M. R., and Ricardo, G., Etude Monographique des Tabanides d'Afrique (Groupe des Tabanus), Paris, 1909 (Pupa of Tabanus bromins, etc.). These figures reproduced in Brumpt (1910).

Wahlberg, P. F., Bidrag till Svenska Dipternas Kännedom. Koningl. Wetenskaps Academiens Handlingar, for år 1838, Stockholm, 1839. (Though Tabanus glaucopis imago is described, nothing is said about the larval stage.) Quoted by Brauer (1883).

Walsh, B. D., On certain remarkable or exceptional larvæ, coleopterous, lepidopterous, and dipterous, with demonstrations of several species injurious to vegetation which have been already published by Agricultural Journals, Proc. Boston Soc. Nat. Hist., 1863, ix, 302-306.

Walton, W. R., Notes on the egg and larva of Goniops chrysocoma O. S., Entomol. News, 1908, xix, 464-465.

Westwood, J. O., Introduction to the modern classification of insects, 1840, ii, 538.

Zetterstedt, Diptera Scandinaviæ, i, 105 (Tabanus larvæ), and 123 (Chrysops). 


\section{Plate 1.}

FIG. 1. Female of Chrysops merens, ovipositing on Typha leaf. After Hine (photograph from life).

FIG. 2. Egg masses of Chrysops merens, on Sparganium leaf. After Hine (photograph).

FIG. 3. Egg mass of Tabanus stygius on Sagittaria leaf. After Hine.

FIG. 4. Egg mass of Tabanus stygius on Peltandra leaf. After Hine.

FIG. 5. Egg mass of Tabanus stygius in unusual location. After Hine.

FIG. 6. Egg masses of Tabanus sp.? After Riley and Johannsen (photograph).

FIG. 7. Egg mass of Tabanus sp.? Natural size $24 \mathrm{~mm}$. After MaxwellLeffroy and Howlett (colored original yellow).

FIG. 8. Egg mass of Tabanus taniola, with chalcid parasites. After King (colored plate).

FIG. 9. $a$, Egg mass of Tabanus teniola; $b$, young larva. After King (colored plate).

FIG. 10. Egg mass of Tabanus par. After King (colored plate).

FIG. 11. Young larva of Tabanus par. Natural size $10 \mathrm{~mm}$. After King (colored plate).

FIG. 12. Egg mass of Tabanus bicallosus on a blade of grass. After Patton and Cragg.

FIg. 13. Two single eggs of Tabanus bicallosus. After Patton and Cragg.

FIG. 14. Egg mass of Chrysops dispar, on a blade of grass. After Patton and Cragg.

FIG. 15. Single egg of Chrysops dispar. After Patton and Cragg.

FIG. 16. Egg mass of Tabanus virgo, on a dry twig. After Patton and Cragg.

FIG. 17. Single egg of Tabanus ditceniatus. After Patton and Cragg.

FIG. 18. Egg mass of Tabanus biguttatus. Natural size $14 \mathrm{~mm}$. After King (colored plate).

Fig. 19. Egg mass of Tabanus speciosus. After Patton and Cragg.

FIg. 20. Egg mass of Tabanus kingi. After King.

King's illustration of a rock situated above water, showing the location of these egg masses, has been omitted. 
MONOGRAPH NO. 13.

PLATE 1.

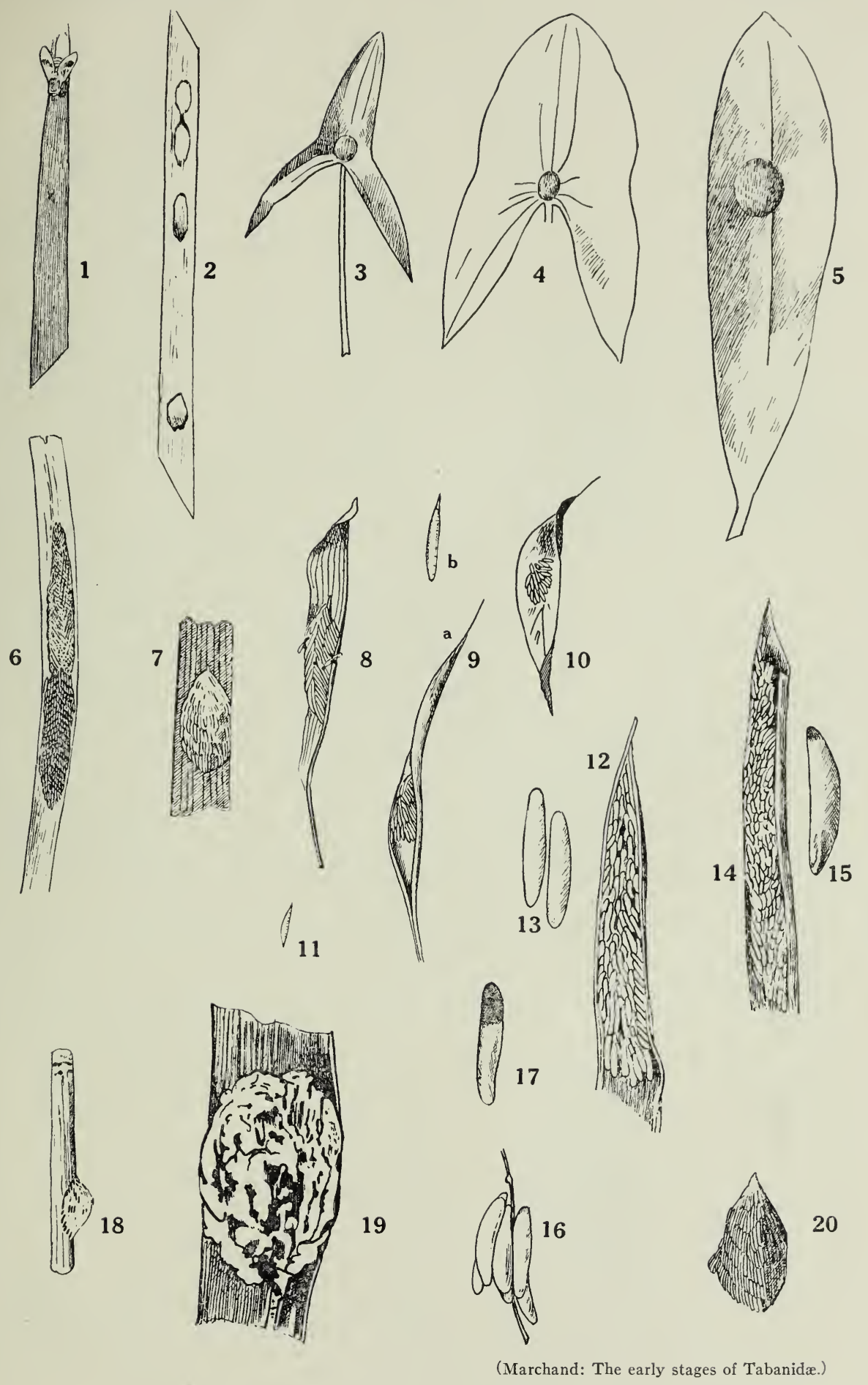




\section{Plate 2.}

Fig. 21. Egg mass of Tabanus diteniatus spread out in a single layer on a blade of grass. After Patton and Cragg.

Fig. 22. Egg mass of Tabanus striatus on paddy leaf. Natural size $13 \mathrm{~mm}$. After Bainbridge and Fletcher.

FIG. 23. Same egg mass, magnified. After Bainbridge and Fletcher.

Fig. 24. Female of Tabanus striatus, ovipositing. Natural size of fly $19 \mathrm{~mm}$. After Mitzmain (photograph).

Fig. 25. Egg masses of Tabanus striatus. After Mitzmain (photograph).

Fig. 26. Empty (?) egg mass of Tabanus striatus. After Mitzmain (photograph).

FIG. 27. Egg mass of Tabanus striatus in process of hatching. After Mitzmain (photograph).

Fig. 28. Female of Goniops chrysocoma, ovipositing. After McAtee (photograph).

FIG. 29. Egg mass of Goniops chrysocoma, seen from above. After Walton.

FIG. 30. Egg mass of Goniops chrysocoma, lateral view. After McAtee (photograph).

Fig. 31. Egg mass of Goniops chrysocoma. Natural size $14 \mathrm{~mm}$. After McAtee (photograph).

Fig. 32. Empty egg mass of Goniops chrysocoma after hatching. After McAtee.

Fig. 33. Double egg mass of Tabanus quatuornotatus. After Lécaillon.

Fig. 34. Two single egg masses of Tabanus quatuornotatus. Natural size 9 mm. After Lécaillon.

Fig. 35. Group of egg masses of Tabanus quatuornotatus on dried twig. After Lécaillon.

FIGS. 36, 37, and 38. Egg masses of Tabanus quatuornotatus, magnified. After Lécaillon. 
MONOGRAPH NO. 13.

PLATE 2.
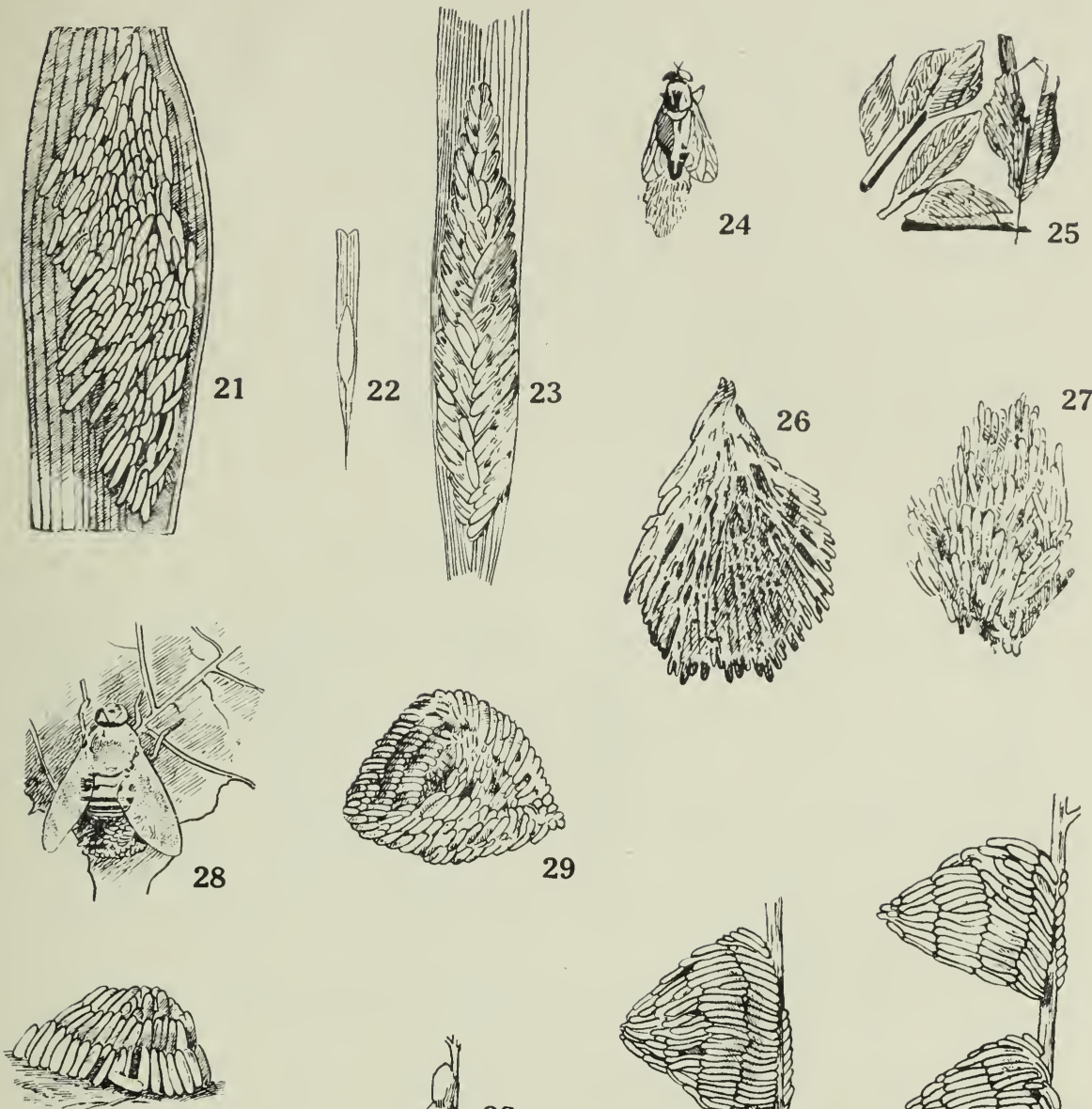

30
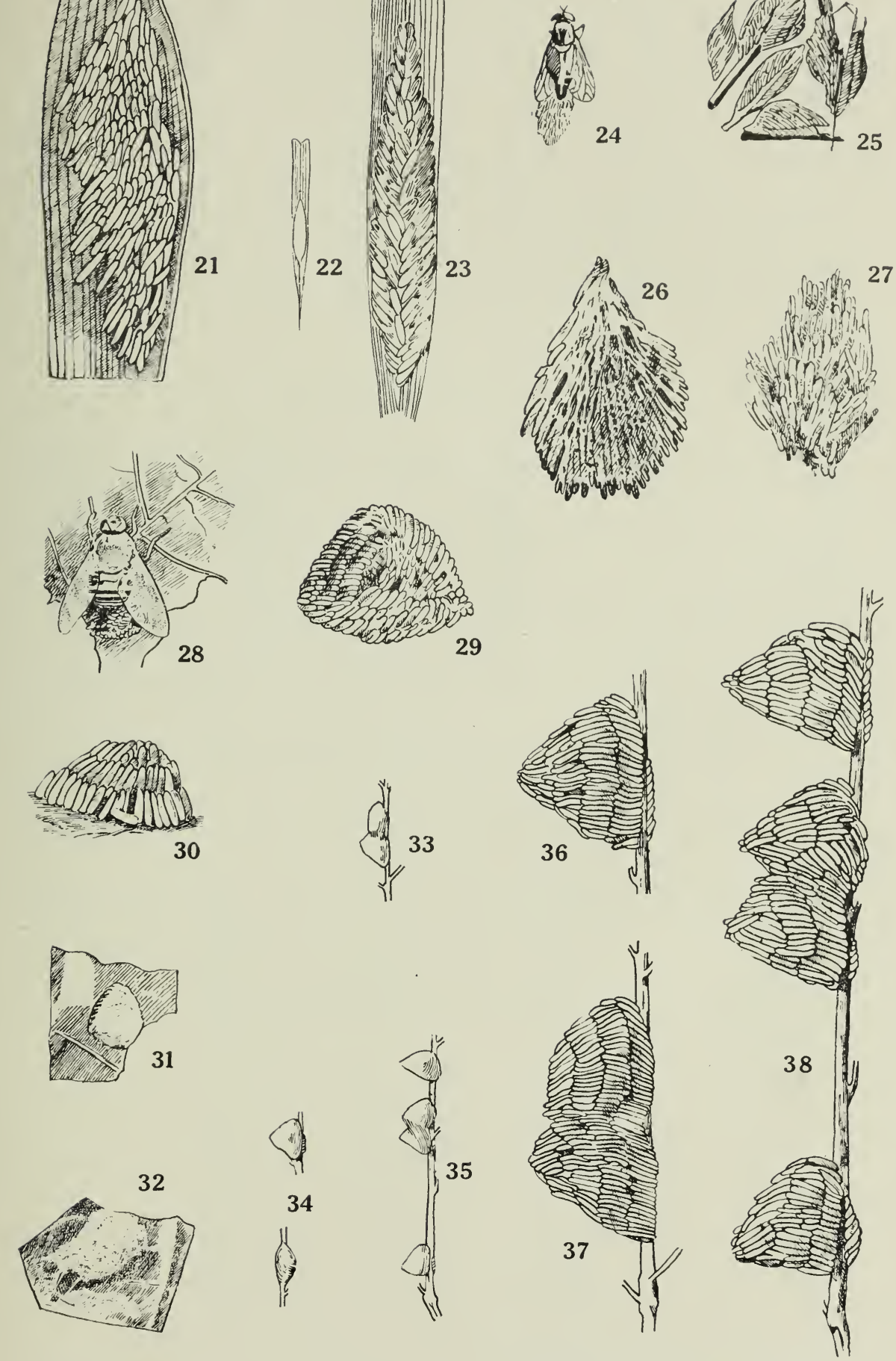

(Marchand: The early stages of Tabanidæ.) 


\section{Plate 3.}

Fig. 39. Larva of Chrysops vittatus. Natural size $15 \mathrm{~mm}$. After Hart (photograph).

FIG. 40. Larva of Tabanus stygius. Natural size $52 \mathrm{~mm}$. After Hart (photograph).

Fig. 41. Larva of Tabanus atratus. Natural size $53 \mathrm{~mm}$. After Hart (photograph).

Fig. 42. Larva of Tabanus sp.? Natural size $24 \mathrm{~mm}$. After Hart (photograph).

FIg. 43. Larva of Tabanus vivax. Natural size $36 \mathrm{~mm}$. After Hine.

Fig. 44. Larva of Tabanus lasiophthalmus. Natural size $23 \mathrm{~mm}$. After Hine.

Fig. 45. Larva of Tabanus atratus. After W. A. Riley and Johannsen (photograph).

FIg. 46. Larva of Tabamus atratus. Natural size $52 \mathrm{~mm}$. After C. V. Riley.

Fig. 47. Larva of Tabanus ditcniatus. Lateral view of immature larva. After King (colored plate).

Fig. 48. Larva of Tabanus par, almost full grown. Natural size $52 \mathrm{~mm}$. After King (colored plate).

Fig. 49. Larva, full grown, of Tabanus taniola. After King (colored plate).

Fig. 50. Larva of Chrysops wellmani. Natural size $13 \mathrm{~mm}$. After Neave (Terzi).

Fig. 51. Larva of Tabanus gratus. Natural size $23 \mathrm{~mm}$. After Neave (Terzi).

Fig. 52. Larva of Tabanus atrimanus. Natural size $32 \mathrm{~mm}$. After Neave (Terzi).

Fig. 53. Larva of Tabanus insignis. Natural size $34 \mathrm{~mm}$. After Neave (Terzi).

Fig. 54. Larva (supposed larva) of Tabanus pertinens. Natural size $36 \mathrm{~mm}$. After Neave (Terzi). 
MONOGRAPH NO. 13.
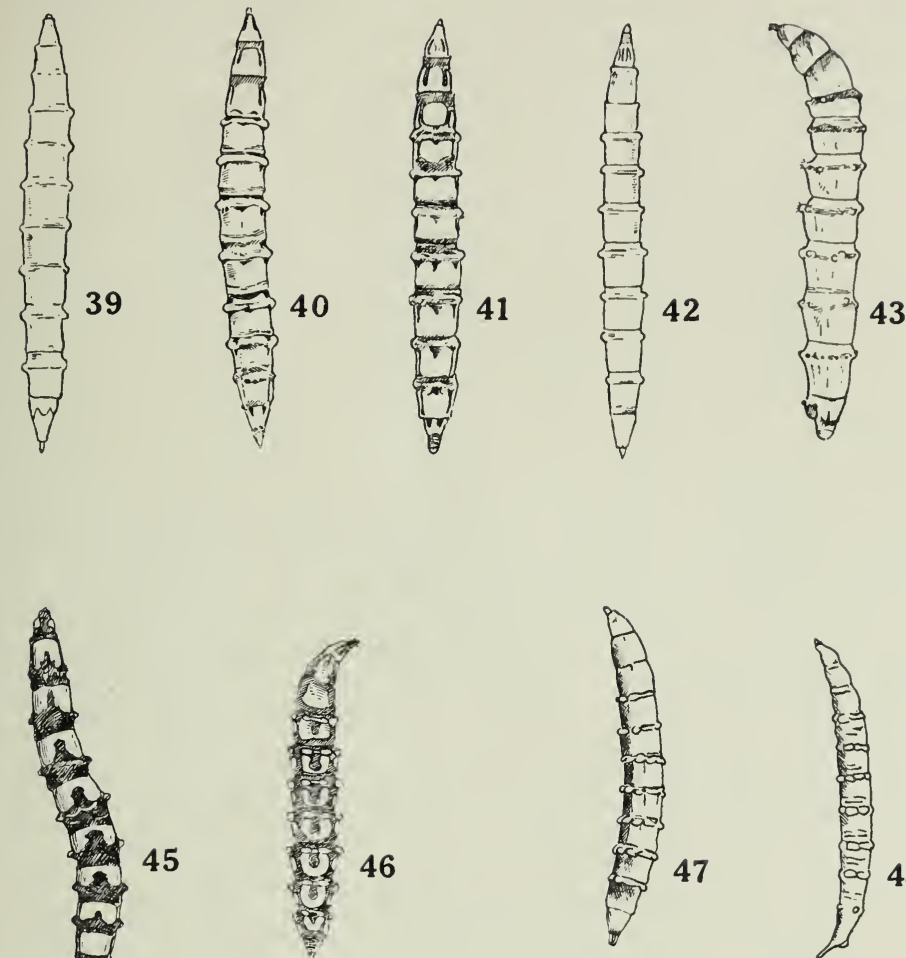

PLATE 3.
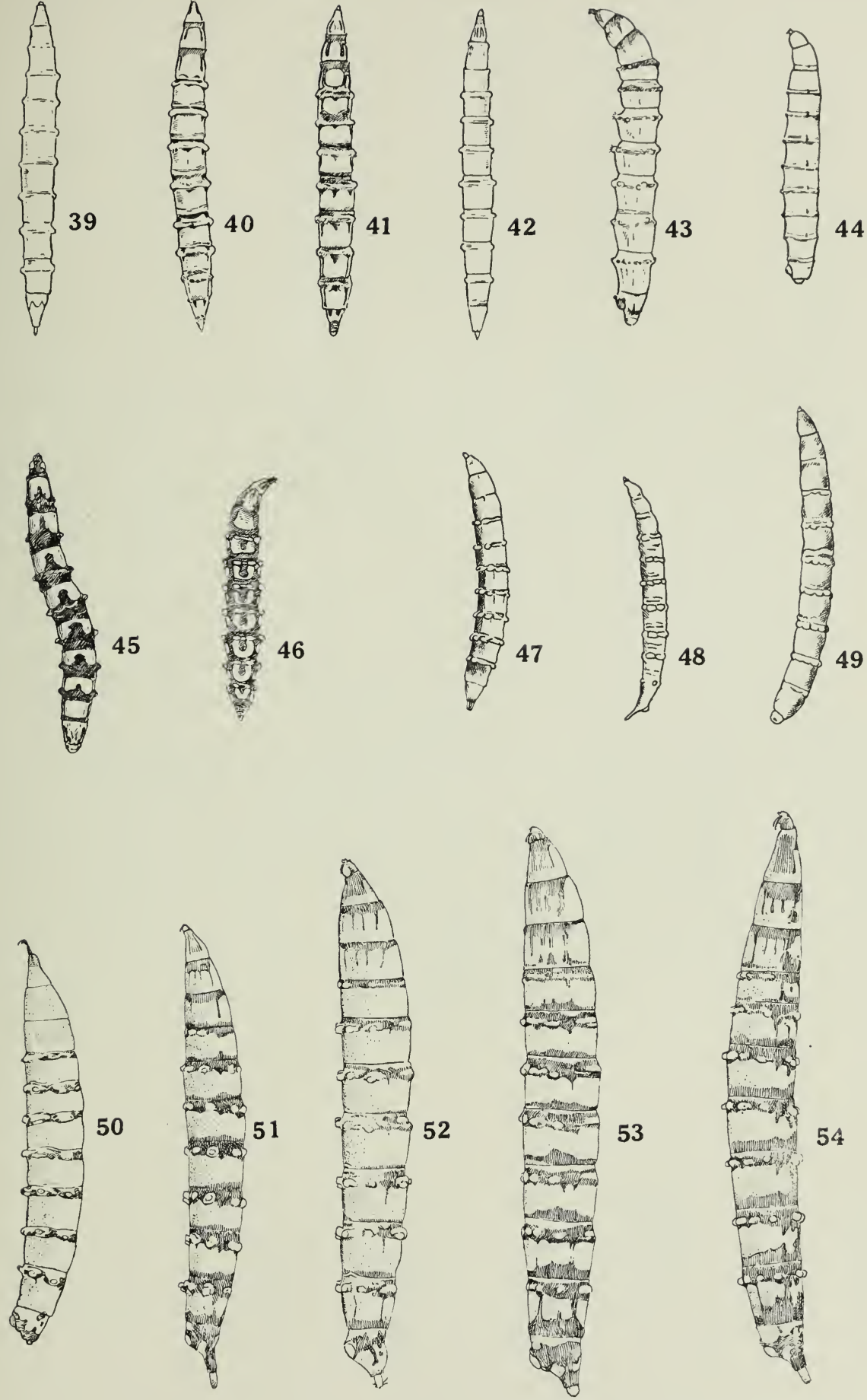

(Marchand: The early stages of Tabanidæ.) 


\section{Plate 4.}

FIG. 55. Larva of Tabanus sp.? a, Ventral view; $b$, cross-section of segment; $c$, dorsal view. Natural size $32 \mathrm{~mm}$. After Brumpt.

Fig. 56. Larva of Tabanus kingi. After King.

Fig. 57. Larva of Tabanus ditcniatus. $a$, Immature larva; $b$, mature larva, lateral view; $c$, 6th and 7 th segments of immature larva, lateral view; $d$, caudal end of immature larva. After King.

Fig. 58. Larva of Tabanus sp.? After Grünberg.

FIG. 59. Early stages of Tabanus bovinus. $a$, Larva; $b$, pupa; $c$, anal end of larva; $d$, anal end of pupa. After Degeer.

FIG. 60. Larva of Tabanus (Atylotus) fulvus (?). a, Entire larva; $b$, head and mouth-parts; $c$, one proleg; $d$, segments 10, 11, and 12 in lateral view. After Sharp.

Fig. 61. Mature larva of Tabanus ditcniatus. After Patton and Cragg.

Fig. 62. Mature larva of Tabanus bicallosus. After Patton and Cragg.

Fig. 63. Mature larva of Tabanus virgo. After Patton and Cragg.

Fig. 64. Larva of Tabanus ditcniatus. a, Segments 3, 4, and 5, lateral view; $b$, segments 11 and 12, lateral view; $c$, segments 11 and 12, ventral view. After King.

Fig. 65. Larva of Tabanus kingi. a, Lateral view of two abdominal segments; $b$, one proleg; $c$, ventral side of anal segment. After King. 
MONOGRAPH NO. 13
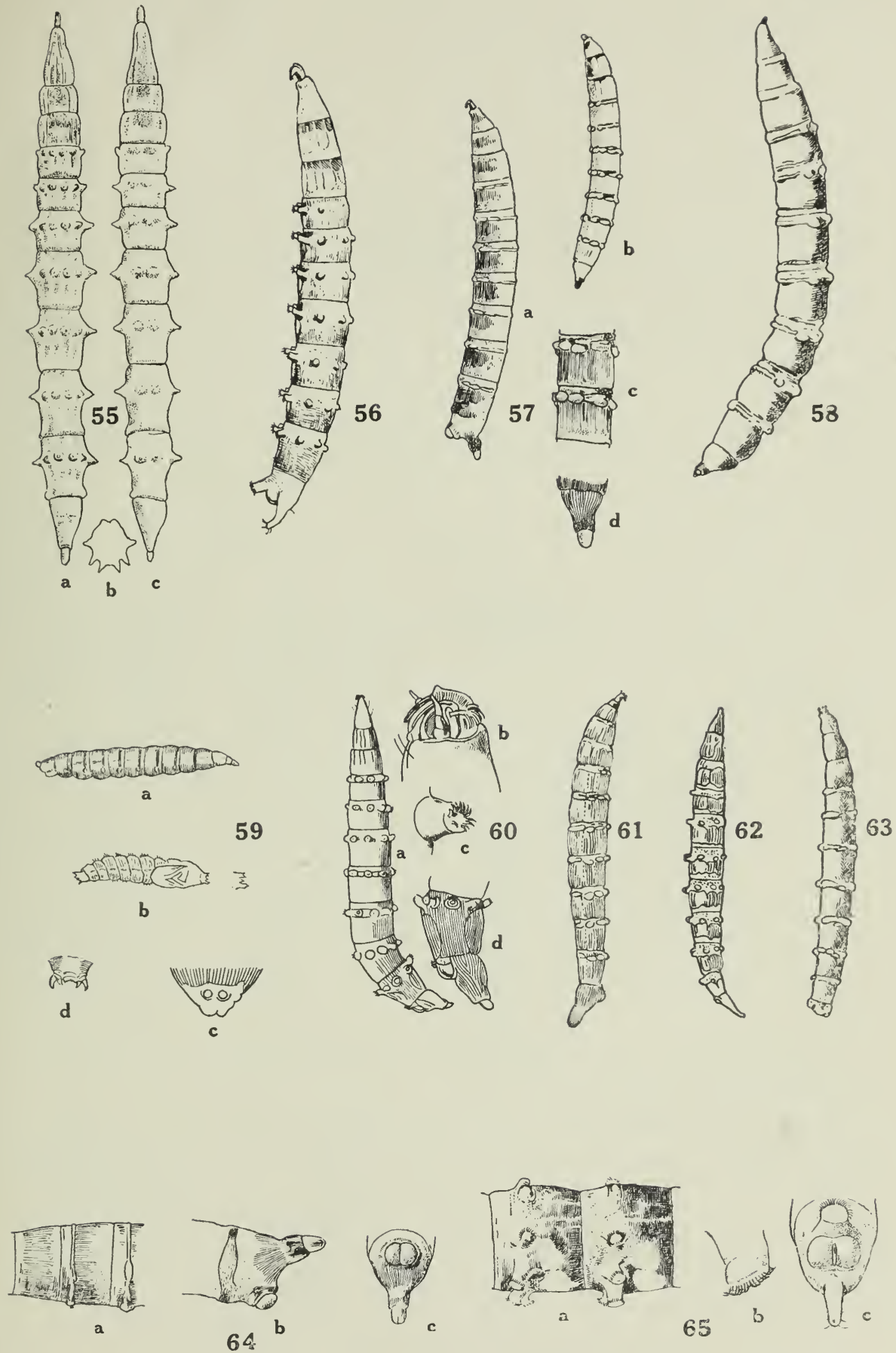

(Marchand: The early stages of Tabanidæ.) 


\section{Plate 5.}

Fig. 66. Caudal end of larva of Tabanus ustus, lateral view. After Neave (Terzi).

Fig. 67. Caudal end of larva of Tabanus corax, lateral view. After Neave (Terzi).

Fig. 68. Caudal end of larva of Tabanus medionotatus, lateral view. After Neave (Terzi).

Fig. 69. Caudal end of larva of Tabanus biguttatus, lateral view. After Neave (Terzi).

FIG. 70. Caudal end of larva of Tabanus variabilis, lateral view. After Neave (Terzi).

Fig. 71. Caudal end of larva of Tabanus maculatissimus, lateral view. After Neave (Terzi).

Fig. 72. Caudal end of larva of Chrysops longicornis, lateral view. After Neave (Terzi).

Fig. 73. Caudal end of Chrysops. Dorsal view; diagram. After Neave.

FIg. 74. Caudal end of Hamatopota. Dorsal view; diagram. After Neave.

Fig. 75. $a, b$, Larva of Tabanus biguttatus. Natural size $42 \mathrm{~mm}$. After King (colored plate).

Fig. 76. a, Young larva of Tabanus sp.? Colored original greenish white. After Maxwell-Leffroy and Howlett (colored plate). $b$, Full grown larva of Tabamus sp.? Same species as Fig. 76, a. Colored original yellow. Natural size $47 \mathrm{~mm}$. After Maxwell-Leffroy and Howlett (colored plate). c, Hymenopterous parasite of same larva. After Maxwell-Leffroy and Howlett (colored plate).

Fig. 77. Head and first segment of larva of Tabanus atratus. After Malloch.

Fig. 78. Mandibles of larva of Tabanus biguttatus. After King (colored plate).

Fig. 79. Mandibles of larva of Tabanus striatus. After Mitzmain (photograph)

FIG. 80. Larval stages of Tabanus striatus. $a$, Newly hatched larvæ; $b$, young larva magnified; $c$, two full grown larvæ. Natural size of the latter $34 \mathrm{~mm}$. After Mitzmain (photograph).

Fig. 81. $a, b, c$, Shed skins (exuviæ) of three different larval stages of Tabanus atratus. After Mitzmain (photograph). 
MONOGRAPH NO. 13.

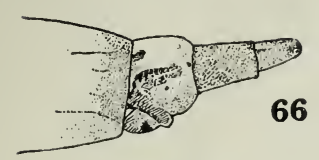

68
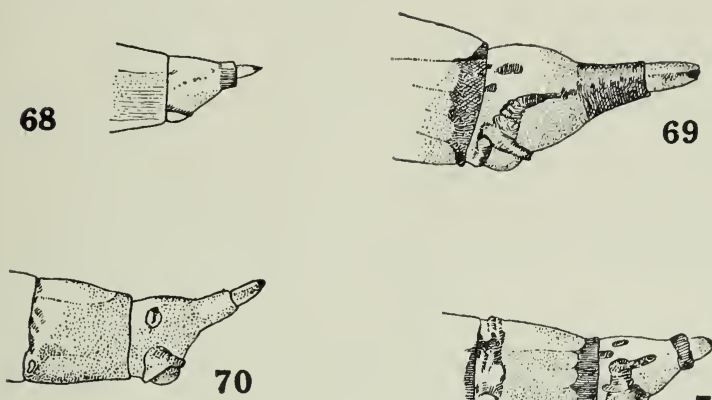

70
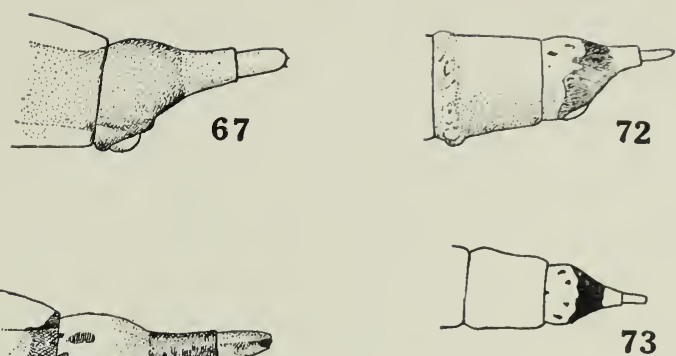

$\longrightarrow 74$
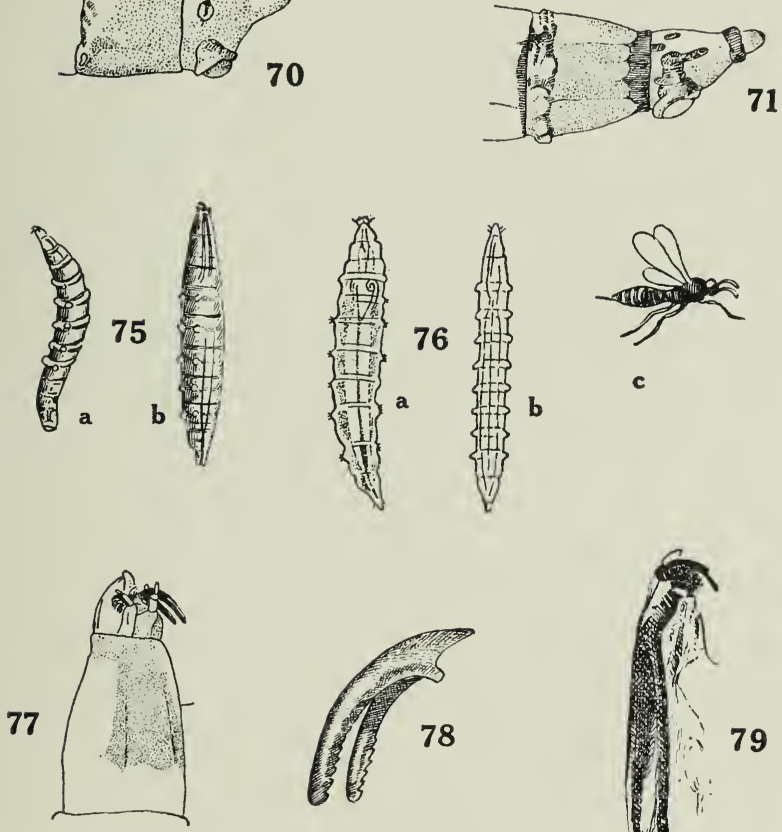

c
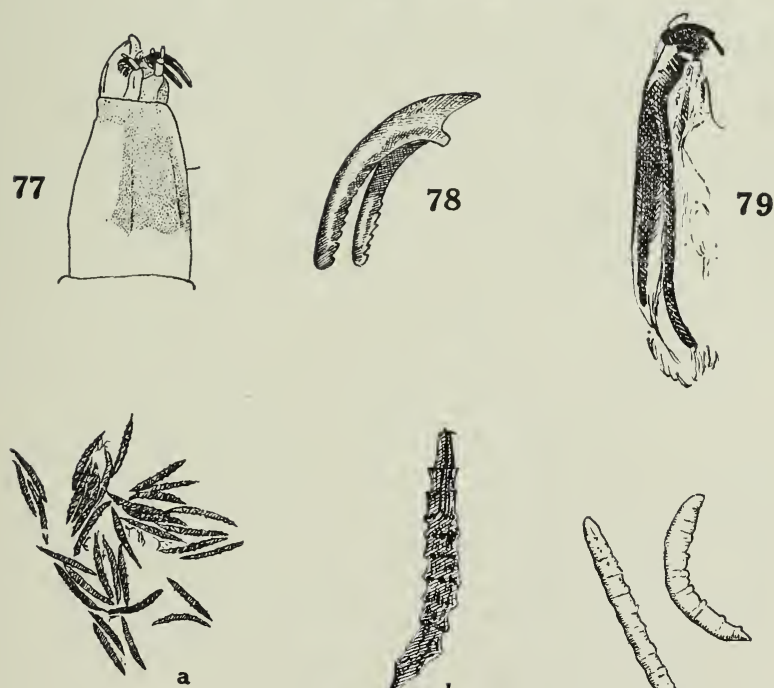
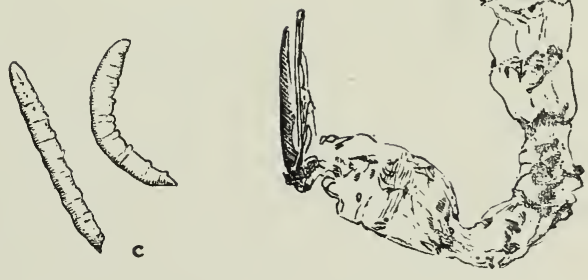

(Marchand: The early stages of Tabanidæ.) 


\section{Plate 6.}

FIg. 82. Early stages of Hamatopota pluvialis. a, Larva, natural size 13 $\mathrm{mm}$; $b$, head and mouth-parts, dorsal view; $c$, head and mouth-parts, lateral view; $d$, ventral view of anal segment; $e$, terminal spiracle; $f$, pupa; $\delta$, pupal structure. After Perris.

FIG. 83. Stages of Hamatopota pluvialis. a, Larva, lateral view, natural size $14 \mathrm{~mm}$.; $b$, terminal spiracle of larva; $c$, pupa; $d$, terminal segment of pupa. After Brauer.

FIG. 84. Head and mouth-parts of Hamatopota pluvialis. ant, antenna; lr, labrum; $l b$, labium; $m d$, mandible; $p$, palpus. After Brauer.

Fig. 85. Larva of Hcematopota crudelis. Natural size $13 \mathrm{~mm}$. After Neave (Terzi).

Fig. 86. Caudal end of larva of Hamatopota insatiabilis. After Neave (Terzi).

Fig. 87. Larva of Tabanus spodopterus. a, Larva magnified; $b$, dorsal view, natural size $45 \mathrm{~mm} . ; c$, lateral view; $d$, caudal end of larva; $e$, terminal spiracle; $f$, head of larva, later.l view, magnified. After Brauer.

Fig. 88. Larva of Tabanus cordiger. a, Ventral view of larva, natural size 35 mm.; $b$, caudal end; $c$, cross-section through segment; $d$, caudal end with tracheæ.

Fig. 89. Larva of Hexatoma pellucens. $a$, Dorsal view of larva; $b$, dorsal view of last three segments of larva, showing pigmentation. Natural size $35 \mathrm{~mm}$. After Brauer.

FIG. 90. Head and mouth-parts of larva of Hexatoma pellucens. a, Lateral view; $b$, lateral view of mouth-parts; $c$, dorsal view of head. $l r$, labrum; $m d$, mandible; $p$, palpus; $a n t$, antenna; $o c$, eye-spot; $l b$, labium. After Brauer.

Fig. 91. Head of larva of Hamatopota pluvialis, dorsal view. Parts as in Figs. 84 and 90 . After Brauer. 
MONOGRAPH NO. 13.

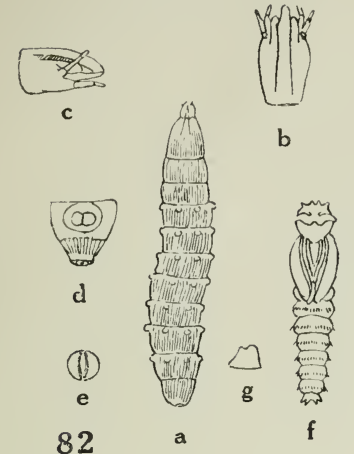

a

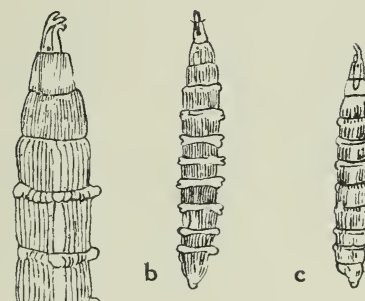

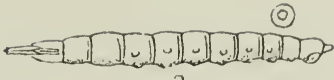

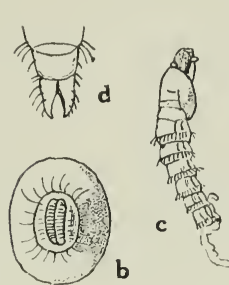

83
PLATE 6.

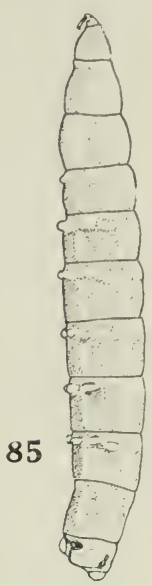

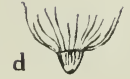

87

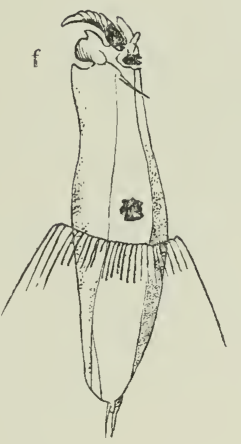

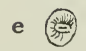

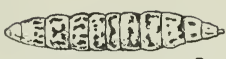

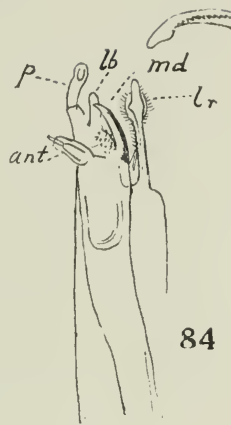

84
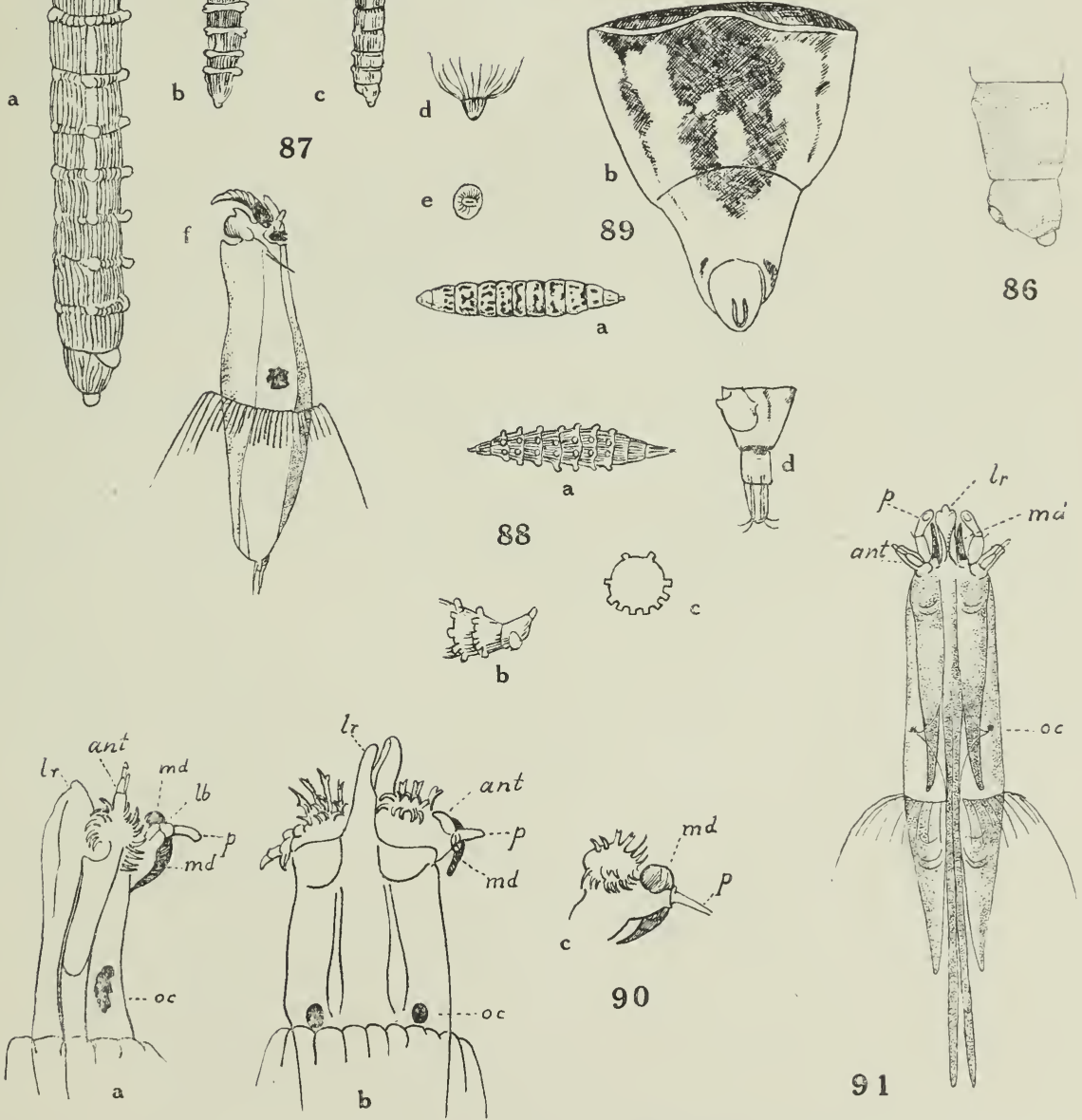

91

(Marchand: The early stages of Tabanidæ.) 


\section{Plate 7.}

Fig. 92. Full grown larva of Goniops chrysocoma. a, Dorsal; b, ventral; $c$, lateral view. Natural size $17 \mathrm{~mm}$. After McAtee (photograph).

FIG. 93. Young larva of Goniops chrysocoma. a, Entire larva, dorsal view; $b$, mouth-parts, magnified, from above; $c$, mouth-parts, lateral view. After Walton.

FIG. 94. Full grown larva of Goniops chrysocoma. After McAtee (photograph).

Fig. 95. $a, b$, Structures of head and mouth-parts of the full grown larva of Goniops chrysocoma. anf, base of antennæ; lbr, labrum; $m x$, maxilla; $m x p$, maxilla palpus. Other details as in Figs. 84, 90, 91. After McAtee.

FIG. 96. a, Larva of Tipula oleracea and b, Tabanus ignotus?, drawn for comparison. After del Guercio. (To judge from the figures, both drawings seem to represent tipulid larvæ.)

FIG. 97. Head of Tabanus albimedius, lateral view. $m d$, mandible; $m x$, maxilla; ant, antenna; $s p$, spines; $l r$, labrum; $p$, palpus. After Patton and Cragg.

Fig. 98. Intestinal tract of the full grown larva of Tabanus albimedius. ces, Esophagus; $p v$, proventriculus; $s l g$, salivary glands; $m g$, midgut; $m p t$, Malpighian tubes. After Patton and Cragg. 


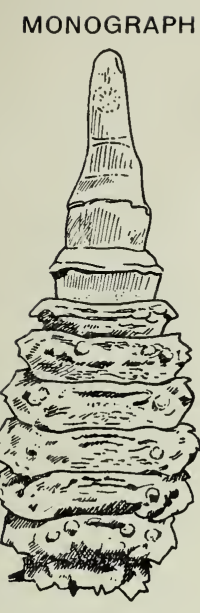

a

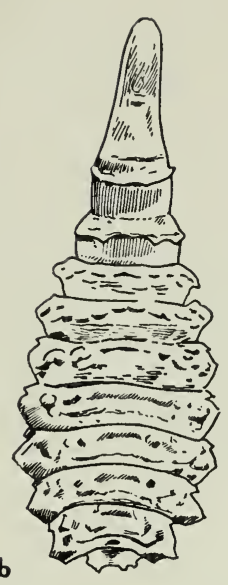

92
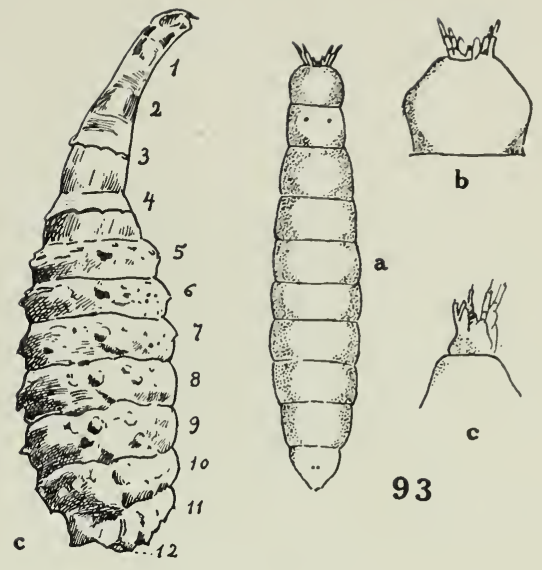

a.

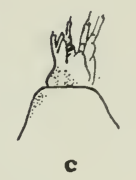

93

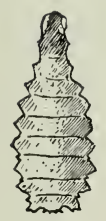

94
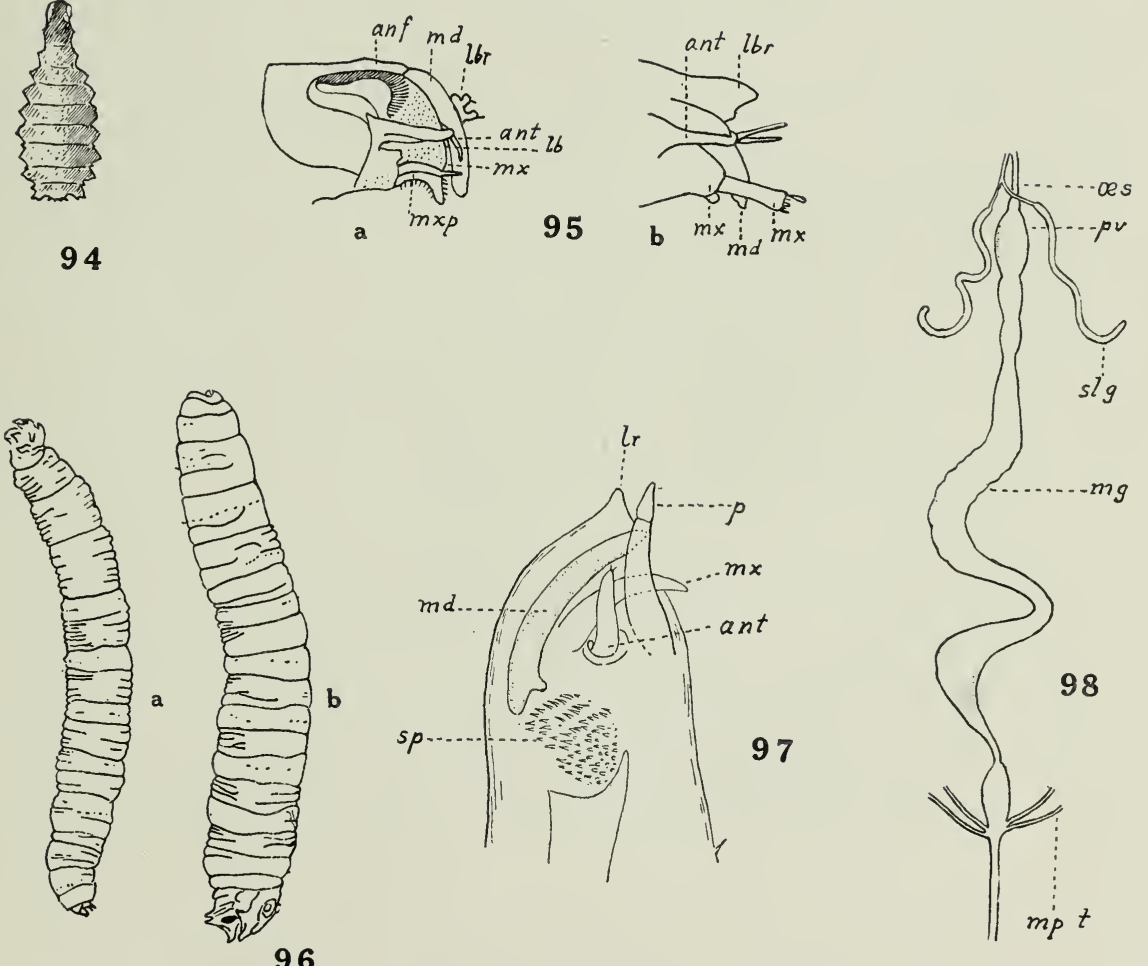

(Marchand: The early stages of Tabanidæ.) 


\section{Plate 8.}

Fig. 99. Newly hatched larva of Tabanus autumnalis (?). $s 1$ to $s 13$, somites (segments) of the body; $w$, prolegs armed with hooks; $t b$, touch-tactile bristle; $p h$, pharynx ; $m d$, midgut ; $c d$, hindgut ; $m a$, Malpighian vessels; $a$, anus; $t r$, tracheal trunks; $t s p$, terminal spine: $g$ sup, upper, $g$ inf, lower cephalic ganglion; $b g$ to $b g$ 11, ventral chain of ganglia; ch 1 to $\operatorname{ch} 3$, chordotonal organs; ot, otocyst-like organs on posterior border of anal segment (Graber's organ). After Graber.

FIG. 100. $a$, Right side of 2 nd and 3rd body segments of young Tabanus larva highly magnified.

2nd segment: $c u$, cuticle; ma, matrix; $m 1$, circular muscles of pharynx; $m 2$, muscles originating on the posterior border of the first segment, and extending forivard and inwards, possessing strongly marked transverse striation and great contractility; $h n$, nerve of the skin; $c k g, m k g$, ganglion cells connected with this nerve and possessing one nucleus $\mathrm{ekg}$, or several $\mathrm{mkg}$; $t b$, tactile bristle; s 2 ch 1 monoscolopic, s 2 ch 2 triscolopic chordotonal organ; li, ligament; st 2, rods; efs, terminal filament; e 1, e 2, e 3, attachments of filaments; $m n$, nerve going to muscle; $t r$, branch of tracheal system; $h g$, ganglion; $n u$, nuclei.

3rd segment, $m \cdot 3$, system of sagittal muscles, freely anastomizing, and in fresh condition smooth (unstriated) in appearance; $b l$, region of integument covered with bristles, in anterior part of segment; $s 3$ ch 1 to $s 3$ ch 6 chordotonal organs (taken from different individuals); (ch 1 and $c h 2$, and again $c h 4,5$, and 6 were observed in the same individual); $e 4, e 5, e 6$, points of attachments of the terminal filaments of $s 3$ ch 5 ; e 7,e 8,e 9, those of $s 3$ ch 2 ; $g$ inf, lower pharyngeal ganglion. After Graber. Zeiss oil immersion lens.

FIG. 100. b, Tactile bristle of young larva of Tabanus autumnalis (?), with its ganglion. $c u$, cuticle; $t b$, tactile bristle, articulating on its place of attachment; ma, matrix (hypoderm), in fresh condition showing no cell limits, with reddish nuclei; starting from it a fine filament torn out of the sheath surrounding the bristle; $k$, nuclei; $n$, nerve; $g$, ganglion. After Graber. Zeiss oil immersion lens.

FIG. 101. Triscolop chordotonal organ of the 2nd segment of the same larva. $n$, nerve; $g 1, g 2, g 3$, the three ganglion cells, lying one above the other, with reddish nuclei; $x f s$, neurit; st, rods; $k o$, heads of rods; $m k$, nucleus of the proximal end; $d k$, of the distal end of the rod; $f_{s} 1$ to $f s 3$, the three terminal filaments. After Graber. Zeiss oil immersion.

FIG. 102. Monoscolop chordotonal organ of the 2nd segment of the same larva $x f s$, neurit visible in the interior of the rod. After Graber. Zeiss oil immersion. 
MONOGRAPH NO. 13.

PLATE 8.

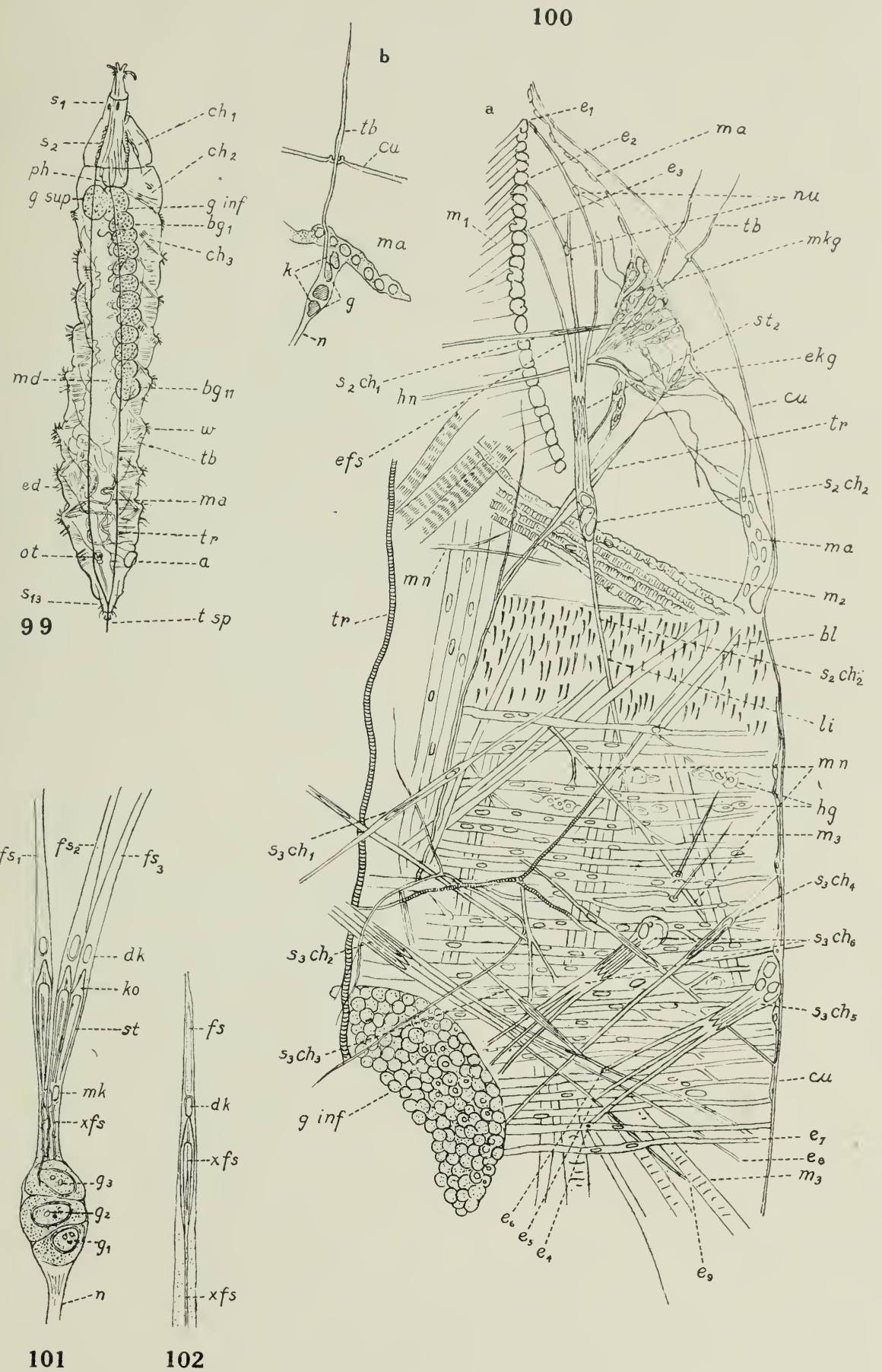

(Marchand: The early stages of Tabanidæ.) 


\section{Plate 9.}

FIG. 103. Larva of Tabanus autumnalis (?). g, Graber's organ. After Graber.

FIG. 104. Posterior end of larva, magnified, comprising 9th, 10th, 11th, and 12th segments. (In the original the numbers are given erroneously as 8, 9, 10, and 11.) $t r$, tracheal trunks; $d v$, dorsal vessel; $g$, Graber's organ; $t$, terminal tube; $m$, two muscles extending forward from Graber's organ. After Graber.

FIg. 105. Graber's organ in situ. $d v$, dorsal vessel; $t r$, lateral tracheal trunks; $f m$, muscle of dorsal vessel; $m$, muscles; $t$, terminal tube; $n$, nerves (?); $f$, fat body; $c u$, cuticle of integument; $h p$, hypoderm. $\times 60$. Zeiss oil immersion. After Graber.

FIG. 106. The organ isolated. $c 1$ to $c 3$, chitinous capsules; $s p$, extremity of capsule; $e p$, its epithelium; $c p 1$ to $c p 4$, pedunculate bodies, (in the original only the first capsule bears this name, while the inner ones are treated as "internal sacs"); $m 1$ to $m 2$, muscles; $n$ to $n 1$, nerves (?); ga, ganglion-like swelling of first nerve; $t$, terminal tube; $o p$, operculum. $\times 133$. Zeiss oil immersion. After Graber.

FIG. 107. One pair of pedunculate bodies. $c p$, body; st, hollow stem or peduncle; $c u$, scaly cuticle to which they are fastened. $\times 333$. Zeiss oil immersion. After Graber.

FIG. 108. A portion of elastic connective tissue from the surroundings of the organ, after treatment with boiling $\mathrm{KOH} . \times 333$. Zeiss oil immersion. After Graber.

Graber's figures, Figs. 103 to 108, were drawn from fresh material. 

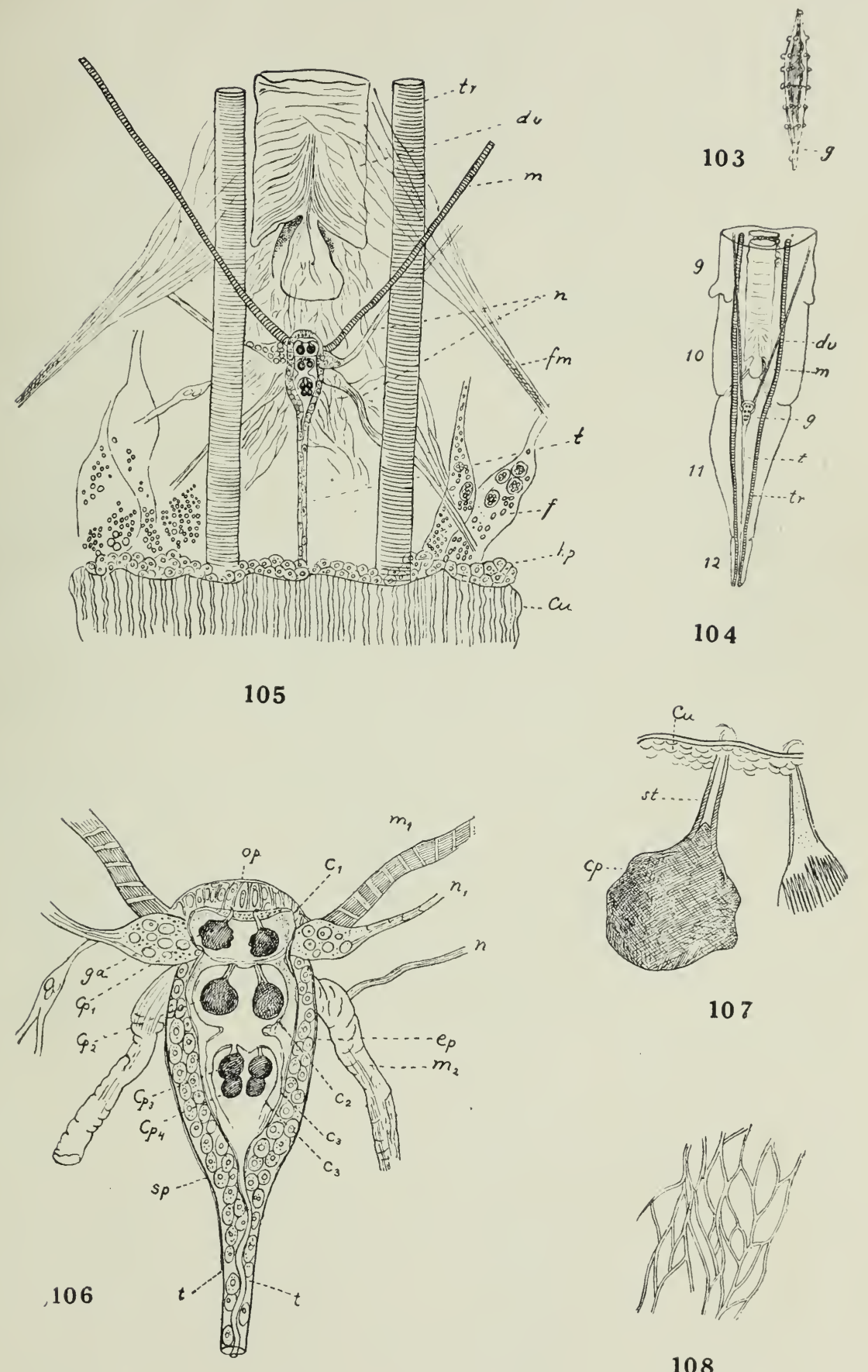

107

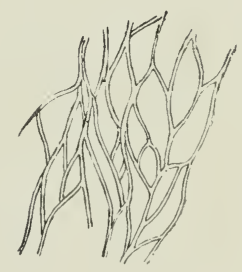


Plate 10.

Fig. 109. Young larva of Tabanussp.? tr, tracheal trunk; g, Graber's organ. After Henneguy.

FIG. 110. Graber's organ, enlarged, of larva figured in Fig. 109. After Henneguy.

FIG. 111. Larva of Tabamus sp.?, showing the location of Graber's organ (the latter drawn larger than in proportion to the size of the larva). After Paoli.

FIG. 112. Graber's organ in full grown larva of Tabanus sp.?, with muscle and nerves attached to it. $c 1$ to $c 7$, capsules; $c p$, pedunculate bodies; $m$, muscle; $n$, nerve. After Paoli.

FIG 113. Hypothetical diagram of the development of Graber's organ. $c 1$, first capsule; $c$ 2, second capsule; $h p$, hypoderm; $c t$, cuticle. After Paoli.

FIG. 114. Terminal tube of Graber's organ. $h p$, hypoderm. After Paoli.

FIG. 115. Last three segments of larva, showing Graber's organ in situ. Dorsal view $t r$, tracheal trunk; $m 1$, muscles of the first pair; $a$, anal tubercle. After Paoli.

FIG. 116. Last three segments of larva, with Graber's organ. Lateral view. $m$ 2, muscle of the second pair; $t$, terminal tube. Other details as in Fig. 115. After Paoli.

FIg. 117. Young larva of Tabanus quatuornotatus. After Lécaillon.

FIGS. 118 and 119. Posterior end of body of larva of Tabanus quatuornotatus, somewhat older than that figured in Fig. 117, showing the pedunculate bodies being expelled through the terminal tube. After Lécaillon.

FIG. 120. Dorsal view of Segments 11 and 12 (syphon) of a young larva Tabanus corax, showing Graber's organ; the dotted lines show the position of the anus. After Neave. 


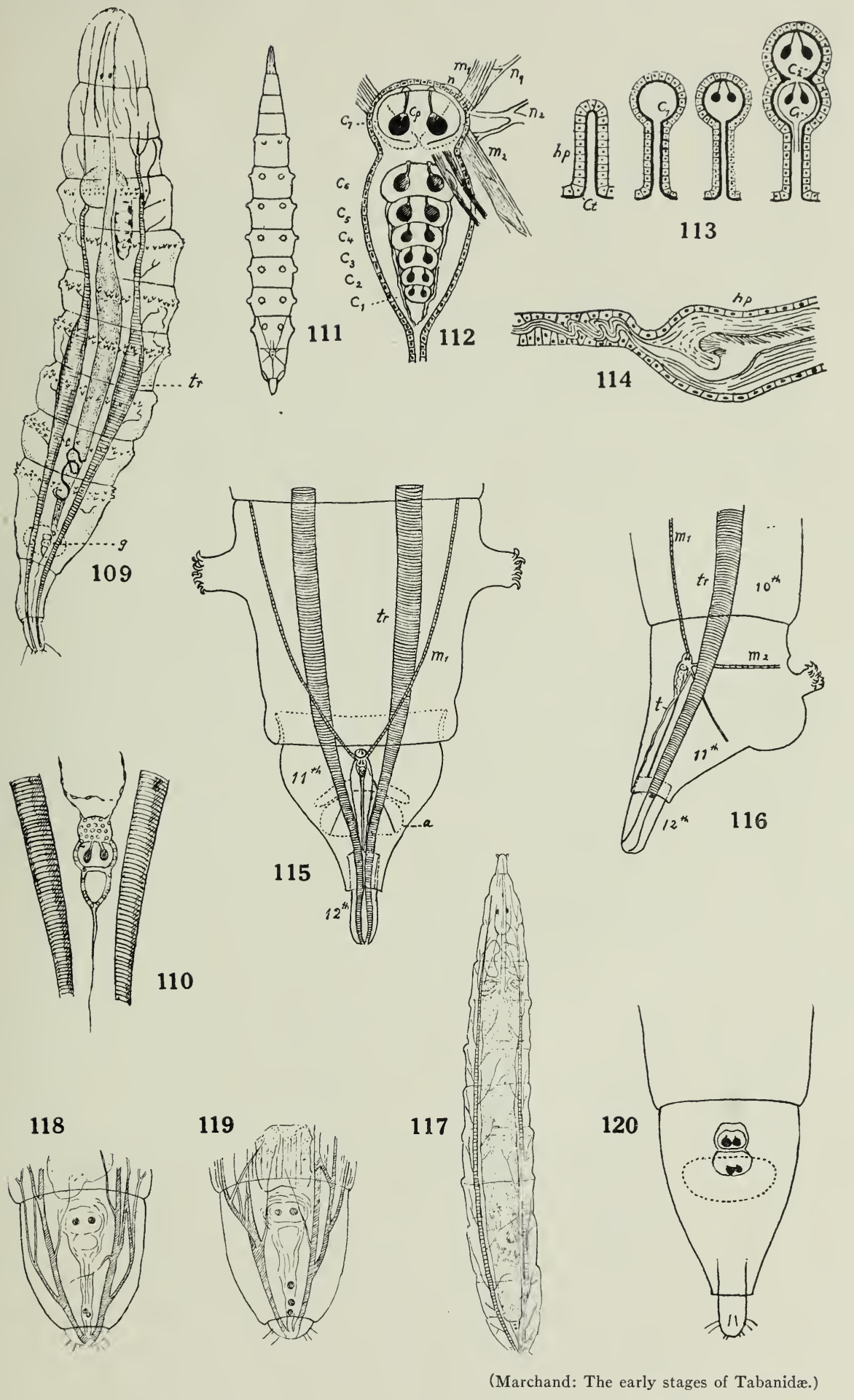


Plate 11.

FIG. 121. Pupa of Goniops chrysocoma. $a$, Dorsal; b, ventral; c, lateral view. After McAtee.

Fig. 122. Pupa of Tipula oleracea. After Paoli.

FIg. 123. Pupa of Tabanus ignotus. Compare with Fig. 122. After Paoli. (See also Fig. 96, $a, b$. No resemblance is found in the pupæ which indicates that Fig. 96, $b$, does not represent a tabanid larva.)

Fig. 124. Pupa of Tabanus atratus. Natural size $31 \mathrm{~mm}$. After Hine.

FIg. 125. Pupa of Tabanus stygius. Natural size $28 \mathrm{~mm}$. After Hine.

Fig. 126. Pupa of Tabanus sulcifrons. Natural size $27 \mathrm{~mm}$. After Hine.

FIg. 127. Pupa of Tabanus lasiophthalmus. Natural size $23 \mathrm{~mm}$. After Hine.

Fig. 128. Pupa of Tabanus vivax. Natural size $23 \mathrm{~mm}$. After Hine.

FIg. 129. Pupa of Tabanus ditceniatus. After King.

FIg. 130. Pupa of Chrysops longicornis. Natural size $11 \mathrm{~mm}$. After Neave (Terzi).

FIG. 131. Pupa of Hamatopota insatiabilis. Natural size $11 \mathrm{~mm}$. After Neave (Terzi).

Fig. 132. Pupa of Tabanus sp.? Natural size $18 \mathrm{~mm}$. After MaxwellLeffroy and Howlett.

Fig. 133. Pupa of Tabanus diteniatus. Ventral view. After Patton and Cragg.

Fig. 134. Pupa of Tabanus virgo. Ventral view. After Patton and Cragg.

Fig. 135. Pupa of Tabanus bicallosus. Ventral view. After Patton and Cragg. 
MONOGRAPH NO. 13.

PLATE 11.
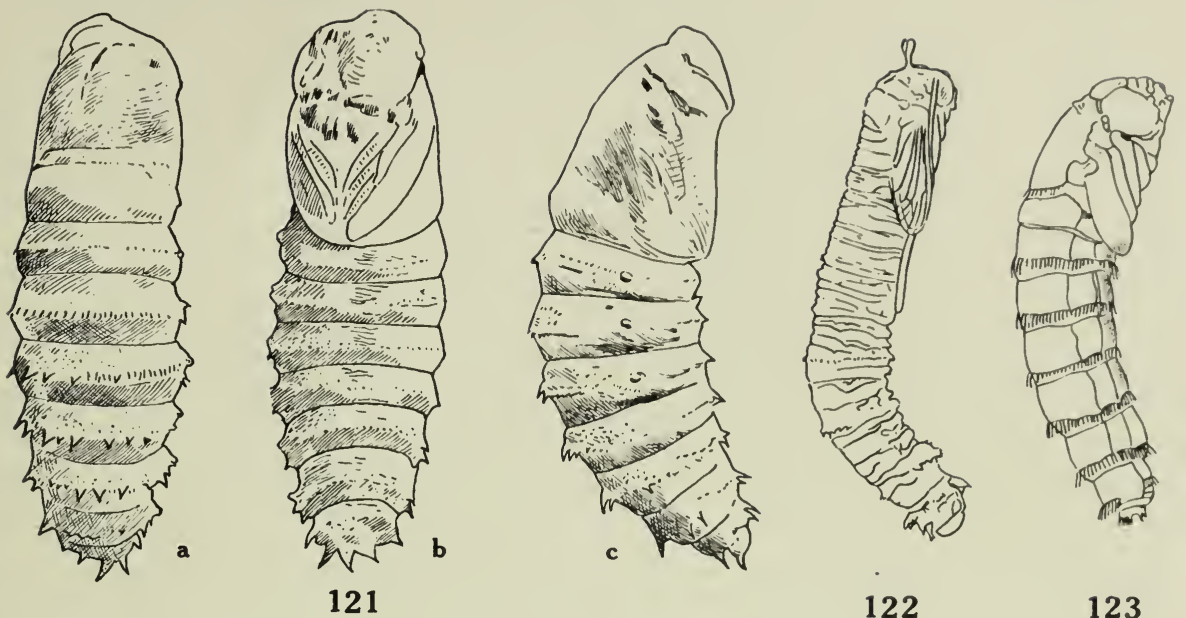

122

123

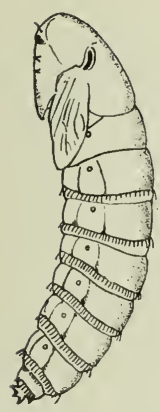

124

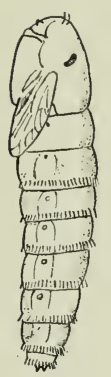

125

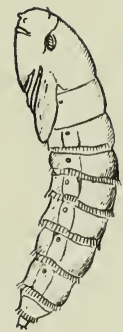

126

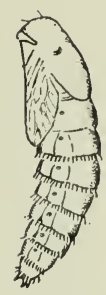

127

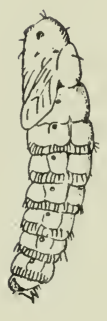

128

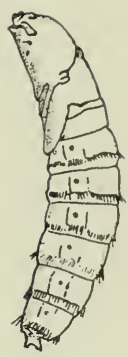

129

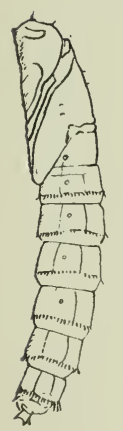

130

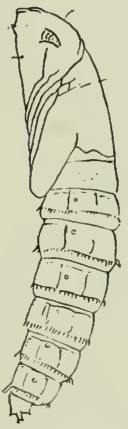

131

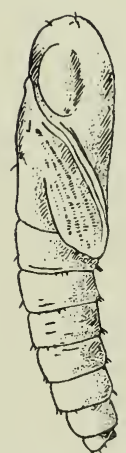

132

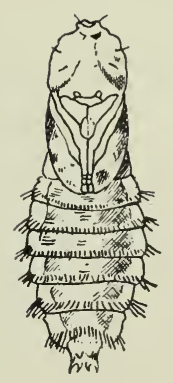

133

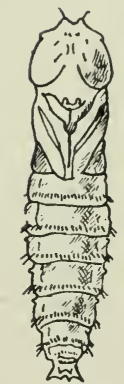

134

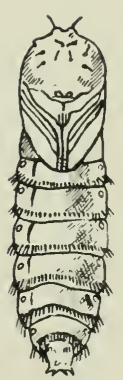

135

(Marchand: The early stages of Tabanidx.) 


\section{Plate 12.}

Fig. 136. Pupa of Tabanus cordiger. After Picard and le Blanc (from pupal shell).

FIG. 137. $a$, Pupa of Tabanus kingi; $b$, caudal end, lateral view; $c$, caudal end, ventral view. After King.

FIg. 138. Pupa of Tabanus variabilis. Natural size $20 \mathrm{~mm}$. After Neave (Terzi).

Fig. 139. Pupa of Tabanus sp.? (see Figs. 7 and 76). Colors of original yellow, thorax grayish. Natural size $21 \mathrm{~mm}$. After Maxwell-Leffroy and Howlett (colored plate).

Fig. 140. Pupa shell of Tabanus atratus. Natural size $31 \mathrm{~mm}$. After C. V. Riley.

FIG. 141. Caudal end of pupa of Tabanus ditcniatus. $a$, Lateral view; $b$, ventral view. After King.

FIg. 142. Pupa of Tabanus par. a, Entire pupa, lateral view, natural size $22 \mathrm{~mm} . ; b$, pupal aster. After King (colored plate).

Fig. 143. Pupal aster of Tabanus striatus. $a$, Pupal aster of male; $b$, pupal aster of female. After Mitzmain (photograph).

FIg. 144. Pupal aster of Tabamus bicallosus o7. After Patton and Cragg.

Fig. 145. Pupal aster of Tabanus bicallosus $९$. After Patton and Cragg.

Fig. 146. Pupal aster of Tabamus virgo. After Patton and Cragg.

Fig. 147. Pupal aster of Tabanus ditæniatus. After Patton and Cragg.

Fig. 148. Pupal aster of Tabamus biguttatus. After King (colored plate).

Fig. 149. Pupa of Tabanus lineola, dorsal view. After Malloch.

Fig. 150. Pupa of Tabanus sp.?, natural size $17 \mathrm{~mm}$. After Surcouf and Ricardo.

FIG. 151. Pupa of Tabanus bromius $\sigma^{7}$ in process of hatching, natural size 23 mm. After Surcouf and Ricardo.

FIG. 152. Pupa of Tabanus striatus. $a$, Lateral view of pupa; $b$, pupa in process of hatching. After Mitzmain. 
MONOGRAPH NO. 13.

PLATE 12.
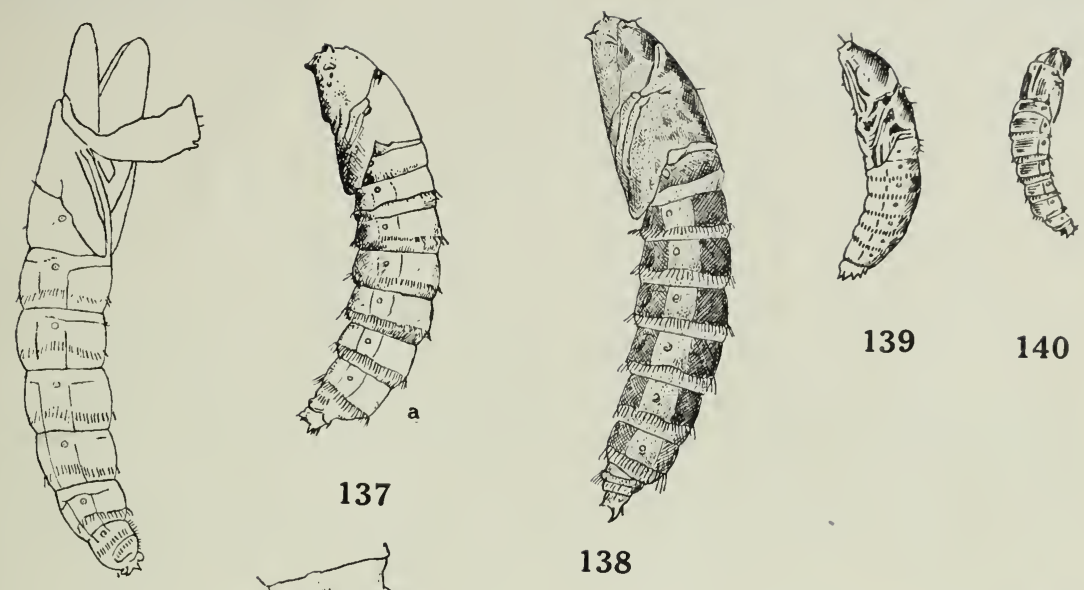

139

140

\section{7}

136
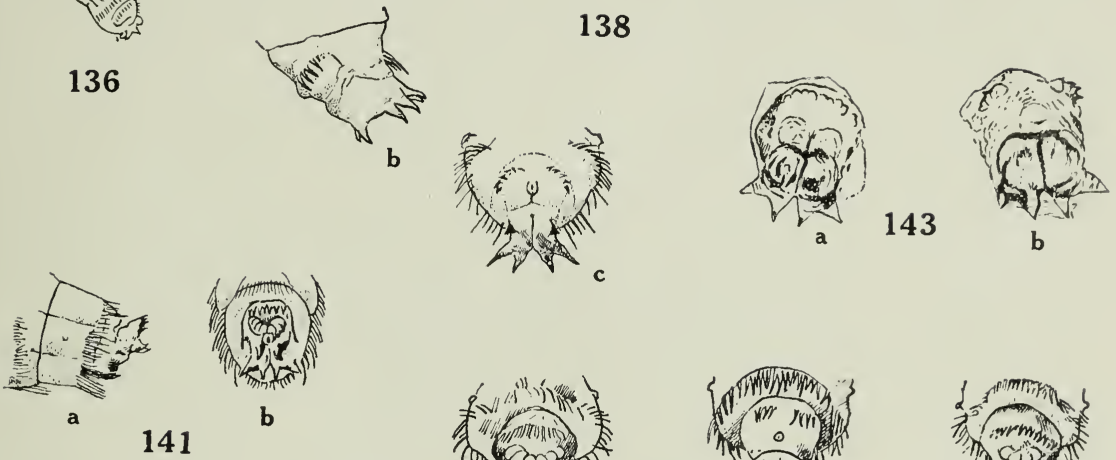

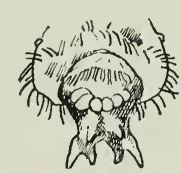

144

138

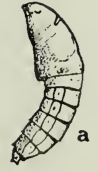

142 b

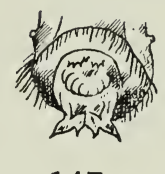

147

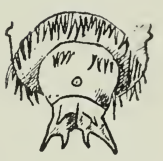

145

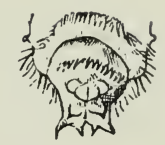

146

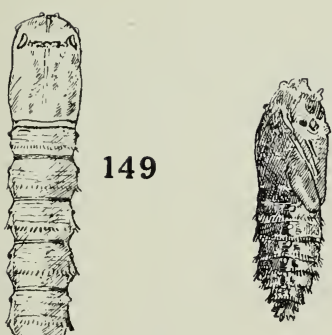

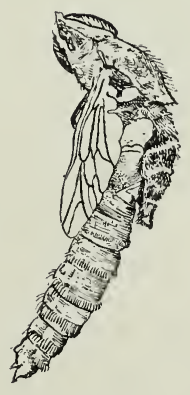

151
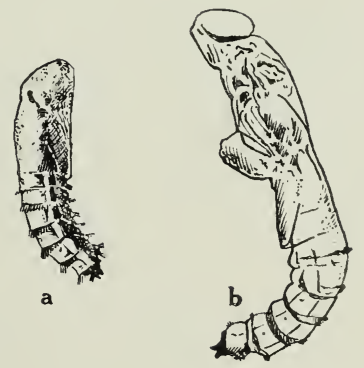

152

(Marchand: The early stages of Tabanidæ.) 
Plate 13.

FIG. 153. Upper half of thorax of pupa of Tabanus stygius, dorsal view. After Malloch.

FIG. 154. Upper half of thorax of pupa of Chrysops vittatus, dorsal view. After Malloch.

FIg. 155. Thorax of pupa of Tabanus cordiger, dorsal view. After Picard and le Blanc.

Fig. 156. Prothoracic spiracle of pupa of Tabanus nigrescens, dorsal view. After Malloch.

FIG. 157. Prothoracic spiracle of pupa of Chrysops vittatus, dorsal view. After Malloch.

Fig. 158. Pupal aster of Tabanus cordiger. After Picard and le Blanc.

FIg. 159. Pupal aster of Tabanus lasiophthalmus. After Hine.

FIG. 160. Pupal aster of Tabanus vivax. After Hine.

FIg. 161. Pupal aster of Tabanus stygius. After Hine.

FIg. 162. Pupal aster of Tabanus lineola. After Hart (photograph).

Fig. 163. Pupal aster of Tabanus atratus. After Hart (photograph).

FIG. 164. Pupal aster of Tabanus atratus. After Hine.

FIg. 165. Pupal aster of Tabanus sulcifrons. After Hine.

Fig. 166. Pupal aster of Chrysops magnifica, var. inornata. $a$, Male; $b$, female. After Neave (Terzi).

FIg. 167. Pupal aster of Chrysops bimaculosa. $a$, Male; $b$, female; $c$, female, side view. After Neave (Terzi).

Fig. 168. Pupal aster of Chrysops wellmani. $a, \sigma^{x} ; b$, ㅇ. After Neave.

Fig. 169. $a$, Pupal aster and b, dorsolateral comb of Hematopota decora + . After Neave.

FIg. 170. Pupal aster of Hematopota crudelis. After Neave.

FIG. 171. Pupal aster of Chrysops longicornis. $a, \sigma^{7} ; b$, ․ After Neave.

FIg. 172. Pupal aster of Hrmatopota insatiabilis $\circ$. $a$, From behind; $b$, side view; $c$, dorsolateral comb. After Neave. 
MONOGRAPH NO. 13.

PLATE 13.
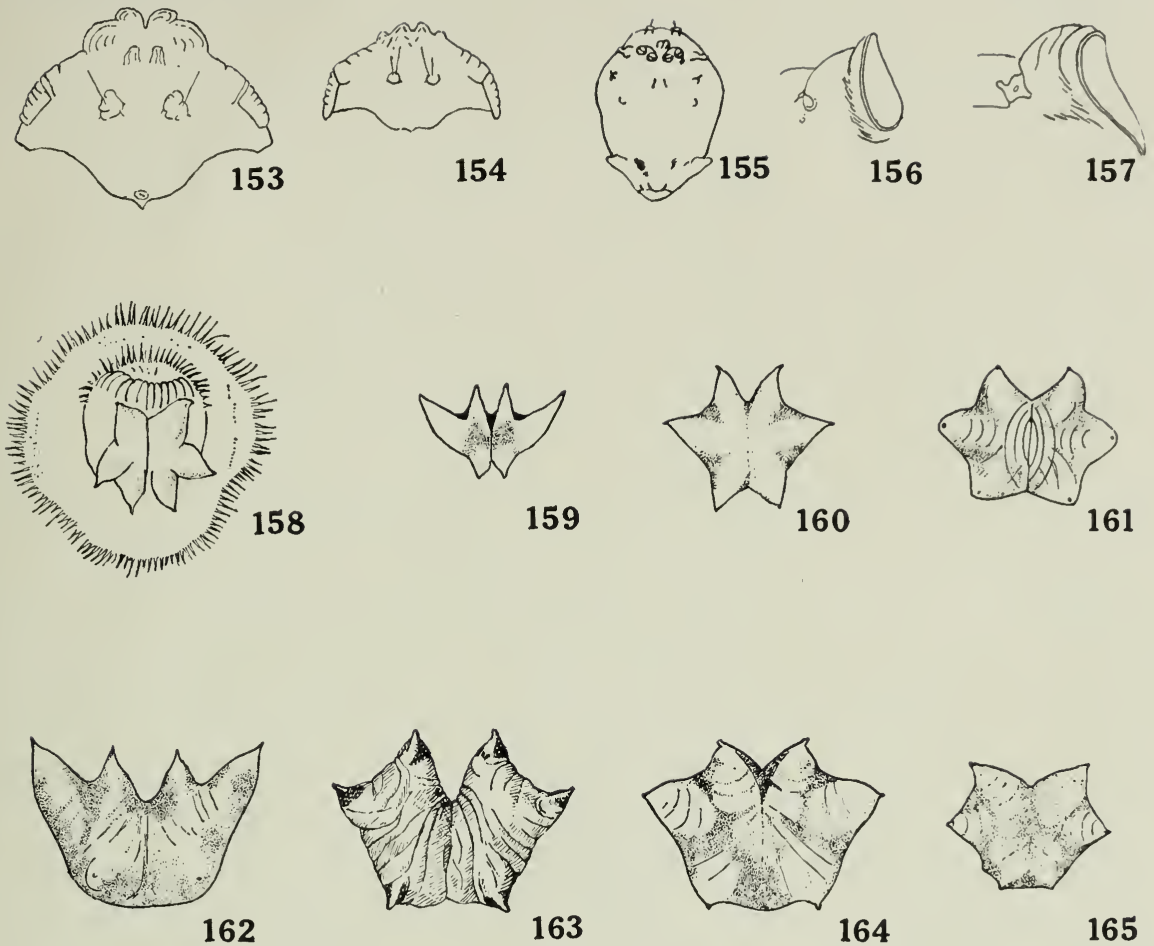

163

164

165

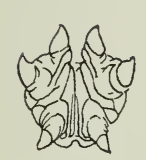

a 166

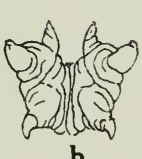

b
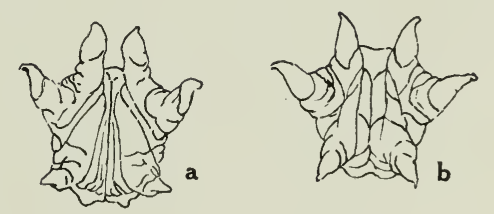

167

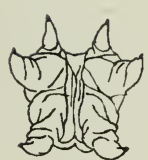

a $\quad 168$

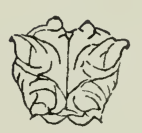

b

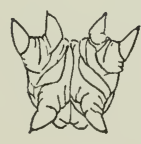

a

171

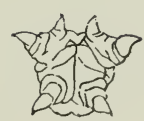

b

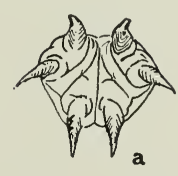

169
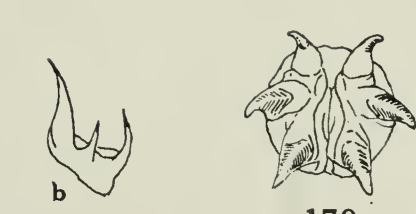

170

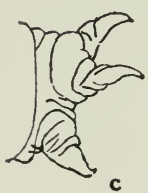

$$
9
$$

$$
\text { . }
$$
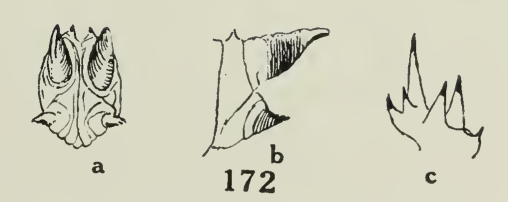

(Marchand: The early stages of Tabanidx.) 
Plate 14.

Fig. 173. Tabanus atrimanus. $a$, Pupal aster of $\sigma^{x} ; b$, dorsolateral comb of o ; $c$, pupal aster of + . After Neave (Terzi).

FIg. 174. Tabanus medionotatus $\sigma^{7}$. $a$, Pupal aster; $b$, profile of last segment of pupa. After Neave (Terzi).

Fig. 175. Tabanus biguttatus. $a$, Pupal aster of $\sigma^{7}$ and $b$, of $q ; c$, dorsolateral comb of $\sigma^{\pi}$ and $d$, of $q$. After Neave (Terzi).

Frg. 176. Tabanus variabilis. $a$, Pupal aster of $\sigma^{x} ; b$, dorsolateral comb of $\sigma^{7} ; c$, dorsolateral comb of $\odot ; d$, pupal aster of $\circ$. After Neave (Terzi).

Fig. 177. Tabanus ustus. $a$, Dorsolateral comb of $\sigma^{7} ; b$, pupal aster o $\sigma^{x}$; $c$, dorsolateral comb of $q$ (with six spines). After Neave (Terzi).

Fig. 178. Tabanus maculatissimus. $a$ and $b$, dorsolateral comb of two different $\sigma^{\top} ; c$, pupal aster of $q$; d dorsolateral comb of $\circ$. After Neave (Terzi). 
MONOGRAPH NO. 13.

PLATE 14.
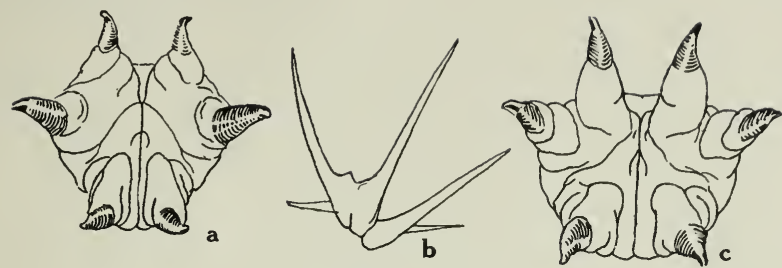

173

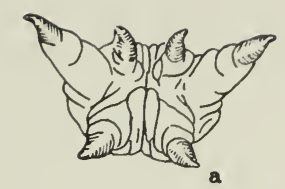

174
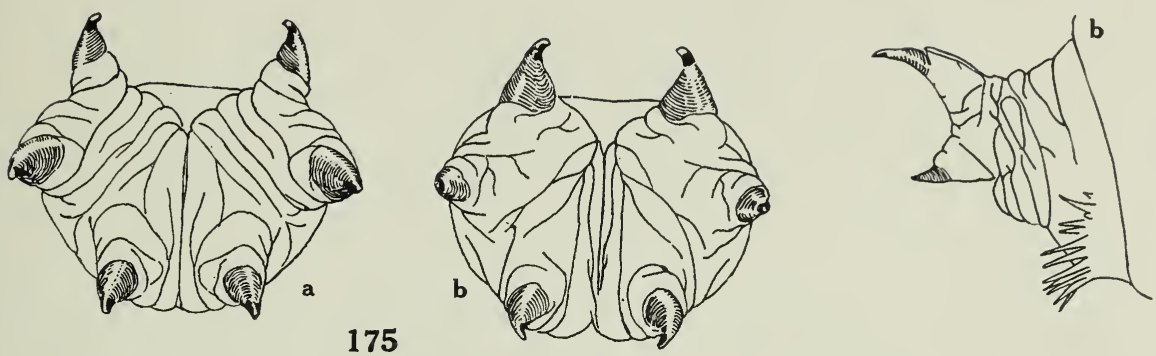

175
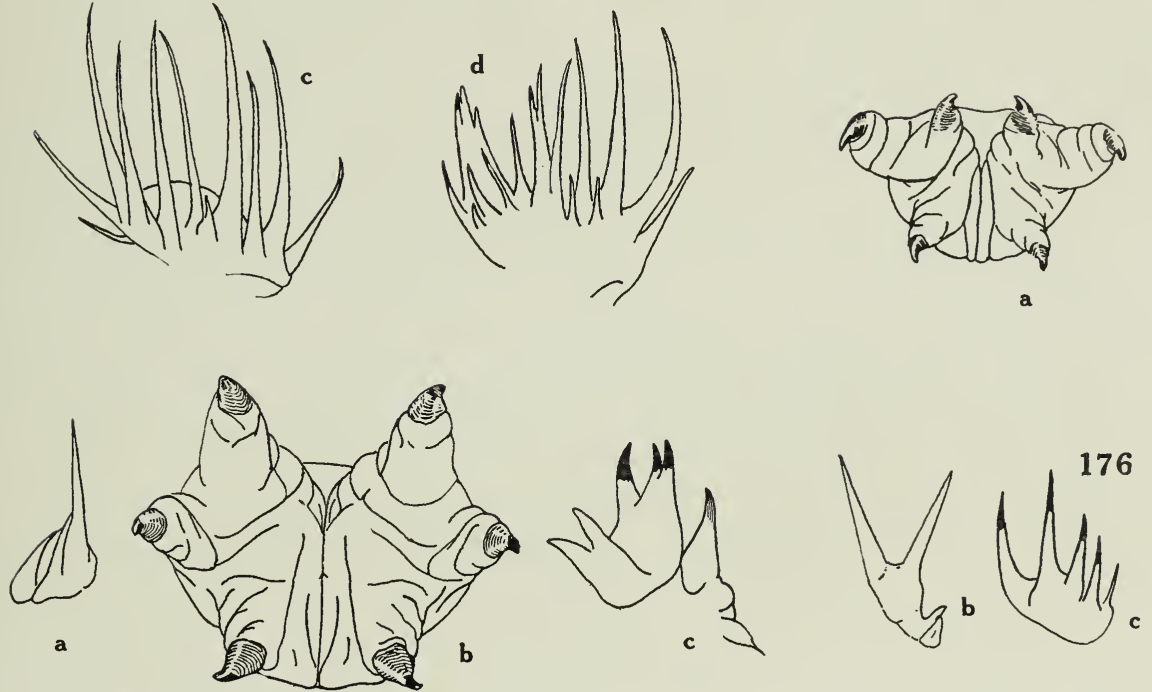

177
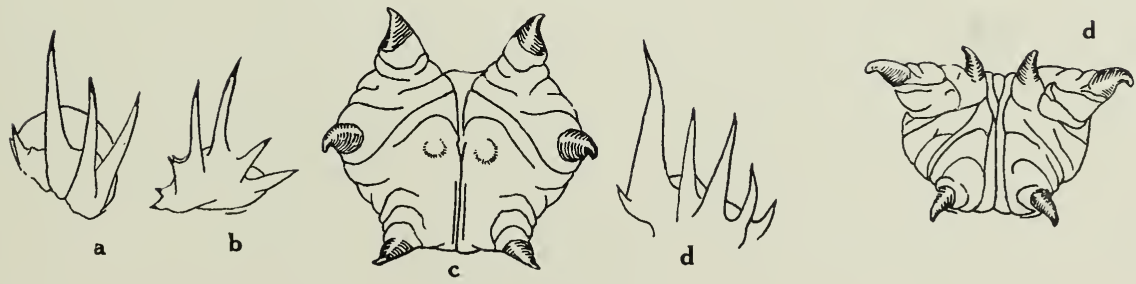


\section{Plate 15.}

Fig. 179. Tabanus nagamiensis $\sigma^{7}$. $a$, Pupal aster; $b$, pupal aster from the side, showing combs, the dorsolateral comb being absent. After Neave (Terzi).

FIG. 180. a, Pupal aster of Tabanus desertus; b, latera! view. After Bodkin and Cleare (Terzi).

FIg. 181. Tabanus corax. $a$, Pupal aster of $\sigma^{7} ; b$, pupal aster of $q ; c$, dorsolateral comb of + . After Neave (Terzi).

FIG. 182. Tabanus fratermus + . $a$, Pupal aster; $b$, dorsolateral comb. After Neave (Terzi).

Fig. 183. Tabanus obscuripes $\sigma^{7}$. $a$, Pupal aster; $b$, profile of last segment of pupa. After Neave (Terzi).

FIg. 184. Tabanus insignis. $a$, Dorsolateral comb of $\sigma^{7} ; b$, pupal aster of $\sigma^{7}$; $c$, dorsolateral comb of $\odot$. After Neave (Terzi).

FIG. 185. Tabanus laverani $\circ$. $a$, Pupal aster; $b$, enlarged view of dorsolateral comb; $c$, pupal aster from the side, showing the combs and the small dorsolateral comb. After Neave (Terzi).

Fig. 186. Tabanus gratus. $a$, Dorsolateral comb of $\sigma^{x} ; b$, pupal aster of $\sigma^{x}$; $c$ and $d$, dorsolateral comb of two different $q$. After Neave (Terzi). 
MONOGRAPH NO. 13.

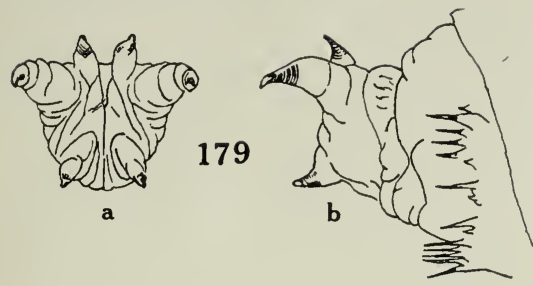

PLATE 15.

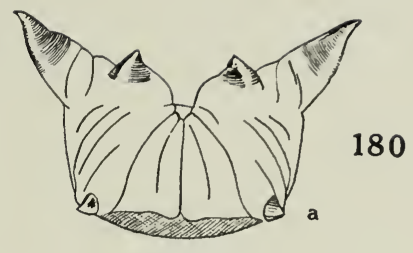

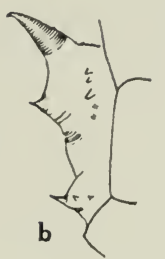

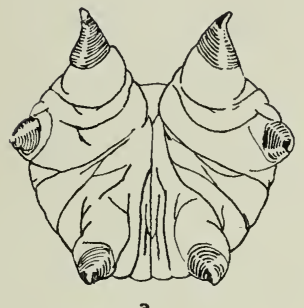

a

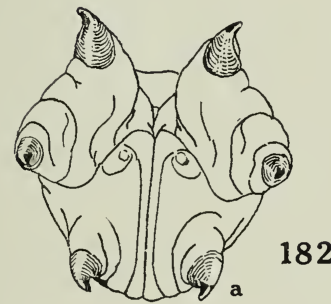

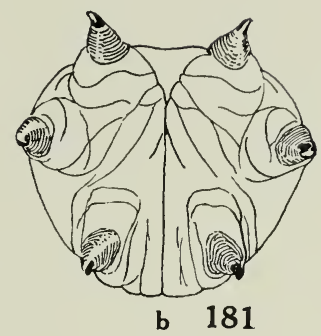

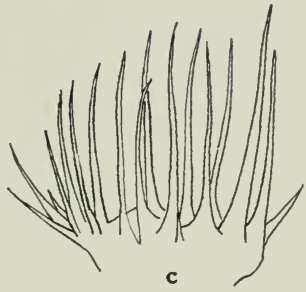

$(\underbrace{}_{y}$

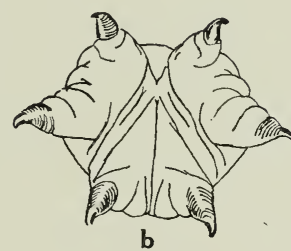

184

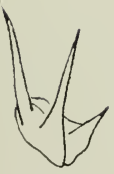

a

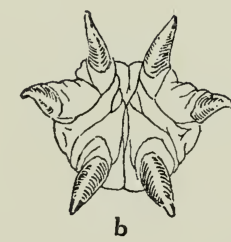

186
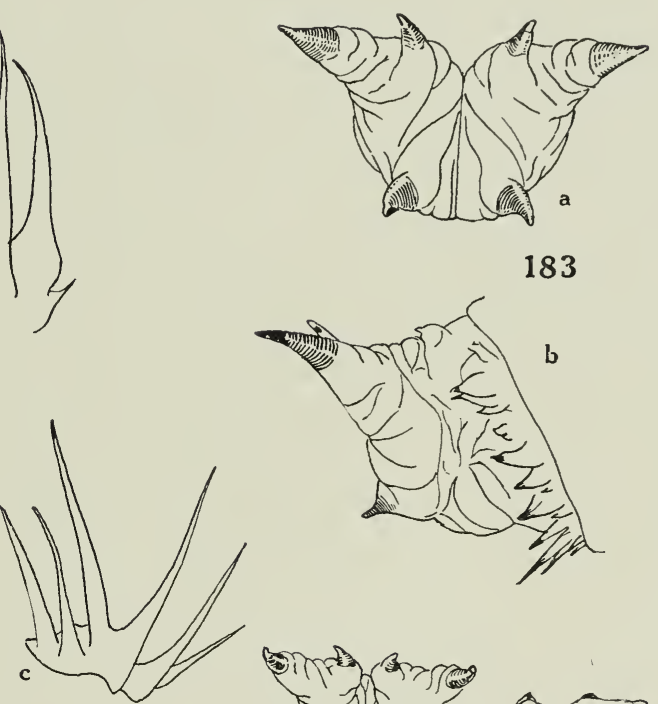

183

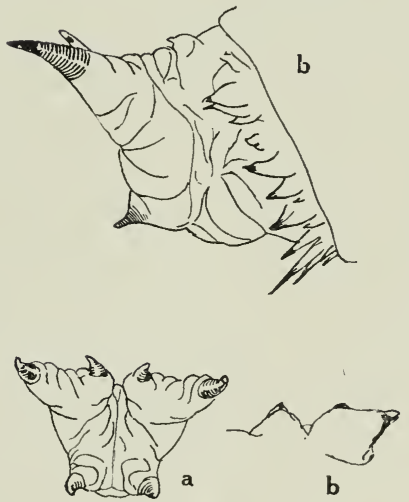

185
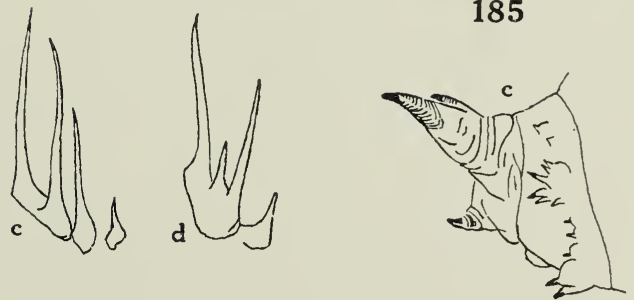

(Marchand: The early stages of Tabanidæ.) 



MONOGRAPHS OF THE ROCKEFELLER INSTITUTE FOR MEDICAL RESEARCH

Under the head of Monographs of The Rockefeller Institute for Medical Research are published from time to time scientific papers which are so extensive, or require such elaborate illustrations, as to render them unsuitable for current periodical issues. The Monographs are published at irregular periods, determined by the available material on hand. A number of free copies, which may be 50 or less according to the size of the Monograph, are given to the author. Monographs will be sent post paid on application, payable in advance. Remittances should be made by draft or check on New York, or by postal money order, payable to The Rockefeller Institute for Medical Research, Avenue A and 66th Street, New York, N. Y.

No. 1. Stmon Flexner and J. W. Jobling. Studies upon a transplantable rat tumor. Plates 1-16. J. W. Jobling. The biology of a mixed tumor of the rat. MAUD L. Menten. Experiments on the influence of radium bromide on a carcinomatous tumor of the rat. J. W. Jobling. Spontaneous tumors of the mouse. Plates 17-28. J. W. Jobling. Transplantation experiments in Macacus rhesus with a carcinomatous teratoma from man. (Issued June 30, 1910.) Price, $\$ 1.00$.

No. 2. William Travis Howard and Oscar T. Schultz. Studies in the biology of tumor cells. Plates 1-6. (Issued February 15, 1911.) Price, $\$ 1.00$.

No. 3. Benjanin T. Terry. Chemo-therapeutic trypanosome studies with special reference to the immunity following cure. (Issued March 15, 1911.) Price, $\$ 1.00$.

No. 4. Francis W. Peabody, George Draper, and A. R. Dochez. A clinical study of acute poliomyelitis. Plates 1-13. (Issued June 24, 1912.) Price, $\$ 1.00$.

No. 5. J. P. Stmonds. Studies in Bacillus welchii, with special reference to classification and to its relation to diarrhea. (Issued September 27, 1915.) Price, \$1.00.

No. 6. James L. Stoddard and Elliotr C. Cutler. Torula infection in man. Plates 1-9. (Issued January 31, 1916.) Price, $\$ 1.00$.

No. 7. Oswald T. Avery, H. T. Chrckering, Rufus Cole, and A. R. Dochez. Acute lobar pneumonia. Prevention and serum treatment. Plates 1-3. (Issued October 16, 1917.) Price, $\$ 1.00$.

No. 8. Ernest C. Dicrson. Botulism. A clinical and experimental study. Plates 1-10. (Issued July $31,1918$.$) Price, \$ 1.00$.

No. 9. James Howard Brown. The use of blood agar for the study of streptococci. Plates 1-34. (Issued January 21, 1919.) Price, $\$ 2.00$.

No. 10. Wriliam G. MacCallum. The pathology of the pneumonia in the United States Army camps during the winter of 1917-18. Plates 1-53. (Issued April 16, 1919.) Price, $\$ 1.50$.

No. 11. Frederick M. Allen, Edgar Stillman, and Reginald Fitz. Total dietary regulation in the treatment of diabetes. 62 charts. (Issued October 15, 1919.) Price, $\$ 4.50$.

No. 12. Lewis H. Weed, Paul Wegeforth, James B. Ayer, and Lloyd D. Felton. A study of experimental meningitis. A series of papers from the Army Neuro-Surgical Laboratory. Plates 1-17. (Issued March 25, 1920.) Price, $\$ 1.00$.

No. 13. Werner Marchand. The early stages of Tabanidæ (horse-flies). Plates 1-15. (Issued November 15, 1920.) Price, $\$ 2.00$.

No. 14. I. J. KLIGLer. Investigation on soil pollution and the relation of the various types of privies to the spread of intestinal infections. (In press.)

No. 15. S. T. Darling. Studies on hookworm infection in Brazil. (In press.)

All inquiries, correspondence, and subscriptions should be sent to the 


\section{PUBLICATIONS OF THE ROCKEFELLER INSTI}

FOR MEDICAL RESEARCH

\section{THE JOURNAL OF EXPERIMENTAL MEDICINE}

EDITED BY

SIMON FLEXNER, M.D.

The Journal of Experimental Medicine is designed to cover the field of experimental medicine. It is issued monthly, two volumes of over 600 pages each appearing in a year. The subscription price per year (two volumes) is $\$ 5.00$, payable in advance. Single copies cost 75 cents. Remittances should be made by draft or check on New York, or by postal money order, payable to The Journal of Experimental Medicine, Mount Royal and Guilford Avenues, Baltimore, Md., or Avenue A and 66th Street, New York, N. Y.

\section{THE JOURNAL OF BIOLOGICAL CHEMISTRY EDITED BY}

STANLEY R. BENEDICT, New York, N. Y. LAFAYETTE B. MENDEL, New Haven, Conn. H. D. DAKIN, Scarborough, N. Y.

DONALD D. VAN SLYKE, New York, N. Y.

The Journal of Biological Chemistry is designed for the prompt publication of original investigations of a chemical nature in the biological sciences. It is issued monthly. Each volume consists of as miany numbers as are required to make a total of between 500 and 600 pages. The subscription price is $\$ 3.00$ per volume to subscribers in the United States and Canada, payable in advance; $\$ 3.25$ to those in other countries. The number of volumes issued yearly averages four. The price of single copies varies; it is given on the back cover of each number. Remittances should be made by draft or check on New York, or by postal money order, payable to The Journal of Biological Chemistry, Mount Royal and Guilford Avenues, Baltimore, Md., or Avenue A and 66th Street, New York, N.Y.

THE JOURNAL OF GENERAL PHYSIOLOGY

EDITED BY

JACQUES LOEB, New York, N. Y.

W. J. V. OSTERHOUT, Cambridge, Mass.

The Journal of General Physiology is devoted to the explanation of life phenomena on the basis of the physical and chemical constitution of living matter. It is issued bimonthly, one volume of about 600 pages appearing in a year. The subscription price per year (one volume) is $\$ 5.00$, payable in advance. Single copies cost $\$ 1.00$. Remittances should be made by draft or check on New York; or by postal money order, payable to The Journal of General Physiology, Mount Royal and Guilford Avenues, Baltimore, Md., or Avenue A and 66th Street, New York, N. Y.

\section{STUDIES FROM THE ROCKEFELLER INSTITUTE FOR MEDICAL RESEARCH}

The published results of investigations conducted in the Institute, or under its grants, are republished at irregular intervals in volumes designated Studies from The Rockefeller Institute for Medical Research. The subscription price is $\$ 2.00$ per volume, payable in advance. A special rate of $\$ 1.00$ per volume is made to those who subscribe to The Journal of Experimental Medicine, The Journal of Biological Chemistry, or The Journal of General Physiology. Remittances should be made by draft or check on New York, or by postal money order, payable to The Rockefeller Institute for Medical Research, Avenue A and 66th Street, New York, N. Y.

\section{MONOGRAPHS OF THE ROCKEFELLER INSTITUTE FOR MEDICAL} RESEARCH

For information regarding the Monographs see the inside of this cover

\section{SEMIANNUAL LIST}

The Institute publishes a Semiannual List of all papers by members of the staff and those working under grants from the Institute, stating the title and place of publication of these reports. The Semiannual List will be sent upon application.

All inquiries, correspondence, and subscriptions should be sent to the

DIVISION OF PUBLICATION

THE ROCKEFELLER INSTITUTE FOR MEDICAL RESEARCH AVENUE A AND 66TH STREET, NEW YORK, N. Y. 